\title{
Direction: Happiness
}

Improving well-being of vulnerable groups

\author{
Laura A. Weiss
}

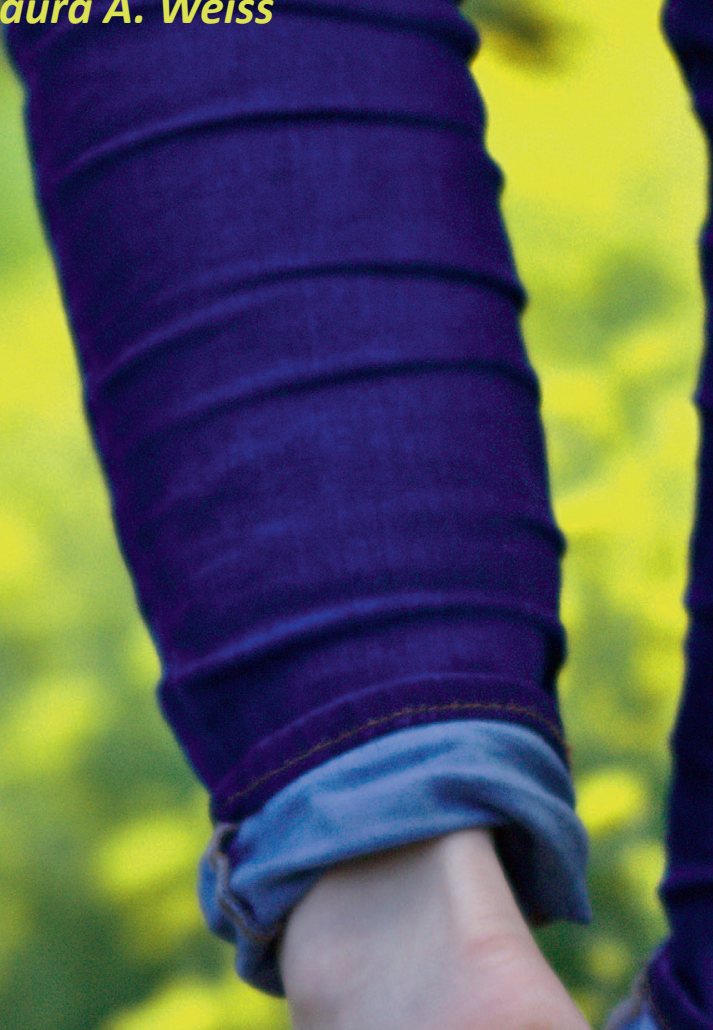





\section{Direction: Happiness}

Improving well-being of vulnerable groups

Laura A. Weiss 
Weiss, L. A. (2016). Direction: Happiness. Improving well-being of vulnerable groups. Enschede, the Netherlands: University of Twente.

(C) Laura A. Weiss

Cover photo: Frank H. A. de Boer

Photo's: Laura A. Weiss \& Frank H. A. de Boer

Printed by Gildeprint, the Netherlands

ISBN: 978-90-365-4181-7

DOI: $10.3990 / 1.9789036541817$ 


\section{DIRECTION: HAPPINESS}

\section{IMPROVING WELL-BEING OF VULNERABLE GROUPS}

\section{PROEFSCHRIFT}

ter verkrijging van

de graad van doctor aan de Universiteit Twente, op gezag van de rector magnificus,

Prof. Dr. H. Brinksma,

volgens besluit van het College voor Promoties

in het openbaar te verdedigen

op donderdag 13 oktober 2016 om 14.45 uur

door

Laura Anne Weiss

geboren op 21 oktober 1986

te Hameln, Duitsland 
Dit proefschrift is goedgekeurd door de promotor Prof. dr. Gerben J. Westerhof en de co-promotor Prof. dr. Ernst T. Bohlmeijer. 


\section{SAMENSTELLING PROMOTIECOMMISSIE}

Promotor:

Prof. dr. G. J. Westerhof, University of Twente

Co-promotor:

Prof. dr. E. T. Bohlmeijer, University of Twente

Leden:

Prof. dr. R. M. Ryan, University of Rochester / Australian Catholic University

Prof. dr. R. Veenhoven, Erasmus University Rotterdam

Prof. dr. A. Need, University of Twente

Prof. dr. A. Machielse, University of Humanistic Studies, Utrecht

Prof. dr. K. M. G. Schreurs, University of Twente

Associate Prof. dr. L. E. van Zyl, North West University, South Africa

Assistant Prof. dr. J. H. Søraker, University of Twente 
Happiness, that grand mistress of the ceremonies in the dance of life, impels us through all its mazes and meanderings, but leads none of us by the same route. 


\section{CONTENTS}

Chapter 1

General Introduction

Chapter 2 Improving the Health Care Sector with a Happiness-Based Approach. The Case of the Happiness Route

Chapter 3 Can We Increase Psychological Well-Being?

The Effects of Interventions on Psychological Well-Being:

A Meta-Analysis of Randomized Controlled Trials

Chapter $4 \quad$ Nudging Socially Isolated People towards Well-being with the 'Happiness Route': Design of a Randomized Controlled Trial for the Evaluation of a Happiness-based Intervention

Chapter 5

The Long and Winding Road to Happiness.

A Randomized Controlled Trial on the Effects of a

Positive Psychology Intervention for Severely Lonely

People with Health Problems

Chapter 6

Exploring the Blackbox of Positive Psychology:

Participants' Perceptions on Basic Psychological

Need Changes during the Happiness Route Intervention

Chapter 7

General Discussion

Samenvatting

Summary in Dutch

Dankwoord

Acknowledgements in Dutch

Publications 


\section{wercose

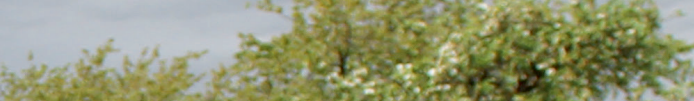

W.

Hy

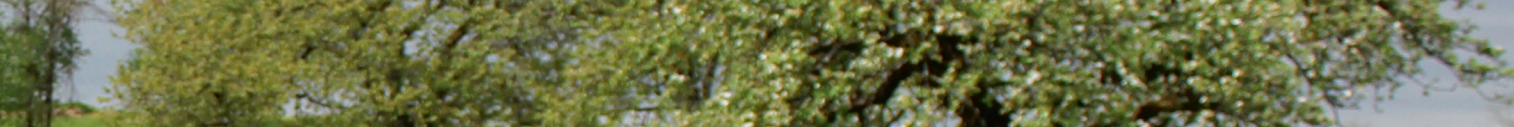

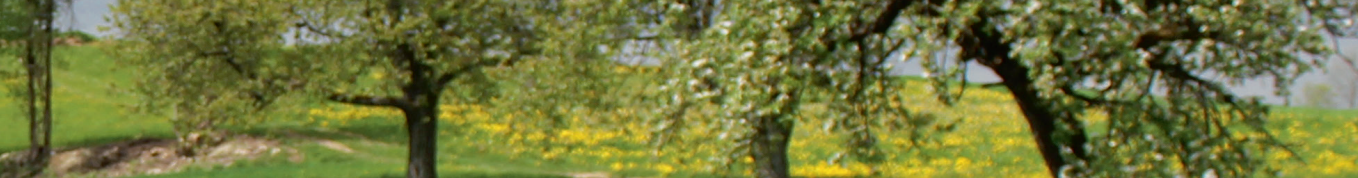

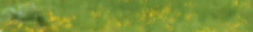

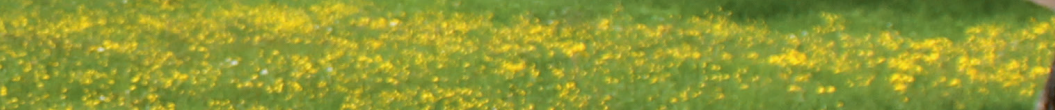

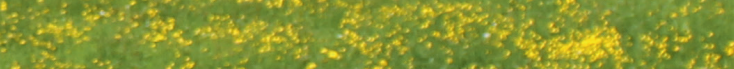

$$
\text { \& }
$$

ach

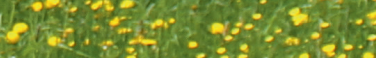

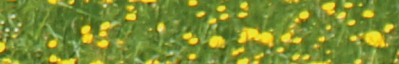

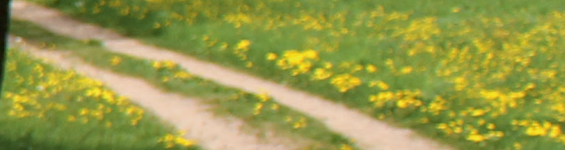

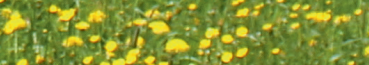

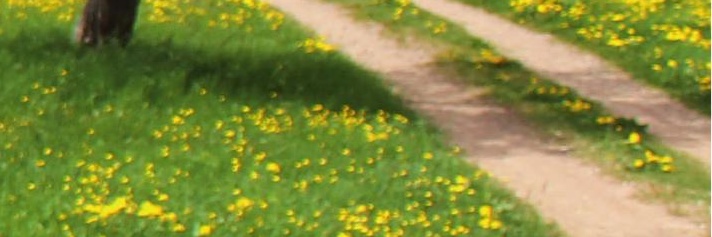
$3=2 i k x$

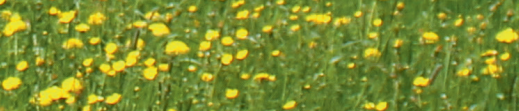

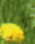

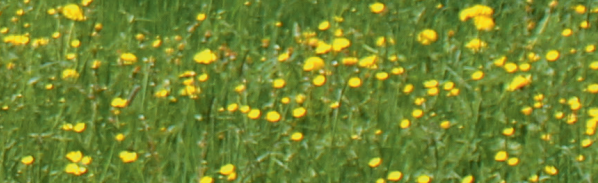
$-6=x+4$ Sablet

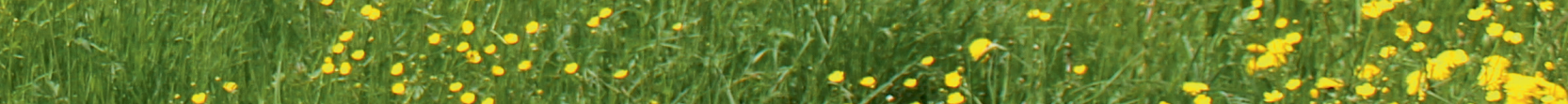

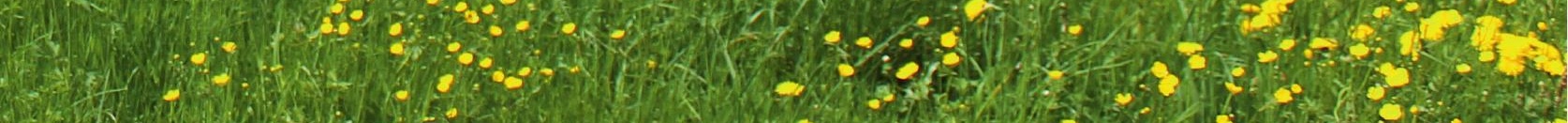
(7) (1).

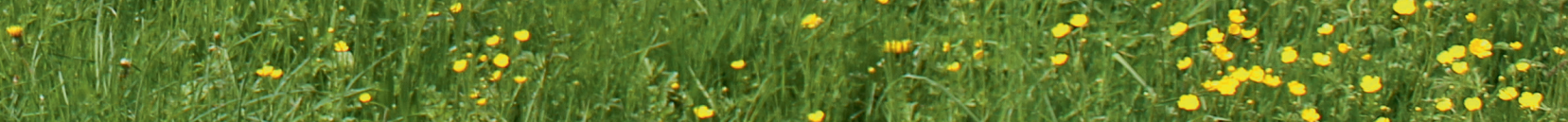

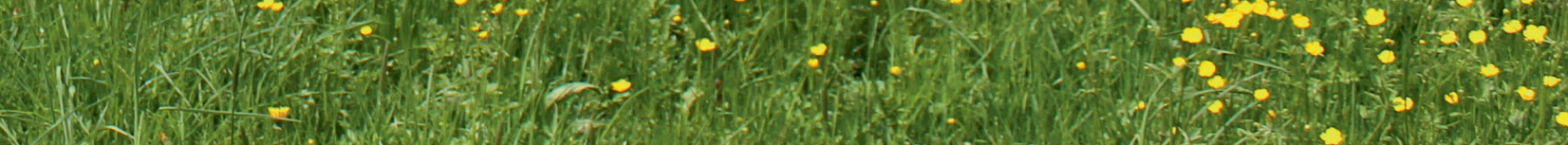
(1) 


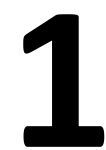

\section{General Introduction}

"I

The purpose of our lives is to be happy.

II

Dalai Lama 
Chapter 1 


\section{General introduction}

Although this might be slightly unusual for a dissertation, I want to start by asking you a personal question:

\section{What do you wish most for a person you love?}

You can think of anyone you like: your child, your sister, your grandfather, your mother, your most favorite colleague, your best friend or whoever comes to your mind. Now please write down your answer.

For

what I wish most is 
There is a fair chance that you wrote down happiness or something related to happiness, such as health, fulfillment, success, a good job, someone to love, or something else, which you hope would ultimately lead to happiness. Happiness is something most of us strive for in our own lives and want for our loved ones (Noddings, 2003). For example, when asked what they want for their children, most parents hope that they will be happy (Seligman, 2012).

How can we support people in one of their most important goals in life - being happy? And who needs this support most? This thesis attempts to answer these important questions. We will evaluate the intervention called the 'Happiness Route', an innovative approach to enhance well-being for lonely people with health problems and a low socio-economic status (SES). Strengthening the well-being of this vulnerable group instead of addressing their health, social and financial problems might be worthwhile. To examine this carefully, we want to discuss six points in this chapter:

1) How to define well-being;

2) Reasons to invest in well-being and how positive psychology interventions can contribute;

3) Positive psychology interventions for vulnerable groups;

4) The target group and why they should be addressed;

5) Description of the Happiness Route;

6) Overview of the thesis and research questions we want to answer.

Let's start at the beginning, for which we have to go quite far back in time.

\section{Happiness - from Ancient Greek philosophers to positive psychologists}

We all use the word happiness and we do so in many different situations. If you would ask 10 persons around you how they define happiness, you would most likely get 10 different answers. This is nothing new, as it has been a discussion of all times. The Ancient Greek philosophers were already debating about happiness. Whereas Aristippus of Cyrene and Epicurus saw happiness as pleasure and the absence of 
pain, the Stoics and Aristotle considered happiness as living well and striving towards excellence, based on one's unique potential (Irwin, 1985; Ryan \& Deci, 2001; Ryff \& Singer, 2008). These different views are respectively called hedonism and eudaimonia (Deci \& Ryan, 2008).

More than 2000 years later, the young field of positive psychology leads the same discussion. Some argue we should define and measure well-being as positive versus negative emotions and satisfaction with life, in line with the hedonic tradition (Kahneman, Diener, \& Schwarz, 1999). They call this subjective or emotional wellbeing, or simply happiness. Others think well-being should be measured as how well someone is functioning, in line with the eudaimonic tradition (Ryff \& Singer, 1996). Eudaimonic well-being can be divided in psychological and social wellbeing. Psychological well-being describes positive functioning on an individual level and includes the dimensions of self-acceptance, environmental mastery, positive relations with others, personal growth, autonomy, and purpose in life (Ryff, 1989; Ryff \& Keyes, 1995). Social well-being describes one's social functioning and refers to five factors: (1) social contribution: feeling useful to others; (2) social integration: sense of belonging to a group; (3) social actualization: believing in positive growth of society; (4) social acceptance: being positive and accepting towards others; and (5) social coherence: being interesting in the world around you and a feeling to understand society (Keyes, 1998).

Lately, there is a trend to put this ongoing discussion to rest, recognizing the inherent value of both types and combining the hedonic with the eudaimonic approach (Henderson \& Knight, 2012). Some researchers have argued that the two approaches may be part of a single umbrella construct of well-being and are operating together, rather than two distinct constructs (Kashdan, Biswas-Diener, \& King, 2008). Positive emotions promote positive functioning by creating social and individual resources and vice versa (Fredrickson, 2003), indicating that hedonic and eudaimonic wellbeing are intertwined. Only with good levels of both eudaimonic and hedonic wellbeing, people flourish. When people have low levels of both hedonic and eudaimonic well-being, they are described as languishing (Keyes, 2009). 
In this thesis, we also use this integrated approach, including both hedonic and eudaimonic aspects of well-being. We use the definition by Corey Keyes (Keyes, 2002b), who describes well-being as a combination of emotional, social and psychological well-being, measured with the Mental Health Continuum - Short Form (MHC-SF) (Keyes et al., 2008; Lamers, Westerhof, Bohlmeijer, ten Klooster, \& Keyes, 2011). This is in line with the intervention we are assessing, which also addresses both hedonic and eudaimonic factors.

Positive psychologists are among the first modern scientists who are investigating topics like well-being, strengths, and virtue (Seligman \& Csikszentmihalyi, 2000). In clinical psychology, it is more common to examine problems and psychopathology. This led to important insights and effective treatments, such as cognitive behavioral therapy. Clinical psychologists can help people dealing with trauma, anxiety, depression and many other mental health problems. The importance of this achievement is immense. Yet, this symptom-based approach does not take into account that the absence of psychopathology is not the same as well-being (Lamers et al., 2011). People without any symptoms of mental illness can have a low wellbeing and vice versa.

\section{Investing in well-being with positive psychology interventions}

Why should we invest in enhancing well-being? A good level of well-being has many positive effects that bring about personal and social benefits. An improved well-being has shown to have positive effects on health and personal functioning (Lyubomirsky, King, \& Diener, 2005). Well-being protects against becoming ill (Veenhoven, 2008) and is associated with reduced mortality (Chida \& Steptoe, 2008). It can contribute to the prevention of mental disorders (Keyes, Dhingra, \& Simoes, 2010). Even when controlling for symptoms of mental illness, mental health is related to work productivity, physical and mental health and health care consumption (Chida \& Steptoe, 2008; Keyes, 2004, 2005). All in all, improving well-being can result in major individual and societal gains. 
But if it is so important, can we actually help people becoming happier? Positive psychology has examined approaches to increase well-being since the beginning of the $21^{\text {st }}$ century (Seligman, Steen, Park, \& Peterson, 2005). Positive psychologists found that although partly genetically determined, a considerable part of happiness is under our own control and can be sustainably enhanced (Lyubomirsky, Sheldon, \& Schkade, 2005). The initial call to study human happiness by Seligman and Csikszentmihalyi (2000) has led to the development and evaluation of various positive psychology interventions (PPIs). PPIs stimulate people to perform positive activities or to develop strategies that promote positive feelings, thoughts and behavior and that satisfy their basic needs, thereby leading to an increased wellbeing (Lyubomirsky \& Layous, 2013). PPIs have proven to be effective, with small to moderate effects in enhancing well-being and decreasing depressive symptoms (Bolier et al., 2013; Sin \& Lyubomirsky, 2009).

\section{Positive psychology interventions for vulnerable groups}

PPIs have mainly been tested in healthy groups (Bolier et al., 2013) and found to be effective in the general population, in school settings, for college students and employees (Bolier et al., 2013; Ruini et al., 2009). These are groups with normal or good levels of well-being. It is both important and effective to further improve the well-being of these populations. The importance of helping people who are moderately mentally healthy to flourish is not to be underestimated. Anything less than flourishing is associated with lower levels of functioning concerning health, psychosocial issues, health care consumption, and missed workdays (Keyes, 2010). However important, knowing how to improve the well-being of the general population is not the whole story.

What about people who do not have an average or high level of well-being, but who are vulnerable and likely to languish? As described by Keyes (2010), languishing is accompanied by feelings of stagnation, emptiness, disinterest and disengagement. In the last years, researchers have acknowledged that it is sensible to target people with very low levels of well-being. For example, Biswas-Diener and colleagues (2011; 2011) argued that positive psychology methods can be used to improve the quality 
of life of people in adverse circumstances, such as the poor, and should be used as tools for social change. Better well-being can boost resilience, improve the quality of life, improve the chance to recover and decrease the risk to relapse in people with psychological disorders (Sin, Della Porta, \& Lyubomirsky, 2011). The physically ill may also profit from high levels of well-being in recovery and survival (Lamers, Bolier, Westerhof, Smit, \& Bohlmeijer, 2012). As Bolier (2015) pointed out, even when well-being has the smallest effect on the prognosis of a health condition, this may have a considerable effect in a diseased population, when enough people are reached. She proposed that is could be useful to direct PPIs to people with (chronic) physical disorders, as increased well-being can enhance self-management practices and prevent mental health disorders in the physically ill.

Bolier (2015) also pointed out that approaching well-being instead of problems or diseases could be more easily accepted by people who need interventions, thereby addressing the mental health gap. This term describes the difficulty to reach the people who are in need of mental health services (Kohn, Saxena, Levav, \& Saraceno, 2004). Working on positive concepts may be perceived as less stigmatizing and threatening than working on mental illness or other serious problems, which might people help to accept an intervention (Fledderus, 2012). Yet we are not sure if PPIs can help vulnerable people in the same way as the general population or whether or not we have to adopt the interventions to better fit vulnerable individuals.

In 2013, a meta-analysis of PPIs found that only 6 of the 31 included studies examined interventions for people with psychosocial problems, such as depression and anxiety symptoms (Bolier et al., 2013). The PPIs targeting this group seemed to be especially effective. The authors concluded that there is need for more studies in diverse clinical populations. A new systematic review and meta-analysis (Chakhssi, Kraiß, Spijkerman, \& Bohlmeijer, work in progress) shows that serious steps have been undertaken to address the specific challenges of clinical groups. Only three years later, they found 28 studies on the effects of PPIs on well-being in clinical populations. 
The authors found PPIs that have been developed for people with physical illnesses, especially for cancer patients: patients in treatment (Lee, Cohen, Edgar, Laizner, \& Gagnon, 2006), patients with advanced cancer (Breitbart et al., 2012; Breitbart et al., 2010; Breitbart et al., 2015; Henry et al., 2010), terminally ill cancer patients (Ando, Morita, Akechi, Okamoto, \& Care, 2010), and cancer survivors (Hsiao et al., 2012). PPIs were also targeted to HIV-infected patients (Drozd, Skeie, Kraft, \& Kvale, 2014; Mann, 2001), people suffering from chronic pain and physical disability (Müller et al., 2016), patients with diabetes (Cohn, Pietrucha, Saslow, Hult, \& Moskowitz, 2014), liver and kidney transplant recipients (Ghetti, 2011), and brain injury survivors with challenging behavior (Andrewes, Walker, \& O'Neill, 2014). There are also a number of PPIs for patients with mental illness; posttraumatic stress disorder (Kent, Davis, Stark, \& Stewart, 2011; Knaevelsrud, Liedl, \& Maercker, 2010; Panagioti, Gooding, \& Tarrier, 2012), depression (Coote \& MacLeod, 2012; Pietrowsky \& Mikutta, 2012), psychosis (Schrank et al., 2016), residual symptoms of affective disorder (Fava, Rafanelli, Cazzaro, Conti, \& Grandi, 1998), generalized anxiety disorder (Fava et al., 2004), and alcohol use disorder (Krentzman et al., 2015). Examples of studied interventions were positive psychotherapy (Seligman, Rashid, \& Parks, 2006), Wellness Recovery Action Planning (Cook et al., 2011), compassion-focused expressive writing (Imrie \& Troop, 2012), and gratitude and kindness interventions (Kerr, O’Donovan, \& Pepping, 2015). Other PPIs for vulnerable people targeted single women suffering from loneliness (Kremers, Steverink, Albersnagel, \& Slaets, 2006), and frail older people (Frieswijk, Steverink, Buunk, \& Slaets, 2006).

The studies were all directed to groups with a specific problem, either a physical or mental disorder (e.g. cancer or depression), a problematic condition (e.g. loneliness), or to a specific age group (e.g. the elderly). However, many people suffer from multiple problems and diseases, which makes them especially vulnerable (Grumbach, 2003). Given their high level of suffering and the negative implications for society, it is time to use PPIs to approach groups with more complex vulnerabilities. Therefore, we want to take the next step and evaluate a PPI for a group with a complex problematic, i.e. an accumulation of psychosocial and different sorts of health problems, both mental and physical, across the lifespan. 


\section{A vulnerable target group at risk for low well-being}

The target group addressed in this thesis has several risk factors for a low well-being: they have a low socio-economic status (SES), suffer from health problems, and experience loneliness. This is likely to make them vulnerable.

\section{$>$ LOW SES}

Lower education, lower average income and unemployment are related to lower levels of emotional, psychological and social well-being (Cole, 2006; Kaplan, Shema, \& Leite, 2008; Pinquart \& Sörensen, 2000; Westerhof, 2013). Having a low SES and not having access to environmental resources can cause vulnerability, which in turn leads to a greater risk of experiencing adverse outcomes, such as a low quality of life, increased morbidity and early mortality (Flaskerud \& Winslow, 1998). A lower SES is not only associated with a large number of negative health outcomes and mental disorders, such as depression (Lorant et al., 2007), but also with lower life expectancy and higher overall mortality rates (Adler et al., 1994; Link \& Phelan, 1995).

\section{$>$ Chronic and multiple health problems}

Poor physical health and chronic illness tend to be related to lower levels of emotional, social and psychological well-being (Lamers, Westerhof, Bohlmeijer, \& Keyes, 2013). The vast majority of studies and clinical guidelines focuses on people with only one medical condition. This means that experiencing disease is conceptualized as if occurring one at a time (Vogeli et al., 2007). In fact, most of the patients with a chronic condition suffer from multimorbidity, i.e., multiple chronic conditions that occur simultaneously (Grumbach, 2003). The number of chronic conditions is associated with the presence and severity of disability (Fried, BandeenRoche, Kasper, \& Guralnik, 1999). Multimorbidity leads to a wide range of barriers to self-care (Bayliss, Steiner, Fernald, Crane, \& Main, 2003), including becoming functionally impaired sooner than patients with fewer chronic diseases (Dunlop, Lyons, Manheim, Song, \& Chang, 2004). Vogeli and colleagues (2007) stressed the importance of gaining a better understanding of how comorbid conditions impact patients with multiple chronic conditions. According to them, facilitating health care for people with multiple chronic conditions is one of the most urgent challenges of our current health care system. 


\section{$>$ Loneliness}

For high levels of well-being, social support is key (Schotanus-Dijkstra et al., 2015). Accordingly, loneliness has negative effects on subjective, social and psychological well-being (Cacioppo, Hawkley, Kalil, Hughes, \& Waite, 2008; Doman \& Le Roux, 2012; VanderWeele, Hawkley, \& Cacioppo, 2012; Veenvliet, 2013). Feeling lonely and being socially isolated heightens feelings of vulnerability, hopelessness and depressive mood (Golden et al., 2009; Hawkley \& Cacioppo, 2010). It is an established risk factor for many physical and mental health conditions (Masi, Chen, Hawkley, \& Cacioppo, 2010). Experiencing deficiencies in social relationships poses people at greater risk for developing coronary heart disease and stroke, two of the leading causes of death and disability in high-income countries (Valtorta, Kanaan, Gilbody, Ronzi, \& Hanratty, 2016). The associations between loneliness and physical and mental health indicate that loneliness influences virtually every aspect of life in our social species. Finally, it is a serious risk factor for early mortality and morbidity (Holt-Lunstad, Smith, Baker, Harris, \& Stephenson, 2015).

The different risk factors are interconnected (Luo, Hawkley, Waite, \& Cacioppo, 2012; Wilkinson, 1997). In the target group of this thesis, they occur together. Serious, chronic and multiple health problems often force people to stop working, leading to financial problems and social isolation. A low SES also influences other factors. As Mandemakers (2011) showed, the psychological impact of major transitions and setbacks, such as going through a divorce, losing one's job or becoming disabled, depends on one's socio-economic status. People with a lower SES, especially a lower educational level, suffer more from negative experiences and experience greater psychological distress. In addition, groups with fewer socio-economic resources are more vulnerable for the negative psychological impact of those transitions. The target group of this thesis is affected by this mechanism, as all of them have experienced the onset of disability, many had to stop working due to their disabling condition(s) and part of them are probably divorced. Apart from obvious problems such as feeling lonely, being ill and having financial trouble, they are likely to languish. Languishing has shown to be associated with severe psychosocial impairment, substantial limitation of daily life and poor emotional health (Keyes, 2002a). 
To conclude, this thesis expands knowledge on vulnerable groups by examining a group with an accumulation of risk factors for a low well-being across lifespan, rather than looking at a target group with a specific disease.

\section{The Happiness Route}

An intervention that supports this target group in a new way is the Happiness Route, developed in 2002 by Gerard Nordkamp, a policy adviser at the municipality of Almelo, a city in the Eastern part of the Netherlands. Almelo wanted to map the problems of the chronically ill and handicapped citizens. Research by Anneke van der Plaats (2002) showed that part of the chronically ill citizens of Almelo suffered from social isolation, which they experienced as worse than their physical complaints. She suggested investing in well-being for this group, as investing in more health did not result in an improvement of the situation. In order to do so, Almelo's municipality allowed this group to spend a budget for activities that would make them happy. The aim was to improve well-being by using the strengths of the individuals and activating them with respect for their autonomy. The idea was that a little nudge (Leonard, 2008) towards the positive aspects in life would get them back on track and would reintegrate them into society. Enhanced well-being can draw people into an upward spiral; well-being leads to positive outcomes in behavior, which leads to greater well-being in turn, and so on (Bolier, 2015). A small improvement in wellbeing could be the first step in this upward spiral, leading to desirable outcomes and a further improved well-being.

Professional counselors helped the participants in finding a passion. To be able to realize the passion in form of an individually chosen activity, people were allowed to spend a budget of $€ 500$. For its non-bureaucratic and innovative approach, the project won national and international awards, such as the European UDiTe Award. The province of Overijssel wanted this successful project to be implemented in other municipalities as well. This was supported by the non-profit foundation Arcon, a research- and consultancy organization in the Netherlands, which helps (local) governments and social support organizations to realize their ambitions. This resulted in an implementation in nine municipalities. Local project leaders, counselors 
and participants were positive and first pilot studies were promising (Francissen, Wezenberg, \& Westerhof, 2010; Kedzia, 2009; Van der Plaats, 2007). Hence, Arcon and the University of Twente worked together to initiate a larger evaluation study, funded by ZonMw. This led to this PhD-thesis, conducted in seven municipalities. Two had already been working with the Happiness Route for years, including Almelo, whereas the intervention was newly implemented in five municipalities throughout the Netherlands in the course of the study.

The intervention was formalized, its theoretical basis was strengthened and evidence-based methods were imbedded, such as behavioral activation (Hermans \& Van de Putte, 2004), and life-review (Bohlmeijer \& Westerhof, 2010; Singer, 2005). The principles of the self-determination theory (SDT) were introduced so the intervention would support the three basic psychological needs of autonomy, competence and relatedness (Ryan \& Deci, 2000). SDT states that every human being has three basic psychological needs, which need to be fulfilled in order to experience ongoing growth and well-being: (1) autonomy refers to the need to be the director of one's own life and make your own choices; (2) competence is the need to feel confident, capable and effective in one's actions; (3) the need for relatedness encompasses the feeling of being understood and connected to others, and of experiencing a sense of belongingness in supportive relationships (Deci \& Ryan, 2000). SDT has been applied in many areas, including health contexts, counseling, behavior change and psychotherapy (Ng et al., 2012; Ryan, Lynch, Vansteenkiste, \& Deci, 2010). Researchers also start to use SDT as framework for PPIs (Lloyd \& Little, 2010; Sheldon et al., 2010). Another important concept in SDT is intrinsic motivation, the inherent tendency to use and strengthen one's capacities, keep learning and seek out to be challenged. This natural interest is a source of enjoyment and vitality, and it is important for cognitive and social development (Ryan \& Deci, 2000). Intrinsically motivated activities contribute to the fulfillment of the three basic psychological needs. One of the aims of the Happiness Route is to find and act on an intrinsically motivated activity. 
Happiness Route counselors are trained to provide autonomy support, amongst others by letting the participant find his or her intrinsic motivation in an autonomous way. During the intervention, talents are explored to choose an activity that allows participants to use their personal strengths and improve existing competences. Finally, relatedness support is provided in the relationship between counselor and participant, but even more so in the activity that provides new opportunities to get connected to others, for example by joining a group or following a course together with others who have the same interests.

\section{Outline of the thesis}

As argued, we hypothesize that improving well-being is an important approach to support vulnerable groups, in addition to treating their health and psychosocial problems. We expect the Happiness Route to promote well-being, as it supports the needs for autonomy, competence and relatedness by finding an intrinsically motivated activity. In order to evaluate this approach and the PPI Happiness Route in particular, this thesis addresses the following questions:

\section{* Why should we adopt a happiness-based approach in the health care and social sector?}

In Chapter 2, we introduce a positive approach that focuses on well-being. We argue why it is important to improve well-being, and why the health care and social sector could contribute from a happiness-based approach, especially regarding vulnerable groups. Finally, we introduce the Happiness Route intervention in more depth, an innovation based on this approach.

\section{* Can behavioral interventions improve psychological well-being?}

In Chapter 3, we argue that it is unclear if current behavioral interventions are able to improve psychological well-being. Earlier meta-analyses have show that PPIs can enhance subjective well-being (Bolier et al., 2013; Sin \& Lyubomirsky, 2009). To gain a better understanding on the effectiveness of interventions of both hedonic and eudaimonic forms of well-being, it is important to also examine the effects on psychological well-being. Therefore, we describe a meta-analysis, in which we 
examined the effects of behavioral interventions on psychological well-being, measured with Ryff's Scales of Psychological Well-Being (Ryff \& Singer, 1996) or the MHC-SF (Keyes et al., 2008).

\section{* How effective is a positive psychology intervention for vulnerable people?} In Chapter 4 and 5, we describe a study that addresses several shortcomings in current research on PPIs. Examining the underrepresented group of people with an accumulation of psychosocial and health problems sheds light on how PPIs work for vulnerable groups with several risk factors for low well-being. The randomized controlled trail (RCT) we conducted is one of the first multi-site PPI trials, conducted in seven municipalities throughout the Netherlands. The practice-based, naturalistic setting, which is rare in the field of positive psychology, adds new knowledge. In Chapter 4, we describe the design of our study in detail. In Chapter 5, we examine if the Happiness Route is effective in terms of an improved well-being, compared to an active control group that also received visits of counselors. Furthermore, improvement in resilience, purpose in life, quality of life and social participation, as well as decreases in loneliness, depression and care consumption are assessed.

\section{* How do participants experience a positive psychology intervention?}

Improving knowledge on change processes is an important step in the improvement of the effectiveness of interventions for individuals (Elliott, 2010). Until now, evaluation studies concerning the group of lonely people directed little attention to other factors than increased loneliness or enlarged social networks (Fokkema \& van Tilburg, 2006). Machielse (2011) therefore advised to also use subjective experiences of participants in order to fully understand the quality of an intervention. In Chapter 6 , we describe participants' perceptions of the intervention. This allows us to test the underlying theoretical framework of SDT by examining how participants changed, regarding their need fulfillment of autonomy, competence and relatedness during the Happiness Route. We also examine if participants develop in a similar way or go through their own unique development. We take a look into the blackbox of PPIs to better understand why they do work for some, and have less or no effects for others. 


\section{* What have we learned?}

In Chapter 7, the general discussion, we share our vision on future directions and on how to improve and study well-being of vulnerable groups. We start by summarizing the key findings of the different studies. We discuss the relevance of the happinessbased approach for vulnerable groups, thereby taking strength and limitations in account, resulting in recommendations for research and practice.

Vulnerable people also have children, siblings, parents or friends who hope that they will be happy, despite all problems. Hopefully this thesis can play a part in supporting the most vulnerable in society, to reach the goal so important to all of us (Diener, 2000): becoming a little bit happier. 


\section{References}

Adler, N. E., Boyce, T., Chesney, M. A., Cohen, S., Folkman, S., Kahn, R. L., \& Syme, S. L. (1994). Socioeconomic status and health: the challenge of the gradient. American Psychologist, 49(1), 15.

Ando, M., Morita, T., Akechi, T., Okamoto, T., \& Care, J. T. F. f. S. (2010). Efficacy of shortterm life-review interviews on the spiritual well-being of terminally ill cancer patients. Journal of Pain and Symptom Management, 39(6), 993-1002.

Andrewes, H., Walker, V., \& O'Neill, B. (2014). Exploring the use of positive psychology interventions in brain injury survivors with challenging behaviour. Brain Injury, 28(7), 965-971.

Bayliss, E. A., Steiner, J. F., Fernald, D. H., Crane, L. A., \& Main, D. S. (2003). Descriptions of barriers to self-care by persons with comorbid chronic diseases. The Annals of Family Medicine, 1(1), 15-21.

Biswas-Diener, R., Linley, P. A., Govindji, R., \& Woolston, L. (2011). Positive psychology as a force for social change. Designing positive psychology: Taking stock and moving forward, 410-418.

Biswas-Diener, R., \& Patterson, L. (2011). Positive psychology and poverty Positive psychology as social change (pp. 125-140): Springer.

Bohlmeijer, E., \& Westerhof, G. J. (2010). Op verhaal komen: je autobiografie als bron van wijsheid: Boom.

Bolier, J. (2015). Positive psychology online: using the internet to promote flourishing on a large scale. (Doctoral thesis). University of Twente, Enschede, the Netherlands.

Bolier, L., Haverman, M., Westerhof, G., Riper, H., Smit, F., \& Bohlmeijer, E. (2013). Positive psychology interventions: a meta-analysis of randomized controlled studies. BMC Public Health, 13(1), 119.

Breitbart, W., Poppito, S., Rosenfeld, B., Vickers, A. J., Li, Y., Abbey, J., . . . Sjoberg, D. (2012). Pilot randomized controlled trial of individual meaning-centered psychotherapy for patients with advanced cancer. Journal of Clinical Oncology, 30(12), 1304-1309.

Breitbart, W., Rosenfeld, B., Gibson, C., Pessin, H., Poppito, S., Nelson, C., . . . Jacobson, C. (2010). Meaning-centered group psychotherapy for patients with advanced cancer: a pilot randomized controlled trial. Psycho-Oncology, 19(1), 21-28.

Breitbart, W., Rosenfeld, B., Pessin, H., Applebaum, A., Kulikowski, J., \& Lichtenthal, W. G. (2015). Meaning-centered group psychotherapy: an effective intervention for improving psychological well-being in patients with advanced cancer. Journal of Clinical Oncology, 33(7), 749-754.

Cacioppo, J., Hawkley, L., Kalil, A., Hughes, M., \& Waite, L. (2008). Happiness and the invisible threads of social connection: The Chicago health, aging, and social relations study. The Science of Subjective Well-being, 195-219.

Chakhssi, F., Kraiß, J., Spijkerman, M., \& Bohlmeijer, E. T. (work in progress). The effects of positive psychological interventions on well-being in clinical populations: a systematic review and meta-analysis.

Chida, Y., \& Steptoe, A. (2008). Positive psychological well-being and mortality: a quantitative review of prospective observational studies. Psychosomatic Medicine, 70(7), 741-756.

Cohn, M. A., Pietrucha, M. E., Saslow, L. R., Hult, J. R., \& Moskowitz, J. T. (2014). An online positive affect skills intervention reduces depression in adults with type 2 diabetes. The Journal of Positive Psychology, 9(6), 523-534.

Cole, K. (2006). Wellbeing, psychological capital, and unemployment: An integrated theory. Paper presented at the Annual Conference of the International Association for Research in Economic Psychology and SABE. 
Cook, J. A., Copeland, M. E., Jonikas, J. A., Hamilton, M. M., Razzano, L. A., Grey, D. D., . . . Carter, T. M. (2011). Results of a randomized controlled trial of mental illness selfmanagement using Wellness Recovery Action Planning. Schizophrenia Bulletin, sbr012.

Coote, H. M., \& MacLeod, A. K. (2012). A self-help, positive goal-focused intervention to increase well-being in people with depression. Clinical psychology \& psychotherapy, 19(4), 305-315.

Deci, E. L., \& Ryan, R. M. (2000). The" what" and" why" of goal pursuits: Human needs and the self-determination of behavior. Psychological Inquiry, 11(4), 227-268.

Deci, E. L., \& Ryan, R. M. (2008). Hedonia, eudaimonia, and well-being: An introduction. Journal of Happiness Studies, 9(1), 1-11.

Diener, E. (2000). Subjective well-being: The science of happiness and a proposal for a national index. American Psychologist, 55(1), 34.

Doman, L. C., \& Le Roux, A. (2012). The relationship between loneliness and psychological well-being among third-year students: a cross-cultural investigation. International Journal of Culture and Mental Health, 5(3), 153-168.

Drozd, F., Skeie, L. G., Kraft, P., \& Kvale, D. (2014). A web-based intervention trial for depressive symptoms and subjective well-being in patients with chronic HIV infection. AIDS Care, 26(9), 1080-1089.

Dunlop, D. D., Lyons, J. S., Manheim, L. M., Song, J., \& Chang, R. W. (2004). Arthritis and heart disease as risk factors for major depression: the role of functional limitation. Medical Care, 42(6), 502-511.

Elliott, R. (2010). Psychotherapy change process research: Realizing the promise. Psychotherapy Research, 20(2), 123-135.

Fava, G. A., Rafanelli, C., Cazzaro, M., Conti, S., \& Grandi, S. (1998). Well-being therapy. A novel psychotherapeutic approach for residual symptoms of affective disorders. Psychological Medicine, 28(02), 475-480.

Fava, G. A., Ruini, C., Rafanelli, C., Finos, L., Salmaso, L., Mangelli, L., \& Sirigatti, S. (2004). Wellbeing therapy of generalized anxiety disorder. Psychotherapy and Psychosomatics, 74(1), 26-30.

Flaskerud, J. H., \& Winslow, B. J. (1998). Conceptualizing vulnerable populations health-related research. Nursing Research, 47(2), 69-78.

Fledderus, M. (2012). Acceptance and Commitment Therapy for Public Mental Health Promotion: Universiteit Twente.

Fokkema, T., \& van Tilburg, T. (2006). Aanpak van eenzaamheid: helpt het. Een vergelijkend effect-en procesevaluatie onderzoek naar interventies ter voorkoming en vermindering van eenzaamheid onder ouderen. Den Haag: NIDI.

Francissen, A., Wezenberg, E., \& Westerhof, G. (2010). De gevolgen van geluk. Achtergronden en toekomst van het geluksbudget. Borne: Arcon.

Fredrickson, B. L. (2003). The value of positive emotions. American scientist, 91(4), 330-335.

Fried, L. P., Bandeen-Roche, K., Kasper, J. D., \& Guralnik, J. M. (1999). Association of comorbidity with disability in older women: the Women's Health and Aging Study. Journal of Clinical Epidemiology, 52(1), 27-37.

Frieswijk, N., Steverink, N., Buunk, B. P., \& Slaets, J. P. (2006). The effectiveness of a bibliotherapy in increasing the self-management ability of slightly to moderately frail older people. Patient Education and Counseling, 61(2), 219-227.

Ghetti, C. M. (2011). Active music engagement with emotional-approach coping to improve well-being in liver and kidney transplant recipients. Journal of Music Therapy, 48(4), 463-485.

Golden, J., Conroy, R. M., Bruce, I., Denihan, A., Greene, E., Kirby, M., \& Lawlor, B. A. (2009). Loneliness, social support networks, mood and wellbeing in community-dwelling elderly. International Journal of Geriatric Psychiatry, 24(7), 694-700. 
Grumbach, K. (2003). Chronic illness, comorbidities, and the need for medical generalism. The Annals of Family Medicine, 1(1), 4-7.

Hawkley, L. C., \& Cacioppo, J. T. (2010). Loneliness matters: a theoretical and empirical review of consequences and mechanisms. Annals of Behavioral Medicine, 40(2), 218-227.

Henderson, L. W., \& Knight, T. (2012). Integrating the hedonic and eudaimonic perspectives to more comprehensively understand wellbeing and pathways to wellbeing. International Journal of Wellbeing, 2(3).

Henry, M., Cohen, S. R., Lee, V., Sauthier, P., Provencher, D., Drouin, P., . . . Drummond, N. (2010). The Meaning-Making intervention (MMi) appears to increase meaning in life in advanced ovarian cancer: A randomized controlled pilot study. Psycho-Oncology, 19(12), 1340-1347.

Hermans, D., \& Van de Putte, J. (2004). Cognitieve gedragstherapie bij depressie: Bohn Stafleu Van Loghum.

Holt-Lunstad, J., Smith, T. B., Baker, M., Harris, T., \& Stephenson, D. (2015). Loneliness and social isolation as risk factors for mortality a meta-analytic review. Perspectives on Psychological Science, 10(2), 227-237.

Hsiao, F.-H., Jow, G.-M., Kuo, W.-H., Chang, K.-J., Liu, Y.-F., Ho, R. T., . . Chen, Y.-T. (2012). The effects of psychotherapy on psychological well-being and diurnal cortisol patterns in breast cancer survivors. Psychotherapy and Psychosomatics, 81(3), 173-182.

Imrie, S., \& Troop, N. A. (2012). A pilot study on the effects and feasibility of compassionfocused expressive writing in Day Hospice patients. Palliative and Supportive Care, 10(02), 115-122.

Irwin, T. (1985). Translation of Nicomachean ethics of Aristotle: Indianapolis, Hacket Publishing Company.

Kahneman, D., Diener, E., \& Schwarz, N. (1999). Well-Being: Foundations of Hedonic Psychology: Foundations of Hedonic Psychology: Russell Sage Foundation.

Kaplan, G. A., Shema, S. J., \& Leite, C. M. A. (2008). Socioeconomic determinants of psychological well-being: the role of income, income change, and income sources during the course of 29 years. Annals of Epidemiology, 18(7), 531-537.

Kashdan, T. B., Biswas-Diener, R., \& King, L. A. (2008). Reconsidering happiness: The costs of distinguishing between hedonics and eudaimonia. The Journal of Positive Psychology, $3(4), 219-233$.

Kedzia, S. (2009). What makes you happy?: evaluating an intervention aimed at promoting social participation of lonely people: identifying concepts that can serve as building blocks of self-chosen activities and developing and testing a questionnaire to measure the success of these activities. (Unpublished master thesis). University of Twente, Enschede, the Netherlands.

Kent, M., Davis, M. C., Stark, S. L., \& Stewart, L. A. (2011). A resilience-oriented treatment for posttraumatic stress disorder: Results of a preliminary randomized clinical trial. Journal of Traumatic Stress, 24(5), 591-595.

Kerr, S. L., O'Donovan, A., \& Pepping, C. A. (2015). Can gratitude and kindness interventions enhance well-being in a clinical sample? Journal of Happiness Studies, 16(1), 17-36.

Keyes, C. L. (1998). Social well-being. Social Psychology Quarterly, 121-140.

Keyes, C. L. (2002a). The Mental Health Continuum: From Languishing to Flourishing in Life. Journal of Health and Social Behavior, 43(2), 207-222.

Keyes, C. L. (2002b). The mental health continuum: From languishing to flourishing in life. Journal of Health and Social Behavior, 207-222.

Keyes, C. L. (2004). The nexus of cardiovascular disease and depression revisited: The complete mental health perspective and the moderating role of age and gender. Aging \& Mental Health, 8(3), 266-274. 
Keyes, C. L. (2005). Mental illness and/or mental health? Investigating axioms of the complete state model of health. Journal of consulting and clinical psychology, 73(3), 539.

Keyes, C. L. (2009). Brief description of the mental health continuum short form (MHC-SF). Atlanta, GA: Emory University.

Keyes, C. L. (2010). The next steps in the promotion and protection of positive mental health. Canadian Journal of Nursing Research, 42(3), 17-28.

Keyes, C. L., Dhingra, S. S., \& Simoes, E. J. (2010). Change in level of positive mental health as a predictor of future risk of mental illness. American Journal of Public Health, 100(12), 2366-2371.

Keyes, C. L., Wissing, M., Potgieter, J. P., Temane, M., Kruger, A., \& van Rooy, S. (2008). Evaluation of the mental health continuum-short form (MHC-SF) in Setswana-speaking South Africans. Clinical Psychology and Psychotherapy, 15(3), 181.

Knaevelsrud, C., Liedl, A., \& Maercker, A. (2010). Posttraumatic growth, optimism and openness as outcomes of a cognitive-behavioural intervention for posttraumatic stress reactions. Journal of Health Psychology, 15(7), 1030-1038.

Kohn, R., Saxena, S., Levav, I., \& Saraceno, B. (2004). The treatment gap in mental health care. Bulletin of the World Health Organization, 82(11), 858-866.

Kremers, I. P., Steverink, N., Albersnagel, F. A., \& Slaets, J. P. (2006). Improved self-management ability and well-being in older women after a short group intervention. Aging and Mental Health, 10(5), 476-484.

Krentzman, A. R., Mannella, K. A., Hassett, A. L., Barnett, N. P., Cranford, J. A., Brower, K. J., . . . Meyer, P. S. (2015). Feasibility, acceptability, and impact of a web-based gratitude exercise among individuals in outpatient treatment for alcohol use disorder. The Journal of Positive Psychology, 10(6), 477-488.

Lamers, S., Westerhof, G. J., Bohlmeijer, E. T., ten Klooster, P. M., \& Keyes, C. L. (2011). Evaluating the psychometric properties of the mental health continuum-short form (MHC-SF). Journal of Clinical Psychology, 67(1), 99-110.

Lamers, S. M., Bolier, L., Westerhof, G. J., Smit, F., \& Bohlmeijer, E. T. (2012). The impact of emotional well-being on long-term recovery and survival in physical illness: a metaanalysis. Journal of Behavioral Medicine, 35(5), 538-547.

Lamers, S. M., Westerhof, G. J., Bohlmeijer, E. T., \& Keyes, C. L. (2013). Mental health and illness in relation to physical health across the lifespan Positive Psychology (pp. 19-33): Springer.

Lee, V., Cohen, S. R., Edgar, L., Laizner, A. M., \& Gagnon, A. J. (2006). Meaning-making intervention during breast or colorectal cancer treatment improves self-esteem, optimism, and self-efficacy. Social Science \& Medicine, 62(12), 3133-3145.

Leonard, T. C. (2008). Richard H. Thaler, Cass R. Sunstein, Nudge: Improving decisions about health, wealth, and happiness. Constitutional Political Economy, 19(4), 356-360.

Link, B. G., \& Phelan, J. (1995). Social Conditions As Fundamental Causes of Disease. Journal of Health and Social Behavior, 80-94. doi:10.2307/2626958

Lloyd, K., \& Little, D. E. (2010). Self-determination theory as a framework for understanding women's psychological well-being outcomes from leisure-time physical activity. Leisure Sciences, 32(4), 369-385.

Lorant, V., Croux, C., Weich, S., Deliège, D., Mackenbach, J., \& Ansseau, M. (2007). Depression and socio-economic risk factors: 7-year longitudinal population study. The British Journal of Psychiatry, 190(4), 293-298.

Luo, Y., Hawkley, L. C., Waite, L. J., \& Cacioppo, J. T. (2012). Loneliness, health, and mortality in old age: A national longitudinal study. Social Science \& Medicine, 74(6), 907-914.

Lyubomirsky, S., King, L., \& Diener, E. (2005). The benefits of frequent positive affect: does happiness lead to success? Psychological Bulletin, 131(6), 803. 
Lyubomirsky, S., \& Layous, K. (2013). How do simple positive activities increase well-being? Current Directions in Psychological Science, 22(1), 57-62.

Lyubomirsky, S., Sheldon, K. M., \& Schkade, D. (2005). Pursuing happiness: The architecture of sustainable change: Review of General Psychology, 9(2), 111.

Machielse, A. (2011). Sociaal isolement bij ouderen: een typologie als richtlijn voor effectieve interventies. Journal of Social Intervention: Theory and Practice, 20(4), 40-61.

Mandemakers, J. J. (2011). Socio-economic differentials in the impact of life course transitions on well-being: Dissertation, Tilburg University.

Mann, T. (2001). Effects of future writing and optimism on health behaviors in HIV-infected women. Annals of Behavioral Medicine, 23(1), 26-33.

Masi, C. M., Chen, H.-Y., Hawkley, L. C., \& Cacioppo, J. T. (2010). A meta-analysis of interventions to reduce loneliness. Personality and Social Psychology Review.

Müller, R., Gertz, K. J., Molton, I. R., Terrill, A. L., Bombardier, C. H., Ehde, D. M., \& Jensen, M. P. (2016). Effects of a tailored positive psychology intervention on well-being and pain in individuals with chronic pain and a physical disability: a feasibility trial. The Clinical Journal of Pain, 32(1), 32-44.

Ng, J. Y., Ntoumanis, N., Thøgersen-Ntoumani, C., Deci, E. L., Ryan, R. M., Duda, J. L., \& Williams, G. C. (2012). Self-determination theory applied to health contexts a meta-analysis. Perspectives on Psychological Science, 7(4), 325-340.

Noddings, N. (2003). Happiness and Education: Cambridge University Press.

Panagioti, M., Gooding, P., \& Tarrier, N. (2012). An empirical investigation of the effectiveness of the broad-minded affective coping procedure (BMAC) to boost mood among individuals with posttraumatic stress disorder (PTSD). Behaviour Research and Therapy, 50(10), 589-595.

Pietrowsky, R., \& Mikutta, J. (2012). Effects of positive psychology interventions in depressive patients - A randomized control study. Psychology, 3(12), 1067.

Pinquart, M., \& Sörensen, S. (2000). Influences of socioeconomic status, social network, and competence on subjective well-being in later life: a meta-analysis. Psychology and Aging, 15(2), 187.

Ruini, C., Ottolini, F., Tomba, E., Belaise, C., Albieri, E., Visani, D., . . Fava, G. A. (2009). School intervention for promoting psychological well-being in adolescence. Journal of Behavior Therapy and Experimental Psychiatry, 40(4), 522-532.

Ryan, R. M., \& Deci, E. L. (2000). Self-determination theory and the facilitation of intrinsic motivation, social development, and well-being. American Psychologist, 55(1), 68.

Ryan, R. M., \& Deci, E. L. (2001). On happiness and human potentials: A review of research on hedonic and eudaimonic well-being. Annual Review of Psychology, 52(1), 141-166.

Ryan, R. M., Lynch, M. F., Vansteenkiste, M., \& Deci, E. L. (2010). Motivation and autonomy in counseling, psychotherapy, and behavior change: A look at theory and practice. The Counseling Psychologist.

Ryff, C. D. (1989). Happiness is everything, or is it? Explorations on the meaning of psychological well-being. Journal of Personality and Social Psychology, 57(6), 1069.

Ryff, C. D., \& Keyes, C. L. (1995). The structure of psychological well-being revisited. Journal of Personality and Social Psychology, 69(4), 719.

Ryff, C. D., \& Singer, B. (1996). Psychological well-being: Meaning, measurement, and implications for psychotherapy research. Psychotherapy and Psychosomatics, 65(1), 14-23.

Ryff, C. D., \& Singer, B. H. (2008). Know thyself and become what you are: A eudaimonic approach to psychological well-being. Journal of Happiness Studies, 9(1), 13-39.

Schotanus-Dijkstra, M., Pieterse, M., Drossaert, C., Westerhof, G., de Graaf, R., ten Have, M. ... Bohlmeijer, E. (2015). What factors are associated with flourishing? Results from a large representative national sample. Journal of Happiness Studies, 1-20. 
Schrank, B., Brownell, T., Jakaite, Z., Larkin, C., Pesola, F., Riches, S., . . Slade, M. (2016). Evaluation of a positive psychotherapy group intervention for people with psychosis: pilot randomised controlled trial. Epidemiology and Psychiatric Sciences, 25(03), 235246.

Seligman, M. E. (2012). Flourish: A visionary new understanding of happiness and well-being: Simon and Schuster.

Seligman, M. E., \& Csikszentmihalyi, M. (2000). Positive psychology: An introduction (Vol. 55): American Psychological Association.

Seligman, M. E., Rashid, T., \& Parks, A. C. (2006). Positive psychotherapy. American Psychologist, 61(8), 774.

Seligman, M. E., Steen, T. A., Park, N., \& Peterson, C. (2005). Positive psychology progress: empirical validation of interventions. American Psychologist, 60(5), 410.

Sheldon, K. M., Abad, N., Ferguson, Y., Gunz, A., Houser-Marko, L., Nichols, C. P., \& Lyubomirsky, S. (2010). Persistent pursuit of need-satisfying goals leads to increased happiness: A 6-month experimental longitudinal study. Motivation and Emotion, 34(1), 39-48.

Sin, N., \& Lyubomirsky, S. (2009). Enhancing well-being and alleviating depressive symptoms with positive psychology interventions: a practice-friendly meta-analysis. Journal of Clinical Psychology, 65, 467 - 487.

Sin, N. L., Della Porta, M. D., \& Lyubomirsky, S. (2011). Tailoring positive psychology interventions to treat depressed individuals. In S. Donaldson, M. Csikszentmihalyi \& J. Nakamura (Eds.), Applied Positive Psychology: Improving everyday life, health, schools, work, and society, (pp.79-96).

Singer, J. A. (2005). Memories that matter: How to use self-defining New York: Tailor and Francis Group. Memories to understand \& change your life: New Harbinger Publications.

Valtorta, N. K., Kanaan, M., Gilbody, S., Ronzi, S., \& Hanratty, B. (2016). Loneliness and social isolation as risk factors for coronary heart disease and stroke: systematic review and meta-analysis of longitudinal observational studies. Heart, heartjnl-2015-308790.

Van der Plaats, J. (2002). Eindrapportage Zorg in Beeld Verlicht. Almelo: Gemeente Almelo

Van der Plaats, J. (2007). Eindrapportage Onderzoek PGB Welzijn. Almelo: Gemeente Almelo.

VanderWeele, T. J., Hawkley, L. C., \& Cacioppo, J. T. (2012). On the reciprocal association between loneliness and subjective well-being. American Journal of Epidemiology, 176(9), 777-784.

Veenhoven, R. (2008). Healthy happiness: effects of happiness on physical health and the consequences for preventive health care. Journal of Happiness Studies, 9(3), 449-469. doi:10.1007/s10902-006-9042-1.

Veenvliet, K. (2013). Risicofactoren voor een laag welbevinden: een onderzoek naar de relatie van eenzaamheid, gezondheidsproblemen en een lage sociaaleconomische status met het welbevinden. (Unpublished master thesis). University of Twente, Enschede, the Netherlands.

Vogeli, C., Shields, A. E., Lee, T. A., Gibson, T. B., Marder, W. D., Weiss, K. B., \& Blumenthal, D. (2007). Multiple chronic conditions: prevalence, health consequences, and implications for quality, care management, and costs. Journal of General Internal Medicine, 22(3), 391-395.

Westerhof, G. J. (2013). The complete mental health model: The social distribution of mental health and mental illness in the Dutch population. In Mental Well-Being (pp. 51-70): Springer.

Wilkinson, R. G. (1997). Socioeconomic determinants of health. Health inequalities: relative or absolute material standards? British Medical Journal, 314(7080), 591. 
General Introduction 

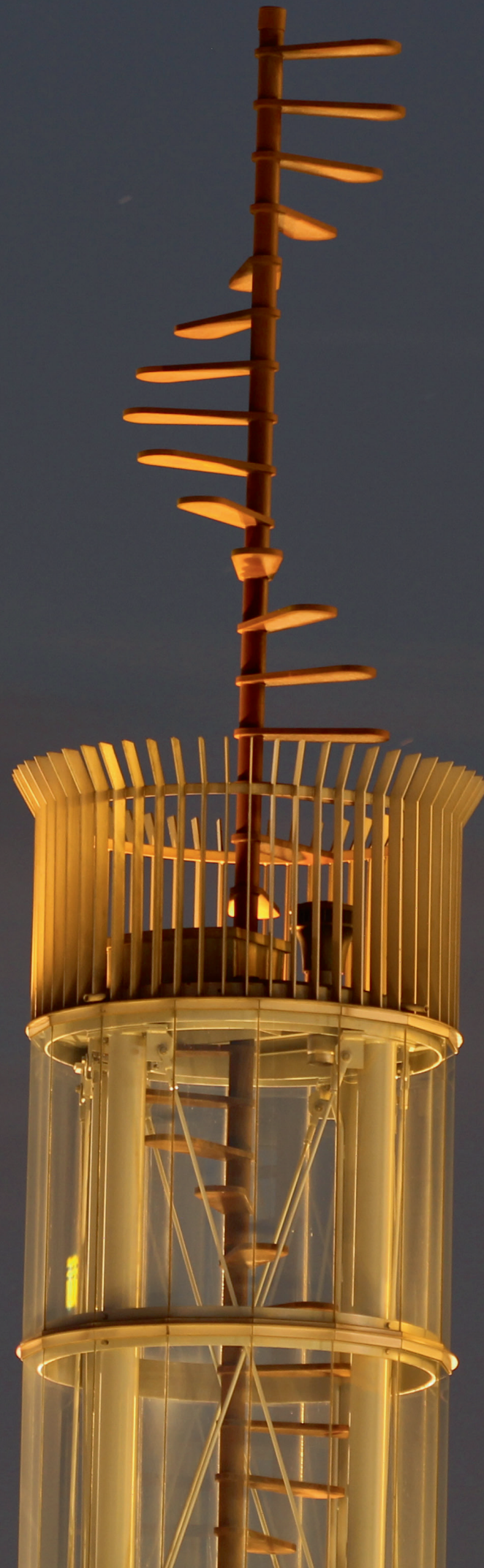


\section{2}

\section{Improving the Health Care Sector with a Happiness-Based Approach The Case of the Happiness Route}

\footnotetext{
11

Before that, I was like a snail, if you touch it, it retreats into its shell. You cannot get out of it on your own. [...] It felt nice that someone put his arm around me and took me along and at a certain point let me continue on my own.

川
}

Participant Happiness Route

This chapter is published as:

Weiss, L. A., Kedzia, S., Francissen, A. A., Westerhof, G. J. (2015). Improving the health care sector with a happiness-based approach. The case of the Happiness Route. In J. H. Søraker, J. W. van der Rijt, J. de Boer, P. H. Wong \& P. Brey (Eds.), Well-Being in Contemporary Society (pp. 59-71). Cham, Germany: Springer. doi:10.1007/978-3-319-06459-8_4 


\begin{abstract}
Background: Traditionally, the healthcare system focused on the prevention and treatment of health problems. Yet, this approach does not meet the challenges of recent societal and economic developments and is not always able to optimally help chronically ill people. We need alternatives for this group to enable them to live a pleasant, engaged and meaningful life. A holistic approach to healthcare, which strives to improve well-being in addition to treat problems and illness, can be beneficial to individuals and society. In recent years, this is acknowledged in welfare policies. Although theories and studies have shown ways to realize this, these insights are rarely translated into practice, with the Happiness Route as one of the few exceptions in the field.
\end{abstract}

Intervention: Well-being can be promoted through behavioural interventions. A recently developed intervention is the Happiness Route, a positive psychology intervention based on self-determination theory. It is aimed at people with an accumulation of risk factors for low well-being; social isolation, health problems and a low socioeconomic status. The goal of the intervention is to increase emotional, psychological and social well-being by engaging in intrinsically motivated activities. Participants receive between two and five home visits by a counsellor. Together, they explore and identify passions, interests, or hobbies that the participant really enjoys doing. The participant is encouraged to find and plan activities in accordance with his or her passion. Participants may spend up to $€ 500$ to engage in this activity.

Conclusions: We conclude that the development of more happiness-based interventions and the practical implementation of methods to promote well-being in health and social care are important. The Happiness Route is in line with the changing health policies that focus on promotion of well-being and can offer the positive focus these policies ask for. 


\section{Introduction}

Traditionally, academic disciplines like economics, sociology, psychology, and biomedical sciences have tended to focus more on what is going wrong than on what is going right. Historically, this made sense: with wars, poverty, social inequality, and other social issues in the first half of the $20^{\text {th }}$ century, there was a high individual and societal need to identify and solve problems. After the Second World War, welfare states arose in Western Europe that took care of the needs of individual citizens by providing social security, health care and retirement pensions. Now that these societies are experiencing the limits of the welfare state in times of economic instability, there is a need for other approaches. In many academic fields, we notice a shifting focus towards happiness and positive functioning. Some examples are happiness economics (Graham 2005), positive education (Seligman et al. 2009), positive leadership (Hannah et al. 2009), positive health (Seligman 2008) and positive psychology (Seligman and Czikszentmihaly 2000). In the Netherlands, this shift is also acknowledged in care and social work, as exemplified in programs that try to change welfare policies towards individual responsibilities and self-management of citizens. In this chapter, we will describe some of the limitations of the traditional problemfocused approach as well as the need to turn to happiness-based approaches. As an example of a happiness-based approach, we will describe an intervention called the 'Happiness Route' as well as some preliminary studies on this intervention.

\section{The Dutch healthcare system: from a problem-based to a happiness-based approach}

The Dutch welfare state mainly supports people in solving their problems, rather than aim to improve their well-being. The health-care system is especially focused on problems: the diagnosis and treatment of health problems is its main aim. Economically, this is supported by the fact that health insurance companies finance treatments based on valid diagnoses. The government has a strong hold on this system through laws and regulations to ensure the quality and accessibility of healthcare. However, it is an open question whether paying for treatment of disorders is actually the same as "caring for health". 
The problem-based approach has been very fruitful over the past fifty years. Partly because of innovations in problem-based health care, people tend to live ever longer. However, more and more people grow older with one or more chronic diseases. Although many people cope well with chronic diseases with the help of traditional health care, some of them continue to experience problems. Their everyday functioning is inhibited by their health problems, in particular when they experience multiple conditions. Especially when they do not have socioeconomic, social, and psychological resources to resiliently manage their disease(s), they may have to withdraw from social relations, work and other forms of societal participation. The response of the welfare state is to provide more support for these people, not only in terms of health care, but also in terms of social work and social security. It is thus not surprising that long term disability goes along with high economic costs for the society as well for the individuals (Valtorta and Hanratty 2013).

In their report on the social state of the Netherlands, Bijl et al. (2011) show that people who perceive their health condition as (very) bad are less happy than others. Whereas the Dutch on average appoint a 7.8 on a scale from 1 to 10 to their satisfaction with life, the group of people who consider themselves in a weak health condition judged themselves with a 6.4. Over the past years this difference has grown (Bijl et al. 2011). Other population studies have shown that well-being is not equally distributed in the population. Besides health limitations, low socio-economic status and social isolation are among the most important conditions of lower levels of well-being (Diener et al. 1999; Veenhoven 1996; Walburg 2008; Westerhof 2013; Westerhof and Keyes, 2010). In particular people who experience an accumulation of risk factors such as illness, low socioeconomic status and social isolation tend to experience low levels of well-being. Although the problem-based approach may help them to control certain problems, this approach seems less effective in helping them along in their life and in promoting their well-being.

Van der Plaats (1994) described the vicious circle in which these people get trapped. Their disease causes them to stop many of the activities they used to do, including their work. This in turn leads to a high risk of getting into idleness, which can be 
more stressful than having a life full of activities. This high stress level causes them to experience even more health-related complaints and, in turn, visit more health professionals for more treatment. Van der Plaats calls this group of people the 'sick sick', as opposed to the 'healthy sick'. The 'sick sick' end up in an almost hopeless situation: they clearly need some kind of help or support, but the traditional healthcare cannot provide this kind of help. New evidence-based interventions to break through this vicious circle have to be found in order to help these people with an accumulation of risk factors for low well-being. Shifting the focus away from more medical care to more well-being and better psychological and social functioning instead, is a promising start to do so (Van der Plaats 2002).

The problems with the traditional problem-based approach are not unrecognized. The professional and scientific field for prevention and treatment of mental and physical health is changing rapidly. It has recently been argued that it is important to complement the traditional focus of public institutions on the prevention and treatment of problems with a new goal: the promotion of positive mental health, well-being, and happiness (Barry and Jenkins 2007; Keyes 2007; Seligman and Csikszentmihalyi 2000; Walburg 2008; Westerhof and Bohlmeijer 2010; World Health Organisation 2005). Mental health has been defined by the World Health Organisation (2005) as a state of well-being, positive psychological functioning and positive social functioning and not merely the absence of disorders and complaints. From this perspective, the absence of problems and illnesses does not necessarily imply that individuals are functioning optimally. It is thus important to promote positive mental health, as the traditional focus on problems does not necessarily lead to a healthy population (Keyes 2007).

In the Netherlands this is acknowledged in social work and in public health, where changes in welfare policies towards individual responsibilities and self-management of citizens have been advocated (VWS 2010; VNG 2010; RVZ 2010). Not only do local councils in the Netherlands carry more legal responsibility for the provision of preventive interventions, there is also a shift in focus. The Dutch Council for Public Health and Health Care (RVZ 2010) has recently advised the Ministry of Health to 
shift the focus from 'illness and care' towards 'behaviour and health'. These changes ask for a more positive focus instead of the traditional problem focused approach and interventions. Not only the patients' problems, but also their well-being have to be a subject of interest. But what exactly is well-being, what are the effects of optimal well-being and how can it be improved?

\section{Well-being}

A theoretical basis for the concept and effects of well-being can be found in the movement of positive psychology. In addition to focussing on problems and how to solve them, this movement concentrates on positive emotions, traits and civic virtues (Seligman and Csikszentmihalyi 2000). The focus lies on well-being rather than on maladjustment and mental disorders.

There are different approaches on how to define and measure well-being. The two main perspectives, the hedonic and the eudaimonic view, are highlighted below. The hedonic view equates well-being with pleasure or happiness. It has a long tradition, reaching back to the ancient Greeks. In the recent hedonic psychology, Diener and Lucas (1999) established the concept of subjective well-being, which consists of life satisfaction, the presence of positive mood and the absence of negative mood. Many studies use this concept to define and measure happiness.

Hedonic Happiness with pleasure attainment as the principal criterion of well-being is rejected by the eudaimonic view. The eudaimonic approach posits meaning, growth and self-realization as core features of well-being. Eudaimonic well-being is described as a condition in which people live in accordance with their potential and values and in which they are fully engaged with their life activities. This state can be reached when people engage in activities that challenge personal growth and active goal-engagement and leads people to feel authentic and alive (Watermann 1993). Ryff and Singer (2010) have operationalized the eudaimonic approach on well-being into the concept of psychological well-being. Besides individual functioning, social functioning is acknowledged as an important aspect of eudaimonic well-being. Social well-being refers to the subjective evaluation of one's functioning in a social context (Keyes 1998). 
A number of studies have indicated that well-being includes aspects of both hedonism and eudaimonia (see Ryan and Deci 2001; Lamers 2011). Therefore, optimal well-being can be characterized as experiencing both high hedonic and eudaimonic well-being (Keyes 2005). Keyes developed an instrument that includes both hedonic (he calls it emotional) well-being and the two aspects of eudaimonic well-being (psychological and social well-being). This instrument is called the Mental Health Continuum - Short Form. In this paper, we use Keyes definition of well-being as emotional, psychological and social well-being.

Cross-sectional and longitudinal studies have shown that well-being has many positive effects. It is related to less medical consumption, better health, personal functioning, productivity, societal participation and even to longevity (Keyes 2002 and 2005; Keyes et al. 2010; Diener and Ryan 2009). Reviews and meta-analyses of hundreds of experimental and population studies show that the promotion of wellbeing will lead to considerable health gains for the individual and society (Lamers et al. 2011; Howell et al. 2007; Chida and Steptoe 2008; Lyubomirksy et al. 2005; Pressman and Cohen 2005; Veenhoven 2008; Cohen and Pressman 2006). But also for unhealthy populations, well-being has a positive influence on physical functioning and mortality (Lamers et al. 2011).

Experimental studies have shown that well-being can be promoted through behavioural interventions (e.g., Fledderus et al. 2010; Korte et al. 2012). Two recent meta-analyses concluded that it is possible to increase well-being (Bolier et al. 2013; Sin and Lyubomirksy 2009). Furthermore, many studies about the factors that might improve well-being have been conducted. Some factors are not changeable, like age, or not easily changeable by an intervention, like socio economic status. Other factors can be changed, thereby making it possible to improve someone's well-being. Goal-directedness and purpose in life are among the most important correlates and predictors of well-being (Diener et al. 1999). In particular, there is an abundance of studies showing that engagement in goal-directed activities is important for wellbeing (Westerhof and Bohlmeijer 2010 provide an overview). 
In conclusion, promoting well-being by enhancing positive psychological function, self-realization and social integration is a promising new approach (WHO 2005). Up to now, most studies on interventions remained experimental and there are only few projects that use this new, designated approach in a practice-based setting. One such project is the 'Happiness Route', a short behavioural intervention to promote well-being.

\section{The Happiness Route: Theoretical Basis}

The Happiness Route is rooted in positive psychology and is aimed at people with an accumulation of risk factors for low well-being; social isolation, health problems and a low socioeconomic status (SES). The primary goal of the intervention is to increase emotional, psychological and social well-being. Enhancing well-being is an important goal in positive psychology. A means of reaching this goal is engaging in intrinsically motivated activities. This helps the target group in becoming more resilient, finding a (new) meaning in life and connecting with others again. These secondary effects, resilience, meaning in life and positive relations with others, are concepts often examined in positive psychology.

With the growing interest in positive psychology, meaning in life has received renewed attention and legitimacy (Ryan and Deci 2001; Seligman and Csikszentmihalyi 2000). It is either seen as a part of psychological well-being (Ryff 1989), facilitating adaptive coping (Park and Folkman 1997) or indicating therapeutic growth (Crumbaugh and Maholick 1964; Frankl 1966). Zika and Chamberlain (1992) found a strong association between meaning in life and well-being. In the eudaimonic approach of well-being, meaning is an important concept. Ryff and Singer (1998) describe meaning as a key component for maximizing one's potentials. For a meaningful life, engaging in meaningful activities is central. Engagement in meaningful activities in turn leads to the experience of ample subjective well-being (Diener 2000).

The Happiness Route is based on the Self-Determination Theory (Ryan and Deci 2000), a theory that is widely used in positive psychology and has been extensively tested. It states that intrinsically motivated activities contribute to well-being, because they 
are important in fulfilling three basic psychological needs: autonomy, relatedness and competence (Ryan and Deci 2000). These needs have to be fulfilled in order to achieve both hedonic and eudaimonic well-being. The theory also acknowledges the social aspect of well-being, as it includes relatedness as one of the three basic human needs. In this sense, the theory fits our definition of well-being as well as our intervention. The Happiness Route stimulates intrinsic goal engagement and support autonomy, relatedness and the feeling of competence.

Besides psychological theories, the intervention Happiness Route draws on recent theoretical insights from economic theories. The economic theory of "nudging" (Thaler and Sunstein 2008; Tiemeijer et al. 2009) proposes that individuals do not always act on the basis of rational choices. It is therefore important to shape social systems in such a way that it is possible for citizens to act autonomously, while at the same time providing them with a gentle push in the right direction; a "nudge". The Happiness Route uses nudging to give participants a gentle push in the direction of positive development. Whereas the default nudge in the Dutch system is "What is your problem?" the Happiness Route provides the nudge: "How do you want to live your life?" and "What makes you happy?". The Happiness Route can thus serve as an example of the integration of the principles of positive psychology and nudging in practice.

\section{The Happiness Route Intervention}

The intervention is aimed at people who have become socially isolated due to health problems. They often have a low education, low financial means or both. But how can this literally invisible group be found? The project, conducted within a municipality, will locate these vulnerable citizens through intermediaries; local professionals or volunteers who are in contact with socially isolated people. The intermediaries may range from the general practitioner, the household help, the social worker, technicians working for the social housing corporation to local religious workers. The project leader of a local Happiness Route informs the intermediaries about the project and encourages them to refer socially isolated citizens to the project. They receive a package with information leaflets and forms relevant to the intervention 
and the ongoing study. This active, outreaching approach has proven to work well in practice. The outreach is necessary, as inactivity is one of the key features of the target group.

Participants receive between two and five home visits by a counsellor. Counsellors who deliver the Happiness Route receive training, where they learn about both theory and methods of positive psychology. After the counsellor forms a picture of the (problem) situation, he or she nudges the participant with questions like: "Let's put the problems aside and start talking about how you want to live your life. What makes you happy?". Together, the counsellor and participant explore and identify passions, interests, or hobbies that the participant really enjoys doing. The participant is encouraged to find and plan activities in accordance with his or her passion. Participants may spend up to $€ 500$ to engage in this activity. They receive this financial incentive, the 'happiness-budget', as most of them have few financial means. Participants receive the budget only once, as it is supposed to serve as a nudge toward a happier, more engaged and more meaningful life. For once, money is not an obstacle to start doing what the participant wants to do. Yet the money is not always needed, as some participants for example choose to do voluntary work. Most importantly, participants are encouraged to think about themselves, their wishes, values, talents and potential, rather than to think about their problems. Finally, an evaluation and early feedback session will be held. Counsellors make use of evidence-based methods during each phase, like behavioural activation and lifereview techniques. 


\section{Case description - Joe}

"Unfortunately, the days all looked the same ... even the food was something that I started to forget about. I didn't heat up my dinner anymore. I actually felt too miserable to heat it in the microwave. Too tired. Is it worth it to make the food hot? Would I eat it?" Joe, aged 66 years, described his situation before he followed the Happiness Route in an interview (Francissen, Wezenberg and Westerhof, 2010). He had lost his wife after two years of illness, around the same that time he retired. He suffered from asthma and chronic heart problems, for which he received the best possible health care. His general practitioner made home visits to his house once a month and he visited the cardiologist four times a year. In addition he received homecare and microwave meal delivery, he had a scoot mobile and he took a lot of medication. In spite of all the care, he felt miserable. Because of the demanding care he provided for his wife he had lost most of his contacts and by retiring he also lost his outdoor contacts. "The only thing I did during a week is go to the store and once to the library". He had slipped into social isolation.

One of the household helps from homecare was the intermediary who assigned him to the Happiness Route. A trained happiness counsellor from the community service visited him three times. The first meeting served as an intake; to get to know Joe, his situation and the things that are important in his life. This is the first phase of the Happiness Route: mutual definition of the situation. During this first visit, the counsellor actively stopped discussing Joe's problems and started applying positive psychology methods. This is where the second phase of the Happiness Route started: goal orientation. The goal of this second phase was to find Joe's passions and talents: things that he used to love doing, activities he was good at, or something he always dreamed to do. To do this, the counsellor made use of methods derived from positive psychology, such as life-review. The counsellors have been specifically trained to respect Joe's autonomy rather than by directing him toward something the counsellor thinks should be good for Joe. During the second home visit, the counsellor asked Joe what he always wanted to do in life. Joe pondered on this question for a while and then answered "Writing. I always wanted to do something with writing, but I never got to it." After having 
explored other talents and wishes, it was clear that writing was Joe's passion, something he was intrinsically motivated for. This made the third phase, choice of the activity in accordance with the passion of the participant, quite easy. Joe chose for a writing course at the local adult education centre. The counsellor asked Joe to find out more about the course, its time, place, costs and how he would get there. Although the counsellor might be quicker doing these things herself, an important part of the Happiness Route is to give the responsibility and control to the participant. Phase four, planning and doing the activity, was completely conducted by Joe himself. The only formality the counsellor had to do was filling in the application form for the happiness budget. Joe received the money on his bank account for one season of the writing course plus train tickets to travel to the adult education centre.

While following the course he performed writing assignments with other students and had to travel every week to the course location. He noticed a positive change in his life: "I was retired, but now that ... during the course, well, I had to talk to my fellow students, and that also affected my life outside the course evenings. I even felt confident and found it simply easier to just speak to someone in the shop or in the street. Not very complicated conversations, but just simple matters. I didn't do that before". Once he started taking part in the course, Joe's counsellor returned for the last phase. This is the so-called booster session, an early evaluation and feedback aimed at finding out whether the writing course was a successful choice.

Thanks to the Happiness Route Joe followed a full season of writing courses. After he had followed the Happiness Route, Joe explained that his heart condition and the severe asthma have not diminished. The amount of medication and homecare has not been changed. However, he described to the interviewer that despite his health issues, he now visits the general practitioner by himself only four times instead of twelve times a year and he visits the cardiologist only twice a year. He indicated that he is much happier in life and that he feels more socially related, not only directly through the course but also in everyday life. Last, but not least, he stated that he still receives home delivered microwave meals, but "now I eat them warm". 
The Happiness Route was developed by the local government of the city of Almelo in 2004 and received Dutch and European prizes for best practice. By now, Happiness Routes have been implemented in ten local councils in the Netherlands, made possible with a grant from the province of Overijssel. Over 80 consultants have been trained and more than 500 participants have been supported through the intervention.

From this practical experience, there is some knowledge on the ingredients for a successful implementation of the Happiness Route. (1) The project needs an organisation to get it started. The organisation must have some relation to the target group. It can be a local council or a civil society organisation like a local Rotary club or a welfare organisation. (2) The project needs an intrinsically motivated project leader who has a substantial local network. (3) Money is needed for the Happiness budgets and can be sourced from (social and health related) funds and / or the local council. The number of participants of most of the Dutch projects varies between 10 to 50 participants per municipality each year. That means the project needs a reserve between $€ 5.000$ and $€ 25.000$ Euro for the individual, one-time-only budgets of $€ 500$. (4) Each project needs a structured set of documentation that can be downloaded from www.geluksroute.nl. (5) A small group of experienced counsellors need a one-day training course on the specifics of the delivery of the happiness-based approach and the structure of the project. These counsellors can be both experienced volunteers and professionals. Most of these professionals work for social welfare organisations, whose job it is for instance, to support senior citizens in need. For these counsellors the Happiness Route will be one of the interventions available, for use with clients. (6) Finally, before the project can actually start, the intermediaries described above have to be informed and inspired to recruit participants. It is one of the tasks of the local project leader to do so.

\section{Empirical studies}

Besides the positive experiences from practice, studies on the Happiness Route have shown that the intervention reaches the intended group, which belongs to the most vulnerable members of society, and is well-received by counsellors and participants (Van der Plaats 2007; Kedzia 2009, Francissen et al. 2010). 
Peeters Weem (2011) conducted a study on the presence of similar projects in the Dutch welfare sector, which promote happiness and related concepts. He concluded that there are only very few interventions that use a happiness-based approach. Most of these projects are based upon pragmatic insights, but lack a theoretical base. The Happiness Route is an exception, as it is rooted in theories of behavioural economy and positive psychology.

A case file analysis showed that the Happiness Route resulted in new intrinsically motivated activities, focusing on establishing new contacts, new experiences, going out, and learning (Kedzia 2009). In this analysis of 80 case files, it was also found that most participants chose an activity that challenged their specific complaint. Given the social isolation and health problems, this analysis revealed a functional use of the budget.

A qualitative pilot study on the Happiness Routes showed that participants retrospectively rated their well-being to be increased by $40 \%$, and their use of healthcare to be decreased by $23 \%$ (Francissen et al. 2010). These effects were found up to two years after the one-time-only intervention was received.

Now that these pilot studies have shown promising results, it is time to conduct a randomized controlled trial and take a closer look at the effect of the Happiness Route. Given the practice based research setting, the study is a pragmatic, nonblind, multi-site randomized controlled trial in nine Dutch cities. The main goal of the proposed project is to study the effectiveness of the Happiness Route compared to the active control group 'Customized Care', for whom the traditional problembased approach is used to optimize the existing health care. The primary outcome is emotional, psychological and social well-being, as measured with the Dutch Mental Health Continuum-Short Form (MHC-SH). Participants will fill in questionnaires at baseline as well as three months and nine months later. Consumption of care will be analysed using data from Vektis, the Dutch information centre for care. Detailed information about the research design can be found in the study protocol (Weiss et al. 2013). The study is currently underway and the final results will be available in 2015. 


\section{Conclusion and discussion}

There is a great deal of evidence that a holistic approach to healthcare that does not only focus on illness but also on well-being can be beneficial for individuals and society. The traditional problem-focused system has reached its boundaries when it comes to dealing with a group of chronically ill people and the challenges of new societal and economic developments. New approaches are needed in order to help chronically ill people with less socioeconomic means and in social isolation to lead a more pleasant, engaged and meaningful life. Theoretical insight and empirical evidence show what needs to be done in order to achieve this goal. Yet these insights are not often translated into practice. The Happiness Route is one of the rare exceptions.

The example of the Happiness Route indicates that the happiness-based approach in the health sector can be effective. It may increase well-being and decrease selfreported health-care consumption. The results so far are promising, but more research is needed. The outcomes of a large RCT will show if a happiness-based approach is superior to the traditional problem-based approach in terms of wellbeing, psychosocial functioning and health care consumption. Existing studies on positive psychological interventions up to now are small, carried out in experimental settings, and with rather privileged groups. The present study tackles these shortcomings and can provide new insights in the possibilities for the promotion of well-being in a naturalistic setting. If the effects of the intervention prove to be positive, this may contribute to the practical implementation of positive concepts such as well-being into policies of governments, health-care organizations and other entities of society and lead to more happiness-based interventions.

\section{Acknowledgement}

We want to thank David Maylia sincerely for proofreading the text and his helpful suggestions. 


\section{References}

Barry, Margaret M., and Rachel Jenkins. 2007. Implementing Mental Health Promotion. Oxford, Churchill Livingstone, Elsevier.

Bijl, Rob, Jeroen Boelhouwer, Mariëlle Cloïn, and Evert Pommer (Eds.). 2011. De sociale staat van Nederland 2011. Den Haag: Sociaal en Cultureel Planbureau.

Bolier, Linda, Merel Haverman, Gerben J. Westerhof, Heleen Riper, Filip Smit, and Ernst T.

Bohlmeijer. 2013. Positive psychology interventions: a meta-analysis of randomized controlled studies. BMC Public Health 13(1): 119.

Chida, Yoichi, and Andrew Steptoe. 2008. Positive psychological well-being and mortality: A quantitative review of prospective observational studies. Psychosomatic Medicine 70: 741-756.

Cohen, Sheldon., and Sarah D. Pressman. 2006. Positive affect and health. Current Directions in Psychological Science 15(3): 122-125.

Crumbaugh, James C., and Leonard T. Maholick. 1964. An experimental study in existentialism: The psychometric approach to Frankl's concept of noogenic neurosis. Journal of Clinical Psychology 20: 200-207.

Diener, Ed. 2000. Subjective well-being: The science of happiness and a proposal for a national index. American Psychologist 55:34-43.

Diener, Ed, and Richard E. Lucas. 1999. Personality and subjective wellbeing. In Well-being: The foundations of hedonic psychology, ed. Kahneman, D., Diener, E., Schwarz, N. 213-229. New York: Russell Sage Foundation.

Diener, Ed, and Katherine Ryan. 2009. Subjective well-being: a general overview. South African Journal of Psychology 39(4): 391-406.

Diener, Ed, Eunkook M. Suh, Richard E. Lucas, and Heidi L. Smith. 1999. Subjective well-being: Three decades of progress. Psychological Bulletin 125: 276-302.

Fledderus, Martine, Ernst T. Bohlmeijer, Filip Smit, and Gerben J. Westerhof. 2010. Mental health promotion as a new goal in public mental health care: A randomized controlled trial of an intervention enhancing psychological flexibility. American Journal of Public Health 100: 2372-2378.

Francissen, Aad, Eddy Wezenberg, and Gerben J. Westerhof. 2010. De gevolgen van geluk; Achtergronden en toekomst van het geluksbudget. Borne: Arcon.

Frankl, Viktor E. 1966. What is meant by meaning? Journal of Existentialism 7: 21-28.

Graham, Carol. 2005. The economics of happiness. World Economics 6(3): 41-55.

Hannah, Sean T., Robert L. Woolfolk, and Robert G. Lord. 2009. Leader self-structure: a framework for positive leadership. Journal of Organizational Behavior 30(2): 269-290.

Howell, Ryan T., Margaret L. Kern, Sonja Lyubomirsky. 2007. Health benefits: Meta-analytically determining the impact of well-being on objective health outcomes. Health Psychology Review 1: 83-136.

Kedzia, Sarah. 2009. What makes you happy? Evaluating an intervention aimed at promoting social participation. (Unpulished master thesis). Enschede: University of Twente.

Keyes, Corey L.M. 1998. Social well-being. Social Psychology Quarterly 61(2): 121-140.

Keyes, Corey L.M. 2002. The mental health continuum: From languishing to flourishing in life. Journal of Health and Social Behavior 43(2): 207-222. Keyes, Corey L.M. 2005. Mental illness and/or mental health? Investigating axioms of the complete state model of health. Journal of Consulting and Clinical Psychology 73: 539-548.

Keyes, Corey L.M. 2007. Promoting and protecting mental health as flourishing: A complementary strategy for improving national mental health. American Psychologist 62: 95-108. 
Keyes, Corey L., Satvinder S. Dhingra, and Eduardo J. Simoes. 2010. Change in level of positive mental health as a predictor of future risk of mental illness. American Journal of Public Health 100(12): 2366-2371.

Korte, Jojanneke, Ernst T. Bohlmeijer, Philippe Cappeliez, Filip Smit, and Gerben J. Westerhof. 2012. Life review therapy for older adults with moderate depressive symptomatology: a pragmatic randomized controlled trial. Psychological Medicine 42(6):1163-73.

Lamers, Sanne M.A., Linda Bolier, Gerben J. Westerhof, Filip Smit, and Ernst T. Bohlmeijer. 2011. The impact of emotional well-being on long-term recovery and survival in physical illness: A meta-analysis. Journal of Behavioral Medicine 35(5): 538-547.

Lyubomirsky Sonja, Laura A. King, and Ed Diener. 2005. The benefits of frequent positive affect: Does happiness lead to success? Psychological Bulletin 131: 803-55.

Park, Crystal L., and Susan Folkman. 1997. Meaning in the context of stress and coping. Review of General Psychology, 1(2): 115-144.

Peters Weem, Bart 2011 Geluk in de Praktijk; Een verkenning van het gebruik van concepten als geluk (happiness) in Nederlandse welzijnsprojecten. Masterthesis. Enschede: Universiteit Twente.

Pressman, Sarah D., and Sheldon. Cohen. 2005. Does positive affect influence health? Psychological Bulletin 131(6): 925-971. Plaats, Anneke J. van der 1994. Geriatrie: een spel van evenwicht. Dissertation. Assen: Van Gorcum.

Plaats, Anneke J. van der 2002. Eindrapportage Zorg in Beeld Verlicht. Almelo: Gemeente Almelo. Plaats, Anneke J. van der 2007. Eindrapportage Onderzoek PGB Welzijn. Almelo: Gemeente Almelo.

Raad voor de Volksgezondheid en Zorg. 2010. Zorg voor je gezondheid! Gedrag en gezondheid: De nieuwe ordening. Den Haag: RVZ.

Raad voor de Volksgezondheid en Zorg RVZ. 2010. Perspectief op gezondheid 20/20. Den Haag: Koninklijke Broese and Peereboom b.v.

Ryan, Richard M. and Edward L. Deci. 2000. Self-Determination Theory and the Facilitation of Intrinsic Motivation, Social Development, and Well-Being. American Psychologist 55: 68-78.

Ryan, Richard M., and Edward L. Deci. 2001. On happiness and human potentials: A review of research on hedonic and eudaimonic well-being. Annual Review of Psychology 52: 141-166.

Ryff, Carol D. 1989. Happiness is everything, or is it? Explorations on the meaning of psychological well-being. Journal of Personality and Social Psychology 57(6): 10691081.

Ryff, Carol D., and Burton Singer. 1998. The role of purpose in life and personal growth in positive human health. In The human quest for meaning: A handbook of psychological research and clinical applications ed. Wong, P.T., Fry, P.S. 213-235. Mahwah, NJ: Lawrence Erlbaum Associates Publishers.

Ryff, Carol D., and Burton Singer. 2010. Psychological well-being: Meaning, measurement, and implications for psychotherapy research. Psychotherapy and Psychosomatics 65(1): 14-23.

Seligman, Martin E.P. 2008. Positive Health. Applied Psychology: An International Review 57: 3-8.

Seligman, Martin E.P., and Mihaly Csikszentmihalyi. 2000. Positive psychology: An introduction. American Psychologist 55: 5-14.

Seligman, Martin E.P., Randal M. Ernst, Jane Gillham, Karen Reivich, and Mark Linkins. 2009. Positive education: Positive psychology and classroom interventions. Oxford Review of Education 35(3): 293-311. 
Sin, Nancy L., and Sonja Lyubomirsky. 2009. Enhancing well-being and alleviating depressive symptoms with positive psychology interventions: A practice-friendly meta-analysis. Journal of Clinical Psychology 65: 467-487.

Thaler, Richard H., and Cass R. Sunstein. 2008. Nudge. Improving decisions about health, wealth and happiness. London: Yale University Press.

Tiemeijer, Will L., Casper A. Thomas, and Henriëtte M. Prast. 2009. De menselijke beslisser. Over de psychologie van keuze en gedrag. Amsterdam: Amsterdam University Press.

Valtorta, Nicole K., and Barbara Hanratty. 2013. Socioeconomic variation in the financial consequences of ill health for older people with chronic diseases: A systematic review. Maturitas 74(4): 313-333.

Veenhoven, Ruut. 1996. Developments in satisfaction research. Social Indicators Research 37: 1-46.

Veenhoven, Ruut. 2008. Healthy happiness: Effects of happiness on physical health and the consequences for preventive health care. Journal of Happiness Studies 9: 449-469.

Vereniging van Nederlandse Gemeenten VNG. 2010. Kantelen in de Wmo: Handreiking voor visieontwikkeling en organisatieverandering. Den Haag: Vereniging van Nederlandse Gemeenten.

Ministerie van Volksgezondheid, Welzijn en Sport. 2010. Welzijn nieuwe stijl. Den Haag: Ministerie van Volksgezondheid, Welzijn en Sport.

Walburg, Jan. 2008. Mentaal vermogen: Investeren in geluk. Nieuw Amsterdam.

Waterman, Alan S. 1993. Two conceptions of happiness: contrasts of personal experience (eudaimonia) and hedonic enjoyment. Journal of Personality and Social Psychology 64: 678-91.

Weiss, Laura A., Gerben J. Westerhof, and Ernst T. Bohlmeijer. 2013. Nudging socially isolated people towards well-being with the 'Happiness Route': design of a randomized controlled trial for the evaluation of a happiness-based intervention. Health and Quality of Life Outcomes, 11(1), 1-11.

Westerhof, Gerben J. 2013. The complete mental health model: The social distribution of mental health and mental illness in the Dutch population. In Mental well-being: International contributions to the study of positive mental health, ed. Keyes, C.L.M 51-70. New York: Springer.

Westerhof, Gerben J., and Ernst T. Bohlmeijer. 2010. Psychologie van de levenskunst. Amsterdam: Boom.

Westerhof, Gerben J., and Corey L.M. Keyes. 2010. Mental illness and mental health: The two continua model across the lifespan. Journal of Adult Development 17: 110-119.

World Health Organization. 2005. Promoting mental health: Concepts, emerging evidence, practice. Geneva: WHO.

Zika, Sheryl, and Kerry Chamberlain. 1992. On the relation between meaning in life and psychological well-being. British Journal of Psychology 83(1): 133-145. 
Improving the Health Care Sector with a Happiness-Based Approach 


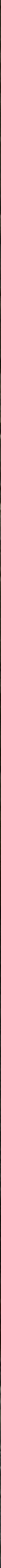




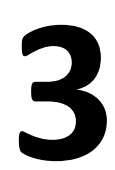

\section{Can We Increase Psychological Well-Being? The Effects of Interventions on Psychological Well-Being: A Meta- Analysis of Randomized Controlled Trials}

"A joyful life is an individual creation that cannot be copied from a recipe.

$\boldsymbol{l}$

Mihaly Csikszentmihalyi

This chapter is published as:

Weiss, L. A., Westerhof. G. J., \& Bohlmeijer, E. T. (2016). Can we increase psychological well-being? The Effects of Interventions on Psychological Well-Being: A Meta-Analysis of Randomized Controlled Trials. PLOS ONE, 11(6). doi:10.1371/journal.pone.0158092 


\begin{abstract}
Background: There is a rapidly growing interest in psychological well-being (PWB) as outcome of interventions. Ryff developed theory-based indicators of PWB that are consistent with a eudaimonic perspective of happiness. Numerous interventions have been developed with the aim to increase PWB. However, the effects on PWB measured as coherent outcome have not been examined across studies yet. This meta-analysis of randomized controlled trials of behavioral interventions aims to answer the question whether it is possible to enhance PWB.
\end{abstract}

Methods: A systematic literature search was performed in PsycINFO, Cochrane and Web of Science. To be included, studies had to be randomized controlled trials of behavioral interventions with psychological well-being as primary or secondary outcome measure, measured with either Ryff's Psychological Well-Being Scales or the Mental Health Continuum - Short Form. The meta-analysis was performed using a random effects model. From the 2,298 articles found, 27 met the inclusion criteria. The included studies involved 3,579 participants.

Results: We found a moderate effect (Cohen's $d=0.44 ; z=5.62 ; p<.001$ ). Heterogeneity between the studies was large $\left(Q(26)=134.12 ; p<.001 ; I^{2}=80.62\right)$. At follow-up after two to ten months, a small but still significant effect size of 0.22 was found. There was no clear indication of publication bias. Interventions were more effective in clinical groups and when they were delivered individually. Effects were larger in studies of lower quality.

Conclusions: It appears to be possible to improve PWB with behavioral interventions. The results are promising for the further development and implementation of interventions to promote PWB. Delivering interventions face-to-face seems to be the most promising option. We recommend to keep including clinical groups in the research of psychological well-being. Heterogeneity is a limitation of the study and there is need for more high-quality studies. 


\section{Introduction}

In the last years, the focus in mental healthcare and prevention has shifted from solely treating or preventing mental health complaints to enhancing positive aspects of mental health. A new goal in mental healthcare is the promotion of well-being (Barry \& Jenkins, 2007; Keyes, 2007; Seligman \& Csikszentmihalyi, 2000; World Health Organization, 2005). However, there are currently many definitions of wellbeing (Dodge, Daly, Huyton, \& Sanders, 2012), with the two main concepts being subjective and psychological well-being.

Subjective well-being builds on a hedonic framework in which striving for positive experiences is central. It is usually measured as satisfaction with life in combination with a balance between positive and negative emotions (Diener, 1984). The standards that people use to judge their subjective well-being were not theorized in this framework. By contrast, Carol Ryff introduced the concept psychological well-being with the intention to develop theory-based indicators of positive human functioning that were consistent with a eudaimonic perspective of happiness (Ryff, 1996). Another well-researched theory in the eudaimonic tradition is the self-determination theory that states that the fulfillment of basic psychological needs is essential to well-being and growth (Ryan \& Deci, 2001).

The variety of concepts and measures makes it difficult to compare studies (Hone, Jarden, \& Schofield, 2015). It is therefore important to be precise in one's definition of well-being. This paper focuses on the concept of psychological well-being according to Ryff's definition (Ryff, 1989b). Earlier meta-analyses have already examined subjective well-being (Bolier, Haverman, Westerhof, et al., 2013; Sin \& Lyubomirsky, 2009). The latest meta-analysis has also included psychological well-being, but measured it in a very broad way with many different instruments (Bolier, Haverman, Westerhof, et al., 2013). We will conduct the first meta-analysis that exclusively examines psychological well-being as defined by Ryff. 
Based on an extensive review of the literature of clinical, humanistic and life-span developmental psychology, as well as existential and utilitarian philosophy, Ryff (1989b) defined psychological well-being as a process of self-realization, consisting of six dimensions: autonomy, environmental mastery, personal growth, positive relations with others, purpose in life and self-acceptance. There is some discussion on the six-factor structure (Abbott et al., 2006) and whether psychological and subjective well-being are two separate but related dimensions or one overarching construct (Disabato, Goodman, Kashdan, Short, \& Jarden, 2015).

Recently Ryff (2014), reviewed over 350 empirical studies on psychological wellbeing that have been conducted in the past decades. Longitudinal studies show that high levels of psychological well-being are a protective factor against mental illnesses and psychopathology (Keyes, Dhingra, \& Simoes, 2010b; Lamers, Westerhof, Glas, \& Bohlmeijer, 2015; Wood \& Joseph, 2010) and that it is also related to biological markers of physical health, reduced risk for various diseases such as Alzheimer's disease, and a longer life-duration (Ryff, 2014). This growing evidence of positive outcomes of psychological well-being makes it worthwhile to study whether we can improve it.

However, as existing studies show that psychological well-being is rather stable across time (Lamers, Glas, Westerhof, \& Bohlmeijer, 2012), an important question is whether it can indeed be promoted in interventions. Answering this question will provide more insight into the state or trait discussion whether characteristics of psychological well-being are more trait-like or state-like (Schimmack, Krause, Wagner, \& Schupp, 2010).

In recent years, there has been a rapid increase of studies on behavioral interventions that included psychological well-being as an outcome measure (e.g. (Fledderus, Bohlmeijer, Smit, \& Westerhof, 2010; Korte, Bohlmeijer, Cappeliez, Smit, \& Westerhof, 2012)). A central aim of interventions such as well-being therapy (Fava, Rafanelli, Cazzaro, Conti, \& Grandi, 1998a; Fava et al., 2005), acceptance and commitment therapy (Hayes, Levin, Plumb-Vilardaga, Villatte, \& Pistorello, 2013), life-review therapy (Westerhof, Bohlmeijer, \& Webster, 2010), and positive psychological 
interventions (Lee Duckworth, Steen, \& Seligman, 2005) is to enhance positive psychological functioning. Meta-analyses have shown that these interventions are successful in enhancing certain aspects of psychological well-being (Bohlmeijer, Roemer, Cuijpers, \& Smit, 2007; Bolier, Haverman, Westerhof, et al., 2013; Sin \& Lyubomirsky, 2009b), but as mentioned, they measured psychological well-being with many different measurement instruments that do not all fit the definition of Ryff. To which extent interventions have an impact on psychological well-being as a coherent construct of positive psychological functioning is unclear. Also, only positive psychological interventions were included, thereby neglecting the increasing number of interventions that addressed psychological well-being in other disciplines.

Hence, we will take the next step in reviewing the evidence on psychological well-being by conducting a meta-analysis on the effects of different behavioral interventions on psychological well-being as a coherent construct across randomized controlled trials. We want to examine whether well-being can be changed as a function of behavioral interventions.

\section{Methods}

\section{Eligibility criteria}

Study eligibility criteria. The research question and inclusion criteria were established before the meta-analysis was conducted. Psychological well-being had to be used as primary or secondary outcome measure. To examine it as coherent construct, it had to be measured either with Ryff's Psychological Well-Being Scales (PWBS) (Ryff, 1989b) with all six dimensions of psychological well-being as study endpoints, or with the subscale 'Psychological Well-Being' of the Mental Health Continuum -Short Form (MHC-SF) (Keyes, 2002b; Keyes et al., 2008b). The MHC-SF also assesses psychological well-being with the six dimensions of Ryff's model. If the MHC-SF was used, the data of the subscale psychological well-being had to be available. Research on the MHCSF in different cultures has provided support for its psychometric properties and its three dimensional factor structure (Joshanloo, Wissing, Khumalo, \& Lamers, 2013; Lamers et al., 2011). The reliability and validity of the PWBS has been established in different versions and across various cultures (e.g. (Cheng \& Chan, 2005; Ryff \& Keyes, 
1995)). Yet it has to be noted that the a priori six-factor structure is debated (Abbott et al., 2006). This problem appears to be exacerbated by the existence of multiple forms of the test, ranging from 18 to 120 items. There is also discussion whether the PWBS is able to discriminate between higher levels of well-being (Abbott, Ploubidis, Huppert, Kuh, \& Croudace, 2010).

Only randomized controlled trials (RCTs) of behavioral interventions were included, excluding pharmacological interventions. We focused on all study populations, including both healthy and clinical populations of any age. Waiting list, no treatment, care-as-usual, placebo, or alternative treatment groups were included as comparators.

Report eligibility criteria. To be included, an article had to be published in Englishlanguage peer-reviewed journals, excluding books, dissertations and conference proceedings. No publication date restriction was imposed. Data necessary to calculate the effect size had to be available in the article or upon request.

\section{Search strategy and selection of studies}

Information sources. A systematic literature search was performed in the databases of the Cochrane Library, PsycINFO, and Web of Science. The last search was run on 13 April 2015. The first and second author developed the search with the help of an information specialist. The first author (LAW) and a trained student assistant (PDW) conducted the search. We screened the reference lists of included studies and of the meta-analyses of Sin and Lyubomirsky (2009), Bolier et al. (2013) and the review of Ryff (2014) for additional potentially eligible studies. Finally, we invited four experts in the field to suggest additional studies that might meet the inclusion criteria.

Search. Search terms were Ryff* or "mental health continuum" or "psychological well-being" or "psychological wellbeing" in all fields of the database, combined with one of the following terms in the title or abstract: intervention or therapy or treatment or random* or control* or trial or RCT. Search strings were adapted to the according database. No limitations were used. 
Study selection. Two data extractors (LAW and PDW) assessed the eligibility independently in a standardized manner. The retrieved records from the database search were screened by title and abstract. First, the extractors screened the first ten publications in PsycINFO together and discussed the results, and then both screened the next 100 studies in PsycINFO independently. They performed an interrater reliability check where Cohen's kappa was 0.71 , which is considered 'good' (Altman, 1990). A consensus procedure for disagreement between them was established and disagreements were resolved by consensus. The remainder of the records were screened by the two researchers independently. After the titles and abstracts were screened for possible inclusion, full articles were assessed for eligibility.

\section{Data collection}

Data items. Information was extracted from each included study on (1) study sample; (2) outcome measure (Ryff's PWBS or MHC-SF) with number of items; (3) type of intervention; (4) number of sessions and treatment duration in weeks; (5) control group; (6) total sample size; (7) mean age of the sample with standard deviation or range; and (8) quality assessment.

Data collection process. LAW extracted the data from the included studies with a data extraction sheet, PDW checked the extracted data. Disagreements were resolved by discussion. We contacted 14 authors through e-mail for additional data. Seven authors responded and provided the unpublished data. In one case, data was obtained via the author of an earlier meta-analysis where the study was included. One author had lost the data due to a hard drive failure. For the remaining five articles, the authors did not respond. All in all, six studies could not be included due to missing data.

\section{Quality assessment}

Quality was assessed with eight criteria, partly based on the criteria of the Cochrane collaboration (Higgins et al., 2011) tailored for the included studies. (1) Was the randomization adequately described? (2) Were drop-out and reasons for dropout properly described? (3) In case of drop-out, was an intention-to-treat analysis 
performed? (4) Were the professionals who delivered the intervention adequately qualified? (5) Was a power analysis carried out or were a total of at least 128 participants included (i.e., could the trial detect a moderate change according to a power analysis with Cohen's $d=.50$, alpha=.05, power (1-beta) =.80)? (6) Was the treatment integrity checked? (7) Were the outcome measures at baseline assessed and study groups comparable? In the case of differences between groups, were adjustments made to correct for baseline imbalance? (8) Were inclusion/exclusion criteria described?

Each criterion was scored with 0 or 1 . As certain criteria were not applicable to some studies, the percentage of items scored 1 across all applicable criteria was calculated. We classified study quality as lower ( $<40 \%$ quality index), intermediate $(41-75 \%)$ or higher (>75\%). For details, see Table 1 . We included quality as a moderator in the moderator analysis, as we hypothesized that the effect size may differ between studies depending on the quality of the studies.

\section{Data analysis}

All analyses were completed with the program Comprehensive Meta-Analysis (CMA, version 2.2.064). We used the random effects model and a $95 \%$ confidence interval with two-tailed tests.

Summary measures. We expected considerable heterogeneity due to diverse intervention types and populations. Therefore, the meta-analysis was performed using a random effects model. If possible, outcomes from an intention-to-treat analysis were used. Samples for completers only were used when intention-to-treat samples were not provided. The primary outcome statistic was the standardized difference in means. For each study, between-group effect sizes were computed, using Cohen's d. When Ryff's PWBS were used, the six dimensions were joined in one outcome measure. Standard deviations were reconstructed from $\mathrm{p}$-values or $\mathrm{t}$ statistics when necessary. Lipsey's rules for interpretation were used: small effect sizes range from 0 to 0.32 , medium effect sizes range from 0.33 to 0.55 and large effect sizes are 0.56 or higher (Lipsey, 1990). 
Table 1. Methodological Quality Assessment Criteria.

\begin{tabular}{lll}
\hline Criteria & $\mathbf{1}$ & $\mathbf{0}$ \\
\hline 1) Randomization & $\begin{array}{l}\text { Adequate description of } \\
\text { randomization in text about how the } \\
\text { randomization was done. }\end{array}$ & $\begin{array}{l}\text { Randomization not described } \\
\text { or only 'participants were } \\
\text { randomly assigned'. }\end{array}$ \\
$\begin{array}{ll}\text { 2) Description of } \\
\text { drop-out }\end{array}$ & $\begin{array}{l}\text { Drop-out was described (numbers } \\
\text { and reason of drop-out) or dropout } \\
\text { analysis was performed, or a flow } \\
\text { chart has been included, or there was } \\
\text { no dropout. }\end{array}$ & $\begin{array}{l}\text { No description of drop-out, } \\
\text { or only stating that there } \\
\text { was drop-out without giving } \\
\text { numbers, or not stating the } \\
\text { reasons. }\end{array}$ \\
$\begin{array}{ll}\text { 3) Intention to treat } \\
\text { analysis }\end{array}$ & $\begin{array}{l}\text { Intention to treat analysis was } \\
\text { performed, or there were no } \\
\text { dropouts. }\end{array}$ & $\begin{array}{l}\text { Completers-only analysis was } \\
\text { used or it was not stated. }\end{array}$ \\
4) Qualified \\
professionals & $\begin{array}{l}\text { At least one of the professionals } \\
\text { was experienced or trained or was a } \\
\text { schooled psychologist / psychiatrist or } \\
\text { health professional. }\end{array}$ & $\begin{array}{l}\text { Specific experience or training } \\
\text { was not reported. }\end{array}$ \\
\end{tabular}

5) Power analysis / Adequate power analysis or a total of No power analysis and less $n \geq 128$ minimal 128 participants (moderate effect of 0.5 , t-test, 2-sided, alpha 0.05 , power 0.8 ). than 128 participants in total or calculated power was not reached.
6) Treatment Treatment integrity was checked integrity (supervision of the professionals during the intervention or recording of the sessions or systematic screening of protocol adherence). Treatment integrity not checked or not reported.

\section{7) Baseline comparability}

Comparability of the outcome measures at baseline. It was explicitly assessed if study groups were comparable at the beginning of the study. It was stated if the groups are comparable or not. In the case of differences between groups at baseline, adjustments were made to correct for baseline imbalance by using appropriate covariates.

8) Inclusion/ exclusion
Inclusion or exclusion criteria were adequately described.
No description for inclusion or exclusion criteria. 
Heterogeneity. To evaluate between-study variability, we tested for heterogeneity with the chi-squared test Cochran's $Q$ and $I^{2}$ statistics, which quantifies the amount of variation in results across studies, beyond the expected chance. The heterogeneity analysis was performed with a random effect model, a 95\% confidence interval and a two-tailed test.

Moderators. Moderator analyses were conducted with the following moderators and categories: (1) target group: clinical (psychopathological or health problems) or non-clinical; (2) age of target group: adolescence/young adulthood ( $\leq 25$ years), adulthood ( $26-55$ years) or later life ( $\geq 55)$; (3) intervention type: self-help, individual face-to-face, or group face-to-face; (2) number of sessions: less ( $\leq 8$ studies) or more (> 8 sessions); (5) instrument: PWBS or MHC-SF; (6) control group: not active (no treatment, waiting list, or care-as-usual) or active (placebo or alternative treatment); (7) quality: lower (<40\%), intermediate $(41 \%-75 \%)$ or higher quality $(\geq 75 \%)$.

Publication bias. The risk of publication bias was estimated using a funnel plot, the Egger's test and a trim and fill analysis.

Follow-up assessment. When available, between-group effect sizes (Cohen's d) were computed for follow-up differences in psychological well-being.

\section{Results}

\section{Study selection}

Figure 1 summarizes the database hits, (reasons for) exclusion and final inclusion in a flow diagram. We found 2631 records from Web of Science (1151), the Cochrane Library (1026), and PsycINFO (454), and Reference lists searches added four studies and expert consultation two studies. After adjusting for duplicates, 2298 studies remained and were screened for title and abstract. Of these, 2150 were discarded as the studies did not meet the inclusion criteria. The full texts of the remaining 148 studies were assessed for eligibility. 121 studies did not meet the inclusion criteria. Finally, a total of 27 studies met the inclusion criteria and were included in the metaanalysis. 


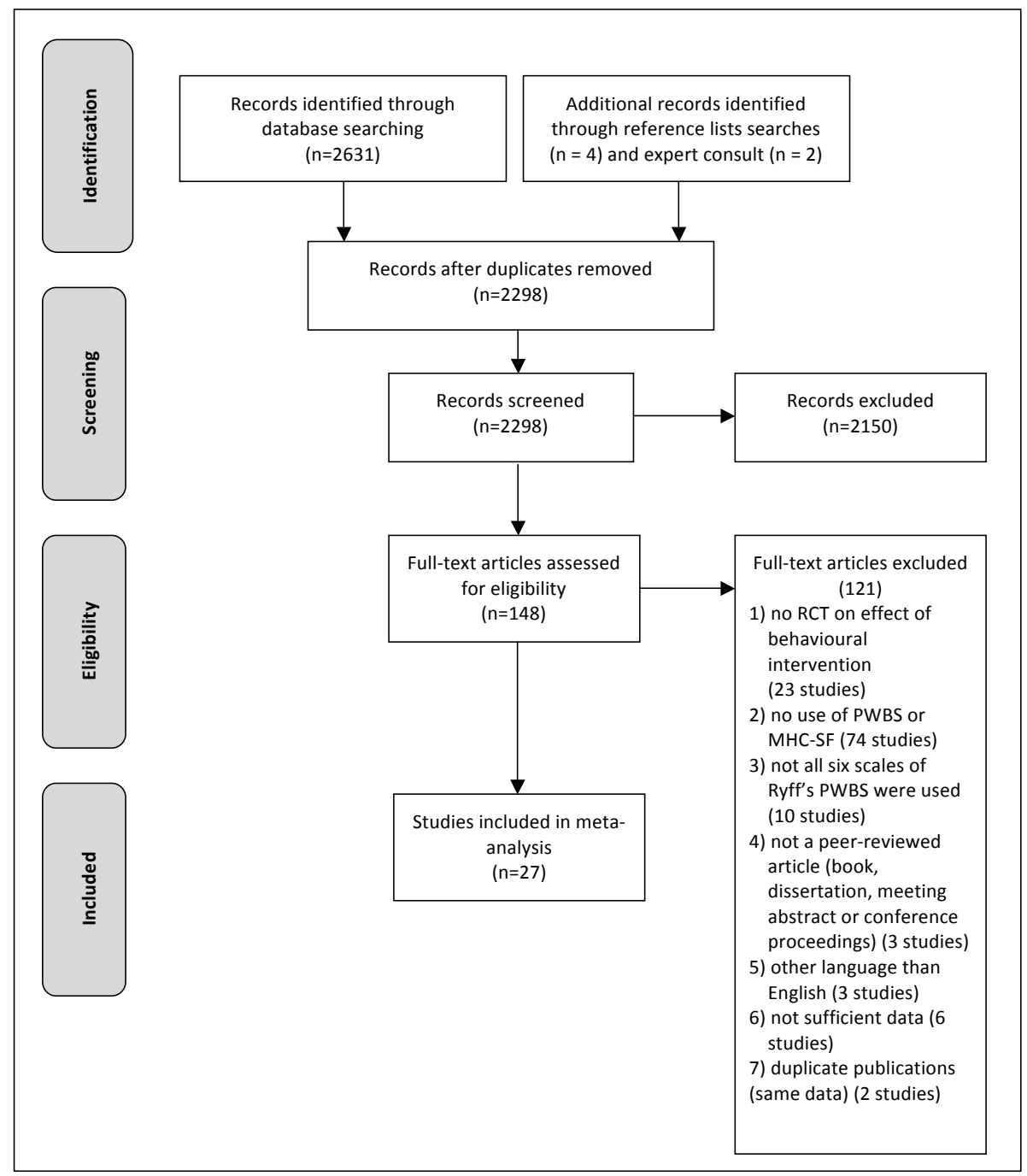

Fig 1. Flow diagram of the search and selection procedure of studies.

\section{Study characteristics}

The main characteristics of the studies are presented in Table 2. All 27 studies were RCTs published in peer-reviewed English journals. The studies were published between 1998 and 2014. The included studies involved 3579 participants. Sample size varied between 20 and 376 participants. 


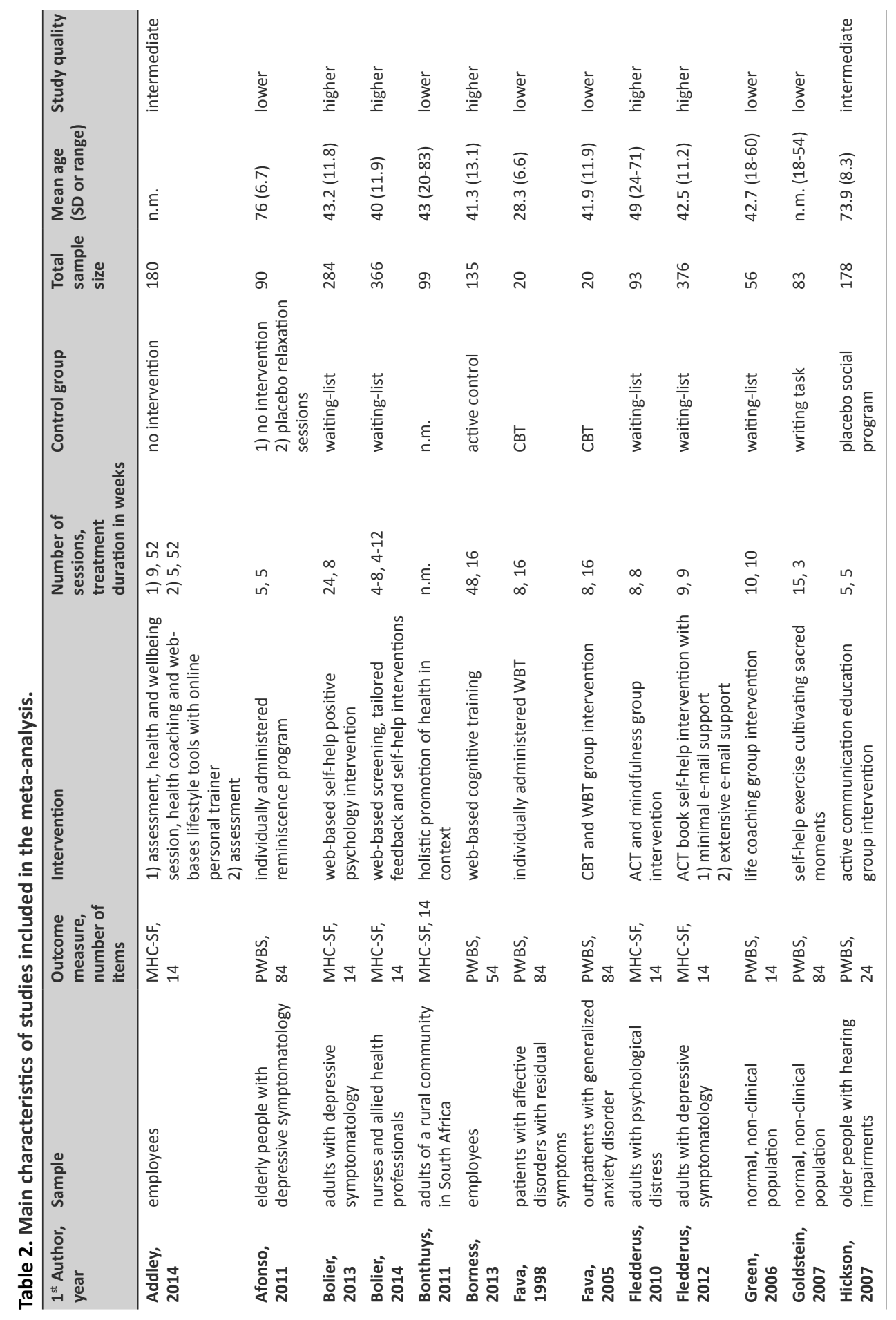




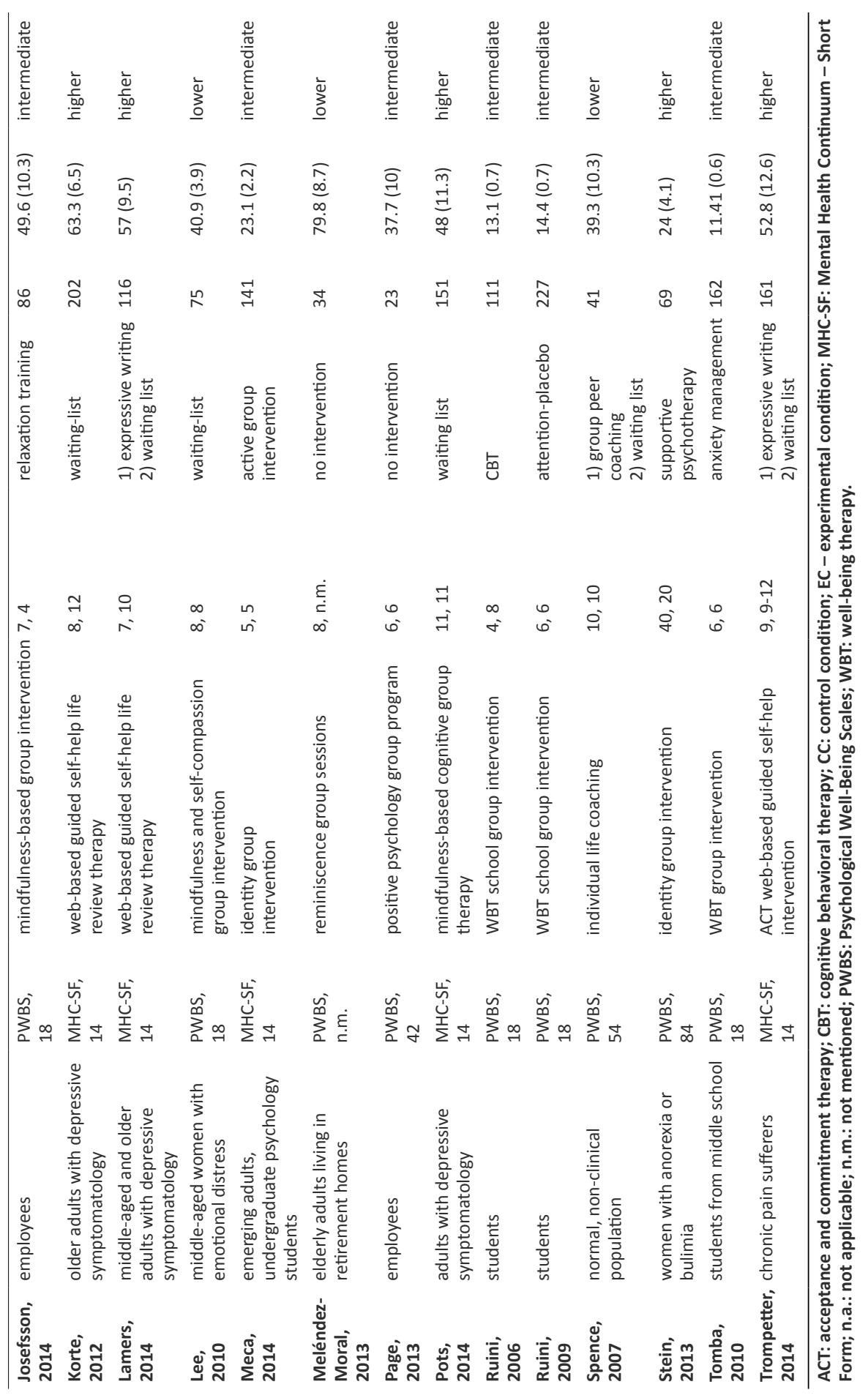


Whereas 14 studies were conducted among non-clinical populations (e.g. employees, students), 13 studies used a clinical sample. The vast majority of the clinical samples had psychological disorders, mostly affective disorders. Only two studies used a population with physical complaints (i.e., hearing impairment (Hickson, Worrall, \& Scarinci, 2007) and chronic pain (Trompetter, Bohlmeijer, Veehof, \& Schreurs, 2014)). The mean age varied between 11 and 79 years. While 4 studies used adolescents or young adults, 18 studies examined adults, and 5 studies had a sample of older people. Interventions included well-being therapy, life review, positive psychology interventions, acceptance and commitment therapy, mindfulness interventions and identity interventions. Seven interventions were self-help (web-based or book), 6 were individually administered and 14 group-based. The duration of the interventions varied between 4 and 52 weeks. Whereas 15 studies had between four (Ruini, Belaise, Brombin, Caffo, \& Fava, 2006) and eight sessions, 10 studies had between 8 and 48 sessions (Borness, Proudfoot, Crawford, \& Valenzuela, 2013).

Sixteen studies used the PWBS as outcome measure, 11 studies the MHC-SF. Six different versions of the PWBS were used, varying between 14 and 84 items. The control conditions included 16 non-active control groups (no intervention, waiting list, care-as-usual) and 13 active control groups (placebos such as relaxation sessions or alternative established interventions such as cognitive behavioral therapy). Nine studies were qualified as having a lower quality, 8 as intermediate and 10 as higher quality studies. Whereas 16 studies declared no conflict of interest (Addley et al., 2014; Bolier, Haverman, Kramer, et al., 2013; Bolier et al., 2014; Borness et al., 2013; Fava, Rafanelli, Cazzaro, Conti, \& Grandi, 1998a; Fava et al., 2005; Fledderus et al., 2010; Fledderus, Bohlmeijer, Pieterse \& Schreurs, 2012; Hickson et al., 2007; Korte et al., 2012; Pots, Meulenbeek, Veehof, Klungers, \& Bohlmeijer, 2014; Ruini et al., 2006; Ruini et al., 2009; Stein, Corte, Chen, Nuliyalu, \& Wing, 2013; Tomba et al., 2010), the other 11 studies did not mention whether there was a conflict of interest.

\section{Results data analysis}

Post-test effects. The random effect model showed that the behavioral interventions had a moderate effect on psychological well-being (Cohen's $d=0.44 ; z=5.62$; 
$p<.001)$. The $95 \%$ confidence interval was between 0.29 and 0.59 , with a standard error of 0.08 . The forest plot in Figure 2 displays the post-test effects.

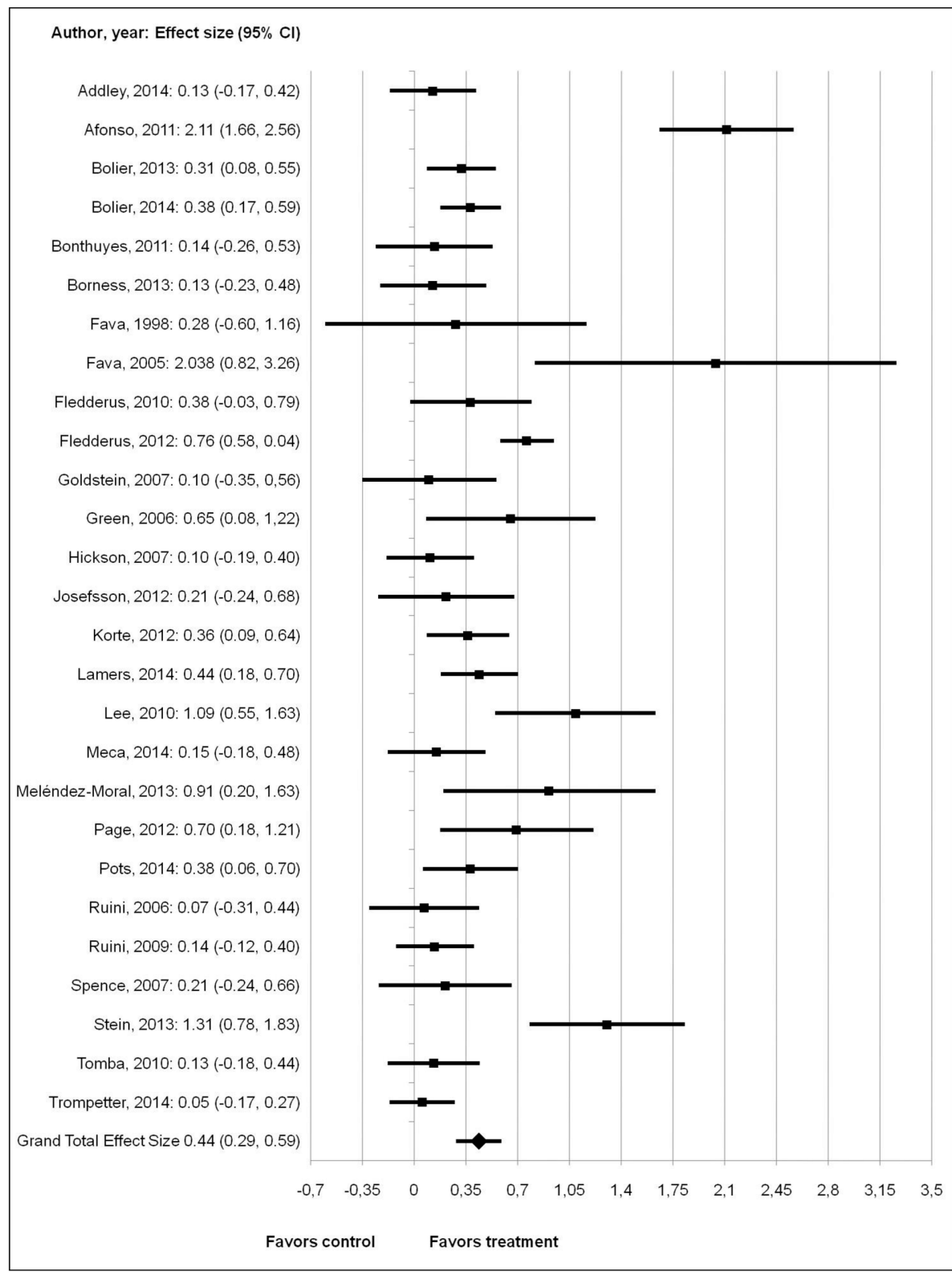

Fig 2. Forest plot for post-test effects of behavioral interventions on psychological well-being. 
Heterogeneity. Effect sizes of studies ranged from 0.05 to 2.11. A heterogeneity analysis revealed significant heterogeneity $(Q(26)=134.12 ; p<.001)$. Heterogeneity was high $\left(I^{2}=80.62\right)$. Therefore, moderator analyses were performed.

Moderators. Table 3 presents the findings of the moderator analyses. A systematic finding is that for 15 out of 17 categories, significant effects were found. No significant effects were found for age of target group, number of sessions, measurement instrument and control group. However, the strength of the effects differed for target group, intervention type and study quality. Interventions in clinical groups showed larger effects than those in non-clinical groups. Individual face-to-face interventions had stronger effects than self-help or group interventions. Studies of lower quality had higher effect sizes than studies of intermediate or higher quality. In a post-hoc analysis, we assessed whether the three significant moderating variables were interrelated among each other. There was no relation between target group and intervention type $\left(\chi^{2}=1.1 ; \mathrm{df}=1 ; \mathrm{p}=0.587\right)$. Target group and study quality were related $\left(\chi^{2}=9.4 ; d f=2 ; p=0.009\right)$. Studies with clinical target groups had higher quality. The higher effects for clinical groups can thus not be attributed to a lower quality of studies. There was a significant relation between intervention type and quality of the study $\left(\chi^{2}=14.1 ; \mathrm{df}=4 ; \mathrm{p}=0.007\right)$. Individual face-to-face interventions were more often assessed in studies with lower quality. Due to this contamination, it remains uncertain whether the intervention type or the quality of the study caused the higher effect sizes.

Publication bias. There is no clear indication of publication bias. Visual inspection of the funnel plot suggested no evidence of publication bias, as the distribution is symmetrical. Egger's regression intercept also suggests that there is no publication bias (intercept=1.53; $t=1.31 ; d f=25 ; p=0.20$ ). Duval and Tweedie's trim and fill analysis indicated that no studies needed to be filled or trimmed, which suggests that the effect size was not affected by publication bias. 
Table 3. Results of moderator analysis.

\begin{tabular}{|c|c|c|c|c|c|}
\hline Variable & Value & $\begin{array}{l}\text { Number } \\
\text { of Studies }\end{array}$ & $\begin{array}{l}\text { Std diff in means } \\
(95 \% \mathrm{Cl})\end{array}$ & $\begin{array}{l}\text { Z-value } \\
\text { (p-value) }\end{array}$ & $\begin{array}{l}\text { Q-value (df), } \\
\text { p-value }\end{array}$ \\
\hline \multirow[t]{3}{*}{ Target group } & Clinical & 13 & $0.63(0.42,0.84)$ & $5.79(<0.01)$ & \\
\hline & Non-clinical & 14 & $0.26(0.06,0.46)$ & $2.49(0.01)$ & \\
\hline & Total between & 27 & & & $6.11(1), 0.013^{*}$ \\
\hline \multirow[t]{4}{*}{$\begin{array}{l}\text { Age of target } \\
\text { group }\end{array}$} & $\begin{array}{l}\text { Adolescencel } \\
\text { young adulthood }\end{array}$ & 4 & $0.12(-0.25,0.50)$ & $0.65(0.51)$ & \\
\hline & Adulthood & 18 & $0.44(0.25,0.63)$ & $4.52(<0.01)$ & \\
\hline & Later life & 5 & $0.72(0.37,1.06)$ & $4.03(<0.01)$ & \\
\hline & Total between & 27 & & & $5.18(2), 0.075$ \\
\hline \multirow{4}{*}{$\begin{array}{l}\text { Intervention } \\
\text { type }\end{array}$} & Self-help & 7 & $0.33(0.05,0.60)$ & $2.34(0.019)$ & \\
\hline & Individual & 6 & $0.90(0.54,1.26)$ & $4.88(<0.01)$ & \\
\hline & Group & 14 & $0.35(0.14,0.56)$ & $3.26(0.001)$ & \\
\hline & Total between & 27 & & & 7.64 (2), $0.022 *$ \\
\hline \multirow{3}{*}{$\begin{array}{l}\text { Number of } \\
\text { sessions }\end{array}$} & Less & 16 & $0.49(0.28,0.70)$ & $4.51(<0.01)$ & \\
\hline & More & 11 & $0.38(0.14,0.62)$ & $3.14(0.002)$ & \\
\hline & Total between & 27 & & & $0.41(1), 0.53$ \\
\hline \multirow[t]{3}{*}{ Instrument } & PWBS & 16 & $0.54(0.33,0.76)$ & $4.97(<0.01)$ & \\
\hline & $M H C-S F$ & 11 & $0.32(0.1,0.55)$ & $2.79(0.005)$ & \\
\hline & Total between & 27 & & & $1.92(1), 0.166$ \\
\hline \multirow{3}{*}{$\begin{array}{l}\text { Control } \\
\text { group }\end{array}$} & Not Active & 16 & $0.51(0.31,0.70)$ & $5.08(<0.01)$ & \\
\hline & Active & 14 & $0.40(0.18,0.62)$ & $3.52(<0.01)$ & \\
\hline & Total between & 30 & & & $0.54(1), 0.461$ \\
\hline \multirow[t]{4}{*}{ Quality } & Lower & 9 & $0.75(0.46,1.03)$ & $5.15(<0.01)$ & \\
\hline & Intermediate & 8 & $0.19(-0.07,0.44)$ & $1.46(0.145)$ & \\
\hline & Higher & 10 & $0.43(0.21,0.66)$ & $3.86(<0.01)$ & \\
\hline & Total between & 27 & & & $8.36(2), 0.015^{*}$ \\
\hline
\end{tabular}

* significant $(p<.05)$

Follow-up effects. Twelve studies (L. Bolier, M. Haverman, J. Kramer, et al., 2013; Bolier et al., 2014; Borness et al., 2013; Fledderus et al., 2010; Goldstein, 2007; Korte et al., 2012; Lamers et al., 2014; Page \& Vella-Brodrick, 2013; C. Ruini et al., 2009; Stein et al., 2013; Tomba et al., 2010; Trompetter et al., 2014) examined follow-up effects after at least 2 months up to 10 months. Nine of these 12 studies examined the follow-up at 6 months. The random effect model showed small but significant effects for psychological well-being, compared with a control group (Cohen's $d=$ $0.22 ; z=4,9 ; p<0.001)$. The $95 \%$ confidence interval was between 0.13 and 0.31 , with 
a standard error of 0.045 . Heterogeneity was low $\left(Q(11)=11.45 ; p<0.41 ; I^{2}=3.89\right)$.

\section{Discussion and conclusion}

Psychological well-being is increasingly used as an outcome in studies on behavioral interventions, besides measures of psychological complaints and psychopathological symptoms. Several studies reported evidence that psychological well-being can indeed be promoted through behavioral interventions. This is the first meta-analysis to assess their overall effect. A moderate effect size of 0.44 was found across studies for psychological well-being, with no indication for publication bias. Significant effects were found across the categories of the moderator variables, illustrating the systematic nature of the effects. In the follow-up assessment, the effect size was still significant, but small (0.22). This result has to be interpreted with caution as only 12 studies could be included in this analysis. It is important that future studies make use of follow-up measures to gain more insight in the longitudinal development of the effects of interventions on psychological well-being.

This study explicitly focused on psychological well-being as an integrated construct that builds on several psychological theories of the twentieth century. The effect size of psychological well-being is somewhat lower than the standardized mean difference of 61 that was reported in a meta-analysis by Sin and Lyubomirsky (2009) and somewhat higher than the effect of .20 for psychological well-being in a metaanalysis by Bolier et al. (2013). These differences may be related to the fact that the first meta-analyses focused on subjective well-being whereas the second one included 10 different measures of psychological well-being in addition to the PWBS and MHC-SF, for example hope, mastery and purpose in life. This might demonstrate the importance of good definitions of well-being as different results may be obtained with instruments derived from different traditions. Furthermore, both previous metaanalyses focused on specific positive psychological interventions, whereas our study included a number of different therapeutic interventions. Because the interventions varied considerably, a reliable subgroup analysis was not possible. When sufficient studies will be published in the future, later meta-analyses could address differences between interventions, for example comparing positive psychological interventions, 
well-being therapy, acceptance and commitment therapy, and life review therapy. Despite the relatively high levels of stability of psychological well-being across time (Lamers, Glas, et al., 2012), these results show that it is possible to improve psychological well-being. Consequently, it might have more state-like characteristics, as a trait would be very hard to change, especially in a short period of time.

The heterogeneity was large with effects ranging from 0.05 (Ruini et al., 2006) to 2.11 (Afonso et al., 2011). Although the statistical power is sufficient for the study in total, it is low for the moderator analyses (Cafri, Kromrey, \& Brannick, 2010). Therefore, it is even more remarkable that we did find three significant moderators out of seven possible moderators. Effects were larger for clinical groups and in individual interventions. Interestingly, these moderators were also found significant in the meta-analyses of Sin and Lyubomirsky (2009) and Bolier et al. (2013). The promotion of psychological well-being seem to be best suited for individuals who suffer from psychological or somatic complaints. One possible explanation is that clinical populations have more impaired levels of psychological well-being at the beginning of the intervention, indicating that there is more room for improvement. This finding is relevant because psychological well-being can be seen as an important component of recovery (Fava, 1996). Higher levels of psychological well-being are associated with better physical health (Ryff, 2014) and buffer against future disorders (Grant, Guille, \& Sen, 2013; Lamers et al., 2015), suggesting that people with higher levels are potentially more resilient (Fava \& Tomba, 2009; Ryff, Love, Essex, \& Singer, 1998). Furthermore, a personal approach with face-to-face contact appears to work better compared to self-help and group interventions. Yet interventions targeted at the general population or using self-help or group interventions showed smaller, but still significant effects. When such interventions have a large enough reach, they might also bring substantive public health gains (2013).

For an interpretation of the results, it is important to be aware of possible limitations of the meta-analysis. First, one third of the studies had lower quality, whereas these studies also showed larger effects. However, the quality might have been underestimated, as it was scored conservatively: not reporting on the randomization 
procedures for example was rated as absence. Lower quality might also be attributed to the fact that new interventions were tested with pilot studies with a small number of participants. The larger effects of studies with lower quality might also contaminated with the finding that individual face-to-face interventions had higher effects. Future research needs RCTs with better quality, such as a larger number of participants based on a priori power analyses and longer follow-ups. Second, there are some limitations due to the search strategy. There was not sufficient data for six studies which met the inclusion criteria, limiting the completeness of the metaanalysis. The search strategy also may have been imperfect, as additional information sources revealed another six studies which were not found with the database search. Still, this possible limitation has been compensated by asking experts in the field and searching through reference lists of relevant articles and meta-analyses. We also excluded grey literature articles that were not peer-reviewed, which might have led to biased results. However, we did not find any indication of a publication bias. Another limitation is that the meta-analysis included highly heterogeneous studies; different outcomes may be due to factors such as different patient populations, protocol characteristics, and enrollment procedures (Fava, Guidi, Rafanelli, \& Sonino, 2015; Jane-Wit, Horwitz, \& Concato, 2010).

A broader point of discussion concerns the fact that the scales rely on self-reports. Selfreported well-being measures correlate with social desirability (Migdal \& MacDonald, 2013). It would therefore be interesting to find new ways of measurements to assess aspects of psychological functioning in a more objective way, for example using biological markers or automatic behavioral analyses. Until the reliability and validity of such methods have been proven, the possible self-reporting biases should be kept in mind when interpreting results of meta-analyses such as the current one.

Despite the limitations, we conclude that psychological well-being can be significantly improved to a moderate extent. This is important evidence for the development and implementation of interventions and policies in the field of mental health promotion. Improvement of psychological well-being is especially successful in clinical populations. Based on this meta-analysis, individual face-to-face interventions can 
be considered as valuable option when developing interventions for an improved psychological well-being. There is a need for higher quality studies in this emerging field to be able to further underpin the promising results of this meta-analysis.

\section{Acknowledgment}

We want to thank Sanne Lamers and Linda Bolier for giving us an introduction to the program Central Meta-Analysis. We are grateful to Mirjam Irene Maas who made a start with her thesis and Pauline de With for helping with the data-search and other tasks that came up. 


\section{References}

Abbott, R. A., Ploubidis, G. B., Huppert, F. A., Kuh, D., \& Croudace, T. J. (2010). An evaluation of the precision of measurement of Ryff's Psychological Well-Being Scales in a population sample. Social Indicators Research, 97(3), 357-373.

Abbott, R. A., Ploubidis, G. B., Huppert, F. A., Kuh, D., Wadsworth, M. E., \& Croudace, T. J. (2006). Psychometric evaluation and predictive validity of Ryff's psychological well-being items in a UK birth cohort sample of women. Health and Quality of Life Outcomes, 4(1), 1.

Addley, K., Boyd, S., Kerr, R., McQuillan, P., Houdmont, J., \& McCrory, M. (2014). The impact of two workplace-based health risk appraisal interventions on employee lifestyle parameters, mental health and work ability: results of a randomized controlled trial. Health Education Research, 29 (2), 247-258.

Afonso, R. M., Bueno, B., Loureiro, M. J., \& Pereira, H. (2011). Reminiscence, psychological well-being, and ego integrity in Portuguese elderly people. Educ Geront, 37(12), 10631080.

Altman, D. G. (1990). Practical statistics for medical research: CRC press.

Barry, M. M., \& Jenkins, R. (2007). Implementing Mental Health Promotion. Oxford: Churchill Livingstone, Elsevier.

Bohlmeijer, E., Roemer, M., Cuijpers, P., \& Smit, F. (2007). The effects of reminiscence on psychological well-being in older adults: a meta-analysis. Aging and Mental Health, $11,291-300$.

Bolier, L., Haverman, M., Kramer, J., Westerhof, G. J., Riper, H., Walburg, J. A., . . Bohlmeijer, E. (2013). An internet-based intervention to promote mental fitness for mildly depressed adults: randomized controlled trial. Journal of Medical Internet Research, 15(9). doi:10.1093/geronb/gbu030

Bolier, L., Haverman, M., Westerhof, G., Riper, H., Smit, F., \& Bohlmeijer, E. (2013a). Positive psychology interventions: a meta-analysis of randomized controlled studies. BMC Public Health, 13(1), 119.

Bolier, L., Ketelaar, S. M., Nieuwenhuijsen, K., Smeets, O., Gärtner, F. R., \& Sluiter, J. K. (2014). Workplace mental health promotion online to enhance well-being of nurses and allied health professionals: A cluster-randomized controlled trial. Internet Interventions, 1(4), 196-204.

Bonthuys, A. (2011). The effect of the Lifeplan ${ }^{\circledR}$ programme on the psychological well-being of a rural community in South Africa. Journal of Psychology in Africa, 21(3), 421-428.

Borness, C., Proudfoot, J., Crawford, J., \& Valenzuela, M. (2013). Putting brain training to the test in the workplace: a randomized, blinded, multisite, active-controlled trial. PLoS ONE, 8(3), e59982.

Cafri, G., Kromrey, J. D., \& Brannick, M. T. (2010). A meta-meta-analysis: Empirical review of statistical power, type I error rates, effect sizes, and model selection of meta-analyses published in psychology. Multivariate Behavioral Research, 45(2), 239-270.

Cheng, S. T., \& Chan, A. C. (2005). Measuring psychological well-being in the Chinese. Personality and Individual Differences, 38(6), 1307-1316.

Diener, E. (1984). Subjective well-being. Psychological Bulletin, 95, 542-574.

Disabato, D. J., Goodman, F. R., Kashdan, T. B., Short, J. L., \& Jarden, A. (2015). Different Types of Well-Being? A Cross-Cultural Examination of Hedonic and Eudaimonic Well-Being. Psychological Assessment, 28(5), 471.

Dodge, R., Daly, A. P., Huyton, J., \& Sanders, L. D. (2012). The challenge of defining wellbeing. International Journal of Wellbeing, 2(3).

Fava, G. (1996). The concept of recovery in affective disorders. Psychotherapy and Psychosomatics, 65(1), 2-13. 
Fava, G. A., Guidi, J., Rafanelli, C., \& Sonino, N. (2015). The Clinical Inadequacy of EvidenceBased Medicine and the Need for a Conceptual Framework Based on Clinical Judgment. Psychotherapy and Psychosomatics, 84(1), 1-3.

Fava, G. A., Rafanelli, C., Cazzaro, M., Conti, S., \& Grandi, S. (1998a). Well-being therapy. A novel psychotherapeutic approach for residual symptoms of affective disorders. Psychological Medicine, 28(2), 475-480. doi:10.1017/s0033291797006363

Fava, G. A., Ruini, C., Rafanelli, C., Finos, L., Salmaso, L., Mangelli, L., \& Sirigatti, S. (2005). Wellbeing therapy of generalized anxiety disorder. Psychotherapy and Psychosomatics, 74(1), 26-30. doi:10.1159/000082023

Fava, G. A., \& Tomba, E. (2009). Increasing Psychological Well-Being and Resilience by Psychotherapeutic Methods. European Journal of Personality, 77(6), 1903-1934.

Fledderus, M., Bohlmeijer, E. T., Smit, F., \& Westerhof, G. J. (2010). Mental health promotion as a new goal in public mental health care: a randomized controlled trial of an intervention enhancing psychological flexibility. American Journal of Public Health, 100(12), 2372. doi:10.2105/AJPH.2010.196196

Fledderus, M., Bohlmeijer, E. T., Pieterse, M. E., \& Schreurs, K. M. G. (2012). Acceptance and commitment therapy as guided self-help for psychological distress and positive mental health: a randomized controlled trial. Psychological Medicine, 42(3), 485-495.

Goldstein, E. D. (2007). Sacred moments: implications on well-being and stress. Journal of Clinical Psychology, 63(10), 1001-1019. doi:10.1002/jclp.20402

Grant, F., Guille, C., \& Sen, S. (2013). Well-being and the risk of depression under stress. PLoS ONE, 8(7), e67395.

Green, L. S., Oades, L. G., \& Grant, A. M. (2006). Cognitive-behavioral, solution-focused life coaching: Enhancing goal striving, well-being, and hope. Journal of Positive Psychology, 1(3), 142-149. doi:10.1080/17439760600619849

Hayes, S. C., Levin, M. E., Plumb-Vilardaga, J., Villatte, J. L., \& Pistorello, J. (2013). Acceptance and Commitment Therapy and Contextual Behavioral Science: Examining the Progress of a Distinctive Model of Behavioral and Cognitive Therapy. Behavior Therapy, 44(2), 180-198. doi:http://dx.doi.org/10.1016/j.beth.2009.08.002

Hickson, L., Worrall, L., \& Scarinci, N. (2007). A Randomized Controlled Trial Evaluating the Active Communication Education Program for Older People with Hearing Impairment. Ear and Hearing, 8(2), 212-230.

Higgins, J. P., Altman, D. G., Gøtzsche, P. C., Jüni, P., Moher, D., Oxman, A. D., . . . Sterne, J. A. (2011). The Cochrane Collaboration's tool for assessing risk of bias in randomised trials. BMJ, 343, d5928.

Hone, L., Jarden, A., \& Schofield, G. (2015). An evaluation of positive psychology intervention effectiveness trials using the re-aim framework: A practice-friendly review. The Journal of Positive Psychology, 10(4), 303-322.

Jane-Wit, D., Horwitz, R. I., \& Concato, J. (2010). Variation in results from randomized, controlled trials: stochastic or systematic? Journal of Clinical Epidemiology, 63(1), 5663. doi:10.1016/j.jclinepi.2009.02.010

Josefsson, T., Lindwall, M., \& Broberg, A. G. (2014). The Effects of a Short-term Mindfulness Based Intervention on Self-reported Mindfulness, Decentering, Executive Attention, Psychological Health, and Coping Style: Examining Unique Mindfulness Effects and Mediators. Mindfulness, 5(1), 18-35. doi:10.1007/s12671-012-0142-1

Joshanloo, M., Wissing, M. P., Khumalo, I. P., \& Lamers, S. M. (2013). Measurement invariance of the Mental Health Continuum-Short Form (MHC-SF) across three cultural groups. Personality and Individual Differences, 55(7), 755-759.

Keyes, C. L. (2002). The mental health continuum: From languishing to flourishing in life. Journal of Health and Social Behavior, 207-222. 
Keyes, C. L., Dhingra, S. S., \& Simoes, E. J. (2010). Change in level of positive mental health as a predictor of future risk of mental illness. American Journal of Public Health, 100(12), 2366.

Keyes, C. L., Wissing, M., Potgieter, J. P., Temane, M., Kruger, A., \& van Rooy, S. (2008). Evaluation of the mental health continuum-short form (MHC-SF) in setswana-speaking South Africans. Clinical Psychology \& Psychotherapy, 15(3), 181-192.

Keyes, C. L. M. (2007). Promoting and protecting mental health as flourishing: A complementary strategy for improving national mental health American Psychologist, 62, 95-108.

Korte, J., Bohlmeijer, E. T., Cappeliez, P., Smit, F., \& Westerhof, G. J. (2012). Life review therapy for older adults with moderate depressive symptomatology: a pragmatic randomized controlled trial. Psychological Medicine, 42(6), 1163.

Lamers, S., Westerhof, G. J., Bohlmeijer, E. T., ten Klooster, P. M., \& Keyes, C. L. (2011). Evaluating the psychometric properties of the mental health continuum-short form (MHC-SF). Journal of Clinical Psychology, 67(1), 99-110.

Lamers, S. M., Bohlmeijer, E. T., Korte, J., \& Westerhof, G. J. (2014). The efficacy of life-review as online-guided self-help for adults: A randomized trial. Journals of Gerontology Series B: Psychological Sciences and Social Sciences, gbu030. doi:10.1093/geronb/gbu030

Lamers, S. M., Glas, C. A., Westerhof, G. J., \& Bohlmeijer, E. T. (2012). Longitudinal evaluation of the mental health continuum-short form (MHC-SF). European Journal of Psychological Assessment.

Lamers, S. M., Westerhof, G. J., Glas, C. A., \& Bohlmeijer, E. T. (2015). The bidirectional relation between positive mental health and psychopathology in a longitudinal representative panel study. Journal of Positive Psychology, 1-8.

Lee Duckworth, A., Steen, T. A., \& Seligman, M. E. (2005). Positive psychology in clinical practice. Annual Review of Clinical Psychology, 1, 629-651.

Lee, W. K., \& Bang, H. J. (2010). The effects of mindfulness-based group intervention on the mental health of middle-aged Korean women in community. Stress Health, 26(4), 341 348. doi:10.1002/smi.1303

Lipsey, M. W. (1990). Design sensitivity: Statistical power for experimental research. In L. Bickman \& D. J. Rog (Eds.), The SAGE handbook of applied social research methods (Vol. 2, pp. 44-76). Thousand Oaks: Sage Publications.

Meca, A., Eichas, K., Quintana, S., Maximin, B. M., Ritchie, R. A., Madrazo, V. L., . . Kurtines, W. M. (2014). Reducing identity distress: Results of an identity intervention for emerging adults. Identity, 14(4), 312-331.

Meléndez Moral, J. C., Ruiz, L. C., Mayordomo, T., \& Galán, A. S. (2013). Effects of a reminiscence program among institutionalized elderly adults. Psicothema, 25(3), 319-323.

Migdal, L., \& MacDonald, D. A. (2013). Clarifying the relation between spirituality and wellbeing. The Journal of Nervous and Mental Disease, 201(4), 274-280.

Page, K. M., \& Vella-Brodrick, D. A. (2013). The working for wellness program: RCT of an employee well-being intervention. Journal of Happiness Studies, 14(3), 1007-1031.

Pots, W. T., Meulenbeek, P. A., Veehof, M. M., Klungers, J., \& Bohlmeijer, E. T. (2014). The Efficacy of Mindfulness-Based Cognitive Therapy as a Public Mental Health Intervention for Adults with Mild to Moderate Depressive Symptomatology: A Randomized Controlled Trial. PLoS ONE, 9(10), e109789.

Ruini, C., Belaise, C., Brombin, C., Caffo, E., \& Fava, G. A. (2006). Well-being therapy in school settings: a pilot study. Psychotherapy and Psychosomatics, 75(6), 331-336. doi:10.1159/000095438

Ruini, C., Ottolini, F., Tomba, E., Belaise, C., Albieri, E., Visani, D., . . . Fava, G. A. (2009). School intervention for promoting psychological well-being in adolescence. Journal of Behavior Therapy and Experimental Psychiatry, 40(4), 522-532. doi:10.1016/j. jbtep.2009.07.002 
Ryan, R. M., \& Deci, E. L. (2001). On happiness and human potentials: A review of research on hedonic and eudaimonic well-being. Annual Review of Psychology, 52(1), 141-166.

Ryff, C. D. (1989). Happiness is everything, or is it? Explorations on the meaning of psychological well-being. Journal of Personality and Social Psychology, 57(6), 1069.

Ryff, C. D. (2014). Psychological well-being revisited: Advances in the science and practice of eudaimonia. Psychotherapy and Psychosomatics, 83(1), 10-28. doi:10.1159/000353263

Ryff, C. D., \& Keyes, C. L. M. (1995). The structure of psychological well-being revisited. Journal of Personality and Social Psychology, 69(4), 719.

Ryff, C. D., Love, G. D., Essex, M. J., \& Singer, B. (1998). Resilience in adulthood and later life. Handbook of Aging and Mental Health (pp. 69-96): Springer.

Ryff, C. D., \& Singer, B. (1996). Psychological well-being: Meaning, measurement, and implications for psychotherapy research. Psychotherapy and Psychosomatics, 65(1), 14-23.

Schimmack, U., Krause, P., Wagner, G. G., \& Schupp, J. (2010). Stability and change of well being: An experimentally enhanced latent state-trait-error analysis. Social Indicators Research, 95(1), 19-31.

Seligman, M. E., \& Csikszentmihalyi, M. (2000). Positive psychology: An introduction (Vol. 55): American Psychological Association.

Sin, N., \& Lyubomirsky, S. (2009). Enhancing well-being and alleviating depressive symptoms with positive psychology interventions: a practice-friendly meta-analysis. Journal of Clinical Psychology, 65, 467 - 487.

Spence, G. B., \& Grant, A. M. (2007). Professional and peer life coaching and the enhancement of goal striving and well-being: An exploratory study. Journal of Positive Psychology, 2(3), 185-194. doi:10.1080/17439760701228896

Stein, K. F., Corte, C., Chen, D. G. D., Nuliyalu, U., \& Wing, J. (2013). A Randomized Clinical Trial of an Identity Intervention Programme for Women with Eating Disorders. European Eating Disorders Review, 21(2), 130-142.

Tomba, E., Belaise, C., Ottolini, F., Ruini, C., Bravi, A., Albieri, E., . . . Fava, G. A. (2010). Differential effects of well-being promoting and anxiety-management strategies in a non-clinical school setting. Journal of Anxiety Disorders, 24(3), 326-333. doi:10.1016/j. janxdis.2010.01.005

Trompetter, H. R., Bohlmeijer, E. T., Veehof, M. M., \& Schreurs, K. M. (2014). Internet-based guided self-help intervention for chronic pain based on Acceptance and Commitment Therapy: A randomized controlled trial. Journal of Behavioral Medicine, 38(1), 66-80.

Westerhof, G. J., Bohlmeijer, E., \& Webster, J. D. (2010). Reminiscence and mental health: A review of recent progress in theory, research and interventions. Ageing and Society, 30(04), 697-721.

Wood, A. M., \& Joseph, S. (2010). The absence of positive psychological (eudemonic) wellbeing as a risk factor for depression: A ten year cohort study. Journal of Affective Disorders, 122(3), 213-217. doi:http://dx.doi.org/10.1016/j.jad.2009.06.032

World Health Organization. (2005). Promoting mental health: Concepts, emerging evidence, practice: Summary Report. 


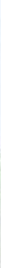
(3) $x+x$

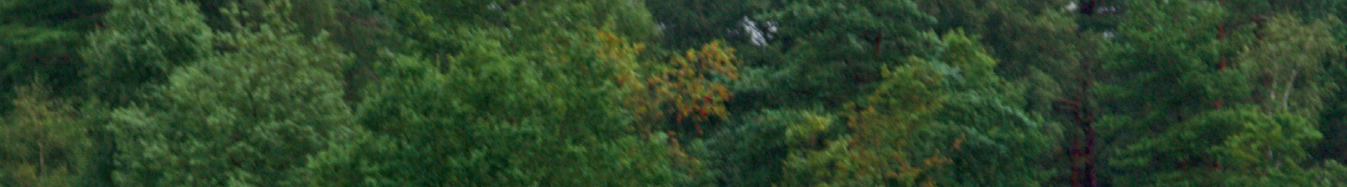

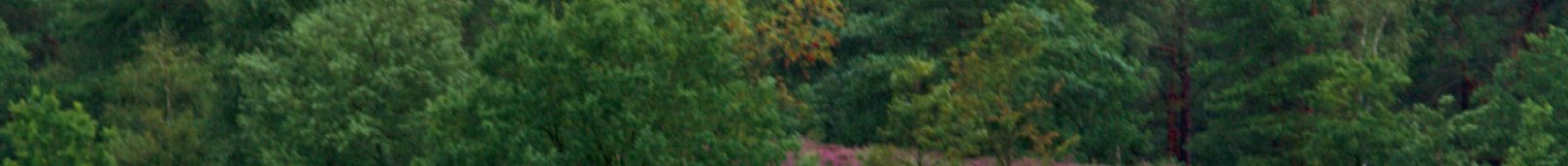

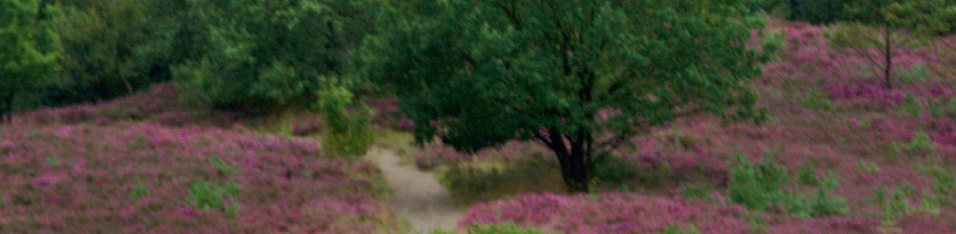
Cyser. 2. $3 x^{208}=2=0$

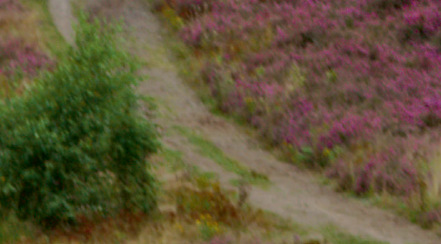

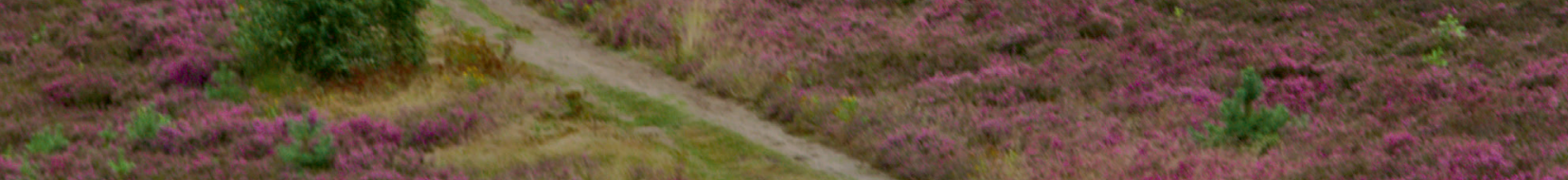
Be. 5.

-

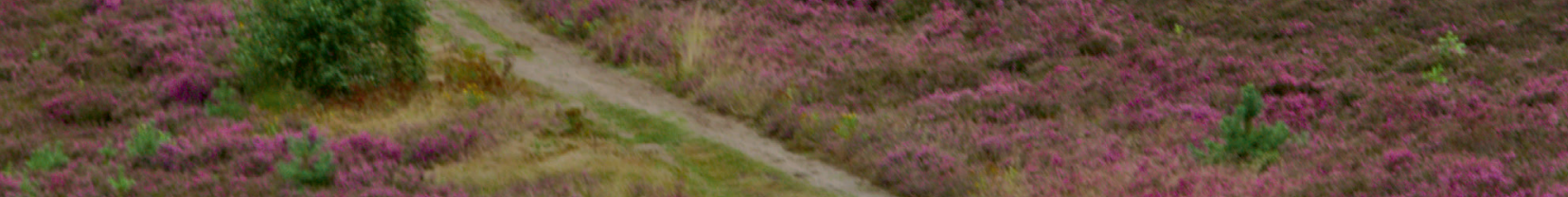

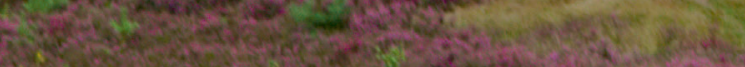
texpents

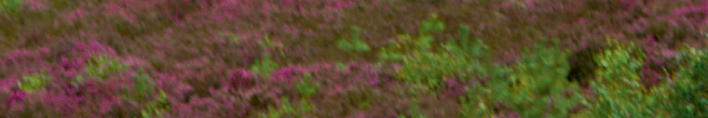

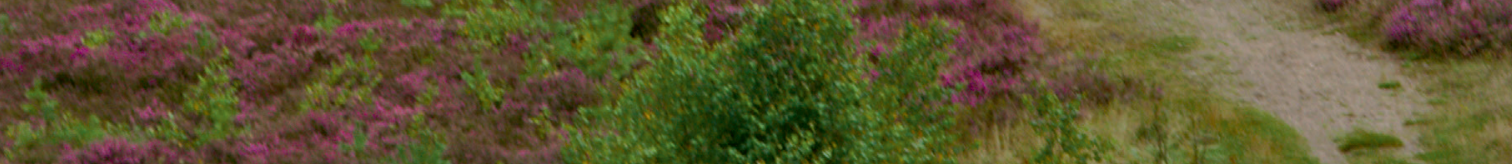

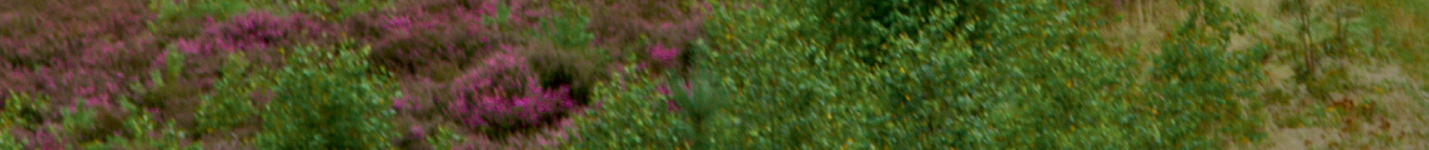

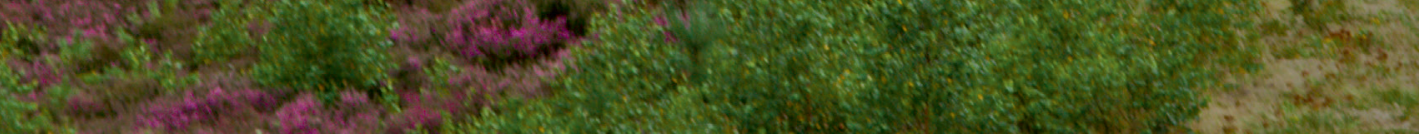

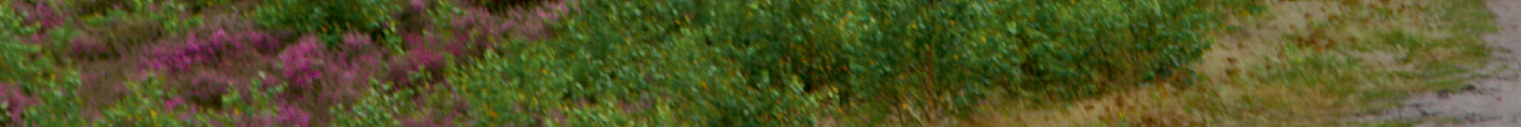

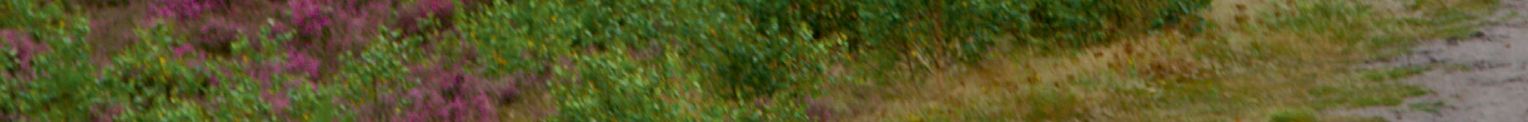

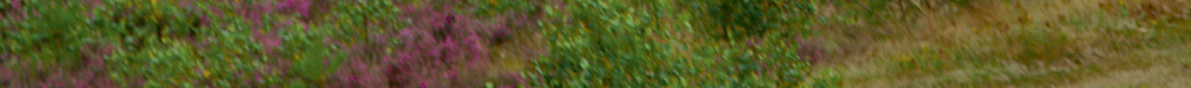

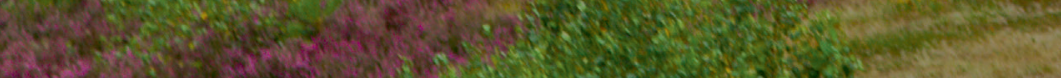

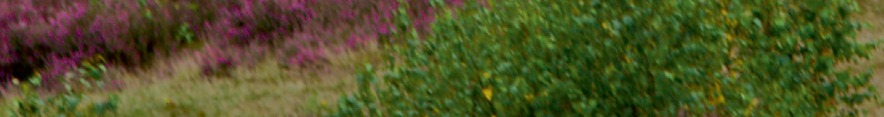
- 


\section{4}

\section{Nudging Socially Isolated People towards Well-Being with the Happiness Route: Design of a Randomized Controlled Trial for the Evaluation of a Happiness- Based Intervention}

/

Sometimes the smallest step in the right direction ends up being the biggest step of your life. Tiptoe if you must, but take a step.

Naeem Callaway

This chapter is published as:

Weiss, L. A., Westerhof. G. J., \& Bohlmeijer, E. T. (2013). Nudging socially isolated people towards well-being with the 'Happiness Route': Design of a randomized controlled trial for the evaluation of a happiness-based intervention. BMC Health and Quality of Life Outcomes, 11(1), 1-11. doi:10.1186/1477-7525-11-159 


\begin{abstract}
Background: The Happiness Route is an innovative intervention that uses a happinessbased approach for people with an accumulation of risk factors for low well-being: socially isolated people with health impairments and a low socioeconomic status. The goal of this intervention is to improve well-being by engaging participants in intrinsically motivated activities with methods from positive psychology. We hypothesize that the primary outcome measure, emotional, social and psychological well-being of participants of the Happiness Route, will increase in comparison to the traditional and commonly-used problem-based approach. Secondary outcome measures are health-related quality of life, psychosocial functioning and health care consumption.
\end{abstract}

Methods and design: Participants will be socially isolated people with health problems and a low socioeconomic status. Participants will be recruited in ten Dutch communities and candidates will be signed up by intermediaries, professionals from the health and social sector. Randomly assigned, half of the participants will follow the Happiness Route and half of the participants will follow the active, problem-focused control group 'Customized Care'. In total, 256 participants will be included. In both conditions, participants will receive counseling sessions from trained counselors. In the control group, participants will talk about their problems and the care they get and counselors help to optimize their care. In the Happiness Route, the counselor ask questions such as "How do you want to live your life?". The intervention helps people to find their 'passion', i.e., a positive goal-engaged and intrinsically motivated activity. It enables them to follow their passion through by a once-only personal happiness budget (maximal $€ 500$ ). We use well-validated and reliable questionnaires to measure primary and secondary outcome measures at baseline, directly after the intervention and at a nine-month follow-up.

Discussion: Shortcomings of earlier intervention studies in positive psychology will be tackled with this study, such as having a target group who is especially vulnerable for low well-being. The practice-based setting is especially interesting, as it can give valuable insights in how positive psychology interventions work in practice, but can also give rise to several challenges.

Trial registration: Dutch Trial Register, trial registration number TC=3377NTR. http:// www.trialregister.nl/trialreg/admin/rctview.asp?TC=3377 


\section{Background}

In the health care system, the problem-based approach is widely used: the goal is to diagnose and treat the health problem. Healthcare and social workers are trained in this problem-based working style. This approach works well for most people. Yet there is a group where this approach does not seem to work. This group has an accumulation of risk factors for low well-being; severe feelings of loneliness, health problems and a low socioeconomic status (SES) (Diener, Suh, Lucas, \& Smith, 1999; Veenhoven, 1996; Walburg, 2008; Westerhof, 2013; Westerhof \& Keyes, 2010). These factors may reinforce each other.

One of the factors that contribute most to well-being is a rich social live (Ryan \& Deci, 2000). But this is not given for everyone. People with health problems and a low SES are at high risk for social isolation. Hence this group suffers from different social, health and financial problems and low well-being. The traditional problembased approach can only provide them with more and more care (Plaats, 1994). Accordingly, this will lead to increased economic costs for the society as well as for the individual (Valtorta \& Hanratty, 2013).

An alternative approach is needed for this target group, one that focuses on promoting positive mental health by stimulating happiness, self-realization and social integration (World Health Organization, 2004): a happiness-based approach. In the Netherlands, this is recently acknowledged in public health, where changes in welfare policies towards individual responsibilities and self-management of citizens have been encouraged (Ministerie van Volksgezondheid Welzijn en Sport, 2010; RVZ, 2010; Vereniging van Nederlandse Gemeenten, 2010). The Dutch Council for Public Health and Health Care (RVZ, 2010) has recently advised the Ministry of Health to shift the focus in health care from 'illness and care' towards 'behavior and health'. These changes ask for a more positive focus instead of the traditional problem focused approach and interventions. The patients' problems should not be the only subject of interest, but their well-being also has to be acknowledged.

Mental well-being, broadly defined as emotional, social and psychological well-being, has many positive effects. Besides the fact that most people strive for happiness in 
their lives, it also improves many aspects of health and longevity (Cohen \& Pressman, 2006; Diener \& Ryan, 2009; Howell, Kern, \& Lyubomirsky, 2007) and personal functioning, such as productivity (Diener \& Ryan, 2009).

Interventions directed to improve well-being seem to have positive effects (Bolier et al., 2013). Meta-analyses show that the promotion of well-being will lead to considerable health gains for the individual and society (Chida \& Steptoe, 2008; Howell et al., 2007; Lamers, Bolier, Westerhof, Smit, \& Bohlmeijer, 2012; Lyubomirsky, King, \& Diener, 2005; Pressman \& Cohen, 2005).

Still, there are only few projects in the Netherlands that make use of this new happiness-based approach. The 'Happiness Route', a short behavioral intervention to promote positive mental health, is one of the few that is directly targeted to improve well-being. This innovative intervention uses insights from positive psychology and a recent theory from behavioral economics, namely 'nudging': giving people a gentle push in the 'right' direction (Thaler \& Sunstein; Tiemeijer, Thomas, \& Prast, 2009). Accordingly, the aim of this short behavioral intervention is to increase well-being by nudging people towards an intrinsically motivated activity. To be able to conduct this activity, participants receive a once-only budget with a maximum of $€ 500$.

The Happiness Route is based on a theory that is often used in positive psychology: the self-determination theory. Deci and Ryan (Ryan \& Deci, 2001) identified three factors that improve someone's well-being: autonomy, relatedness and competence. Intrinsic motivation has an important function for being able to fulfill these three basic psychological needs. The Happiness Route aims to support these needs. Autonomy is central to the intervention, as participants are encouraged to find their own individual passion and act on their own initiative. By activating participants, they often get in contact with others (Kedzia, 2009), so that the feeling of relatedness will be improved. Finally, participants probably will feel (more) competent when they are conducting an intrinsically motivated activity that fits their individual talents and strengths. 
The intervention was invented in the Netherlands in 2006. It has been implemented in ten Dutch cities, many counselors have been trained and over 500 participants followed the Happiness Route. Three pilot studies have shown that the intervention reaches the intended group and is well-received by both counselors and participants (Francissen, Wezenberg, \& Westerhof, 2010; Kedzia, 2009; Van der Plaats, 2007). A client file analysis showed that the budget was used in a highly functional way and resulted in intrinsically motivated activities, focusing on establishing new contacts and new experiences (Kedzia, 2009). Participants retrospectively reported an increase of $40 \%$ in well-being and a decrease in consumption of care of $23 \%$ (Francissen et al., 2010). As both the practical experience and pilot studies were promising, it is the right time to start a large and thorough study on the effectiveness of the intervention. This article thus describes the design of a large evaluation study on the Happiness Route. Based on the pilot studies and practical experiences, we hypothesize that emotional, social and psychological well-being of participants of the Happiness Route will increase in comparison to the traditional and commonly-used problembased approach and health care will decrease. Furthermore, we will study whether the intervention decreases loneliness, depressive symptoms and consumption of care and whether it increases purpose in life, resilience, social participation and health-related quality. Last, we will examine if characteristics of both participants and counselors have moderating effects. As we handle strict inclusion and exclusion criteria and all counselors will receive the same thorough training, we do not expect moderating effects.

Existing studies on positive psychological interventions mostly had a limited amount of participants, were carried out in experimental settings, and with rather privileged groups with no psychosocial problems, such as students (Bolier et al., 2013). The present study will belong to the $10 \%$ of the largest trials on positive psychological interventions (Sin \& Lyubomirsky, 2009). It is among the first to examine such an intervention in a practice-based research setting with several partners in the field of social work. Our study is also among the first to use an outreaching approach to target individuals with an accumulation of risk factors for low levels of well-being: lower socioeconomic status, social isolation, and health limitations (Diener et al., 
1999; Veenhoven, 1996; Walburg, 2008; Westerhof, 2013; Westerhof \& Keyes, 2010). The study will thus provide new insights into the opportunities for mental health promotion in realistic settings.

\section{Methods and design}

\section{Study design}

To evaluate the effectiveness of the project 'Happiness Route', we will carry out a pragmatic multi-site randomized controlled trial with a follow-up at nine months. Participants will be randomly assigned to either the 'Happiness Route' intervention or the active control condition 'Customized Care', where care will be optimized in two home visits. Measurements will take place at baseline, and three and nine months later. This study has been approved by the Twente Medical Ethics Committee under the file number P12-14 and is registered in the Dutch trial register (3377 NTR). Participation is voluntary and all participants will give written informed consent prior to inclusion. A flowchart of the study can be seen in Figure 1.

\section{Setting}

The study will be carried out in the field of healthcare and social work in ten municipalities in the Netherlands by the University of Twente and Arcon, an organization in the welfare sector. The study is funded by ZonMw (the Netherlands Organisation for Health Research and Development) under the prevention program. A municipal officer will generally be the local project leader, but in some cases, the local project leader works in one of the participating institutions. The local project leader is responsible for the recruitment through intermediaries, the allocation of participants to counselors and for the final approval on spending the budget in the Happiness Route. Municipalities mostly provide financial support for the training of counselors, the appointment of the local project leader, as well as the budget for the Happiness Routes. In other cases, the project is financed by social funds.

The recruitment of participants will be carried out by intermediaries who work as professionals in local care and social work institutions. Examples of intermediary organizations and professions are home care, housing associations, after-care nurses, psychiatric nurses, religious institutions, well-being institutions and organizations for 
people with mental disabilities. Intermediaries are in direct contact with the target group in their daily work. They can suggest possible candidates to the local project leader, who informed the intermediaries about the study and the target group.

Counselors are experienced professionals, such as social workers, and in some cases experienced volunteers. They are responsible for the intake and the delivery of the experimental and control interventions. To avoid contamination between the experimental and the control conditions, counselors will only deliver interventions in one of these conditions. Both counselors providing the Happiness Route and counselors providing the control condition will receive suitable training.

0 months:

Baseline measurement

(TO)

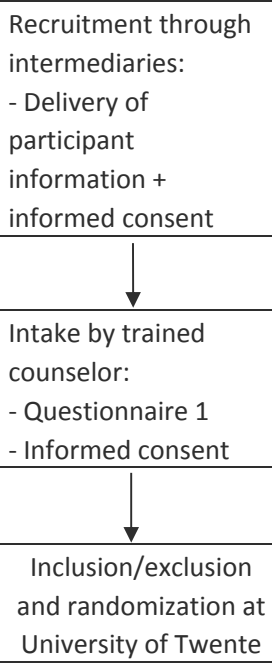

Start Interventions

Post-measurement

(t1)

9 months:

Follow-up

measurement (t2)
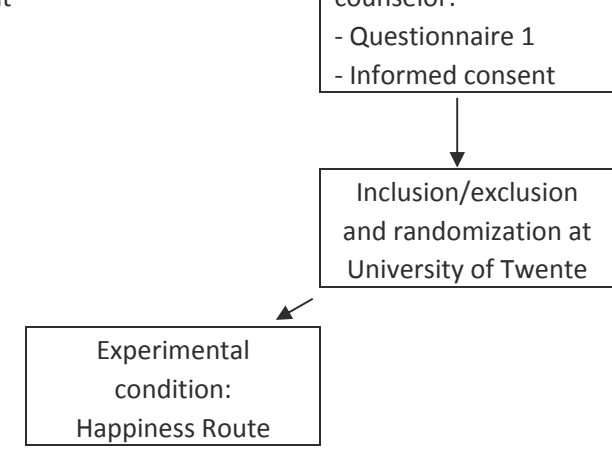

$\downarrow$

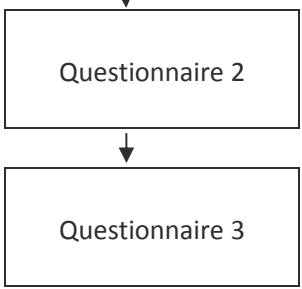

Control condition:

Customized Care

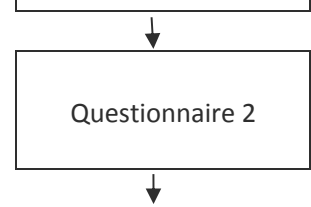

Questionnaire 3

Figure 1. Study flowchart 


\section{Participants}

The population in this study consists of adults who are in social isolation, have health problems and a low socio-economic status (SES). Social isolation, poor health and low SES are important correlates of low positive mental health (Diener et al., 1999; Veenhoven, 1996; Walburg, 2008; Westerhof, 2013; Westerhof \& Keyes, 2010). Moreover, they often occur together and mutually influence each other (Hawkley, Masi, Berry, \& Cacioppo, 2006; Keyes, 2007; Wilkinson \& Pickett, 2006). Social isolation is common: $8 \%$ of the Dutch adults only have a minimal level of social contacts and $22 \%$ feel lonely (Machielse \& Hortulanus, 2006). Several studies found that loneliness often occurs together with poor income (Rijken \& Groenewegen, 2008; Routasalo, Savikko, Tilvis, Strandberg, \& Pitkälä, 2006; Savikko, Routasalo, Tilvis, Strandberg, \& Pitkälä, 2005), health problems (Australia, 2005; Rokach, Lechcier-Kimel, \& Safarov, 2006) and low well-being (Kaplan, Shema, \& Leite, 2008). Socially isolated people with a low SES and health problems are thus an especially vulnerable group with an accumulation of disadvantage.

The following inclusion criteria must all be fulfilled:

- Age: $\geq 18$ years

- Social isolation: a score of 3 or higher on the loneliness scale (De Jong Gierveld \& Van Tilburg, 1999);

- Low socioeconomic status (SES): a low educational level (no more than lower secondary education), or a low employment status (no paid employment), or limited financial means, or a combination of these factors. We use the CBS (Statistics Netherlands) budget approach which includes income for basic means as well as participation: $€ 1000$ per month for a single household and $€ 1370$ for a couple or a single parent with one or more children (Centraal Bureau voor de Statistiek, 2011);

- Health limitations, i.e., at least one health limitation on the EuroQol (Brooks \& Group, 1996). 
Candidates will be excluded if they fulfill one of the following exclusion criteria:

- High positive mental health: a high score on the Mental Health ContinuumShort Form (Keyes et al., 2008; Lamers, Westerhof, Bohlmeijer, ten Klooster, \& Keyes, 2011). To avoid ceiling effects, we use a score of more than one standard deviation above the mean of the Dutch population (i.e., 4.83 or higher) to exclude candidates.

- Serious, untreated clinical depression: a score of 39 or higher on the Center for Epidemiology Depression Scale (CES-D) (Bouma, Ranchor, Sanderman, \& Van Sonderen, 1995; Radloff, 1977).

- Crisis situation: candidates who are in an acute crisis, such as people who have recently lost someone and are still in mourning, who are addicted to alcohol or drugs, or who are homeless. This is judged by the counselor during the intake.

- Insufficient linguistic and cognitive skills to be able to complete the questionnaires, as judged by the counselor during the intake.

\section{Randomization}

When the written informed consent and the baseline questionnaire are received by regular mail, inclusion will be carried out on the basis of the criteria. Each included participant will be appointed randomly to either the intervention or the control condition, based on an a priori computer-generated randomized number list. No stratification will be carried out.

The principal investigator informs the local project leader of the outcomes of the inclusion and randomization procedure, so that the local project leader can appoint a counselor to deliver the intervention in the experimental condition (Happiness Route) or the control condition (Customized Care). It is not possible to blind the conditions to the counselors.

\section{Experimental condition: The Happiness Route}

The intervention builds on the existing intervention Happiness Route but has been formalized and strengthened with the help of existing intervention methods from positive psychology. The goal of the intervention is to promote well-being by means 
of engagement in intrinsically motivated activities. Methods to promote this are counseling sessions run by trained counselors, based on (positive) psychological interventions. The intervention includes a budget to carry out the activities. The Happiness Route gives participants a financial nudge, i.e., a means to activation, because participants with low socio-economic status tend to have few (monetary) means to engage in activities. The intervention consists of five stages: (1) mutual definition of the situation by the participant and counselor; (2) goal orientation; (3) choice of an activity; (4) planning and carrying out the activity; and (5) early evaluation and feedback in a 'booster' session.

Sessions will take place at the home of the participant, with a maximum of 1,5 hours per session. Previous experience has shown that some participants are relatively quick in finding a suitable goal, whereas others need more time and support. Therefore the number of sessions varies between one to four sessions (after the intake), plus the final booster session. The first four stages are flexibly divided over the number of sessions, whereas the booster session always involves early evaluation and feedback between participant and counselor. The aim is to complete the whole process within three months, after which the second measurement will be carried out.

\section{Mutual definition of the situation}

The first stage involves the definition of the situation. After having looked at health complaints and problems, the problems are put aside. Instead, the participant is motivated to think about life values. The counselor asks the participant questions such as: "What makes you happy?" and "How do you want to live your life?"

\section{Goal orientation}

The second stage serves to make an inventory of personal goals and possible activities for the Happiness Route. The counselor can make use of methods from existing theoretically based and empirically effective interventions in life review that focus on a productive use of autobiographical memories (Bohlmeijer \& Westerhof, 2010; Singer, 2005). The participants are asked to recall and name memories from their lives which are particularly important to them. The focus will be on positive memories 
about activities that made the person happy, engaged, and connected to others. This will be helpful in making a list of possible intrinsically motivated activities that were important in the participants past life. The list can be completed with activities that the participant always wanted to do, like dreams from their childhood and youth, as well as with activities that the participant would like to carry out, independently of memories of past activities.

\section{Choice of the activity}

The third stage serves to choose an activity. The list that was made earlier can be discussed in terms of opportunities for intrinsic motivation and in being helpful in increasing competence, autonomy, relatedness and well-being. The method of 'anticipated regret' is used in order to stimulate a choice that is high on personal relevance and motivation (Abraham \& Sheeran, 2004; Bode, De Ridder, Kuijer, \& Bensing, 2007): "In a couple of years, which activity would you particularly regret when not carrying it out?" The participant decides which activity will be targeted and how the budget (maximum of $€ 500,-$ ) will be spent. The counselor makes no requirement about the activity, other than that the participant should be intrinsically motivated. A report will be filled out for the local project leader. The project leader decides whether the budget can be transferred to the participant or not. If the project leader is in doubt, the counselor will be asked to spend the next session on a further clarification of how the budget will contribute to the goal engagement of the participant. In a pilot study, it was found that participants spent an average of $€ 422$ on activities, focusing on establishing new contacts and going out, as well as learning and making new experiences (Kedzia, 2009). Furthermore, many participants chose an activity that challenged their health problem. An example is a former participant with a cognitive impairment, who learned a new language and another participant with a physical impairment, who decided to take swimming lessons. Given the social isolation and health problems, this analysis revealed a highly functional use of the budget (Kedzia, 2009). 


\section{Planning and doing the activity}

The fourth stage uses the method of behavioral activation from behavioral therapy to help the participant in planning and carrying out the intended activity (Hermans \& Van de Putte, 2004). The counselor and the participant discuss the steps to be taken and the participants' behaviors that are needed to actually carry out the activities. The goal of behavioral activation in the present context is to organize positive reinforcement for participants. Socially isolated participants may experience a lack of positive reinforcement in their social environment, due to their lack of contacts. The counselor supports the participants in discovering those reinforcements that the activity is expected to bring.

\section{Early evaluation and feedback}

The fifth stage is the so-called booster session. During this final session, the participant and counselor evaluate the progress in planning and carrying out the activity. They discuss the benefits of the activities as well as possible pitfalls for continuing the activities.

\section{Control condition: Customized Care}

The goal of the active control condition is to provide the best possible care in the traditional problem-focused manner and to give control subjects attention. This will be done in two home-sessions with a maximum of 1,5 hours per session. After the intake, participants receive two home visits to ensure the optimization of their use of existing care facilities. The approach is the traditional problem-oriented work style. During the sessions, the counselor and the participant work towards a consensual definition of the participant's (health-related) problems. The counselor and participant then take stock of the use of care and services and the opportunities for optimizing them. The participant is asked how satisfied he or she is with the actual care and services provided and whether there is a mismatch between the problems discussed and the care and services delivered. Does the participant experience problems that are not addressed? Are any care and services redundant, because they do not match the needs of the participant anymore? The counselor and participant then discuss various options for optimizing care and services. As not all participants 
will know about all services, the counselor informs the participant about all available options to achieve an optimal choice in maintaining, starting or reducing services and helps the participant to realize the optimal choice.

\section{Measures}

\section{Data collection}

An overview of the measures can be seen in Table 1. Participants will have to complete paper and pencil questionnaires during the intake (baseline), after the end of the intervention (three months after the baseline), and nine months after the intake (follow up). All outcome measures will be recorded at all three measurements. Demographic variables will be filled out only at baseline. The baseline questionnaire will be filled out during the intake. Participants fill it out by themselves, but can ask the counselor when help is needed. The second and third questionnaires will be sent by regular mail to participants, accompanied by reply-paid envelopes. If participants need help with filling in the questionnaire, their counselor can help them. Otherwise, the counselor is not involved in the second and third measurement. An overview of the measures can be seen in Table 1.

Moreover, Vektis, the Dutch Information Centre for Care, will be asked to provide group statistics about the actual use of care. Vektis registers the use of healthcare by every Dutch citizen. Participants will be asked to provide their health insurance policy number and the name of their health insurance company on the informed consent, together with their permission to use the information as registered by Vektis. Vektis will execute the statistical analyses on possible differences in health care consumption before and after the intervention and to compare the use of care services between the experimental group and the control group. 


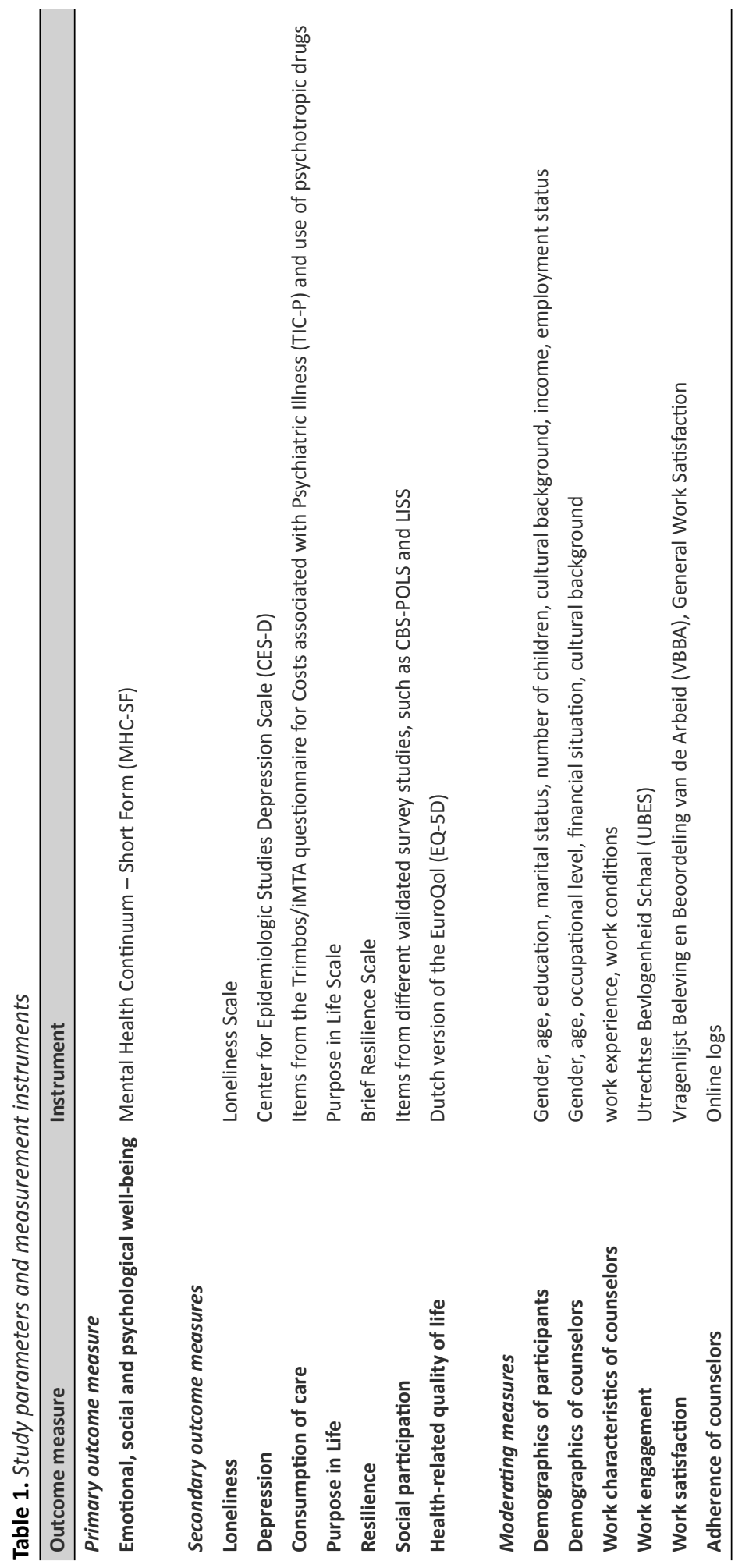


Counselors also will have to fill out a questionnaire before they start with their work for the study. Measures include demographic information, work experience, work conditions, work engagement (UBES; Utrechtse Bevlogenheidschaal) (Schaufeli \& Bakker, 2004) and work satisfaction (Brewster, Suutari, \& Bonache, 2005; Van Veldhoven, Meijman, Broersen, \& Fortuin, 2002). All counselors have to fill in online logs after each session. Happiness-counselors will give information about the recruitment, note the date of the session, give a short description of the session and describe their impression of the participant. They also have to answer questions about the motivation of the participant, the quality of their relation with the participant, the progress of the participant, the methods used in the session, and the current stage they are at. They also have room for further, free-text comments. The control counselors have to fill out similar, but somewhat shorter logs. After the second session, they have to fill out which changes were initiated, concerning the provision of care.

To assess treatment integrity, counselors will tape a session using a voice recorder. To gain more insight in the evaluation of the Happiness Route from the point of view of participants and counselors, we will conduct interviews with counselors and participants at the end of the study. Counselors and participants will be asked individually whether they want to participate in these interviews.

\section{Primary outcome measure}

Positive mental health is the primary outcome. It is measured using the Dutch Mental Health Continuum - Short Form (MHC-SF) (Lamers et al., 2011). The MHC-SF is a 14item questionnaire that measures three core dimensions of positive mental health (Keyes, 2002), which match the three dimensions of the definition of the World Health Organization (2004):

- emotional well-being (3 items), defined in terms of the experience of positive feelings and satisfaction with life;

- social well-being (5 items), defined in terms of the self-report of positive functioning in community life (being of social value); 
- psychological well-being (6 items), defined in terms of the self-report of positive functioning in individual life (self-realization).

Participants are asked to rate the frequency of feelings they have experienced in the past month. Items are scored on a six-point scale ranging from 'never' to 'every day'. A higher score means more well-being.

Following classical test theory, the three subscales have been found in exploratory and confirmatory factor analyses. The internal consistency, concurrent and discriminant validity of the instrument and its subscales is good. The instrument has satisfactory test-retest reliability, indicating that it is sensitive to change. This is also supported by recent intervention studies (Fledderus, Bohlmeijer, Smit, \& Westerhof, 2010; Korte, Bohlmeijer, Cappeliez, Smit, \& Westerhof, 2012). A recent analysis based on item response theory shows that the reliability of the individual items is high across demographics, physical and mental health status, as well as across time (Lamers, Glas, Westerhof, \& Bohlmeijer, 2012). A pilot study suggested that there would be no interpretation problems caused by this questionnaire in the target group (Kedzia, 2009).

\section{Secondary outcome measures}

\section{Loneliness}

Loneliness is measured using the eleven-item loneliness scale developed by De Jong Gierveld and Van Tilburg (De Jong Gierveld \& Van Tilburg, 1999). Loneliness is measured as the subjectively experienced lack of embeddedness in social relations. The experience of loneliness is an inclusion criterion for the study. The intervention targets socially isolated people and aims to 'nudge' them out of their isolation. Loneliness is measured to assess if this aim is reached at the level of subjective experiences.

\section{Depression}

To measure if candidates decrease in depressive symptoms, the Dutch version of the Center for Epidemiological Studies-Depression Scale (CES-D) (Bouma et al., 1995; 
Radloff, 1977) is used. It is also used to test the exclusion criterion that a candidate may not have an untreated serious depression.

\section{Consumption of care}

Using items from the TIC-P (Trimbos/iMTA questionnaire for Costs associated with Psychiatric Illness) (Hakkaart-van Roijen, Van Straten, Donker, \& Tiemens, 2002), we can assess our hypothesis that the self-reported consumption of care reduces after participating in the Happiness Route. As the outcomes are still self-reported, Vektis, the Dutch information center for care, will carry out analyses on the actual differences in the use of healthcare between the experimental and control group, both before and after the intervention.

\section{Purpose in Life}

The Purpose in Life Scale (Ryff, 1989; Ryff \& Keyes, 1995) measures the feeling that there is a meaning in life, a sense of directedness and a clear comprehensibility of life's purpose (Ryff, 1989). The Happiness Route aims to help participants find a (new) aim and purpose in their lives.

\section{Resilience}

Resilience is measured using the Brief Resilience Scale (Smith et al., 2008). We hypothesize that people who follow the Happiness Route will develop greater resilience. Resilience is often seen as an important individual resource for mental health, especially in difficult situations.

\section{Social participation}

We measure social participation using items that assess paid or voluntary work, social contacts and activities outside the house. The items are derived from validated national survey studies. The items measure whether the aim of the Happiness Route to nudge people into more social participation is reached.

\section{Health-related quality of life}

The Dutch version of the EuroQol (EQ-5D) (Brooks \& Group, 1996) is used to measure 
if participants will have an improved health-related quality of life after following the Happiness Route. It is also used as an inclusion instrument for assessing whether or not participants have health limitations.

\section{Moderating measures}

To address the question whether the effect of the intervention is different for participants with varying backgrounds, we will examine whether age, gender, and cultural background moderate the effectiveness of the intervention.

To address the question whether the effect of the intervention depends on the characteristics of counselors, we will examine the moderating effects of the characteristics of counselors: work experience, work satisfaction, and adherence. For work experience we will compute an index that is based on educational level and number of years' experience. For work satisfaction, we will compute an index that is based on work engagement (Schaufeli \& Bakker, 2004) and job satisfaction (Brewster et al., 2005; Van Veldhoven et al., 2002). Furthermore, counselors will fill out online logs for each participant after every home visit. These logs can be used to measure adherence.

\section{Statistical analyses}

\section{Descriptive statistics}

A CONSORT flow chart of participation during the total study will be drawn. Reasons for drop-out will be summarized. Percentages of missing values and dropout will be displayed. The evaluation interviews with counselors and participants will be subject to a content analysis and the descriptive statistics of the categories resulting from this content analysis will be computed.

\section{Univariate analyses}

Univariate analyses on the differences between the intervention and control groups at baseline (chi-square and t-tests) will be performed to check whether the randomization has succeeded. 


\section{Multivariate analyses}

We will first do a missing data analysis for all participants on the second and third measurement point. A logistic regression analysis will be conducted with having complete data as the dependent variable, and demographic and psychosocial characteristics at baseline measurement as independent variables to assess nonrandom missings. We will use multiple imputations (five data sets) to replace missing values and carry out the analyses on the pooled data set. Hence, all participants who were randomized can be included in the statistical analyses. The results from this imputed intention-to-treat sample will be compared to the results of the observed data only.

We will use MANOVA analyses to assess the effectiveness of the intervention in reaching its primary and secondary outcomes. The measures at baseline, posttreatment, and follow-up are repeated measures and the experimental condition versus the control condition is the independent variable. In all analyses, we take into account that the observations are clustered as participants are 'nested' in each of the ten local institutions. Therefore, robust standard errors will be computed using the first-order Taylor-series linearization method.

Standardized mean differences (Cohen's d) at post-intervention and follow-up will be calculated as the difference between the means of the treatment and control condition divided by the standard error of the control condition. We expect a small to moderate effect size for the primary outcome (Cohen's $d=0.35$ ).

To answer the question on moderating participant factors, we will analyze the moderating effects of demographic characteristics (age, gender, and cultural background) on the effectiveness of the intervention. Following Kraemer et al. (Kraemer, Wilson, Fairburn, \& Agras, 2002), we will enter the change score of positive mental health at nine months minus baseline as a dependent variable in a linear regression model. The condition dummy (experimental versus control condition), the potential moderator, and their interaction are independent variables. When the interaction effect is significant, there is a differential effect of the intervention for 
this particular moderator. Analyses will be carried out for each of the three potential moderator variables separately.

We will do similar regression analyses to answer the question on moderating counselor factors. The potential moderators are the indices for work experience, work satisfaction, and adherence to the program as measured with the questionnaire for counselors and the logs of the counselors.

\section{Power calculation and sample size}

Based on a meta-analysis of previous studies in positive psychology, conducted with instruments that are similar to the MHC-SF (Sin \& Lyubomirsky, 2009), we expect a small to medium effect size for the intervention Happiness Route (Cohen's $d=0.35$ ). A pilot study (Francissen et al., 2010) and experiences from previous practice showed that there are no negative effects on the well-being of participants. We therefore specified a one-tailed test with an alpha level of 0.05 under the assumption that the Happiness Route will be more effective than the Customized Care group, as the latter is not intended to improve positive mental health. This has also been shown in previous studies on positive psychological interventions (Sin \& Lyubomirsky, 2009). Given ethical considerations, Knottnerus and Bouter (2011) argued that one-sided testing is preferable under these circumstances. Power analysis with the program GPower with a power of 0.80 (1 - beta of 0.20), indicates that 102 participants are needed in each condition. We used a maximal drop-out rate of $20 \%$ which is a conservative estimate from previous experience. In everyday practice, the drop-out was about $10 \%$ of the more than 500 people who already participated in a Happiness Route. With a maximal drop-out of $20 \%$, we need 128 participants in each condition, 256 in total.

\section{Discussion}

A recently published meta-analysis of randomized controlled trials (RCTs) on positive psychology interventions (Bolier et al., 2013) found that, though the interventions can be effective in the enhancement of well-being, the quality of studies was not high. In most studies that examined interventions directed at subjective and psychological 
well-being, the number of participants was relatively small. Furthermore, the subjects already had a medium to high well-being and no psychosocial problems. A third of the studies included in the meta-analysis were aimed at college students. Only seven of the 38 studies used inclusion criteria to target a group with psychosocial problems. Randomization procedures were often unclear. Also, Bolier et al. stated that statistical analysis could have seriously biased the results, as most studies conducted completers-only analysis instead of intention-to-treat analysis. Many studies took place in experimental settings, so that little is known about their implications and practicability in the field. Most studies described self-help interventions, whereas it was found that individual face-to-face interventions had generally significantly higher effect sizes. Moreover, the control conditions were mostly non-active conditions: only four studies had an active (care-as-usual) control group, whereas 27 studies had either no intervention, a placebo intervention or a waiting list as control condition.

This study tackles the shortcomings named above. First of all, the study belongs to the $10 \%$ of the largest studies in the field of positive psychology (Bolier et al., 2013; Sin \& Lyubomirsky, 2009). Secondly, the target group has serious psychosocial problems. Thirdly, randomization procedures are strictly handled and described and an intention-to-treat analysis will be conducted. Furthermore, this is a field study where participants are recruited by referral from practitioners from the health care and social sector. The Happiness Route is not a self-help intervention, as a majority of the positive psychology studies, but is delivered individually and face-to-face to participants. Also, the control condition of this study is an active condition, where the subjects in the control group receive two home visits, to make sure that both groups get attention by a health professional. Furthermore, the control consultant will make sure that the subjects in the control group receive an optimal care-as-usual.

There are several points that make this study especially interesting. This project is directed at an especially vulnerable target group with an accumulation of risk factors: social isolation, poor health and low SES. They are at high risk of suffering from poor well-being. This in turn can have a negative effect on their already poor physical health. This makes this group also a high-cost group in the healthcare sector. The Happiness 
Route can help to nudge participants towards improved well-being by helping them to find their passion and carrying out an intrinsically motivated activity related to that passion. The outreaching approach to recruit socially isolated participants and the happiness-based working style are innovative ways of approaching and supporting this group. Instead of focusing on their problems and their care, the focus lies on their well-being, connectedness to others, as well as their autonomy and competences. This method is based on the well-proven self-determination theory (Ryan \& Deci, 2000) and effective methods from well-tested interventions are used, such as life review (Bohlmeijer \& Westerhof, 2010; Singer, 2005), anticipated regret (Abraham \& Sheeran, 2004; Bode et al., 2007) and behavioral activation (Hermans \& Van de Putte, 2004). By taking this innovative approach, it is expected that not only will participants' well-being and psychosocial function improve, but also that their care consumption will decrease.

This is the first study to describe the evaluation of a practice-based program that nudges a target group suffering from health problems and low SES out of their social isolation towards more well-being by a happiness-based approach. Our study will answer questions concerning the effectiveness of this happiness-based approach. We will follow an intervention in practice, from recruitment, intake, and inclusion up to conducting the intervention and measuring effects. We will not only take a closer look at the effects of the Happiness Route, but also study if participants benefit in a similar way. We expect that the inclusion criteria will make sure that the intervention is beneficial to all included participants. We also assume that counselor characteristics will not influence the effectiveness of the intervention, as we train them all in a similar way. To test these assumptions, we will examine the role of characteristics of both participants and counselors. Another strength of this study is the expected high external validity, as the intervention will be examined in a real-life setting and the recruitment for the study is the same as the actual recruitment for the Happiness Route.

However, this RCT also has some limitations. Firstly, the available time to detect a possible change in the outcome measures will be only nine months in total (from 
intake to follow-up measure) and only six months after the intervention ended. Some changes, especially in the consumption in health care, might only take place later in time, also because institutions are often slow in changing care schemes, such as domestic help. Nine months are however a standard time for follow-up in psychological research. In fact, many studies in the field of positive psychology do not satisfy this standard and use no or shorter follow-up measurements (Bolier et al., 2013).

A further limitation is that the participants in the control condition do not receive any money and will only receive two home visits from a counselor, whereas the participants who follow the Happiness Route will receive three to five home-visits and also will receive a budget. Therefore, it is possible that this extra social and financial attention could be partly an explanation for better effects in the experimental group as compared to the control group. On the other hand, the control group is an active condition where participants will receive home sessions from a trained professional who can help them optimizing their health care, which is better than the often used waiting list condition, in which participants receive no attention at all.

If the intervention has positive effects, we cannot be sure which part of the intervention helped. A positive effect could be due to new social contacts, activation, a new aim and direction in life, a feeling of autonomy or competence or a combination of any of these factors. Thus we can tell if the intervention is effective, but we will not be able to specifically point out which parts of the intervention cause the possible effectiveness. We also will not know if the intervention would also be equally effective with a lesser amount of effort, time and money or which level is enough. However, the current aim is to study the effectiveness of this practice-based intervention. Further studies can clarify which elements and which 'dose' of social and financial support will reach the effect.

The study also has to face some challenges. Especially the real life setting is challenging for the internal validity of the study. Different cities have different ideas and requirements about the project, which sometimes conflict with the internal 
validity of the study. The demands of the study cannot always be met, due to personal circumstances of the counselors. Illness of a counselor can for example cause a delay in the delivery and consequently a delay in filling in the second questionnaire. These circumstances can lead to differences between subjects. Conversely, the results will have more external validity, as the study is performed in a real life setting.

Primarily, the study will evaluate if a happiness-based approach can increase wellbeing of a vulnerable group. Secondarily, the study will examine if the Happiness Route can decrease loneliness, depressive symptoms and consumption of care and whether it improves purpose in life, resilience, social participation and health-related quality of life. If the hypothesis of the intervention's superiority over an optimized care as usual approach can be demonstrated, this could convince more communities to use a more happiness-based working style, especially if the study shows that this could result in less health care consumption and thus save money. The results of the study will become available in 2015.

\section{Competing interests}

The authors declare that they have no competing interests.

\section{Acknowledgements}

We want to thank Aad Francissen and Eddy Wezenberg who made substantial contributions to the conception and design. We are grateful that this study is subsidized by the Netherlands Organization for Health Research and Development (ZonMw), the Hague, grant 200210013 (awarded to Eddy Wezenberg, Arcon). 


\section{References}

Abraham, C., \& Sheeran, P. (2004). Deciding to exercise: The role of anticipated regret. British Journal of Health Psychology, 9(2), 269-278.

Australia, S. (2005). Sane Research Report 1: Mental illness and social isolation. SANE Australian website.

Bode, C., De Ridder, D. T., Kuijer, R. G., \& Bensing, J. M. (2007). Effects of an intervention promoting proactive coping competencies in middle and late adulthood. The Gerontologist, 47(1), 42-51.

Bohlmeijer, E., \& Westerhof, G. J. (2010). Op verhaal komen: je autobiografie als bron van wijsheid: Boom.

Bolier, J., Haverman, M., Westerhof, G., Riper, H., Smit, F., \& Bohlmeijer, E. (2013). Positive psychology interventions: a meta-analysis of randomized controlled studies. $B M C$ Public Health, 13(1), 119.

Bouma, J., Ranchor, A., Sanderman, R., \& Van Sonderen, E. (1995). Het meten van symptomen van depressie met de CES-D. Een handleiding. Groningen, Noordelijk Centrum voor Gezondheidsvraagstukken, Rijksuniversiteit Groningen, 2-24.

Brewster, C., Suutari, V., \& Bonache, J. (2005). Job satisfaction among expatriates, repatriates and domestic employees: The perceived impact of international assignments on workrelated variables. Personnel Review, 34(1), 110-124.

Brooks, R., \& Group, E. (1996). EuroQol: the current state of play. Health policy, 37(1), 53-72.

Centraal Bureau voor de Statistiek, C. (2011). Armoedesignalement 2011: Sociaal en Cultureel Planbureau.

Chida, Y., \& Steptoe, A. (2008). Positive psychological well-being and mortality: a quantitative review of prospective observational studies. Psychosomatic medicine, 70(7), 741-756.

Cohen, S., \& Pressman, S. D. (2006). Positive affect and health. Current Directions in Psychological Science, 15(3), 122-125.

Connolly, M. K., Quin, E., \& Redding, E. (2011). Dance 4 your life: exploring the health and well-being implications of a contemporary dance intervention for female adolescents. Research in Dance Education, 12(1), 53-66. doi:10.1080/14647893.2011.561306

De Jong Gierveld, J., \& Van Tilburg, T. (1999). Manual of the Loneliness Scale 1999. Department of Social Research Methodology, Vrije Universiteit Amsterdam, Amsterdam (updated version 18.01. 02).

Diener, E., \& Ryan, K. (2009). Subjective well-being: A general overview. South African Journal of Psychology, 39(4), 391-406.

Diener, E., Suh, E., Lucas, R., \& Smith, H. (1999). Subjective Well-Being: Three Decades of Progress. Psychological Bulletin, 125, 276-302.

Fledderus, M., Bohlmeijer, E. T., Smit, F., \& Westerhof, G. J. (2010). Mental health promotion as a new goal in public mental health care: a randomized controlled trial of an intervention enhancing psychological flexibility. American Journal of Public Health, 100(12), 2372. doi:10.2105/AJPH.2010.196196

Francissen, A., Wezenberg, E., \& Westerhof, G. (2010). De gevolgen van geluk. Achtergronden en toekomst van het geluksbudget. Borne: Arcon.

Hakkaart-van Roijen, L., Van Straten, A., Donker, M., \& Tiemens, B. (2002). Trimbos/iMTA questionnaire for costs associated with psychiatric illness (TIC-P). Rotterdam: Institute for Medical Technology Assessment.

Hawkley, L. C., Masi, C. M., Berry, J. D., \& Cacioppo, J. T. (2006). Loneliness is a unique predictor of age-related differences in systolic blood pressure. Psychology and Aging, 21(1), 152.

Hermans, D., \& Van de Putte, J. (2004). Cognitieve gedragstherapie bij depressie: Bohn Stafleu Van Loghum. 
Howell, R., Kern, M., \& Lyubomirsky, S. (2007). Health benefits: meta-analytically determining the impact of well-being on objective health outcomes. Health Psychological Review, $1,83-136$.

Kaplan, G. A., Shema, S. J., \& Leite, C. M. A. (2008). Socioeconomic determinants of psychological well-being: the role of income, income change, and income sources during the course of 29 years. Annals of Epidemiology, 18(7), 531-537.

Kedzia, S. (2009). What makes you happy? Evaluating an intervention aimed at promoting social participation of lonely people: identifying concepts that can serve as building blocks of self-chosen activities and developing and testing a questionnaire to measure the success of these activities. Unpublished master-thesis, University of Twente, Enschede, the Netherlands.

Keyes, C. (2007). Promoting and protecting mental health as flourishing: a complementary strategy for improving National Mental Health. American Psychologist, 62, 95 - 108.

Keyes, C. L. (2002). The mental health continuum: From languishing to flourishing in life. Journal of Health and Social Behavior, 207-222.

Keyes, C. L., Wissing, M., Potgieter, J. P., Temane, M., Kruger, A., \& van Rooy, S. (2008). Evaluation of the mental health continuum-short form (MHC-SF) in Setswana-speaking South Africans. Clinical Psychology and Psychotherapy, 15(3), 181.

Korte, J., Bohlmeijer, E., Cappeliez, P., Smit, F., \& Westerhof, G. (2012). Life review therapy for older adults with moderate depressive symptomatology: a pragmatic randomized controlled trial. Psychological Medicine, 42, 1163 - 1173.

Kraemer, H. C., Wilson, G. T., Fairburn, C. G., \& Agras, W. S. (2002). Mediators and moderators of treatment effects in randomized clinical trials. Archives of General Psychiatry, 59(10), 877-883.

Lamers, S., Bolier, J., Westerhof, G., Smit, F., \& Bohlmeijer, E. (2012). The impact of emotional well-being on long-term recovery and survival in physical illness: a meta-analysis. Journal of Behavioral Medicine, 35, 538 - 547.

Lamers, S., Westerhof, G. J., Bohlmeijer, E. T., ten Klooster, P. M., \& Keyes, C. L. (2011). Evaluating the psychometric properties of the mental health continuum-short form (MHC-SF). Journal of clinical psychology, 67(1), 99-110.

Lamers, S. M., Glas, C. A., Westerhof, G. J., \& Bohlmeijer, E. T. (2012). Longitudinal evaluation of the mental health continuum-short form (MHC-SF). European Journal of Psychological Assessment.

Lyubomirsky, S., King, L., \& Diener, E. (2005). The benefits of frequent positive affect: does happiness lead to success? Psychological Bulletin, 131(6), 803.

Machielse, A., \& Hortulanus, R. (2006). Sociaal isolement bij ouderen. Geron, 2, 1-3.

Ministerie van Volksgezondheid Welzijn en Sport, V. (2010). Welzijn Nieuwe Stijl. Brochure. Den Haag.

Plaats, J. J. (1994). Geriatrie, een spel van evenwicht: een theoretische bijdrage aan de zorg voor langdurig zieke ouderen: Van Gorcum/Dekker \& van de Vegt.

Pressman, S., \& Cohen, S. (2005). Does positive affect influence health? Psychol Bull, 131, $925-971$.

Radloff, L. S. (1977). The CES-D scale a self-report depression scale for research in the general population. Applied Psychological Measurement, 1(3), 385-401.

Rijken, M., \& Groenewegen, P. P. (2008). Money does not bring well-being, but it does help! The relationship between financial resources and life satisfaction of the chronically ill mediated by social deprivation and loneliness. Journal of Community \& Applied Social Psychology, 18(1), 39-53.

Rokach, A., Lechcier-Kimel, R., \& Safarov, A. (2006). Loneliness of people with physical disabilities. Social Behavior and Personality: An International Journal, 34(6), 681-700. 
Routasalo, P. E., Savikko, N., Tilvis, R. S., Strandberg, T. E., \& Pitkälä, K. H. (2006). Social contacts and their relationship to loneliness among aged people-a population-based study. Gerontology, 52(3), 181-187.

RVZ. (2010). Zorg voor je Gezondheid! Gedrag en gezondheid: De nieuwe ordening. Den Haag: RVZ.

Ryan, R., \& Deci, E. (2001). On happiness and human potentials: a review of research on hedonic and eudaimonic well-being. Annual Review of Psychology, 52, 141 - 166.

Ryan, R. M., \& Deci, E. L. (2000). Self-determination theory and the facilitation of intrinsic motivation, social development, and well-being. American Psychologist, 55(1), 68.

Ryff, C. (1989). Happiness is everything, or is it? Explorations on the meaning of psychological well-being. Journal of Personality and Social Psychology, 57, 1069 - 1081.

Ryff, C. D., \& Keyes, C. L. (1995). The structure of psychological well-being revisited. Journal of Personality and Social Psychology, 69(4), 719.

Savikko, N., Routasalo, P., Tilvis, R. S., Strandberg, T. E., \& Pitkälä, K. (2005). Predictors and subjective causes of loneliness in an aged population. Archives of Gerontology and Geriatrics, 41(3), 223-233.

Schaufeli, W. B., \& Bakker, A. B. (2004). Bevlogenheid: een begrip gemeten.

Sin, N., \& Lyubomirsky, S. (2009). Enhancing well-being and alleviating depressive symptoms with positive psychology interventions: a practice-friendly meta-analysis. J Clin Psychol, $65,467-487$.

Singer, J. A. (2005). Memories that matter: How to use self-defining memories to understand \& change your life: New Harbinger Publications.

Smith, B. W., Dalen, J., Wiggins, K., Tooley, E., Christopher, P., \& Bernard, J. (2008). The brief resilience scale: assessing the ability to bounce back. International Journal of Behavioral Medicine, 15(3), 194-200.

Thaler, R. H., \& Sunstein, C. R. Nudge: Improving Decisions About Health, Wealth, and Happiness: HeinOnline.

Tiemeijer, W. L., Thomas, C., \& Prast, H. (2009). De menselijke beslisser: over de psychologie van keuze en gedrag (Vol. 22): Amsterdam University Press.

Valtorta, N. K., \& Hanratty, B. (2013). Socioeconomic variation in the financial consequences of ill health for older people with chronic diseases: a systematic review. Maturitas, 74(4), 313-333.

Van der Plaats, J. (2007). Eindrapportage Onderzoek PGB Welzijn. Almelo: Gemeente Almelo.

Van Veldhoven, M., Meijman, T., Broersen, J., \& Fortuin, R. (2002). Handleiding VBBA. SKB Vragenlijst services.

Veenhoven, R. (1996). Developments in satisfaction-research. Social Indicators Research, 37(1), 1-46.

Vereniging van Nederlandse Gemeenten, V. (2010). Kantelen in de Wmo: Handreiking voor visieontwikkeling en organisatieverandering. Den Haag.

Walburg, J. A. (2008). Mentaal vermogen: investeren in geluk: Nieuw Amsterdam.

Westerhof, G. J. (2013). The complete mental health model: The social distribution of mental health and mental illness in the Dutch population Mental Well-Being (pp. 51-70): Springer.

Westerhof, G. J., \& Keyes, C. L. (2010). Mental illness and mental health: The two continua model across the lifespan. Journal of Adult Development, 17(2), 110-119.

Wilkinson, R. G., \& Pickett, K. E. (2006). Income inequality and population health: a review and explanation of the evidence. Social Science \& Medicine, 62(7), 1768-1784.

World Health Organization, W. (2004). Promoting mental health: Concepts, emerging evidence, practice: Summary report. 


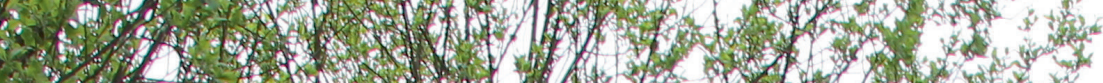

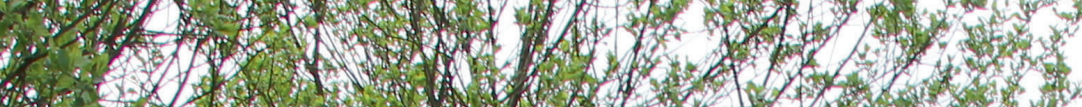
9. $\rightarrow 0$.

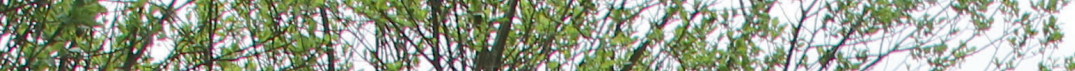
2.

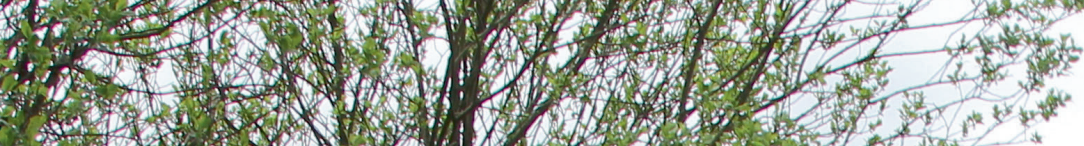

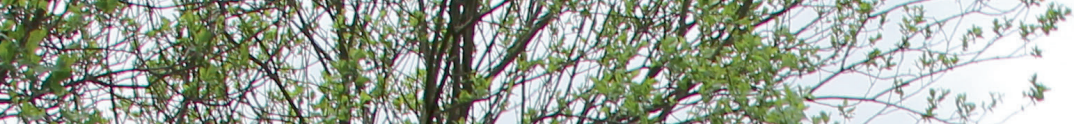

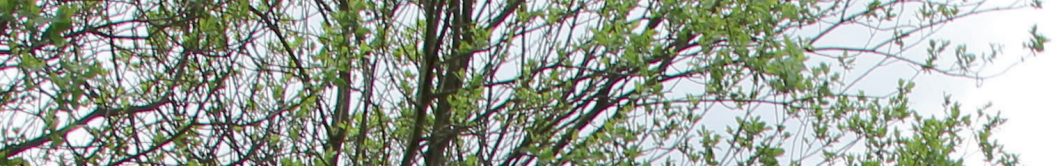
- 121010

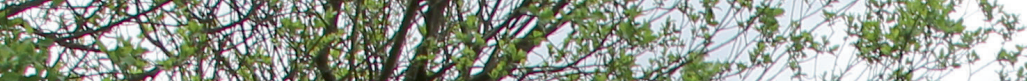

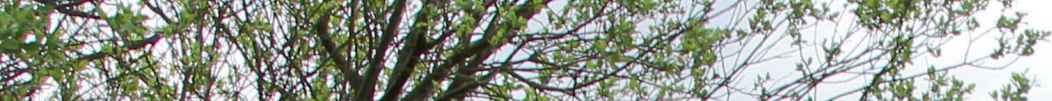

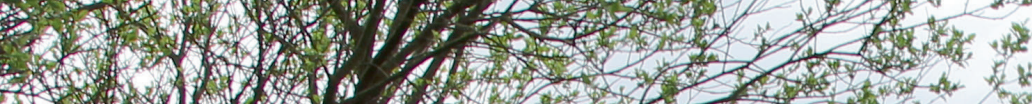
$+1 \times 10 \%$ 1 No (1)

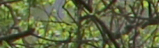
7 (1)

$$
40 \frac{1}{2+4}
$$

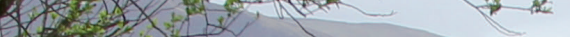
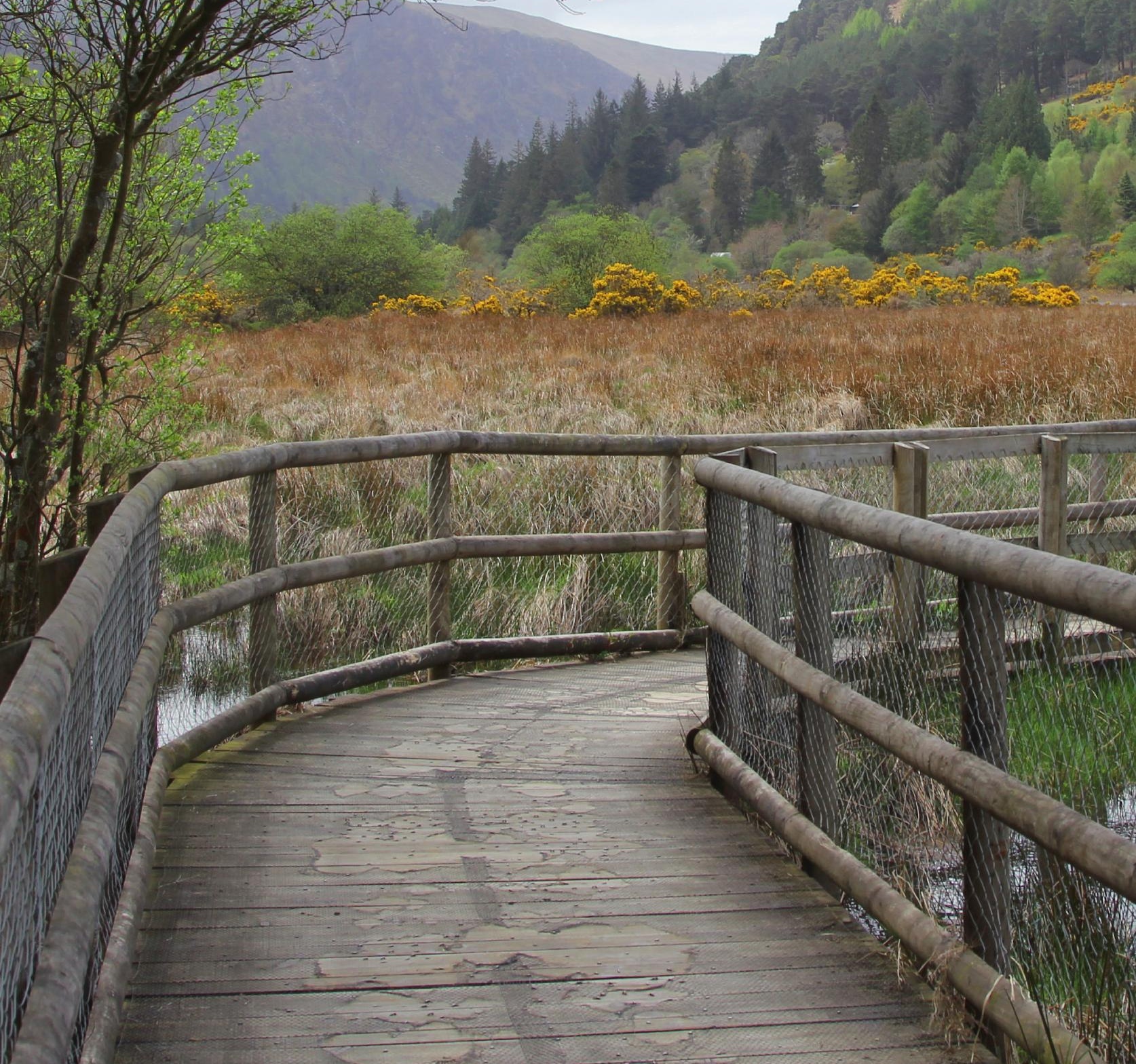


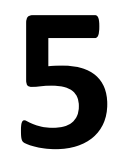

The Long and Winding Road to Happiness. A Randomized Controlled Trial on the Effects of a Positive Psychology Intervention for Severely Lonely People with Health Problems

1

It was outside, a summer evening. With all of us together in a circle and tall trees everywhere, they held the sound so wonderfully. And then with each other.

Oh marvelous, what a sound! And all around us nature and there were statues

in the garden. [...] How I have laughed. I enjoyed that so much!

Participant Happiness Route who followed a djembe course

Weiss, L. A., Oude Voshaar, M. A. H., Bohlmeijer, E. T., \& Westerhof, G. J. (submitted). The Long and Winding Road to Happiness. A Randomized Controlled Trial on the Effects of a Positive Psychology Intervention for Vulnerable People. BMC Health and Quality of Life Outcomes. 


\begin{abstract}
Background: This paper describes a randomized controlled trial on a positive psychology intervention, the Happiness Route, in a practice setting. The intervention is directed at vulnerable people and aims to improve well-being rather than treating symptoms. This approach is in line with current developments in public health in the Netherlands. Interventions that aim to increase well-being have proven to be effective. Yet, only few studies target groups with multiple health and psychosocial problems. Our objective was to evaluate if the Happiness Route is more effective than an active control group, with well-being as primary outcome.
\end{abstract}

Methods: We conducted a randomized, half-blind, active-controlled, parallel-group study in the Netherlands in seven municipalities. To be eligible, participants had to be aged 18 or older, experience loneliness, suffer from health problems and have a low socio-economic status. Care professionals who have contact with the target group during their daily work in their community recruited participants. Each group received a couple of home visits by a trained counselor. In the Happiness Route, a happiness-based approach was used, whereas the control group used the traditional problem-based approach. Participants were blinded, but counselors knew which intervention they delivered. We used well-validated instruments to measure wellbeing (MHC-SF) as primary outcome and several secondary outcome measures.

Results: 50 participants were randomized to the control group, 58 to the experimental group. All 108 participants were analyzed with intention-to-treat. Participants were severely lonely and had an average of three health problems. Less than $5 \%$ had paid work, almost $60 \%$ had a low education, and nearly $70 \%$ had an extreme low income. No significant interaction between time and condition effect was found. The total score of the MHC-SF, emotional and social well-being, depression and loneliness improved significantly over the 9 month period in both conditions $(p<0.05)$. Languishing decreased significantly from $33 \%$ at baseline to $16 \%$ at follow-up in the Happiness Route, but did not change significantly in the control condition. No significant improvement over time was found in psychological well-being, resilience, purpose in life, health-related quality of life and social participation. Participants in the Happiness Route were significantly more satisfied with the intervention than the control group.

Conclusions: It proved very hard to include this vulnerable group and fewer participants were included than intended. The Happiness Route proved as effective as a problem-based approach. Still, less participants were languishing after the Happiness Route and participants were significantly more satisfied than the participants receiving traditional care. The Happiness Route seems to be an adequate alternative intervention for vulnerable people. 


\section{Introduction}

For some people, it never rains, but it pours. This saying is especially true for the target group of this randomized controlled trial: vulnerable people that have to deal with multiple chronic health and psychosocial problems.

In the Netherlands, almost a third of the population has to deal with at least one chronical condition. In older adults, this number may be as high as $70 \%$ (Gijsen, Van Oostrom, \& Schellevis, 2014). The number of people with chronic illness is still growing, as the population is aging and people with chronic conditions live longer (Wagner et al., 2001). Chronic illness is a serious public health problem. Costs associated with the incapacity to work due to chronic illness are more than 10 billion euro and the health care costs for chronically ill people make up $70 \%$ of the total health care costs in the Netherlands, and are still rising (Van den Berg et al., 2014). Despite their high medical care consumption, many studies have found that quality of life and well-being is significantly impaired in people with chronic illness (Doll, Petersen, \& Stewart-Brown, 2000; Rubin \& Peyrot, 1999; Stewart et al., 1989; Wikman, Wardle, \& Steptoe, 2011; Wolman, Resnick, Harris, \& Blum, 1994). Research has shown that low levels of well-being in turn affect health and psychosocial functioning (Lamers, Bolier, Westerhof, Smit, \& Bohlmeijer, 2012). How does such a downward spiral develop?

Suffering from physical or mental health problems can trigger such a negative spiral, especially when there is a lack of resources (e.g. low socio-economic status), or an accumulation of negative life-events (e.g. divorce) which impairs social networks (Machielse, 2011; Van der Plaats, 2002). This downward spiral is characterized by social isolation, development of problems in other life domains and finally a serious loss of well-being. This may affect the ability to participate in important social roles and prevent the pursuit of leisure activities, leading to feelings of emptiness and inactivity. In turn, this may lead to an exacerbation of symptoms as well as increased experiences of mental health problems. The current way to deal with this problem is to provide people with more health care, which is associated with becoming more dependent on professional workers and increased economic costs for these individuals, as well as for society (Valtorta \& Hanratty, 2013). More health care for problems may not always be the best solution (Van der Plaats, 2002). A happiness- 
based approach could possibly break the negative spiral (Weiss, Kedzia, Francissen, \& Westerhof, 2015b).

In this study, we examined an approach that is directed to improve well-being of this group of vulnerable adults rather than treating symptoms, based on the principles of positive psychology. The field of positive psychology has expanded traditional psychology by including and examining topics such as strengths, growth and wellbeing (Seligman \& Csikszentmihalyi, 2000). Our approach is in line with current developments in public health in the Netherlands towards using the strengths, selfreliance, active participation, and social network of citizens (Weiss et al., 2015). The promotion of well-being is now widely recognized as a new goal in mental healthcare to complement the traditional focus on preventing and treating problems (Barry \& Jenkins, 2007; Herrman, Saxena, \& Moodie, 2005; Keyes, 2007). Improved well-being has positive effects on health and personal functioning, resulting in health gains on an individual and societal level (Lyubomirsky, King, et al., 2005). Yet we still have little knowledge on the effectiveness of positive psychology interventions (PPIs) implemented in the daily practice of social workers working with vulnerable people.

One of the few happiness-based interventions that has been successfully implemented in practice in the Netherlands is called the 'Happiness Route'. It is directed to lonely people with health problems and a low socio-economic status (SES), which are known risk factors for diminished well-being (Cole, 2006; Diener, Suh, Lucas, \& Smith, 1999; Golden et al., 2009; Keyes, 2007; Keyes \& Shapiro, 2004; Mangelli, Gribbin, Büchi, Allard, \& Sensky, 2002; Pinquart \& Sörensen, 2000; Ryff \& Singer, 2008). Although it has been implemented successfully in several local communities (Francissen et al., 2010), its effectiveness has not yet been tested in a randomized study.

There is increasing evidence that interventions that aim to enhance well-being are effective. Several meta-analyses show that PPIs can improve emotional and psychological well-being, although effect sizes were mostly small (Bolier et al., 2013; Sin \& Lyubomirsky, 2009; Weiss, Westerhof, \& Bohlmeijer, 2016). To date, only few studies target groups with multiple health and psychosocial problems, despite earlier 
findings that PPIs tend to yield better results in these populations (Bolier et al., 2013, Weiss et al., 2016). This study belongs to the few that are directed at vulnerable groups with an accumulation of risk factors. Furthermore, it is one of the first PPIs to use a multicenter trial design and test the intervention as it is delivered in everyday practice, comparing it to an active control condition (Hone et al., 2015).

The aim of this study was to examine the reach, effectiveness, and satisfaction of the Happiness Route intervention in comparison to optimized care in a randomized controlled study. We tested the effects of the happiness-based intervention on wellbeing (primary measure) and the secondary measures of resilience, purpose in life, depression, health-related quality of life, loneliness, social participation and health care consumption.

\section{Methods}

\section{Design}

The trial was a multicenter, equally randomized, parallel-group study with an experimental and active control group, conducted in the Netherlands. The randomization with participants as unit had an allocation ratio of $1: 1$ for the two groups. Participants were blinded to the condition, whereas counselors had to know which intervention was administered. A detailed description of the study design is published in a research protocol (Weiss, Westerhof, \& Bohlmeijer, 2013). Instead of the 10 centers that were planned originally, 7 centers took part, as 3 centers dropped out. Also, the number and distribution of participants across the centers was not as originally planned, as inclusion of participants was challenging and progressed differently between centers.

\section{Intervention}

\section{Experimental group: the Happiness Route}

The Happiness Route has been developed in the municipality of Almelo in the Netherlands and was implemented by the non-profit organization Arcon in multiple other cities in the region. It was adapted and formalized by the University of Twente to be more theory-driven. It is a positive psychology intervention, using 
the principles of self-determination theory (Ryan \& Deci, 2000b), as it supports the autonomy, competence and relatedness of participants. The aim of the intervention is to increase well-being by supporting participants to find and act on a passion or intrinsically motivated activity.

Counselors paid participants between two and six home visits during a time span of three months. Practice has shown that the number of sessions varied between participants, as they differed widely in how quick they are with identifying a passion and their need of support. A session had a maximum duration of 90 minutes. After shortly talking about the current situation, problems were explicitly 'laid aside'. Instead, the counselor asked questions that were aimed to find sources of happiness for the participant. The counselor could choose from a set of evidence-based methods that he or she considered fitting to the individual participant and situation, such as examining values, behavioral activation (Hermans \& Van de Putte, 2004) or life-review methods (looking back on their childhood and reflecting on happy memories) (Bohlmeijer \& Westerhof, 2010; Singer, 2005).

To explore all options, all named interests, dreams and possibilities were written down on a list. Finally, the participant had to choose an activity to carry out. This could be supported with the method of 'anticipated regret'; imagining what you would regret most if you had not done it in a couple of years (Hermans \& Van de Putte, 2004). Counselors supported participants in the process of finding an activity and acting on it, but participants were explicitly encouraged to actively search and plan a preferably long-lasting activity. Possible pitfalls and how to deal with them were discussed. The choice for an activity should be made by the participant to strengthen feelings of autonomy. Ideally, existing talents could be used or skills could be developed during the activity, to strengthen the feeling of competence. It is also an advantage if the participant is able to get in contact with others during the activity to strengthen the feeling of relatedness. However, none of this was explicitly demanded. The only requirements were that the participant had to spent the budget for him/herself for something that is related to a passion or intrinsically motivated activity. 
The participants were allowed to spend up to $€ 500$ to realize their passion. The money could be used to pay for an activity (e.g., a painting course), or to purchase materials (e.g., a camera). When a suitable activity was found, an application form for the budget was filled out by the counselor and participant together and was sent to the project leader. The project leader decided if the activity fitted the passion and usually sent the money directly to the account of the participant. However, the money was not always needed, for example when people chose to engage in voluntary work as activity.

The aim was to find an activity and start with it in three months. The last session was an early feedback session, so that first experiences could be shared, the activity could be evaluated and, if needed, adjusted. In practice, some participants started with the activity after three months, often due to practical reasons, such as the starting date of a course.

\section{Control group: Customized Care}

The active control group, called 'Customized Care', encompassed two home visits by a health care professional with a maximum duration of 90 minutes, during a time span of three months. Aim was that the participants of both the control and experimental group received professional attention. A problem-based approach was used: the current situation, problems, and received care were noted down and discussed. Participants were asked how satisfied they were with the care they receive. In case that they were dissatisfied or missed help for certain problems, the counselor tried to improve the situation. This could include any form of help the counselor considered appropriate, such as organizing less, more or different care. Counselors ensured that participants got the best possible care and optimized the care if needed. Beforehand, it was estimated that three hours would be enough to work through all steps, but practice showed that in a couple of cases, one or two more sessions were needed. After having filled out the last questionnaire, participants of the control group were debriefed and given the opportunity to take part in the Happiness Route as well. 


\section{Counselors}

Of the 66 counselors trained, 53 were professionals from the health care and welfare sector and 14 were experienced volunteers. All counselors received intensive training on how to conduct the research and intervention by the main researcher (LAW): 46 were trained to deliver the Happiness Route and 20 to deliver the control intervention. Volunteers were all in the Happiness Route condition. All counselors received regular (peer) intervision (about twice a year), supervised by LAW. Counselors had a mean age of 50.09 years (SD 12.81), ranging between 23 and 70 years. $83 \%$ of the counselors were female, $92 \%$ were Dutch, $93 \%$ followed higher education, while $7 \%$ had a medium education level. They had a mean of 18 years (SD 12.61) work experience in the health care or welfare sector, with a maximum experience of 43 years.

\section{Participants}

\section{Recruitment and setting}

Intermediaries, who regularly get in contact with the target group in their daily work, recruited the participants. These are professionals from the health and welfare sector, such as social workers, general practitioners, nurses, or people working in home care. The counselors of the intervention could also propose candidates. Intermediaries were identified and informed by the project leader of a municipality. The data was collected in seven local municipalities throughout the Netherlands (Hengelo $n=43$, Almelo $n=26$, Zeist $n=21$, Woerden $n=8$, Nijmegen $n=4$, Tynaarlo $n=3$, Assen $n=3$ ). The population size of the municipalities ranged from 32.000 (Tynaarlo) to 172.000 (Nijmegen). The project leaders were located in a local municipality (Hengelo), a foundation that supports leisure time for people with a disability (Almelo), a service club (Woerden), a mental healthcare organization (Nijmegen) and welfare organizations (Zeist, Tynaarlo, Assen). Two of the project leaders were volunteers (Woerden and Zeist).

\section{Inclusion and exclusion criteria}

Eligible participants were aged 18 or older; experiencing loneliness (scoring 3 or higher on the loneliness scale (De Jong Gierveld \& Van Tilburg, 1999)); suffering from 
(mental and/or physical) health problems (having at least one health limitations in the EuroQol questionnaire (Brooks \& Group, 1996)); with a low socio-economic status, defined as low education (no more than lower secondary education) and/ or low employment status (not having a paid job) and/or low financial income (as defined by the Statistics Netherlands (Centraal Bureau voor de Statistiek, 2013): less than $€ 1000$ per month for a single household and between $€ 1000$ and $€ 1500$ for a couple or a single household with at least one child).

Candidates were excluded if they met one or more of the following criteria: high well-being (one standard deviation above the mean of the Dutch population on the Mental Health Continuum-Short Form: a score of 4.83 or higher (Lamers et al., 2011)); severe, untreated depression (scoring 39 or higher on the Center for Epidemiology Depression Scale, CES-D, without being under psychological treatment (Bouma, Ranchor, Sanderman, \& Van Sonderen, 1995; Radloff, 1977)); being currently in a crisis situation, such as being homeless, or having recently lost a partner (judged by the counselor during the intake); insufficient cognitive or linguistic skills to fill out a questionnaire (judged by the counselor during the intake).

\section{Power analysis}

A small to medium effect size was expected for the Happiness Route intervention (Cohen's $\mathrm{d}=.35$ ), based on a meta-analysis on positive psychology interventions (Bolier et al., 2013b). Preceding the study, the Gpower program was employed to determine that a total sample size of 204 would be required to have an $80 \%$ chance to detect an effect of this magnitude at $\alpha=.05$ (one-sided). To account for a maximum of $20 \%$ drop out, 256 participants were to be included; 128 in each condition. However, the study could not be completed with the sample size and power originally planned, as the recruitment proved to be hard. Instead, 108 participants were included, 58 in the Happiness Route and 50 in the control condition. None of the municipalities could recruit the intended number of participants. 


\section{Procedure and materials}

An intermediary could apply for a candidate that seemed eligible by sending an application form, signed by the candidate, to the project leader. The project leader checked the application form and sent either a Happiness Route or Customized Care counselor to do an intake. Beforehand, the candidate received a letter with information about the aim of the project, eligibility, what it means to participate, how it works, the benefits of participation, that it is voluntary, what happens with the data, and whom to contact with questions. During intake, the research-project was explained in more detail, and if willing to participate, the candidate signed an informed consent and filled out the baseline questionnaire. If needed, the counselor provided assistance. The informed consent and questionnaire were sent to the primary investigator (LAW).

\section{Randomization and blinding}

Eligible participants were randomized to either the experimental or the control group. The random allocation sequence was generated $a$ priori by a computer-generated randomized number list, made with randomizer.org. No restriction or stratification was used. The list was concealed and only used when the next participant had to be assigned to one of the two groups. LAW generated the random allocation sequence. Enrolling and assigning participants was performed by LAW, and partly by a student assistant (PDW) under supervision and after having received a thorough training.

The project leaders and counselors were not involved in the sequence generation and allocation concealment in any way. LAW or PDW informed the local project leader about the outcome of the inclusion and randomization, who then appointed a suitable counselor to the participant, if possible the same wo conducted the intake. The counselor informed the participant about which group he or she was randomized to and delivered the intervention during the following three months.

Project leaders, counselors who delivered the interventions and partially helped collecting data, and investigators who assessed the outcomes were all aware of the allocated condition. Participants were kept blinded to the allocation. They were 
informed that they would be randomly assigned to one of two groups which both had a different approach to deliver optimal care. After the inclusion was completed, they were told to which group they were assigned. They were not informed that one group was a control group and the other the intervention that was studied. None of the participants had to be unblinded during the conduct of the trial.

\section{Outcome measures}

A paper and pencil questionnaire was used at three time points: at baseline, after three months, and nine months after baseline. The same questionnaire with 92 items was used all three times, with the exception that the first one, filled out during the intake, also included 13 questions on personal characteristics, and the last two included 4 questions to evaluate the intervention. Participants filled out the questionnaires by themselves at home. At baseline, the counselor was always present and could help. The second and third questionnaires were sent by post. In case the participants needed help filling them out, they could ask the counselor for help. If the questionnaire was not sent back after two weeks, the investigator contacted the counselor with the question to check on the participant and help if needed.

\section{Primary outcome}

The primary outcome of this study was well-being, measured with the Dutch Mental Health Continuum - Short Form (MHC-SF) (Keyes, 2009; Lamers et al., 2011). The scale has 14 items and 3 subscales: emotional well-being (items 1-3), social wellbeing (items 4-8) and psychological well-being (items 9-14). Participants were asked to rate the frequency of certain feelings they have experienced during the past month on a six-point scale from 'never' to 'every day'. The score ranges from 0 to 5 , with a higher the score indicating higher well-being.

In a study by Lamers et al. (Lamers et al., 2011), the three factor structure has been confirmed in a Dutch sample. Reliability (Cronbachs alpha) of the three subscales was .83 for both emotional and psychological well-being and .74 for social well-being.The instrument had a satisfactory test-retest reliability (0.65). The 9 month test-retest reliability for the scales was .46 for emotional well-being, .47 for social well-being and .53 for psychological well-being. The three components had good convergent validity (Lamers et al., 2011). 
With the MHC-SF, it can also be determined in which category of positive mental health someone falls (Keyes, 2009). Someone is described as flourishing when having scored 'every day' or 'almost every day' at least one time for the three emotional well-being items and at least six times for the eleven items of social and psychological well-being. When someone scores 'never' or 'once or twice' at least once on the emotional well-being items and at least six times on the social and psychological well-being items, he or she is categorized as langhuishing. Individuals who are neither languishing nor flourishing are described as moderately mentally healthy.

\section{Secondary outcomes}

All secondary outcomes were previously developed and validated scales. For a detailed description of the scales, see study design (Weiss et al., 2013). The following concepts were measured:

- Resilience: Brief Resilience Scale (Smith et al., 2008) with six items on a fivepoint scale with a minimum score of 0 and a maximum score of 5 ;

- $\quad$ Purpose in life: the Purpose in Life Scale (Ryff, 1989a; Ryff \& Keyes, 1995; Steverink, Westerhof, Bode, \& Dittmann-Kohli, 2001), one of the six subscale from Ryff's Psychological Well-being Scales with five items on a five-point scale from 'strongly disagree' to 'strongly agree', with scores ranging from 5 to 25;

- Depression: CES-D (Bouma et al., 1995; Radloff, 1977) with 20 items on a four-point scale. Scores reach from 0 to 60 , with higher scores indicating more depressive symptoms;

- $\quad$ Health-related quality of life: EQ-5D (Brooks \& Group, 1996) with five items with a maximum score of 1 , indicating full health:

- Loneliness: Loneliness Scale (De Jong Gierveld \& Van Tilburg, 1999) with 11 items on a five-point scale, ranging from 0 to 11 . The total score can be categorized into four levels: not lonely (0 - 2), moderately lonely (3-8), severely lonely (9-10), and very severely lonely (11).

- Social participation: items from validated national survey studies, i.e. from the Permanent Onderzoek LeefSituatie (POLS) (voor de Statistiek, 2005), and the Longitudinal Internet Studies for the Social Sciences (LISS) panel 
(Scherpenzeel, 2009). Measured with three items on contact with family, friends and neighbors on a five-point scale from 'at least once a week' (1) to 'rarely or never' (5), and seven items on activities, such as voluntary work, study, helping others, religious activities or hobbies, with yes or no as answer options. A score between 0 and 5 was computed, with higher scores indicating higher levels of social participation.

- Care consumption: items from the TiC-P (Hakkaart-van Roijen, Van Straten, Donker, \& Tiemens, 2002) with nine items on received health care and six items for other forms of received help during the last four weeks. We determined the cost prices for each volume of consumption. To calculate costs, volumes of health care use were multiplied by the cost prices for each volume of care. The standard cost prices derived from the user manual of the TiC-P and additional sources (Hakkaart-van Roijen, 2002; Hakkaartvan Roijen et al., 2004; Hoefman, Van Exel, \& Brouwer, 2011). Originally, it was planned to also use data on care consumption from Vektis, the Dutch Information Centre for Care. Due to a change in their policy, this was not possible anymore at the moment the data was fully collected.

\section{Treatment satisfaction}

Treatment satisfaction was measured with mostly open questions at the end of the second and third questionnaire. At post-test, participants were asked (1) How good was your relationship with the counselor on a scale from 1 to 10 (1=not good at all, 10=extremely good)?; (2) What is your opinion about the home visits of the counselor?; (3) Did the project have any effects on your life and if yes, can you describe these effects shortly? At follow up, participants were asked (1) What is your opinion about the project? (2) Did the project have any effects on your life and if yes, can you describe these effects shortly? Responses were coded negative, neutral/ambivalent (both negative and positive aspects) or positive by the principal investigator. 


\section{Statistical analyses}

Baseline characteristics for continuous variables were summarized, using mean and standard deviation (SD), and compared between the Happiness Route and control group using t-tests for independent samples. Percentages of categorical baseline characteristics were calculated and compared between groups using chisquare statistics. At baseline, there were no significant differences between the two conditions on any of the demographic variables, neither on primary or secondary outcome measures, suggesting a successful randomization.

All analyses of primary and secondary outcomes were performed according to the intention-to- treat principle. All participants were analyzed in the condition to which they were randomized. Multiple imputation by chained equations was performed to replace missing values. The imputation model included all primary and secondary outcomes. Forty datasets with imputed plausible values were obtained, with 200 iterations between data sets. The method proposed by Licht (Licht, 2010) was used to obtain pooled p-values. In the study protocol, we planned to use five data sets. It turned out that the differences were very large between data sets, probably due to the smaller sample size. Therefore, we decided to increase the data sets from 5 to 40 . The results of the intention-to-treat analysis were compared to the observed data only sample. Repeated-measures analysis of variance (MANOVA) was used to compare baseline to follow-up scores at three and nine months on the primary and secondary outcome measures between the Happiness Route and Customized Care.

At follow-up, standardized mean differences (Cohen's d) were calculated for all primary and secondary outcomes as the difference between the means of the baseline and follow-up measurements per condition, divided by their pooled standard deviation. To interpret effect sizes, we used the interpretation for psychological and behavioral treatment, where effect sizes of 0 to 0.32 can be interpreted as small, effect sizes from 0.33 to 0.55 are seen as medium, and effects of $0.56-1.2$ are considered large (Lipsey \& Wilson, 1993). We did not conduct moderator analyses, as originally planned, as the power was too small. All statistical analyses were performed with SPSS 23. 


\section{Results}

\section{Reach of participants}

Participants had a mean age of 58.2, ranging from 26 to 89 years (SD 15.16). 75 were female, 16 were male. For more details on the baseline characteristics of the participants, see Table 1.

Table 1. Baseline characteristics of participants

\begin{tabular}{|c|c|c|c|}
\hline & $\begin{array}{l}\text { All } \\
(n=108)\end{array}$ & $\begin{array}{l}\text { Happiness Route } \\
(n=58)\end{array}$ & $\begin{array}{l}\text { Control group } \\
(n=50)\end{array}$ \\
\hline Age, mean in years $(S D)^{a}$ & $58.2(15.2)$ & $57.5(14.9)$ & $59.0(15.6)$ \\
\hline Gender: male ${ }^{b}$ & $30.6 \%$ & $27.6 \%$ & $34.0 \%$ \\
\hline Cultural background: Dutch ${ }^{\mathrm{b}}$ & $85.2 \%$ & $84.5 \%$ & $86.0 \%$ \\
\hline Martitial status: married ${ }^{b}$ & $15.7 \% \%$ & $20.7 \%$ & $10.0 \%$ \\
\hline Living situation: alone ${ }^{b}$ & $71.4 \%$ & $62.1 \%$ & $82.0 \%$ \\
\hline \multicolumn{4}{|l|}{ Daily activities $^{\mathrm{b}}$} \\
\hline Paid employment & $4.6 \%$ & $6.9 \%$ & $2.0 \%$ \\
\hline Unemployed/household & $28.2 \%$ & $25.8 \%$ & $30.0 \%$ \\
\hline disability pension & $38.0 \%$ & $44.8 \%$ & $30.0 \%$ \\
\hline Retired & $21.3 \%$ & $15.5 \%$ & $28.0 \%$ \\
\hline $\begin{array}{l}\text { Other (student, day care, volunteer work, } \\
\text { caregiver, hobby) }\end{array}$ & $8.4 \%$ & $6.8 \%$ & $10.0 \%$ \\
\hline \multicolumn{4}{|l|}{ Education $^{\mathrm{b}}$} \\
\hline Low & $59.4 \%$ & $57.1 \%$ & $62.0 \%$ \\
\hline Intermediate & $23.6 \%$ & $23.2 \%$ & $24.0 \%$ \\
\hline High & $17.0 \%$ & $19.6 \%$ & $14.0 \%$ \\
\hline \multicolumn{4}{|l|}{ Monthly income $e^{\mathrm{b}}$} \\
\hline$<€ 1000$ for singles; $<€ 1500$ for couples & $67.3 \%$ & $63.2 \%$ & $72.0 \%$ \\
\hline$<€ 2000$ for singles; $<€ 2500$ for couples & $32.7 \%$ & $36.8 \%$ & $28.0 \%$ \\
\hline Health problems, mean (SD) ${ }^{\mathrm{a}}$ & $3.47(1.87)$ & $3.52(1.74)$ & $3.42(2.03)$ \\
\hline Health grade, mean $(S D)^{a}$ & $5.67(1.84)$ & $5.49(1.79)$ & $5.88(1.88)$ \\
\hline Psychotropic drug use, $\mathrm{n}(\%)^{\mathrm{b}}$ & $45.4 \%$ & $43.1 \%$ & $48.0 \%$ \\
\hline $\begin{array}{l}\text { Mean hours outside per day, mean in } \\
\text { hours (SD) }\end{array}$ & $1.68(1.54)$ & $1.62(1.76)$ & $1.62(1.76)$ \\
\hline Days inside per week, mean in days (SD) ${ }^{\mathrm{a}}$ & $5.71(1.89)$ & 5.84 (1.87) & $5.57(1.91)$ \\
\hline
\end{tabular}

Note. ${ }^{a}$ No significant differences between intervention and control condition ( $t$-test with $p>.05)$. ${ }^{b}$ No significant differences between intervention and control condition ( $\chi^{2}$-test with $p>05)$. 
Loneliness. Participants had a mean score of 9.01 (SD 2.25) on the loneliness scale, which is considered as severely lonely (Jong-Gierveld, 1999). When comparing the score to the norm scores for a Dutch population, the included group scored almost twice as high as the group with the highest average loneliness scores (4.9), i.e., single divorced older adults with a small network (De Jong Gierveld \& Van Tilburg, 1999). Participants spent most of their time at home, being less than two hours outside per day on average, and spending an average of almost 6 days per week inside.

Health problems. Participants had a mean of 3.47 health problems (SD 1.82), with a minimum of 1 and a maximum of 10 diseases, indicating a high level of comorbidity. The most frequent proportion occurring across all health problems were internal medicine diseases (36.96\% of all diseases mentioned, e.g. rheumatic and endocrinological diseases), mental disorders (17.02\%, e.g. depression and personality disorder), orthopedics and accident surgery diseases (18.35\%, e.g. arthrosis and osteoporosis), neurological diseases (7.98\%, e.g. epilepsy and stroke) and nonspecific symptoms and diseases (9.30\%, e.g. concentration problems). Less often occurring diseases were otorhinolaryngology diseases (2.66\%), diseases of the eye (2.13\%), surgical diseases (1.86\%), urinary system diseases (1.33\%), skin diseases $(1.06 \%)$, genetic diseases $(0.80 \%)$ and dental diseases $(0.27 \%)$. A person could score in several categories and more than once in one category. Only one participant did not report having any health problem, but still had an impaired health-related quality of life.

The mean of health-related quality of life, measured with the Dutch EQ-5D, was .45 at baseline. The SD of .30 indicated a large variation in health-related quality of life. Compared to a representative sample of the Dutch population (Stolk et al., 2007), who scored .87 (SD .18) in total, our group scored almost half as low. This indicates that health-related quality of life of our target group was seriously impaired. The health-related quality of life of our target group was comparable with patients with moderate depressive symptoms, who scored .46 (Sobocki et al., 2007). The mean CES-D score of participants was 26.06 (SD 12.16), which is much more than the cutoff score of 16 that is indicative of clinically relevant depressive symptomatology (Lewinsohn, Seeley, Roberts, \& Allen, 1997). Almost half of the participants (45.4\%) 
took psychotropic drugs; $23.1 \%$ took benzodiazepines, $23.1 \%$ took antidepressants, 9.3\% took sleep-inducing drugs, and 9.3\% took antipsychotic drugs.

SES. Socio-economic status was low. Only $4.6 \%$ had paid work. Almost $60 \%$ have a low education and almost $70 \%$ had a low income.

Well-being. Well-being was very low, with a total mean score of 1.99 (SD 0.91), more than a standard deviation below the mean of the normal Dutch population on the MHC-SF, which is 2.98 (SD .85) on a scale from 0 to 5 (Lamers et al., 2011). 31\% of the participants were languishing at the start of the intervention, a high number compared to the $5 \%$ languishing people in the Dutch population (Westerhof \& Keyes, 2008). To conclude, we included an extremely vulnerable group.

\section{Treatment adherence and completion}

For details about the participant flow, see Fig 1 . Of the 123 candidates assessed for eligibility, 108 participants were randomized. Ten candidates were excluded because they did not have 'enough' problems, whereas four had too severe problems and one had been a participant of the Happiness Route before. Of the 58 participants randomized to the Happiness Route, 23 did not fully adhere. They did not apply for a budget or did not take part in an activity, because they had to stop due to health or psychological problems, because they had no need for help, or because of other reasons. Of the 50 included participants in the Customized Care group, 1 participant did not adhere to the intervention, due to psychological problems. There were no significant differences between intervention adherers $(n=35)$ and non-adherers $(n=23)$ of the Happiness Route at baseline, with the exception of 'daily activity' $\left(\chi_{7}^{2}=14.87, p=.04\right)$. Intervention adherers were more often unemployed and receivers of a disability pension and less often retired than non-adherers.

Of the participants who did adhere to the intervention, $43 \%$ followed a course (e.g., photography course, painting class, music lessons), 25\% made a purchase (e.g., computer, library card, camera, e-bike, walking boots), $16 \%$ followed a social activity (e.g., bingo, dating, community center activities), and 16\% started with sports (e.g., 
gym membership, yoga, martial arts). The mean of the budget that was spent was $€ 369$.

Examples for the actions undertaken in the Customized Care group were more health care, e.g. support by a social psychiatric nurse, ambulant counseling, a social worker at the workplace, (more) domestic help, or extra hours physiotherapy. One participant wanted less domestic help, which was arranged. Others got more social support, e.g. becoming part of a senior club or going on bus trips with a group, and several participants joined a buddy project. Other forms of help were also organized, e.g. help for the son of a participant, or getting help for financial questions from someone from the participant's own social network.

The response rate was $100 \%$ at baseline, $73.15 \%$ at 3-month post-test ( 79 completers of 108 ), and $77.78 \%$ at 9-month follow-up (84 completers of 108). While at post-test, the difference in response rate between Customized Care and Happiness Route was non-significant ( $78 \%$ vs. $69 \% ; \chi_{1}^{2}=1.12, p=.29$ ), it was significant at follow-up ( $88 \%$ vs. $\left.69 \% ; \chi_{1}^{2}=5.63, p=.018\right)$. No significant differences at baseline emerged between participants who completed all three measurements $(n=76)$ and non-completers $(n=32)$, with the exception of income $\left(\chi_{1}^{2}=4.16, p=.04\right)$ and resilience $\left(t_{(106)}=-2.08\right.$; $p=.04)$. More completers (71\%) than non-completers (51\%) had a low income level. Completers were less resilient than non-completers (2.51 vs. 2.85). No harm was measured or reported in the two groups during the time period of the study. 


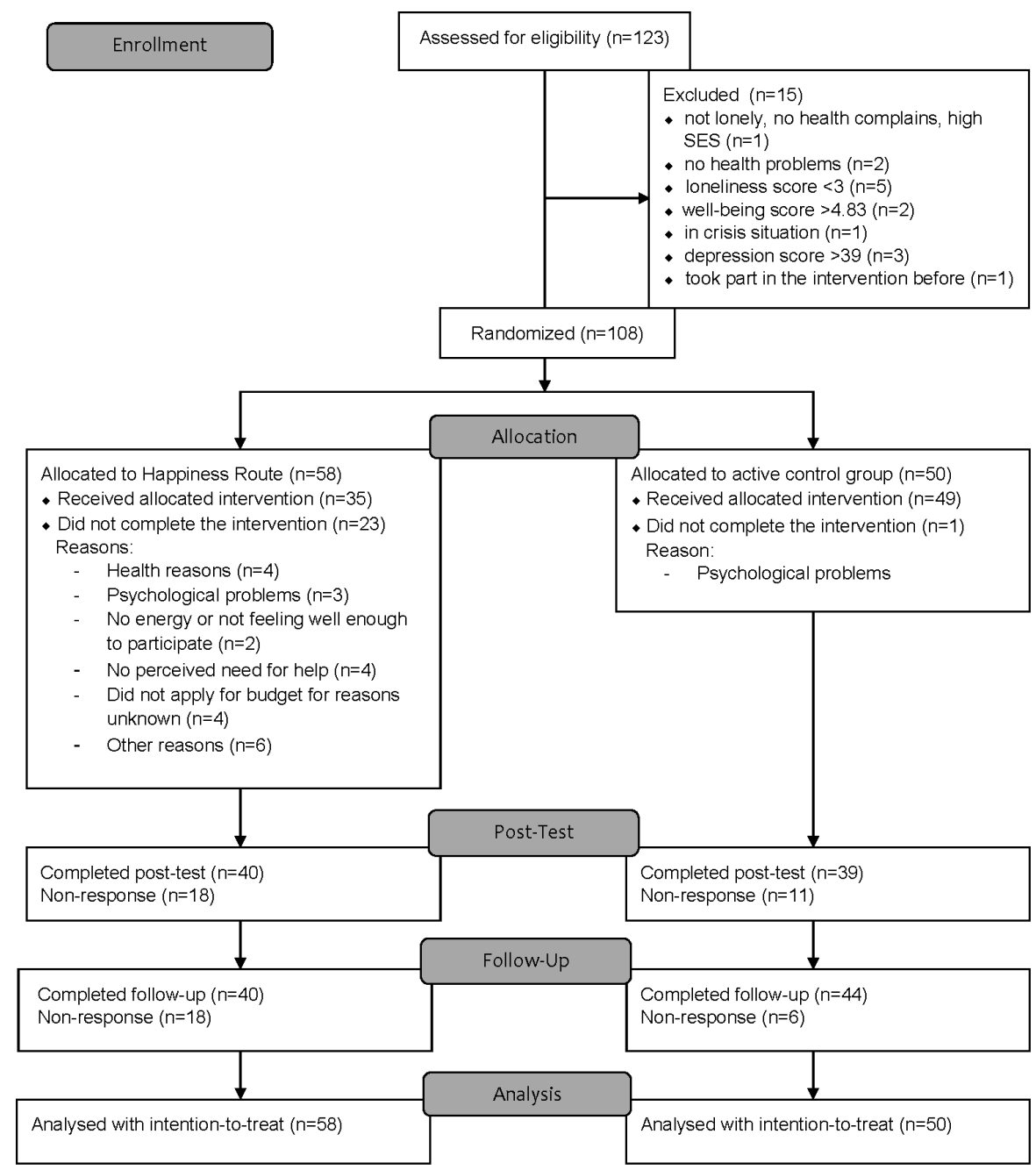

Figure 1. Participant flow

\section{Outcomes}

\section{Primary and secondary outcome measures}

Table 2 provides the means, standard errors (S.E.) at baseline, post-test and followup, a well as tests and effect sizes for the effectiveness on the primary outcome, wellbeing, and the secondary outcome measures, resilience, purpose in life, depression, health-related quality of life, loneliness and social participation. 


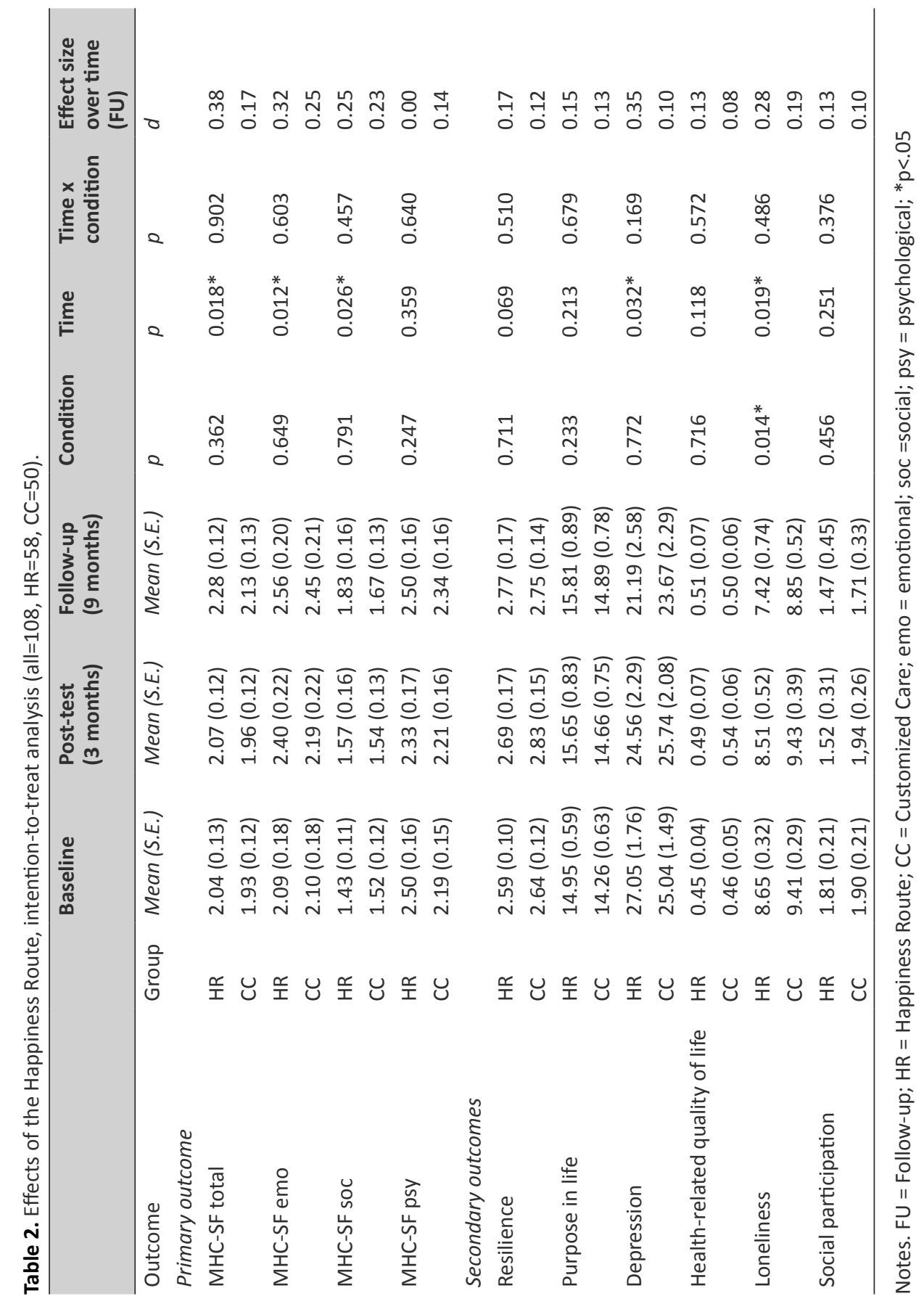


Primary outcome. The total score of the MHC-SF and the subscales of both emotional and social well-being improved significantly over the 9-month period in both groups $(p<0.05)$. No significant improvement was found in the subscale of psychological wellbeing. No significant interaction effect between time and condition was found for the total scale, nor the subscales of the MHC-SF. The effect size (Cohen's d) for the total score of well-being was somewhat higher for the Happiness Route (0.38), compared to Customized Care (0.17). The effect size for the Happiness Route can be considered moderate, whereas the effect size for the control group is considered small (Lipsey \& Wilson, 1993). Effect sizes for emotional (0.32 vs. 0.25 ) and social well-being $(0.25$ vs. 0.23$)$ were all small. There were no differences in results when adherers-only to the Happiness Route were compared to the control condition. The analyses for the completers-only also provided similar results as the intention-to-treat-analysis.

Table 3. Number of participants and percentages (\%) in the three mental health categories for completers only.

\begin{tabular}{|c|c|c|c|}
\hline & Mental health category & Happiness Route & Customized Care \\
\hline \multirow[t]{3}{*}{ Baseline } & Languishing & $19(32.8 \%)$ & $14(28.0 \%)$ \\
\hline & Moderately mentally healthy & 32 (55.2\%) & $34(68.0 \%)$ \\
\hline & Flourishing & 7 (12.1\%) & $2(4.0 \%)$ \\
\hline \multirow[t]{3}{*}{ Post-test } & Languishing & $14(36.8 \%)$ & $12(27.9 \%)$ \\
\hline & Moderately mentally healthy & $20(52.6 \%)$ & $39(69.8 \%)$ \\
\hline & Flourishing & $4(10.5 \%)$ & $1(2.3 \%)$ \\
\hline \multirow[t]{3}{*}{ Follow-up } & Languishing & $6(15.8 \%)$ & $10(23.3 \%)$ \\
\hline & Moderately mentally healthy & 27 (71.1\%) & $32(74.4 \%)$ \\
\hline & Flourishing & $5(13.2 \%)$ & $1(2.3 \%)$ \\
\hline
\end{tabular}

In Table 3, the three mental health categories were used to assess the development of well-being. Across the conditions and across time, there were no significant differences at baseline $\left(\chi_{2}^{2}=3.84, p=.147\right)$. Most participants had a moderate mental health, followed by those who were languishing. The percentage of languishers decreased significantly from $32.8 \%$ at baseline to $15.8 \%$ at follow-up in the Happiness Route (marginal homogeneity test with $p=.029$ ). The control group did not change significantly; it started with $28.0 \%$ languishers and ended with $23.3 \%$ (marginal homogeneity test with $p=0.593$ ). 
Secondary outcomes. Concerning the secondary outcome measures, no significant interaction effect between time and group was found. Significant improvement over time was found for both groups in depression and loneliness $(p<0.05)$, but not for resilience, purpose in life, health-related quality of life and social participation. The effects tend to be somewhat larger in the Happiness Route than in Customized Care (Cohen's $d$ for depression is .35 versus .10 and for loneliness .28 versus .19).

\section{Care consumption}

The mean health care costs participants made in the past four weeks prior to baseline measurement were $€ 686.10$ (SD 780.94) in the Happiness Route, which dropped to $€ 415.87$ (SD613.47) at follow up. In the control group, costs dropped from $€ 612.66$ (SD 700.59) at baseline to $€ 554.92$ (SD 613.47) nine months later. Drop in health care costs in the Happiness Route was $€ 270.23$ (SD 628.87; 95\% confidence interval, bias-corrected and accelerated bootstrap analysis ranged from €95.77 to $€ 457.82$ ), compared to $€ 57.74$ (SD 818.99) in the Customized Care condition (95\% bca-corrected bootstrap analysis from $€-151.63$ to $€ 295.05$. There was no difference in health care drop over time $\left(\mathrm{t}_{(80)}=0.186\right)$.

\section{Treatment satisfaction}

Participants from the Happiness Route evaluated the intervention more positively than participants from Customized Care.

Post-test. At post-test, the difference between the grade the participants gave to the relationship with their counselor was significant between conditions $\left(_{(69)}=3.12\right.$; $p=.003)$. The participants of the Happiness Route gave the relationship a mean grade of 8.49 (SD 1.37) on a scale from 1 to 10, whereas participants of Customized Care gave a mean grade of 7.25 (SD 1.95).

The open question how participants experienced the home visits of the counselor during the post-test was answered by 78 participants, 39 in both groups. Happiness Route participants were significantly more likely to be positive about the visits $\left(\chi_{3}^{2}=14.18, p<.01\right)$. None of the participants of the Happiness Route evaluated the 
visits of the counselor negatively, $2.6 \%$ gave a neutral or ambivalent judgement (e.g. 'Okay') and 92.3\% were positive (e.g. 'Very nice, it helped me a great deal to help me get back on track. It taught me to look after myself, as well. And also to stand up for myself and now decide about a lot of things on my own.'). 5.1\% of the answers were missing. In the Customized Care group, $15.4 \%$ of the participant evaluated the home visits negatively (e.g. 'I have not experienced that home visit as pleasant. Too much about the past. [...]'). 20.5\% gave a neutral or mixed evaluation (e.g. 'She couldn't do a lot for me, but she listened well and gave tips.') and $61.5 \%$ were positive (e.g. 'Good. I am very satisfied with it. It was a nice and sweet woman. A listening ear.'), $2.6 \%$ of the answers were missing.

During post-test, 77 participants gave a judgment on the effects of the intervention, 38 from the Happiness Route and 39 from Customized Care. Participants of the experimental group were significantly more likely to experience positive effects than the participants of the control group $\left(\chi_{3}^{2}=11,88, p=.008\right) .18 .4 \%$ of the participants of the Happiness Route have not experienced any (positive) effects, $15.8 \%$ gave a neutral or mixed judgement on effects, $50.0 \%$ have experienced positive effects, and $15.8 \%$ of the answers were missing. In the Customized Care group, $56.4 \%$ of the participant have not experienced effects, $7.7 \%$ were neutral or mixed about effects, $28.2 \%$ experienced positive effects, and $7.7 \%$ did not gave an answer.

Follow-up. In the follow-up measurement, 79 participants evaluated the intervention, of whom 39 from the Happiness Route and 41 from Customized Care. Participants of the experimental group were significantly less likely to be negative and more likely to be satisfied with the intervention than the participants of the control group $\left(\chi_{3}^{2}=10.30\right.$, $p=.016) .10 .5 \%$ of the participants of the Happiness Route evaluated the intervention negatively (e.g. 'Disappointing.'), 15.8\% gave a neutral or mixed judgement (e.g. 'It has not realized its full potential yet.'). $71.1 \%$ of the participants were positive (e.g. 'Yes, it certainly has given me the opportunity to go out of the house more, and to come in contact with people more. I am more active, also by going to a gym. Thank you!'), and $2.6 \%$ of the answers were missing. In the Customized Care group, $22.0 \%$ of the participant evaluated the intervention negatively (e.g. 'Not interesting. I do 
not see any progress and I find it tiring.'). 26.8\% gave a neutral or mixed judgment (e.g. 'A good project with the right intentions. It's too bad that it's unclear to me what the project is all about.') and $36.6 \%$ were positive (e.g. 'Was very pleased with the help. I really had the impression that society was done with me. I felt no low-life criminal now in contact with the organization or instance.'), and $14.6 \%$ did not gave an answer.

The effects of the intervention were evaluated by 72 participants during followup (34 Happiness Route, 38 Customized Care). Happiness Route participants were significantly more likely to describe positive effects than the Customized Care participants $\left(\chi_{3}^{2}=9.35, p=.025\right) .26 .5 \%$ of the participants of the Happiness Route have not experienced any (positive) effects (e.g. 'No effect, it did not bring any changes. The activity of hiking was something that I already did before.) $14.7 \%$ gave a neutral or mixed judgement on effects (e.g. 'It was not the right timing yet. But it has given me ideas.'). 55.9\% have experienced positive effects (e.g. 'Enthusiastic, discovered that there are things that I can enjoy again. Being proud of what I do on at the course and getting compliments for it.'), and 2.9\% were missing answers. In the Customized Care group, $52.6 \%$ of the participant have not experienced any effects (e.g. 'No effect due to minimal guidance.'), and $13.2 \%$ were neutral or had mixed feelings about effects (e.g. 'I have a buddy from Humanitas [social service], that is nice. Personally, no effect.'). $23.7 \%$ experienced positive effects (e.g. 'Moved to a very nice house. Even got help from social services. Due to mentioned emotional stimuli, I really started thinking about how I ended up in this bad situation.'), and $10.5 \%$ of the answers were missing.

\section{Discussion and conclusion}

This was the first study that evaluated a PPI for people with an accumulation of risk factors for a low well-being in a practice-based multi-site trial. Our aim was to examine the reach, effectiveness and satisfaction of the Happiness Route intervention in comparison to optimized care in a randomized controlled study. 
We reached an extremely vulnerable group. No differences were found between the Happiness Route and Customized Care on primary and secondary outcomes. Both groups improved significantly in well-being, depression, and loneliness. The standardized effect sizes were somewhat higher for the Happiness than for Customized Care and the percentage of languishers decreased significantly from $32.8 \%$ at baseline to $15.8 \%$ at follow-up in the Happiness Route, but not in the control group. No effects were found for the other secondary outcomes; resilience, purpose in life, health-related quality in life and drop in health care costs. Participants adhered less often in the experimental than in control group, but they were more satisfied with the Happiness Route than with the control group.

Our first research interest concerned reaching out to a vulnerable group. Recruitment turned out to be very difficult. First, the 'invisibility' of the target group of lonely people could have hindered finding candidates in the first place. Being socially isolated and thus having no contact to the outside world makes it very hard to detect these people. As Machielse stated, structurally socially isolated people are 'invisible' to society (Machielse, 2011). Second, the vulnerability of the group could have been a restricting factor for application. Intermediaries who could apply for them often wanted to protect these people from any extra stress any project could expose them to, as they already were extremely vulnerable. Last, the fact that the intervention was part of a study with a control group could have played a role in the limited amount of applications. People had to fill out questionnaires and the chance that they could be randomized to the control group was a reason for intermediaries to decide to not apply for otherwise suitable candidates.

Although recruitment proved to be hard, a very vulnerable group was reached, which makes our target group especially interesting. The group we included was even more vulnerable than expected, based on the inclusion criteria. They were severely lonely, with a high comorbidity of diseases and serious depressive symptoms, low levels of well-being and health-related quality of life, scoring far under the mean Dutch population. The yearly mean health costs they produced at baseline were around $€ 8000$. Their high level of suffering and the high level of care consumption show that it is indeed an important group to pay attention to and to study. 
Only $12 \%$ of the participants that have been applied for had to be excluded, indicating that the intermediaries knew quite well who to apply. However, the extreme scores of the participants could be a sign that intermediaries had a picture of the target group that was too extreme. For example, candidates were allowed to take part with a loneliness score of 3, while the mean score at baseline was around 9. Probably the intermediaries mostly only applied for people who were extremely lonely, thus having a wrong picture of how vulnerable the target group had to be. This could have impeded recruitment, as $28 \%$ of the Dutch population is moderately lonely and only $4 \%$ is severely or extremely lonely (De Jong Gierveld \& Van Tilburg, 1999). For the future, we recommend to carefully inform the intermediaries about the characteristics and emphasize that moderate levels of for example loneliness are also an indication to apply for someone.

Although the real life setting held limitations for the recruitment, it also means that the external validity of this study is good, as it took place in the field and the recruitment and intervention was conducted as it was usual in practice. Our second question concerned the effects of the Happiness Route intervention. We did not find significant differences between groups. There are at least three possible reasons why an interaction effect was not found. First, power was too low. The power size calculated beforehand was not reached. Second, differences in the approach might have been smaller than expected. For example, some counselors registered participants in the control group for a social activity, such a activities in a senior club, or social support, such as a buddy project. Furthermore, counselors looked at the whole picture of care in the Customized Care condition, whereas in everyday practice, different care professionals often approach specific problems from more isolated areas of expertise. This could mean that Customized Care was somewhat different from care-as-usual.

Third, the adherence-rate was much smaller in the Happiness Route compared to the control group. This could be explained by the fact that the Happiness Route was more intensive and asked more of the participants than the more passive control condition. It required an active participation in an activity, often after years of isolation and 
inactivity. We have to realize that this could be a big, perhaps frightening step for many people of this group. When they did persevere, they were very satisfied with the Happiness Route and the effect it had on them.

Although there were no differences between the conditions, we found effects in emotional and social well-being, depression, and loneliness over time. That could have been due to regression toward the mean (Barnett, van der Pols, \& Dobson, 2005), as baseline scores were extremely low. On the other hand, scores for the MHCSF have proven to be remarkable stable over a period of nine months in a large panel, representative for the Dutch population (Lamers, Glas, et al., 2012). Also, it seems very difficult to improve loneliness with interventions (Findlay, 2003; Fokkema \& van Tilburg, 2006). Furthermore, only three measures improved over time, whereas resilience, purpose in life and health-related quality also have started extremely low, but did not improve significantly over time. These are all strong arguments against the regression to the mean explanation.

Meta-analyses on PPIs have shown that - even under more controlled conditions and often with non-active control groups - effect sizes were small, with standardized mean difference of .34 for subjective well-being, .20 for psychological well-being and .23 for depression (Bolier et al., 2013). This is in line with the effect sizes we found, except for psychological well-being.

The third aim was to evaluate the level of satisfaction of participants. It is a relevant finding that participants have been very satisfied with the Happiness Route. They rated the relationship with their counselor highly with a grade of 8.5 . It is notable that none of the participants was negative about the intervention at post-test and more than $90 \%$ were positive. More than half of them said to have experienced positive effects at both post-test and follow-up.

It is interesting that, while there were no significant differences in effect between groups when measured quantitatively, participants from the Happiness Route were significantly more likely to experience positive effects than participants of 
Customized Care, both directly after the intervention and six months after the home visits stopped. Many participants in the Happiness Route mentioned positive effects in the open evaluation. This could mean that the questionnaire was less sensitive to change than participants' own perceptions.

Concerning future research, it would be interesting to also compare the Happiness Route to a waiting-list condition. The intervention could also be studied with other target groups at risk for a languishing condition, for example refugees. Due to the small sample size, we could not conduct any moderator or mediator analysis. This would be relevant to differentiate for whom the intervention works best.

The findings suggest that the Happiness Route is as effective as the current, problembased care in the Netherlands for a very vulnerable part of the population. It might be even better to help languishing people to become moderately mentally healthy, which can lead to great individual and social benefits (Keyes, 2010). Participants who completed the intervention evaluated it more positively than problem-based care. As participants benefitted from the Happiness Route, it seems to be an adequate alternative intervention for vulnerable people that fits current developments in health and social care.

\section{Competing interests}

The authors declare that they have no competing interests.

\section{Acknowledgement}

We are grateful that this study is subsidized by the Netherlands Organization for Health Research and Development (ZonMw), the Hague, grant 200210013 (awarded to Eddy Wezenberg, Arcon). We want to thank our team from Arcon, project leader Aad Francissen and administrative head Eddy Wezenberg, who initiated the research project and made substantial contributions to the conception, design and Aad especially during the implementation. We are deeply thankful for the hard work and enthusiasm of the dedicated project leaders Marja Scheper, Chantal Bloemen (and former project leader Lizzy Meijerink), Adri de Raaf, Johan Strik, Anoeska van 
Gorkum, Janet Dekker, Jan Bouwman, Carla Eefting and the founder of the Happiness Route, Gerard Noordkamp. We also want to thank all counselors of 'Zorg op Maat' in both the Happiness Route and the control group. We are thankful for the medical expertise Irina Pologos provided us so kindly with and her help with categorizing the diseases. We are most grateful to our participants, without whom this study would not have been possible. 


\section{References}

Barnett, A. G., van der Pols, J. C., \& Dobson, A. J. (2005). Regression to the mean: what it is and how to deal with it. International journal of Epidemiology, 34(1), 215-220.

Barry, M. M., \& Jenkins, R. (2007). Implementing mental health promotion: Elsevier Health Sciences.

Bohlmeijer, E., \& Westerhof, G. J. (2010). Op verhaal komen: je autobiografie als bron van wijsheid: Boom.

Bolier, J., Haverman, M., Westerhof, G. J., Riper, H., Smit, F., \& Bohlmeijer, E. (2013). Positive psychology interventions: a meta-analysis of randomized controlled studies. $B M C$ Public Health, 13(1), 1.

Bolier, L., Haverman, M., Westerhof, G. J., Riper, H., Smit, F., \& Bohlmeijer, E. (2013). Positive psychology interventions: a meta-analysis of randomized controlled studies. $B M C$ Public Health, 13(1), 119.

Bouma, J., Ranchor, A., Sanderman, R., \& Van Sonderen, E. (1995). Het meten van symptomen van depressie met de CES-D. Een handleiding. Groningen, Noordelijk Centrum voor Gezondheidsvraagstukken, Rijksuniversiteit Groningen, 2-24.

Brooks, R., \& Group, E. (1996). EuroQol: the current state of play. Health policy, 37(1), 53-72.

Centraal Bureau voor de Statistiek, C. B. S. (2013). Armoedesignalement 2013: Sociaal En Cultureel Planbureau.

Cole, K. (2006). Wellbeing, psychological capital, and unemployment: An integrated theory. Paper presented at the Annual Conference of the International Association for Research in Economic Psychology and SABE.

De Jong Gierveld, J., \& Van Tilburg, T. (1999). Manual of the Loneliness Scale 1999. Department of Social Research Methodology, Vrije Universiteit Amsterdam, Amsterdam.

Diener, E., Suh, E., Lucas, R., \& Smith, H. (1999). Subjective Well-Being: Three Decades of Progress. Psychological Bulletin, 125, 276-302.

Doll, H. A., Petersen, S. E., \& Stewart-Brown, S. L. (2000). Obesity and physical and emotional well-being: associations between body mass index, chronic illness, and the physical and mental components of the SF-36 questionnaire. Obesity Research, 8(2), 160-170.

Findlay, R. A. (2003). Interventions to reduce social isolation amongst older people: where is the evidence? Ageing and Society, 23(05), 647-658.

Fokkema, T., \& van Tilburg, T. (2006). Aanpak van eenzaamheid: helpt het. Een vergelijkend effect-en procesevaluatie onderzoek naar interventies ter voorkoming en vermindering van eenzaamheid onder ouderen. Den Haag: NIDI.

Francissen, A., Wezenberg, E., \& Westerhof, G. (2010). De gevolgen van geluk. Achtergronden en toekomst van het geluksbudget. Borne: Arcon.

Gijsen, R., Van Oostrom, S., \& Schellevis, F. (2014). Hoeveel mensen hebben één of meer chronische ziekten? Volksgezondheid Toekomst Verkenning, Nationaal Kompas Volksgezondheid. RIVM Bilthoven.

Golden, J., Conroy, R. M., Bruce, I., Denihan, A., Greene, E., Kirby, M., \& Lawlor, B. A. (2009). Loneliness, social support networks, mood and wellbeing in community-dwelling elderly. International Journal of Geriatric Psychiatry, 24(7), 694-700.

Hakkaart-van Roijen, L. (2002). Handleiding TiC-P (vragenlijst voor zorggebruik en productieverliezen bij psychische aandoeningen). iMTA. Erasmus Universiteit Rotterdam: Rotterdam.

Hakkaart-van Roijen, L., Van Straten, A., Donker, M., \& Tiemens, B. (2002). Trimbos/iMTA questionnaire for costs associated with psychiatric illness (TIC-P). Rotterdam: Institute for Medical Technology Assessment. 
Hakkaart-van Roijen, L., Hoeijenbos, M., Regeer, E., Ten Have, M., Nolen, W., Veraart, C., \& Rutten, F. (2004). The societal costs and quality of life of patients suffering from bipolar disorder in the Netherlands. Acta Psychiatrica Scandinavica, 110(5), 383-392.

Hermans, D., \& Van de Putte, J. (2004). Cognitieve gedragstherapie bij depressie: Bohn Stafleu Van Loghum.

Herrman, H., Saxena, S., \& Moodie, R. (2005). Promoting mental health: concepts, emerging evidence, practice: a report of the World Health Organization, Department of Mental Health and Substance Abuse in collaboration with the Victorian Health Promotion Foundation and the University of Melbourne: World Health Organization.

Hoefman, R., Van Exel, N., \& Brouwer, W. (2011). iVICQ. iMTA valuation of informal care questionnaire. Retrieved, 2, 12.

Hone, L., Jarden, A., \& Schofield, G. (2015). An evaluation of positive psychology intervention effectiveness trials using the re-aim framework: A practice-friendly review. The Journal of Positive Psychology, 10(4), 303-322.

Jong-Gierveld, J. d. (1999). Cesuurbepaling van de eenzaamheidsschaal. Tijdschrift voor Gerontologie en Geriatrie, 30, 158-163.

Keyes, C. L. (2007). Promoting and protecting mental health as flourishing: a complementary strategy for improving national mental health. American Psychologist, 62(2), 95.

Keyes, C. L. (2009). Brief description of the mental health continuum short form (MHC-SF). Atlanta, GA: Emory University.

Keyes, C. L. (2010). The next steps in the promotion and protection of positive mental health. Canadian Journal of Nursing Research, 42(3), 17-28.

Keyes, C. L., \& Shapiro, A. D. (2004). Social well-being in the United States: A descriptive epidemiology. How healthy are we, 350-372.

Lamers, S., Westerhof, G. J., Bohlmeijer, E. T., ten Klooster, P. M., \& Keyes, C. L. (2011). Evaluating the psychometric properties of the mental health continuum-short form (MHC-SF). Journal of Clinical Psychology, 67(1), 99-110.

Lamers, S. M., Bolier, J., Westerhof, G. J., Smit, F., \& Bohlmeijer, E. T. (2012). The impact of emotional well-being on long-term recovery and survival in physical illness: a metaanalysis. Journal of Behavioral Medicine, 35(5), 538-547.

Lamers, S. M., Glas, C. A., Westerhof, G. J., \& Bohlmeijer, E. T. (2012). Longitudinal evaluation of the mental health continuum-short form (MHC-SF). European Journal of Psychological Assessment.

Lewinsohn, P. M., Seeley, J. R., Roberts, R. E., \& Allen, N. B. (1997). Center for Epidemiologic Studies Depression Scale (CES-D) as a screening instrument for depression among community-residing older adults. Psychology and Aging, 12(2), 277.

Licht, C. (2010). New methods for generating significance levels from multiply-imputed data. (Doctoral thesis) Otto-Friedrich-University Bamberg, Bamber, Germany.

Lipsey, M. W., \& Wilson, D. B. (1993). The efficacy of psychological, educational, and behavioral treatment: confirmation from meta-analysis. American Psychologist, 48(12), 1181.

Lyubomirsky, S., King, L., \& Diener, E. (2005). The benefits of frequent positive affect: does happiness lead to success? Psychological Bulletin, 131(6), 803.

Machielse, A. (2011). Sociaal isolement bij ouderen: een typologie als richtlijn voor effectieve interventies. Journal of Social Intervention: Theory and Practice, 20(4), 40-61.

Mangelli, L., Gribbin, N., Büchi, S., Allard, S., \& Sensky, T. (2002). Psychological well-being in rheumatoid arthritis: Relationship to 'disease'variables and affective disturbance. Psychotherapy and Psychosomatics, 71(2), 112-116.

Pinquart, M., \& Sörensen, S. (2000). Influences of socioeconomic status, social network, and competence on subjective well-being in later life: a meta-analysis. Psychology and Aging, 15(2), 187. 
Radloff, L. S. (1977). The CES-D scale a self-report depression scale for research in the general population. Applied Psychological Measurement, 1(3), 385-401.

Rubin, R. R., \& Peyrot, M. (1999). Quality of life and diabetes. Diabetes/Metabolism Research and Reviews, 15(3), 205-218.

Ryan, R. M., \& Deci, E. L. (2000). Self-determination theory and the facilitation of intrinsic motivation, social development, and well-being. American Psychologist, 55(1), 68.

Ryff, C. D. (1989). Happiness is everything, or is it? Explorations on the meaning of psychological well-being. Journal of Personality and Social Psychology, 57(6), 1069.

Ryff, C. D., \& Keyes, C. L. (1995). The structure of psychological well-being revisited. Journal of Personality and Social Psychology, 69(4), 719.

Ryff, C. D., \& Singer, B. H. (2008). Know thyself and become what you are: A eudaimonic approach to psychological well-being. Journal of Happiness Studies, 9(1), 13-39.

Scherpenzeel, A. (2009). Start of the LISS panel. Sample and Recruitment of a Probabilitybased Internet Panel. Tilburg: CentERdata.

Seligman, M. E., \& Csikszentmihalyi, M. (2000). Positive psychology: An introduction (Vol. 55): American Psychological Association.

Sin, N. L., \& Lyubomirsky, S. (2009). Enhancing well-being and alleviating depressive symptoms with positive psychology interventions: A practice-friendly meta-analysis. Journal of Clinical Psychology, 65(5), 467-487.

Singer, J. A. (2005). Memories that matter: How to use self-defining memories to understand \& change your life: New Harbinger Publications.

Smith, B. W., Dalen, J., Wiggins, K., Tooley, E., Christopher, P., \& Bernard, J. (2008). The brief resilience scale: assessing the ability to bounce back. International Journal of Behavioral Medicine, 15(3), 194-200.

Sobocki, P., Ekman, M., Ågren, H., Krakau, I., Runeson, B., Mårtensson, B., \& Jönsson, B. (2007). Health-related quality of life measured with EQ-5D in patients treated for depression in primary care. Value in Health, 10(2), 153-160.

Steverink, N., Westerhof, G. J., Bode, C., \& Dittmann-Kohli, F. (2001). Dutch Aging Survey: Onderzoekdesign en instrumenten. Een onderzoek naar de leefsituatie en het welbevinden van mensen vanaf 40 jaar. University of Nijmegen, Sectie Psychogerontologie.

Stewart, A. L., Greenfield, S., Hays, R. D., Wells, K., Rogers, W. H., Berry, S. D., . . Ware, J. E., Jr. (1989). Functional status and well-being of patients with chronic conditions. Results from the Medical Outcomes Study. Jama, 262(7), 907-913.

Stolk, E., Krabbe, P., Busschbach, J., Stolk, E., Krabbe, P., \& Busschbach, J. (2007). Using the Internet to collect EQ-5D norm scores: a valid alternative. Paper presented at the Proceedings of the Plenary Meeting of the EuroQoL Group, The Hague.

Valtorta, N. K., \& Hanratty, B. (2013). Socioeconomic variation in the financial consequences of ill health for older people with chronic diseases: a systematic review. Maturitas, 74(4), 313-333.

Van den Berg, M., de Boer, D., Gijsen, R., Heijink, R., Limburg, L., \& Zwakhals, S. (2014). Zorgbalans 2014: De prestaties van de Nederlandse gezondheidszorg. RIVM rapport 2014-0038.

Van der Plaats, J. (2002). Eindrapportage Zorg in Beeld Verlicht. Almelo: Gemeente Almelo. voor de Statistiek, C. B. (2005). Permanent onderzoek leefsituatie.

Wagner, E. H., Austin, B. T., Davis, C., Hindmarsh, M., Schaefer, J., \& Bonomi, A. (2001). Improving chronic illness care: translating evidence into action. Health Affairs, 20(6), 64-78.

Weiss, L. A., Kedzia, S., Francissen, A., \& Westerhof, G. J. (Eds.). (2015). Improving the Health Care Sector with a Happiness-Based Approach: Springer. 
Weiss, L. A., Westerhof, G. J., \& Bohlmeijer, E. T. (2013). Nudging socially isolated people towards well-being with the 'Happiness Route': design of a randomized controlled trial for the evaluation of a happiness-based intervention. Health and Quality of Life Outcomes, 11(1), 1-11.

Weiss, L. A., Westerhof, G. J., \& Bohlmeijer, E. T. (2016). Can We Increase Psychological WellBeing? The Effects of Interventions on Psychological Well-Being: A Meta-Analysis of Randomized Controlled Trials. PLOS ONE, 11(6), doi:10.1371/journal.pone.0158092

Westerhof, G. J., \& Keyes, C. L. (2008). Geestelijke gezondheid is meer dan de afwezigheid van geestelijke ziekte. MGV-Maandblad geestelijke volksgezondheid, 63(10), 808-820.

Wikman, A., Wardle, J., \& Steptoe, A. (2011). Quality of life and affective well-being in middleaged and older people with chronic medical illnesses: a cross-sectional population based study. PLOS ONE, 6(4), e18952.

Wolman, C., Resnick, M. D., Harris, L. J., \& Blum, R. W. (1994). Emotional well-being among adolescents with and without chronic conditions. Journal of Adolescent Health, 15(3), 199-204. doi:10.1016/1054-139X(94)90504-5 


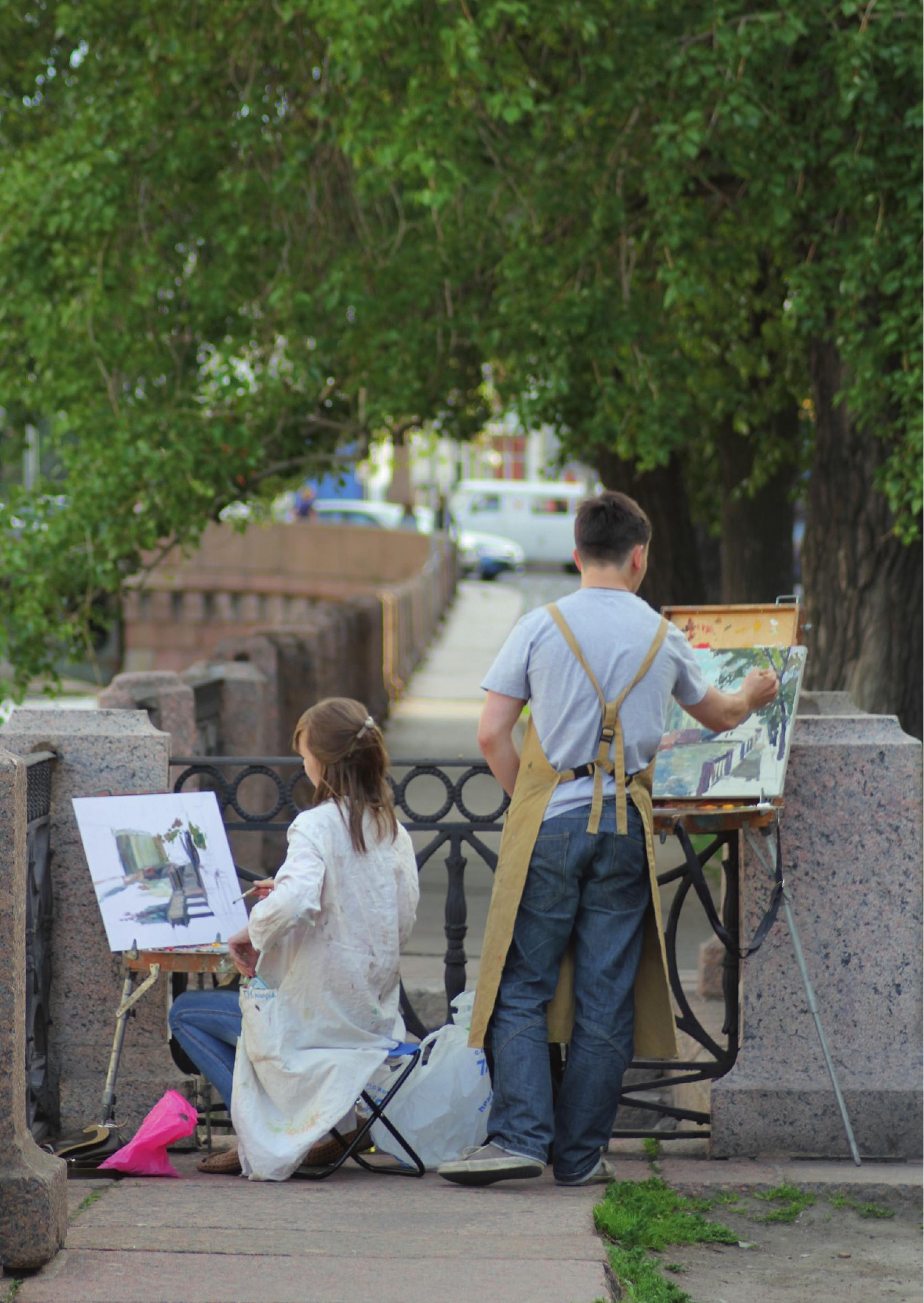




\section{6}

\section{Exploring the Blackbox of Positive Psychology: Participants' Perceptions on Basic Psychological Need Changes during the Happiness Route Intervention}

"I

Life is not just crap. It is an apple pie that consists of a number of slices.

And you take just one piece, and that is only happiness, only the good stuff.

I don't care what happens on the outside. It's just that, only that small slice. [...]

It's not only worries and problems.

II

Participant Happiness Route

Weiss, L. A., Janssen, S., Bohlmeijer, E. T. \& Westerhof, G. J. (submitted). Exploring the Blackbox of Positive Psychology: Participants' Perceptions on Basic Psychological Need Changes during the Happiness Route Intervention. The Journal of Positive 


\begin{abstract}
Background: Studies on the perspective of participants in positive psychology interventions (PPIs) are rare but important to understand how PPIs work and how they can accommodate individual experiences. We examined how participants in the PPI 'Happiness Route' experienced change in their satisfaction of autonomy, relatedness and competence - the three basic psychological needs of self-determination theory. The Happiness Route is an intervention in which a counselor supports vulnerable people to choose and act on an internally motivated activity.
\end{abstract}

Methods: Semi-structured interviews with twenty former participants of the Happiness Route were conducted. Interviews were conducted by one of four interviewers. Analyses were conducted by two of the authors for the basic needs, and bottom-up for other factors of change. Change or continuity in the fulfillment of autonomy, competence and relatedness was rated for every participant individually. Interrater reliability was good.

Results: We clearly found the three needs described in the narratives, as well as instrinsic and extrinsic motivation, activation, positive emotions and selfdevelopment. Analyses yielded four main findings. First, in many cases, need fulfillment was low at the start of the intervention. Second, the counselor played an important role for need fulfillment. Third, the activity participants chose seemed to be crucial for change to occur. Fourth, people benefitted most when all three needs were fulfilled in the end. In addition, four types of change and continuity were distinguished: all-over improved $(n=8)$, partly improved $(n=6)$, specific-need improved $(n=3)$ and non-changer $(n=3)$.

Conclusions: In conclusion, a PPI can contribute to well-being of vulnerable people across the adult lifespan by fulfilling basic psychological needs and that the Happiness Route is best offered to people who start low on psychological needs. 


\section{Introduction}

Since the introduction of positive psychology at the beginning of the 21st century (Seligman \& Csikszentmihalyi, 2000), we have come to know a great deal about the effectiveness of positive psychology interventions (PPIs) in enhancing well-being (Bolier et al., 2013a; Sin \& Lyubomirsky, 2009a; Weiss et al., 2016). Nevertheless, there is a lack of knowledge concerning how participants experience PPIs, especially for vulnerable groups with psycho-social problems (Bolier et al., 2013a). In this study, we examined how participants experienced change in a particular PPI called the Happiness Route, in which a counselor supports vulnerable people to choose an internally motivated activity. Lonely people with health problems and a low socioeconomic status (SES) discover their passion with the help of a counselor. To carry out an intrinsically motivated activity, participants are allowed to spend a budget of $€ 500$. Since the intervention is based on the self-determination theory (SDT), its main focus is on improving three basic psychological needs which are considered vital for well-being: autonomy, relatedness and competence (Ryan \& Deci, 2000b).

To gain a better understanding of processes of change during PPIs, quantitative research designs need to be complemented with qualitative research that investigates the perspective of participants (Elliott, 2010). A number of qualitative studies have addressed the experiences of (vulnerable) participants of PPIs (Brownell, Schrank, Jakaite, Larkin, \& Slade, 2015; Lloyd \& Little, 2010; Swindells et al., 2013).

Swindells and colleagues (2013) studied engagement in an art activity amongst elderly people and those with mental health problems. Self-expression, autonomy, and challenges were considered most important by the participants. In addition, some participants also advanced their competences. Participants were positive about the role of project leaders and facilitators who gave them the space to develop their own direction in a non-intrusive way, without judgment.

A second study focused on participants with psychosis who were part of group positive psychotherapy (Brownell et al., 2015). Participants reported that they learned to savor experiences, which encouraged them to spend more time doing the activities 
they enjoyed. Therapist supportiveness was important from the participants' point of view, and they noted that their ability to identify and develop strengths was useful in their daily lives, helping them to deal autonomously with obstacles, which, in turn, strengthened their feelings of competence to cope with the symptoms of the psychosis.

Lastly, Lloyd and Little (2010) examined women's participation during a sports festival and how it affected their psychological well-being within the framework of SDT (Ryan \& Deci, 2000b). They found that the key themes in the women's narratives broadly reflected the key elements of SDT. Participants said they experienced selfdetermination through activities that they freely chose, within an environment that supported autonomy, interested them and helped them pursue goals that were important to them. Learning new skills and stepping out of their comfort zone by trying new activities gave the women the feeling of being competent. Relatedness was reflected by sharing their experiences with existing contacts, creating new connections and learning with and from other women during and after the activities. Social support enhanced enjoyment and participation in the activities.

These studies revealed elements that were important for changes in well-being from the perspective of participants. Although only one study used SDT as a framework (Lloyd \& Little, 2010), all three studies found that taking part in activities helped participants to gain autonomy, advance their competences and relate to others. Counselors also played an important role in their fulfillment of needs.

While these aspects clearly reflect the three basic needs of SDT, the studies did not examine how the participants understood the change in their fulfillment of these basic needs. This knowledge is vital, as it can facilitate counselors' ability to better accommodate their clients' needs during an intervention, which ultimately contributes to optimizing their well-being. Therefore, this study explored clients' perceptions of change in the fulfillment of their basic needs. We conducted semistructured interviews with a vulnerable group of participants who participated in the Happiness Route. 
As the Happiness Route is explicitly based on the framework of SDT (Weiss et al., 2015b) it is especially interesting to compare participants' experiences with the theory. The Happiness Route has been implemented and studied in multiple locations in the social work domain throughout the Netherlands, as provided by several trained counselors (Weiss et al., 2015b). Hence, the Happiness Route intervention in the Netherlands provided us with the opportunity to gain insight into the diversity of experiences in a real life setting, with its advantages and pitfalls for change in needfulfillment.

In this study, we first explored how the three basic psychological needs were described in the narratives of the participants of the Happiness Route. Secondly, we examined other possible factors of change that could emerge from the interviews, other than autonomy, competence and relatedness. Last of all, we examined the participants' perspectives on change (or continuity) with regard to their basic need fulfillment. To do so, we assessed the patterns of change and continuity within each participant, from which we ultimately developed a typology of four types.

\section{Methods}

\section{Design and Intervention}

The experiences of participants of the Happiness Route were explored using qualitative semi-structured interviews. This study was done in the context of a larger randomized controlled trial (RCT) that investigated the effects of the Happiness Route (Weiss et al., 2013). Participants had to meet six inclusion criteria to be able to take part in the RCT, measured with a questionnaire: a minimum age of 18 years; a low socio-economic status based on education, financial status and employment status; health limitations; low to average well-being; no serious untreated depression; and a feeling of loneliness (Weiss et al., 2013).

The aim of the Happiness Route intervention is to increase the fulfillment of basic needs by helping participants to find and conduct an intrinsically motivated activity with the support of trained counselors, thereby increasing their well-being (Weiss et al., 2015b). Counselors visit a participant at home between two and six times for a 
maximum of $1 \frac{1}{2}$ hours per session. To realize their activity, participants are provided a budget of $€ 500$. Ideally, the activity is autonomously chosen and will stimulate the participant's competence and relatedness to others.

\section{Participants}

The interviews were conducted with 20 former participants of the Happiness Route. These participants were part of the 108 who had taken part in the previous RCT (Weiss et al., 2013). The first 25 participants who finished the RCT were asked by their counselor to take part in the interview study. Three persons did not want to participate and two were not able to be interviewed due to severe illness. The remaining 20 participants were called by the four interviewers, who explained the interview study in more detail, answered questions, verified the participant's willingness to take part, and set a date. All twenty participants agreed to take part in the interview study and signed informed consent.

The 20 participants (18 female; 2 male) had a mean age of 57.7 years (SD 16.1), ranging from 30 to 87 years. They came from six different cities where the Happiness Route was implemented. The educational level was low for 10 participants, medium for 7 and high for 2. All participants had limited financial means (below $€ 1500$ a month), 9 had debts. None of the participants were employed: 6 participants were retired and 14 were either unemployed or unable to work. Health problems varied: 13 participants suffered from severe and chronic physical diseases and complaints (e.g. rheumatism, diabetes); 2 had mental disorders (e.g. depressive symptoms, anxiety); and 5 participants had both physical and psychological disorders. Four participants were married, 10 divorced, 3 widowed and 3 never married. Fifteen participants had between one and five children, whereas 5 participants were childless. Fifteen participants were Dutch, and 5 participants were from Romania, Belgium, Spain, Afghanistan and Namibia.

\section{Interviews}

Interviews were conducted in Dutch at the clients' homes by one of four trained interviewers. A semi-structured interview scheme consisting of two parts was used, 
based on a narrative approach. The interview started with open-ended questions about the participant's experiences with the Happiness Route, loosely based on the Adler and McAdams (2007) method. Participants were asked to tell about their situation before the intervention and afterwards, the specific activity they chose, important moments during the intervention, and their evaluation of the intervention.

The second part of the interview consisted of specific questions to obtain a detailed understanding of changes in the fulfillment of the three basic psychological needs. Participants were asked whether they felt they could direct their lives before and after the Happiness Route (autonomy), to name things they are good at and how they could show and use these skills before and after the intervention (competence), and to describe their contacts with others before and after the Happiness Route (relatedness).

Questions were tailored to the target group and phrased in an easy and descriptive way. Rephrasing and probing were used when an answer needed further explanation. All participants gave permission to record the interview with a voice recorder. The interviews took 32 minutes on average, varying between 11 and 67 minutes.

\section{Data Analysis}

The interviews were transcribed verbatim, except for names, cities and other personal information, which were substituted with functional descriptors to ensure confidentiality. Selected quotes for this article have been translated into English by a professional translator.

Coding consisted of four phases. In the first phase, four interviews were selected by randomly choosing one interview from each interviewer. The transcriptions were read by two researchers (LAW and SJ), who then independently assigned codes. The researchers coded meaningful fragments for the three basic needs (autonomy, competence and relatedness). They also found factors that could not be coded as need, but were meaningful and relevant for change as well. These other factors of change were classified bottom-up into four categories: motivation, activation, 
positive feelings and self-development. Differences in coding were discussed until consensus was reached. This discussion resulted in a first version of the codebook, containing a definition for each code (need or factor of change), examples from the interviews, and rules for applying the codes.

Second, eight subsequent interviews were coded by LAW to refine the codebook. In this phase, the development of the three basic needs was determined per participant in all eight interviews, by rereading all coded text passages for a certain need. Based on these texts, it was decided whether need fulfillment was high or low before and after the intervention. This resulted in four possible outcomes: stayed high, stayed low, reinforced or improved (see Table 1). These four outcomes were also described in the codebook.

In the third phase, LAW analyzed the remaining eight interviews, based on the improved codebook. No adjustments in the codebook were needed during this phase, suggesting that a high degree of saturation was reached. Lastly, based on this final codebook, ten randomly chosen interviews were also independently coded by SJ, resulting in Cohen's kappa's of .73 for needs and other change factors, .77 for the situation before/after and .70 for change, which is considered as good (Altman, 1990). By discussing different interpretations, consensus on the coding was reached for the ten interviews.

Once the coding was complete, we compared patterns of change across participants and, based on the continuity and change in the fulfillment of the three needs, we defined four types of patterns: all-over improved, partly improved, specific-need improved and non-changer. All possible context information from the interviews was used to provide a full understanding of the narrative. 


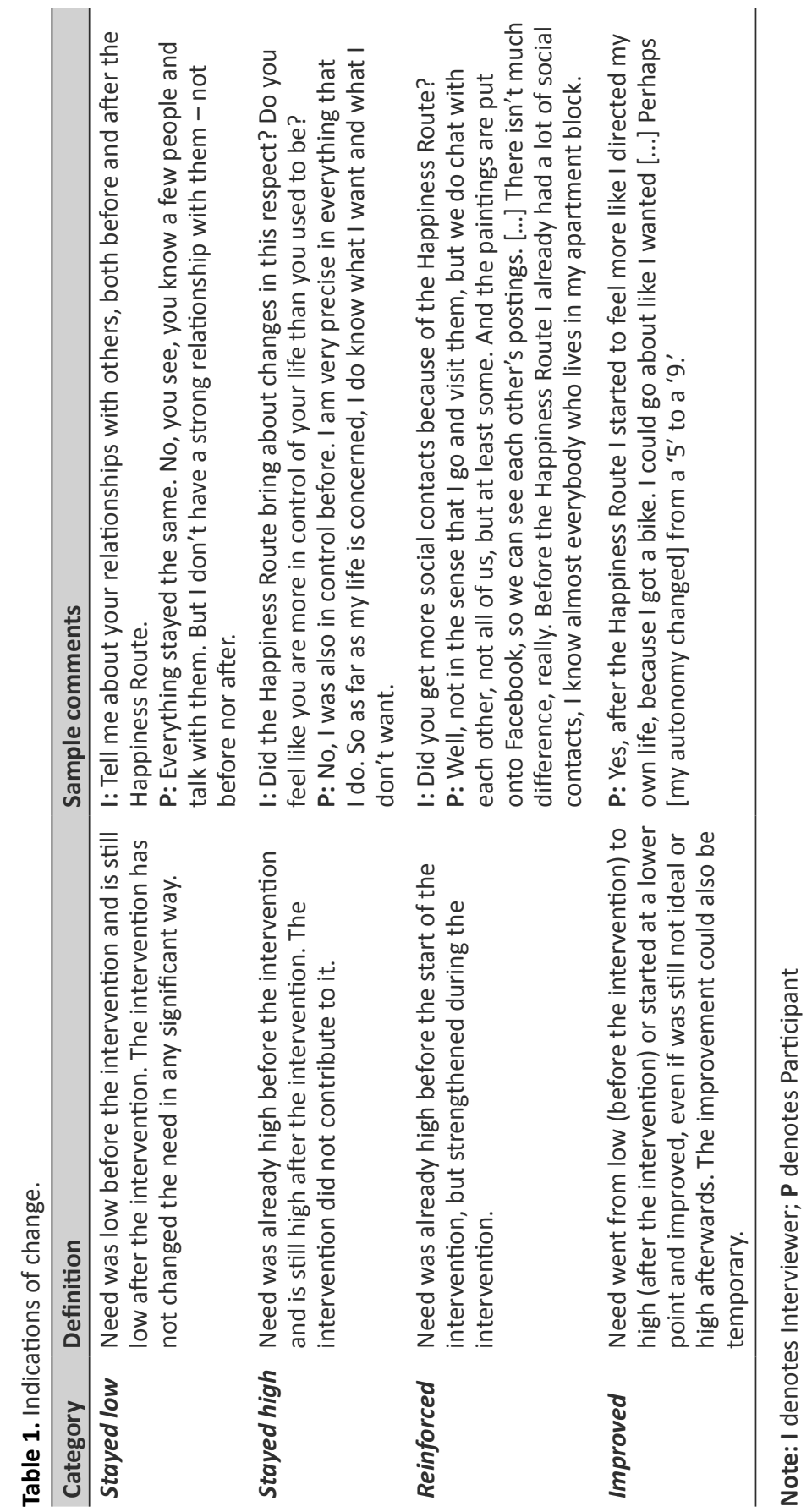




\section{Results}

In this section, we provide rich descriptions with specific and varied examples of how the different needs and other factors of change were found in the participants' narratives. Then we describe the four types of patterns - all-over improved, partly improved, specific-need improved and non-changer - based on prototypical cases for each type. The names of the participants have been changed and the number after a name indicates the age.

\section{The Three Needs of the Self-Determination Theory}

\section{Autonomy}

Autonomy was coded for answers that showed the need for a sense of selfdetermination, choice, and volition (Stone, Deci, \& Ryan, 2009). Autonomy was extensively described in all stories but one. A lack of autonomy before the intervention was a reoccurring topic. Participants often felt that external circumstances determined their life: financial problems, (traumatic) past experiences, loss of work, lack of choice, or the environment (e.g. living in a retirement home). III health was also often mentioned as it led to impaired mobility, inactivity, embarrassment, and a feeling of being at the mercy of the healthcare system. III health also restrained participants' possibilities to connect with others and take part in enjoyable activities. Participants felt forced by their illness to drop hobbies and give up things they liked. Furthermore, being dependent on others (e.g. ex-partners) or institutions took away participants' feelings of independence and freedom. For example, Francine (60), described how her autonomy was severely impaired by her mental disorder:

Depression can take over, even if you don't want it to. [...] Of course, all arises from this, an accumulation of misery in one's life. [...] And in a way you would like to fight such a monster, but you don't have the strength for that, so for a while you lose control over your life.

In many cases, this feeling changed during the Happiness Route, leading to a renewed feeling of mastery. Common themes were freedom, independence, empowerment or having a choice. Freedom was experienced both in a practical way (e.g. mobility and flexibility through a newly acquired public transport card) and as a feeling by 
means of doing something they liked, which was not normally assessable: 'After the Happiness Route, I started to feel more like I directed my own life, because I got a bike. I could go about like I wanted' (Greta, 36). Feeling independent was also often mentioned, such as not needing help anymore or having something just for oneself. In several narratives, empowerment was an important aspect of the newfound feeling of autonomy. Examples of empowerment included participants daring to say no, doing things that they once feared (e.g. joining a group) and feeling as important as others. Some participants described that they were proud that they stood up for themselves or for their partner for the first time.

Last, the counselor played an important role. Autonomy was notably strengthened when the counselor gave the participant the space to freely choose how to spend the budget and the 'freedom to speak.' Participants particularly valued the support from their counselors in their discovery of their interests and the activity that best suited them. In a couple of cases, the participants felt nudged 'in the right direction' and encouraged to think about what they wanted in life.

\section{Competence}

Competence was coded for answers that showed the participants' need to feel confident and skillful when interacting with their surroundings (Deci \& Ryan, 2000). Competence was found in all stories but one. In both parts of the interview, participants named things they were good at: skills (e.g. sewing), hobbies, housework, creativity (e.g. decorating), competences (e.g. being social) or knowledge about a certain topic. Despite knowing which competences or talents they possessed, they felt unable to use them before the intervention. They gave various reasons, such as physical limitations and illness, missing contacts, a lack of confidence, language barriers, financial problems, no time, a low education, obstructions imposed by their family, or lack of energy. Many felt incompetent and useless, as they were unable to work or contribute to others and society.

However, many participants described how they regained a sense of competence in the course of the intervention through the realization that they were still able to do certain things. Some participants gained the feeling that they could fall back on 
their own strengths, whereas others developed a general feeling of being capable of dealing with challenging situations: 'My life is not an easy one, but I know that I can cope with it' (Dionne, 55).

Most participants were able to make use of their competences and even improve them through the activity they chose. Others regained the motivation to pursue their interests. Many participants stated that they learned new things during the Happiness Route or the activity. Making a conscious decision for an activity often enabled participants to keep using their competences even when a course had ended. While some learned new skills and gained new ideas during a course that they could use at home, others regained their self-confidence:

I said, 'That is another thing I know how to do,' and so then I did it. [...] I started to dare to do things again. [...] So that is what I discovered, that I can do that indeed. I can give a workshop, and that is a real eye-opener for me. It does feel scary [...] but I do know how to do it. (Marlies, 56)

Participants' contacts, especially their relationship with the counselor, played an important role in the use of their competences. Often, participants stressed that they learned from others, especially from the counselor but also from a new friend or the teacher of the activity. An essential result was that participants felt they could finally do something for others, by using their talents. For example, one participant made a painting to thank her daughter who had always been there for her. Some participants also mentioned receiving compliments on their skills, which made them feel proud. Being able to show their strengths to others was mentioned as a positive aspect of the activity. Competences also helped to improve contacts, for example through conversations about a new hobby.

\section{Relatedness}

Relatedness was coded for answers that showed the need to belong, to experience positive interactions and to have caring reciprocal relationships (Baumeister \& Leary, 1995). Relatedness was described extensively in all twenty interviews. 
Prior to the intervention, many participants felt lonely due to having moved, language barriers, mental disorders or a lack of self-confidence. Some were bound to their house because of their health condition or their role as informal caregiver and had, consequently, become inactive and socially isolated. Many participants described how not having employment impaired their feeling of relatedness: 'I also had the feeling that there was no longer any use for me, that I could no longer find a job, that [...] I am of no use to society anymore' (Francine, 60). Existing relationships often could not completely fulfill participants' need for relatedness, even though some had contact with a family member, church community or neighbors. Others experienced problems with existing contacts, were disappointed by friendships or (ex-)partners, or found it hard to connect with their neighbors. Some disconnected from their family because they did not feel supported when ill or because of divorce: 'All the others condemned me. I left. I am the guilty one' (Odette, 62). Some participants stated that they did not need contacts and were satisfied with their situation.

In the course of the intervention, their sense of relatedness changed for many participants. Their counselor was a major source of relatedness as the participants perceived the contact and conversations as pleasant and enjoyable. Many felt that they 'clicked' with their counselor, others even described their counselor as a friend. Some said that they had built a bond of trust, which was normally difficult for them. Many participants felt taken care of by the counselor or mentioned that they could pour their heart out to the counselor. These feelings of being heard, understood and supported were extremely valued.

It felt great to me that, so to say, an arm was put around me, that took me along and at a certain moment let me go on my own. The idea that someone is listening and thinking along with you. Who gives advice and asks how you're doing. The result was that I find it less difficult to get out there. (Marlies, 56)

The downside was that some participants were disappointed when the contact ended after the intervention. 
The chosen activity also provided participants the opportunity to establish contacts with others. Sometimes their activity was chosen specifically to become acquainted with other people or to be amongst others. They especially valued the sociability they experienced in group activities, and shared interests facilitated their ability to connect with others. Some mentioned that they felt accepted: Pauline (55) stayed in contact with members of her painting class through social media: 'We chat with each other, not all of us, but at least some. And the paintings are put onto Facebook, so we can see each other's postings.' For some, the Happiness Route allowed them to mean something to others, which made them proud and happy.

I was very happy with knitting for my granddaughter, as I had no money to give her a present[...] And my daughter-in-law was very proud of my knitting those trinkets. She was happy with them, really. I remember all of that, as it is something that I did for them. (Charlotte, 70)

Some participants improved their social and communication skills, gained new selfconfidence, and learned how to make contact:

Before I had fewer contacts [and since then] I became more inclined to talk. [...] Before, I would greet someone and then just keep walking. Certain people would address me and then I would start talking to them, but I would not be the first to start. Now I do begin the conversation on my own. (Charlotte, 70)

Some participants made new friends, others improved existing contacts. Sometimes, practical solutions (e.g. having access to transportation) made it possible to establish contact again. Some forgave family members. A couple of participants mentioned that their new positive attitude improved their contacts.

However, relatedness did not improve for every participant. Sometimes, when participants joined a group for their chosen activity (e.g. a painting course), they felt course members were too different or had already formed a group, making it difficult for them to fit in. Other times, the activity was not suitable for establishing contact with others (e.g. swimming). 


\section{Factors of change}

To determine whether other factors besides the three SDT needs had changed or influenced change, we further analyzed reasons for and outcomes of change. Four other factors that were not addressed in SDT were found (see Table 2). The first factor, motivation, included intrinsic and extrinsic reasons for change, whereas the other three factors - activation, positive emotions and self-development - described outcomes of change.

\section{Motivation}

Extrinsic motivation. In some instances, participants described their behavior as being motivated by external reasons, most often when explaining how they spent their budget. Reasons to participate in an activity included: another person, money, the feeling of not being competent enough to know how to deal with the circumstances, wanting to win, being motivated by the result, killing time, and practical reasons for spending the budget.

Intrinsic motivation. In many cases, the motivation to do something, mostly in relation to the chosen activity, was clearly intrinsic, as participants had a heartfelt interest in their chosen activity and enjoyed doing it. Participants often described the motivation for the activity as innate. 


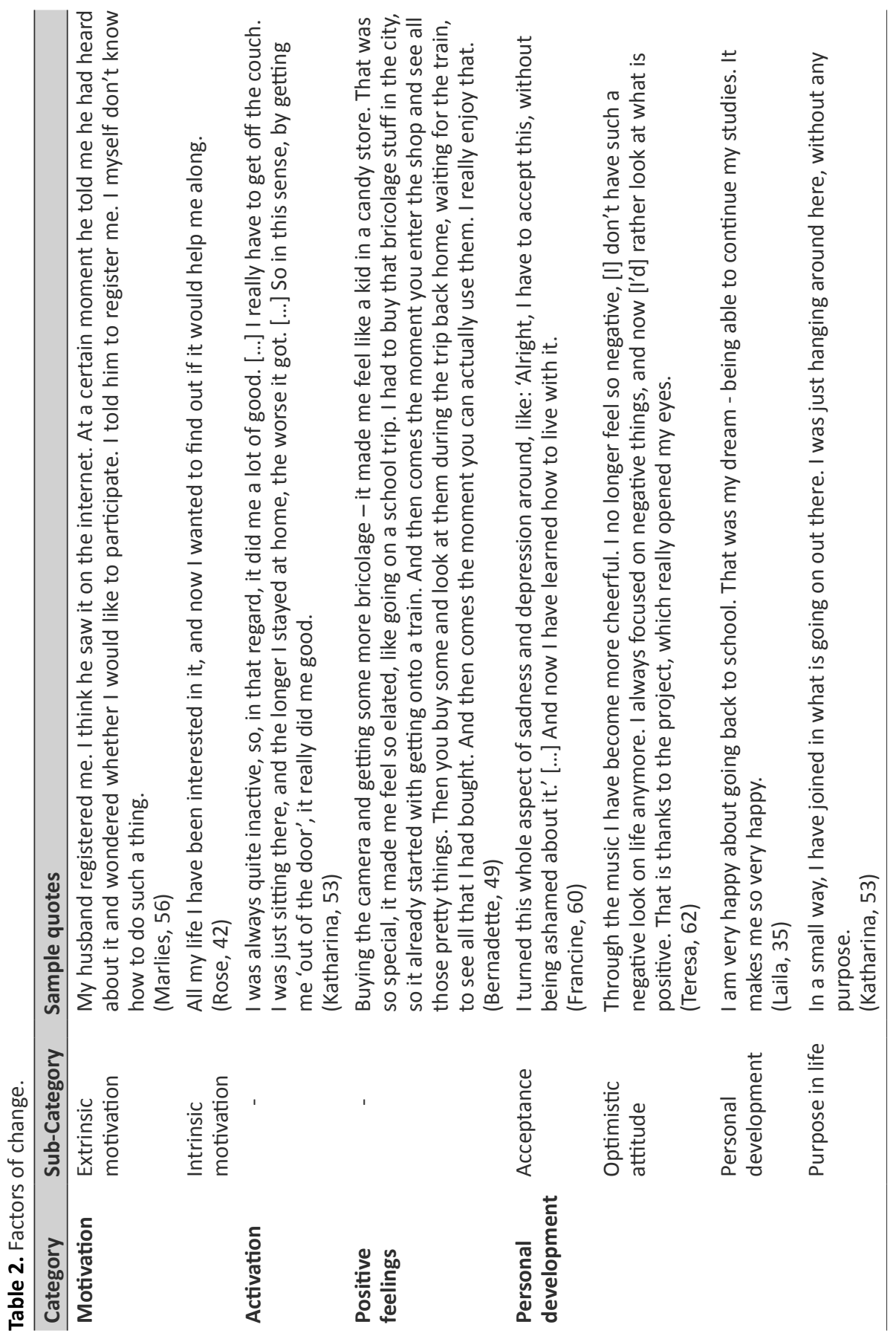




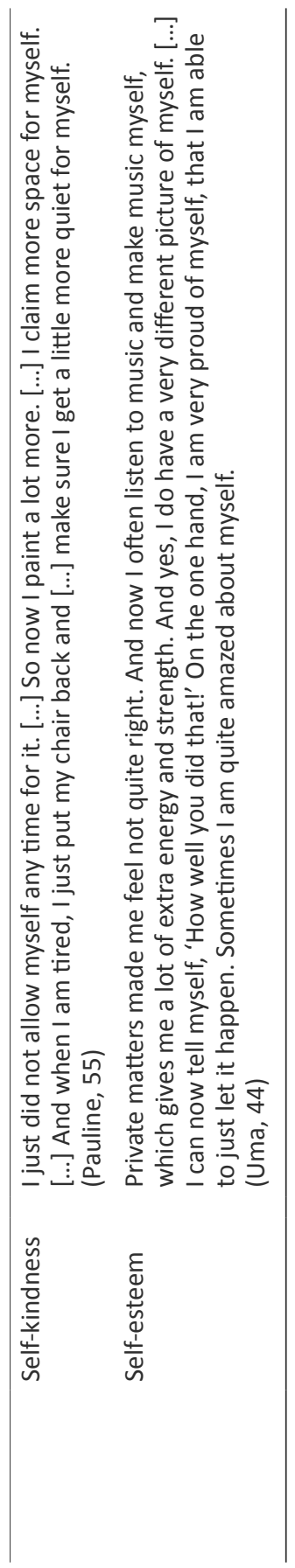




\section{Activation}

Many participants became more active in general. They explained that the activity stimulated them to 'get out of the house', and some even said it gave them the courage to do so. Remarkably, participants also said that they were 'forced' to become active again, for which they were grateful. Sometimes, the activity was also seen as a distraction. They enjoyed it because it gave them something that kept them busy and helped them to stop thinking about things. The activation was sometimes described as 'a nudge'. In several cases, participants not only followed the activity; many went outside more often and some enrolled in other courses. Two participants even started working part time. Additional activation did not seem directly linked to how successful an activity was perceived. For example, one participant was not satisfied with how she had spent her budget for a dating agency, as the dates had not been successful. Yet, she did start several other activities on her own initiative, such as a painting course and following activities in a community center.

\section{Positive feelings}

Most participants described experiencing positive emotions during the intervention. Positive feelings that were often reported to occur during an activity included: feeling good, cheerful and enthusiastic; having a carefree feeling; being able to release their thoughts while being active. These positive feelings occurred during different phases and were described as 'looking forward to it', 'having fun doing it', 'savoring the feeling afterwards' and 'enjoying the memory/result afterwards'.

Many participants also described positive emotions as a broader outcome of the intervention. Reoccurring themes were serenity, zest, and gratefulness. Whilst some emphasized feeling generally more peaceful and calm, others described having more energy or even having developed a 'fighting spirit'.

\section{Self-development}

People developed themselves in various personal ways. They accepted problems and complaints, became more positive, strived to improve themselves by learning more, gained new aims, treated themselves more kindly and improved the way they looked 
at themselves. Self-development therefore included five sub-categories: acceptance, an optimistic attitude, personal development, pursuit in life, self-kindness and selfperception.

Acceptance. Accepting negative aspects in life and the things they could not change were fundamental to the change process for many participants. People stated that they were able to accept, to forgive and to let go (of pain).

Optimistic attitude. Many participants experienced a change in attitude, from a negative focus to a positive one and, consequently, a more optimistic view on life. One common theme was the ability to focus on the things you have and the things you are still able to do, instead on the things you lost. Some described the intervention as a turnaround or eye-opener.

Personal development. A couple of participants used the activity for their personal development, often in the form of learning something new. For example, one participant spent her budget to finish secondary education to be able to follow a study afterwards.

Purpose in life. Some participants gained a new goal in life during the intervention, for example become part of society again.

Self-kindness. During the course of the intervention, many participants became milder and kinder to themselves, allowing themselves to enjoy their life more. Topics around self-kindness included: being self-compassionate, respecting yourself, and thinking about yourself in a milder way. Self-kindness often manifested itself in participants taking time and space for themselves, doing something for themselves, and having something just for them.

Self-esteem. The way participants saw themselves changed positively for many participants. 


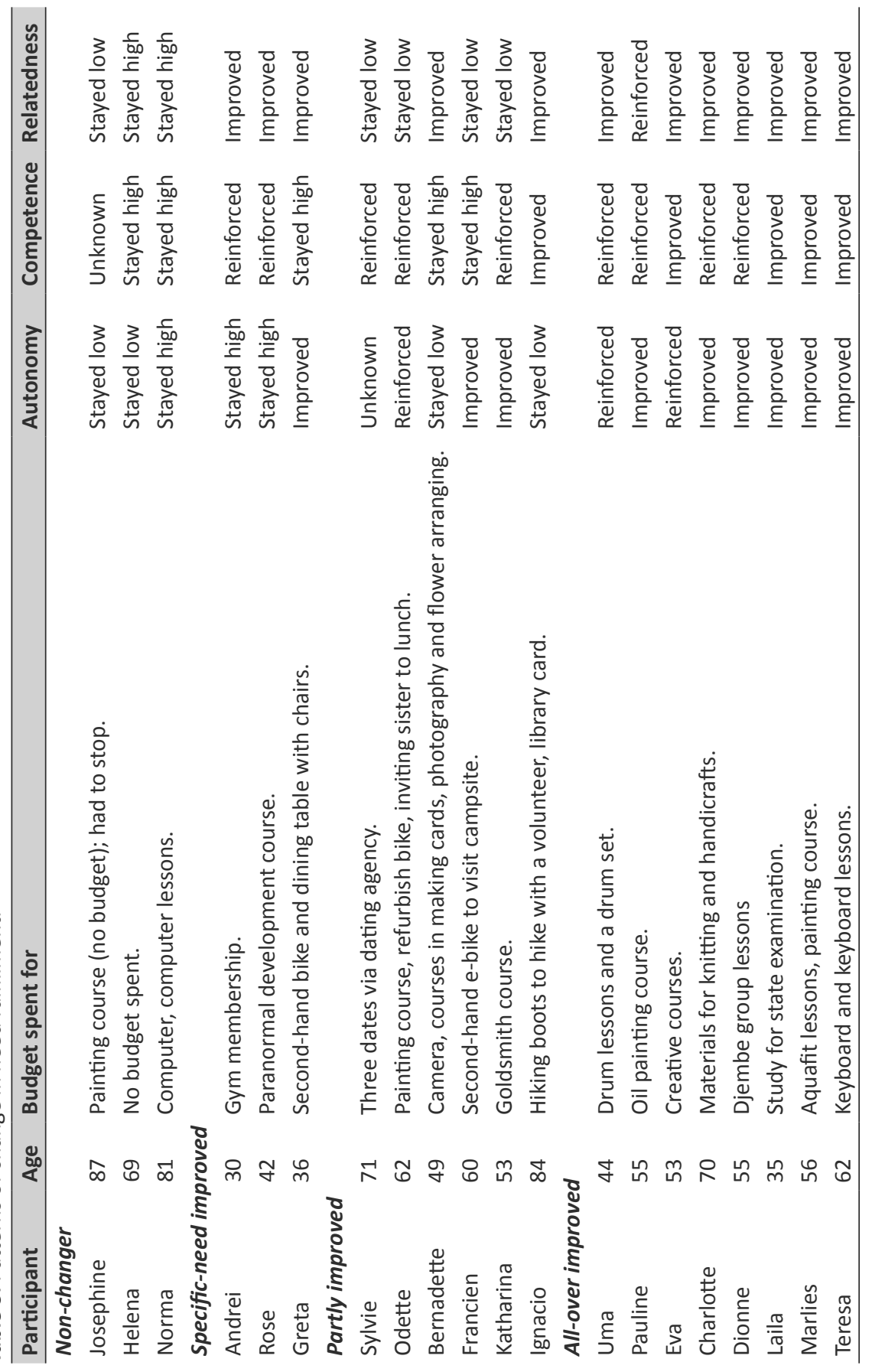




\section{Patterns of Change in Need Fulfillment}

In addition to analyzing the interviews for participants' perception of autonomy, competence, relatedness, and other factors, we explored how participants described change or continuity in their need satisfaction. Four different types of patterns emerged: the all-over improved, partly improved, specific-need improved, and the non-changer (see Table 3).

\section{The All-over Improved}

The all-over improved group was the largest of the four groups. Eight people were identified as being all-over improved in that they improved or reinforced all three needs.

A typical example was Teresa, 62 years old, suffering from rheumatic disorders and unable to work. Divorced, she had a low education and low financial means with debts. She used to live on a boat but became the victim of a fraud and lost her boat, forcing her to move to an apartment, where she had not even unpacked her suitcases. She described how miserable the situation felt for her:

Somber. [...]. I was always completely focused on the fact that I wanted to get back to the boat. [...] For some reason, I could not let go of it. I always had the feeling that all of this was just temporary. That is why I no longer undertook anything.

When she was asked to think about things that made her happy, music directly came to mind. Learning to play the piano was always something she wanted to do, so she spent her budget on a keyboard and lessons. The fulfillment of all three needs for Teresa drastically improved. Autonomy was very low before the intervention:

I always cared for myself. I always did things myself, without any help, and

this last year-and-a-half I have needed only help. It makes me dependent on others, and I have lost my feeling of freedom.

She turned this around: 'There is a difference in that I now start to act more from my own strength, and I also see that I am still able to do quite a few things.' Teresa's level of competence was so low before the intervention, that she saw no longer saw any value in her life: 
I also did not feel inclined to move forward in life. I really had a feeling that life was over [...] that I can no longer sail [...]. I really got stuck in what I was actually no longer able to do.

During the intervention, she regained the feeling of being competent. Other people were instrumental in helping her realize her skillfulness:

And when I hear all the others say, 'Whoa, that is brilliant!' and 'How nicely you did that,' well, then I think, 'So, I am handy after all.' Also friends say: 'You know, you are so handy, do you mind helping me for a moment?' Well, I must say that I am pleased with that.

She also experienced more relatedness through music:

I have been going out a little more. Through the music I also got to know other people. I started to widen my world. [...] It all happened very quickly, indeed. I could hardly keep up with it. I made acquaintances at once. I

suddenly have a friend with whom I got quite close.

Because of the change in her attitude, her contacts improved:

I have more contact with others because I take on a more positive attitude while before I always was gloomy. [...] I talk less about wanting to go back to a boat, which was keeping me at a distance from everything. That made it hard for people to get in touch with me.

She felt close to her counselor, who 'could really have been a friend.' She appreciated the project's personal approach, 'because it gave me the feeling that I was really looked at, instead of being simple labeled 'depressed' or 'Ionely'. Her piano teacher also played a role in her change process. Teresa gained a new sense of acceptance with regard to no longer owning her boat: 'The second step of acceptance of losing the boat happened when I started to make that music. It made me think: "This a very nice alternative, something I cannot do on a boat".' Teresa was activated and enjoyed doing things again. Feeling at home in her apartment at last, she managed to unpack her bags and decorate her apartment.

Teresa is an example of how the Happiness Route works in an ideal case. For two other participants in this group, all three needs also improved; for three others, two needs improved and one was reinforced. For the other two participants in this group, 
two needs that were already largely fulfilled were further reinforced and one need improved. For all eight participants of this group, the intervention was a turning point in their lives.

\section{The Partly Improved}

Six participants were identified as partly improved, in that they improved or reinforced two needs, whereas one need stayed low.

One example of the partly improved participant was Katharina. In her early fifties, she was divorced, with a medium education, low financial means and debts. She suffered from Crohn's disease, rheumatism, diabetes and asthma and was unable to work, leading to social isolation from her former colleagues and family. She had to move to a care facility, where as the only young person, she had no contacts. Katharina concluded: 'At a given moment, you realize you are alone.'

Katharina lost a large deal of her former autonomy when she got ill and, as a result, had to stop working. She won her autonomy back when she made the decision to use her budget to follow a goldsmith course in jewelry-making: 'And then I had to carefully search on the internet for what I'd really like to do.'

Competence was reinforced during the intervention. Katharina had always been creative, and in the course, she learned new things: 'It really is kind of funny that you learn so many things. How everything comes about, that you don't understand how you managed with nothing but a piece of iron.' She used her creativity in a unique way and with the means she had. When the course stops, she plans to continue at home. 'You know now how to go about it [...]. It gave me some nice ideas.' By developing this new skill, other aspects of her life also improved:

I was completely inert. And now, for instance, it was great for my friend, who happened to have some nice stone, when I said, 'Well, let's see if I can make something nice out of it. These are different things, different conversations. 
Yet relatedness, for her the most important need, stayed low:

I had expected more from the course, I do notice that. As far as the characters [in the course] are concerned and the types and jobs. I think we did not fit together. I feel sorry about that, for I had hoped to find a few new friends [...]. They are a different type of women. And I am a late arrival. They all know each other.

However, she did gain new goals in life and the intervention forced her to became more active. 'Other things came up. I have a part-time job. I give demos in supermarkets.' Her new work gave her an additional boost. The intervention seemed to have been the starting point for an upward spiral in her life: 'So it's like everything is turning out well. I am again a little part of what is going on out there.'

Katharina was considered as a good example for the partly improved because her autonomy improved, competence was reinforced, but her relatedness stayed low. Her experience shows the typical pattern of this group for which the fulfillment of needs differed. Despite the intervention improving or strengthening two needs, the third need stays low. Katharina was one of the four participants in this group who stated that their need for relatedness was not fulfilled to their satisfaction. For the other two, relatedness improved, but autonomy stayed low.

\section{The Specific-need Improved}

The specific-need improved participants needed help for one specific, key need that was, by the end of the intervention, improved or reinforced. Another characteristic of this group was that at least one need already was high and stayed high without being reinforced, indicating that the participants in this group did not need help for all three needs.

A typical example for the specific-need improved was Andrei, who was in his late twenties. Single, he lived alone. He emigrated alone from an Eastern European country to the Netherlands. Andrei had a medium educational level, low financial status and debts, and suffered from diabetes and a severe renal disease. For 
his activity, Andrei chose to go to the gym. He chose this activity because it challenged his physical limitations. He wanted to become 'stronger, fitter.'

Andrei had always felt in control of his own life and his feeling of autonomy did not change during the Happiness Route. 'No, I was like that before. Very precise in everything that I do. As far as my life is concerned, I do know what I want and what I don't want.'

His feeling of competence was already high as well, but was reinforced by his activity. Andrei described himself as being precise in his accomplishments which he would perform in a secure manner and that he had perseverance, which he could use in his activity of going to the gym.

Relatedness was most important for him and the only of the three needs that was poorly satisfied before the Happiness Route. He used to be 'at home a lot. Not many activities. I did not have much to do.' Going to the gym offered him the possibility of meeting new people:

I do meet people there, and have a chat [...] over a cup of tea [...]. When you stay at home, you never meet anybody [...]. It does offer you the possibility to get to know people.

Making contact with others is 'better and easier than before'. He said that the counselor had 'really helped me and in the end offered me the gym membership in order that I might find more activities and social contacts and friends, which worked out very well.' He was content with his contact with the counselor, especially because 'she really made time for me.' He highly valued that his counselor truly made things work.

While Andrei's feelings of autonomy and competence were already high before the intervention, his need for relatedness was strong but not satisfied. Before the intervention, he had no contacts because he was home all day and lived alone, without any family nearby. By going to the gym, his need was met and relatedness improved. He concluded: 'And now my life has really changed, with a lot more activities outside of my home.'

Andrei was typical of the two other participants who were also categorized in the specific-need improved group, as the Happiness Route supported all three in one area in their lives. All three had only one need that was not satisfied before the 
intervention, and they chose an activity to improve this specific need. Rose (42) had exactly the same pattern of change as Andrei. The third participant, Greta (36), improved her sense of autonomy by purchasing a bike, which improved her general well-being. Although the bike helped her to visit family and friends, Greta had no urgent need for more relatedness and her need for competence was not further strengthened. All in all, these participants had one area in their lives where they were supported by the Happiness Route.

\section{The Non-Changer}

Three persons experienced no change in their need satisfaction; either their need satisfaction stayed low, stayed high, or a combination of these two (see Table 2).

An example of those in the non-changer group was Helena. She was in her late sixties, retired, had a low educational level and few financial means. Divorced, with one child, she had complaints of mild depression and fractures due to an accident. The intervention was not successful for her. A first possible reason was that she had found a way to accept her situation before she took part in the project. She already felt competent: 'For the rest, I can do everything myself.'. She had activities she liked to do: 'I can keep myself busy very well, I have many hobbies and am interested in many different things.' Her need for relatedness was also already fulfilled before the intervention started:

I really find my happiness in the people around me, my children and daughter, my son-in-law and grandchildren, of which I have three. I am also surrounded by a very sweet church community, that created a 'caring circle' because I was so terribly alone and could not cope with it.

Therefore, she felt no need to change regarding competence and relatedness. Secondly, Helena did not feel autonomous during the intervention. Her counselor had the idea of using her budget to purchase a computer, which she did not want:

I felt like I was told to do something [...]. Yes, and because of that, I kind of lost it with my supervisor. She wanted to give me [a PC], as that would open up a whole new world to me - that was what I was missing out on. Well, 
sorry, it was not negative, but I felt somewhat run over by her. At such a moment, I don't know how to react; my reaction always comes later. [...] I don't dare to say no.

The lack of autonomous choice even led to Helena feeling stress: 'And my neighbor felt that I was tense.' In the end, her son called the counselor to say that Helena did not want a computer and that she want to stop with the intervention.

Helena was chosen as an example of the no-changer group because some of her needs stayed low (autonomy) and others stayed high (competence and relatedness), whereas the needs of the other two non-changers stayed either only high or only low. Norma (81) was satisfied with her social contacts, with the autonomy she had and with the things she was still capable of doing well. The intervention was not successful in helping her find her intrinsic motivation. Similar to Helena, she had accepted her situation and felt no need for change. Josephine (87) however, was a different story; her need fulfillment was already low and stayed low. Although she found an intrinsically motivated activity in joining a painting class, she had to stop the lessons because of her disabilities, which hindered her from satisfying her needs.

\section{Comparison}

When comparing the groups, the all-over improved and the partly improved had a much lower need fulfillment in the beginning, with two of the three needs or all three needs starting low. In the majority of the cases of the non-improved and specific-need improved, only one need started low.

\section{Discussion}

This study examined the blackbox of the Happiness Route intervention to determine what happens during a PPI from the perspective of the participants. First, we explored how the three basic psychological needs of the SDT were described in the narratives of the participants of the Happiness Route. In accordance with SDT, autonomy, competence, and relatedness all played a central role. We also found that participants were either intrinsically or extrinsically motivated for an activity, became more active, experienced positive emotions as an outcome of the activity, and developed themselves. 
This study adds to the existing literature by examining participants' perspectives on change and continuity with regard to the fulfillment of their basic needs. By comparing the individual patterns of how the needs of participants developed, we found four different types: the all-over improved $(n=8)$, partly-improved $(n=6)$, specific-need improved $(n=3)$, and non-changer $(n=3)$.

These four patterns provide us with valuable information on how participants perceive their individual development during a PPI, helping us to understand why the intervention is working well for some, but not for others. This study indicates that need fulfillment could be a possible working mechanism to explain why PPIs can lead to an improvement in well-being.

Four findings were of particular interest. First, in many cases, need fulfillment was low at the start of the intervention. Loss of health was seen as a threat to autonomy, competence, and relatedness, because it forced people to relinquish activities and relationships. This low starting point was especially true for relatedness and autonomy. For almost half of the group, two or three of the needs were low in the beginning. The all-over improved and partly improved participants had a much lower need fulfillment in the beginning than the specific-need improved and the partly improved. This indicates that the intervention may be more effective for participants with low need fulfillment.

Second, the counselor played an important role for need fulfillment. The narratives often included the counselor as a central and enabling factor. Participants felt understood, respected and cared for and supported in their feelings of competence and autonomy. SDT also suggests that need support in healthcare is related to higher levels of well-being (Ng et al., 2012). Similar to Brownell and colleagues' study (2015), participants described support by the counselor for their autonomy as central to finding and going their own way. In both studies, this was realized by the counselors' ability to give the participants space in a non-judgmental and non-intrusive manner. 
This is in accordance with earlier research that shows that high-quality relationships can not only satisfy the need for relatedness, but also the need for autonomy and partly the need for competence (Deci \& Ryan, 2014). Only those relationships in which autonomy support is provided are deeply satisfying of the need for relatedness. In the current study, autonomy-supportive behaviors of the counselors were crucial for the intervention as well.

In our study, it appeared that only when the counselor initiated the change, be it emotional or practical, was the participant able to begin his or her own process of change. Establishing a relationship with the counselor might be beneficial or even necessary before participants are able to (re)connect with other people. In accordance with research on psychotherapy and counseling, the nonspecific factor of unconditional and genuine positive regard on the part of the counselor is seen as necessary and sufficient for catalyzing change (Rogers, 1957). The therapeutic alliance is a good predictor of treatment outcome (Martin, Garske, \& Davis, 2000) and differences between therapists and their specific way to motivate, relate and connect with the patient has been shown to impact the effectiveness of the treatment (Baldwin, Wampold, \& Imel, 2007).

Third, the activity participants chose partly determined if change occurred. When they chose an activity that was related to their passion, participants reported that they connected with others from the group and learned something that interested them. The importance of the activity and its social context was also found in previous studies (Brownell et al., 2015; Lloyd \& Little, 2010; Swindells et al., 2013). The explanation of why the selected activity is so essential derives from the participant's intrinsic motivation, another concept of SDT that has shown to effect need fulfillment (Deci \& Ryan, 1980). Once participants find and act on their intrinsic motivation, there appears to be more of an opportunity for need fulfillment. For example, intrinsic motivation is directly related to an autonomous choice for an activity as only the participant (not the counselor) can say what he or she is passionate about, leading to an improved fulfillment of autonomy. In the narratives, we found that an intrinsically motivated activity is likely to be something in which the participant is either skilled or 
has an interest to become skilled, which strengthens the need for competence. Such a chosen activity also gives the participant an opportunity to fulfill one's need for relatedness by meeting and connecting with others with the same interest.

It also works the other way found in the way that need fulfillment also supports intrinsic motivation. To foster intrinsic motivation, people must experience both competence and autonomy, as explained by Cognitive Evaluation Theory, a subtheory of SDT. A social context that is beneficial to feel competent during an activity can enhance intrinsic motivation for that activity. Yet this is only the case if feelings of competence are accompanied by a sense of autonomy (Ryan \& Deci, 2000a).

Fourth, people benefitted most when all three needs were fulfilled in the end. The all-over improved participants seemed to have made the most significant life change, and the specific-need improved also seemed to have profited more than the partlyimproved and non-changers. The difference was that in the former two, all three needs were fulfilled in the end. That is in accordance with the Basic Psychological Needs Theory, which argues that all three needs are essential and endangering any will lead to distinct functional costs (Deci \& Ryan, 2002). In the narratives, if often appeared that needs were mutually reinforcing each other, which corresponds to the understanding that in SDT, all three needs have to be fulfilled in order to achieve optimal well-being.

This study showed that it is possible to conduct a PPI for vulnerable people across the adult lifespan. Although the target group had serious health, social, and financial problems, they were able to change in a positive direction, according to themselves, despite their vulnerabilities. The fulfillment of basic psychological needs both by the counselor and the activity played an important role for those, in particular, who felt that their needs were unfulfilled in the beginning and subsequently reported an upward spiral in the satisfaction of their basic needs. However, in addition to the three needs, we also found other factors that played a role in the process of change. They can help explain how the upward spiral could work. 
Deci and Ryan (1980) gave a possible explanation why being intrinsically motivated could lead to new resources. They suggest that, when people are intrinsically motivated, they will seek optimally challenging situations that fit their own abilities. Intrinsic motivation directs someone's attention towards an activity that requires him or her to extend their abilities or to learn new things. We can also identify this process in the interviews. The participants who were intrinsically motivated mostly chose an activity and situation where they could use and further strengthen their own abilities.

In order to explain how discovering and subsequently conducting an intrinsically motivated activity can lead to various positive outcomes, it is interesting to take a look at the broaden-and-build theory (Fredrickson, 2001). As found in the interviews, finding an acting on a passion leads to the experience of positive emotions. According to Fredrickson, positive emotions broaden participants' momentary thought-action repertoires, which, in turn, build new and lasting intellectual, psychological, social, and physical resources (Fredrickson, 2003b). We clearly found these newly build resources in many participants' stories of change. One might see these resources in terms of becoming more competent and feeling more related to others, but participants also mentioned signs of newly built psychological resources, like optimism, purpose in life and self-esteem.

The finding that positive emotions seem to lead to improved psychological resources can provide further insights with regard to the discussion if well-being should be seen as a hedonic concept of positive emotions and life satisfaction (Diener, 2000) or an eudaimonic concept of positive functioning (Ryff \& Singer, 2008). Our findings support an integrated approach of well-being that advocates to combine both viewpoints (Delle Fave, Brdar, Freire, Vella-Brodrick, \& Wissing, 2010; Keyes, 2002a). We found that both hedonic factors (positive emotions) and eudaimonic dimensions (need fulfillment, self-development) were demonstrated throughout the interviews and might reinforce each other. 


\section{Limitations}

This study, however, and its findings need to be interpreted within certain limitations in mind. The low representation of men $(n=2)$ in the interview study is one example of how the 20 participants did not fully represent all the participants of the Happiness Route. In fact, none of the men were in the largest group of all-over improved who profited most from the intervention, but this could also be a coincidence.

Another limitation is inherent to the methodology of self-reporting. Reflecting verbally about a certain experience can change the experience itself (Polkinghorne, 2005). A retrospective reflection on the process of the intervention may not only be influenced by the participant's current mood, but it may also be different from reflections that would be given during the intervention. Whereas qualitative interviews seem to be the best way to reveal opinions and emotions about the intervention (Lub, 2015), further research could also implement a study design where participants would reflect on their change after every session.

Lastly, we used SDT as a framework for data analysis, as the intervention was based on this theory. This predefined framework might have influenced our interpretations, but we also took into account other factors that emerged bottom-up. It would be interesting to conduct studies to determine whether our findings also apply to other PPIs, especially if these are not based on SDT. Because the basic psychological needs are universal aspects of human functioning, this seems likely. Earlier studies indicated that SDT elements are described as important, even though the intervention, the interview scheme, nor the analysis was based on SDT (Brownell et al., 2015; Swindells et al., 2013).

\section{Implications}

Despite these limitations, our study offers insights into how the Happiness Route intervention might be improved, which could also be relevant for other PPIs. As the counselor played a central role, it is essential to train them to be able to provide relatedness, competence and especially autonomy support. Counselors also should ensure that the activity fits the participant's intrinsic motivation, as this seems to be 
central to its success and influence. Furthermore, in the future, possible candidates for the intervention should be more carefully assessed for inclusion, as their basic needs might already be fulfilled or participants might not want to change. Counselors could also explore the status of the three needs in an early stage of the intervention. The counselor might then better determine whether the chosen activity has the possibility to strengthen those needs. Before completing the intervention, it should be discussed if the participant feels that his or her needs are satisfactorily fulfilled. Both eudaimonic well-being and hedonic well-being should be addressed in positive psychology interventions. Finally, the study results strongly suggest that the intervention should use a personalized approach; intrinsic motivation can only be found when the counselor is responsive to the unique interests of the participant.

\section{Conclusion}

Our study was the first to address changes in need-fulfillment in a PPI from the perspective of its participants. SDT seemed to be a useful framework to describe and understand individual change in interventions. Analyzing participants' narratives revealed that the success of the intervention depended on (1) the satisfaction of the needs in their initial situation, (2) the type of support the counselor gave and (3) the possibilities for need satisfaction given in the activity. Only when all three needs could be improved or strengthened, the participants could fully profit from the intervention.

Not only have we demonstrated that basic psychological needs are fundamental to development and that it is vital to address autonomy, competence and relatedness in an intervention that aims to improve well-being, but we also showed that such needs should be addressed differently for every individual. By taking a look into the blackbox of a PPI, the lesson learned was: When we want to realize the best possible change in well-being with PPIs, one size does not fit all.

\section{Disclosure Statement}

The authors acknowledge that they have no financial interest or benefits arising from the direct application of our research. 
Chapter 6

\section{Acknowledgement}

We want to thank Trèske Heere and our students Leonie Stein, Milou Droste and Pauline de With, who conducted and transcribed the interviews. Our thanks also goes to Catherine Ann Lombard, who carefully edited the manuscript and translated all quotes. We are very thankful to the participants for taking the time to so openly share their personal stories and their experience of the intervention. Without them, this study would not have been possible. 


\section{References}

Adler, J. M., \& McAdams, D. P. (2007). The narrative reconstruction of psychotherapy. Narrative Inquiry, 17(2), 179-202.

Altman, D. G. (1990). Practical statistics for medical research: CRC press.

Baldwin, S. A., Wampold, B. E., \& Imel, Z. E. (2007). Untangling the alliance-outcome correlation: Exploring the relative importance of therapist and patient variability in the alliance. Journal of Consulting and Clinical Psychology, 75(6), 842.

Baumeister, R. F., \& Leary, M. R. (1995). The need to belong: desire for interpersonal attachments as a fundamental human motivation. Psychological Bulletin, 117(3), 497.

Bolier, L., Haverman, M., Westerhof, G. J., Riper, H., Smit, F., \& Bohlmeijer, E. (2013). Positive psychology interventions: a meta-analysis of randomized controlled studies. BMC Public Health, 13(1), 119.

Brownell, T., Schrank, B., Jakaite, Z., Larkin, C., \& Slade, M. (2015). Mental health service user experience of positive psychotherapy. Journal of Clinical Psychology, 71(1), 85-92.

Deci, E. L., \& Ryan, R. M. (1980). The empirical exploration of intrinsic motivational processes. Advances in Experimental Social Psychology, 13(2), 39-80.

Deci, E. L., \& Ryan, R. M. (2000). The" what" and" why" of goal pursuits: Human needs and the self-determination of behavior. Psychological Inquiry, 11(4), 227-268.

Deci, E. L., \& Ryan, R. M. (2002). Handbook of self-determination research: University Rochester Press.

Deci, E. L., \& Ryan, R. M. (2014). Autonomy and need satisfaction in close relationships: Relationships Motivation Theory Human motivation and interpersonal relationships (pp. 53-73): Springer.

Elliott, R. (2010). Psychotherapy change process research: Realizing the promise. Psychotherapy Research, 20(2), 123-135.

Lloyd, K., \& Little, D. E. (2010). Self-determination theory as a framework for understanding women's psychological well-being outcomes from leisure-time physical activity. Leisure Sciences, 32(4), 369-385.

Lub, V. (2015). Kwalitatief evalueren in het sociale domein. Mogelijkheden en beperkingen: Boom Lemma uitgevers.

Martin, D. J., Garske, J. P., \& Davis, M. K. (2000). Relation of the therapeutic alliance with outcome and other variables: a meta-analytic review. Journal of Consulting and Clinical Psychology, 68(3), 438.

Ng, J. Y., Ntoumanis, N., Thøgersen-Ntoumani, C., Deci, E. L., Ryan, R. M., Duda, J. L., \& Williams, G. C. (2012). Self-determination theory applied to health contexts a meta-analysis. Perspectives on Psychological Science, 7(4), 325-340.

Polkinghorne, D. E. (2005). Language and meaning: Data collection in qualitative research. Journal of Counseling Psychology, 52(2), 137.

Rogers, C. R. (1957). The necessary and sufficient conditions of therapeutic personality change. Journal of Consulting Psychology, 21(2), 95.

Ryan, R. M., \& Deci, E. L. (2000a). Intrinsic and extrinsic motivations: Classic definitions and new directions. Contemporary Educational Psychology, 25(1), 54-67.

Ryan, R. M., \& Deci, E. L. (2000b). Self-determination theory and the facilitation of intrinsic motivation, social development, and well-being. American Psychologist, 55(1), 68.

Seligman, M. E., \& Csikszentmihalyi, M. (2000). Positive psychology: An introduction (Vol. 55): American Psychological Association.

Sin, N. L., \& Lyubomirsky, S. (2009). Enhancing well-being and alleviating depressive symptoms with positive psychology interventions: A practice-friendly meta-analysis. Journal of Clinical Psychology, 65(5), 467-487. 
Chapter 6

Stone, D. N., Deci, E. L., \& Ryan, R. M. (2009). Beyond talk: Creating autonomous motivation through self-determination theory. Journal of General Management, 34(3), 75.

Swindells, R., Lawthom, R., Rowley, K., Siddiquee, A., Kilroy, A., \& Kagan, C. (2013). Eudaimonic well-being and community arts participation. Perspectives in Public Health, 133(1), 6065. doi:10.1177/1757913912466948

Weiss, L. A., Kedzia, S., Francissen, A., \& Westerhof, G. J. (Eds.). (2015). Improving the Health Care Sector with a Happiness-Based Approach: Springer.

Weiss, L. A., Westerhof, G. J., \& Bohlmeijer, E. T. (2013). Nudging socially isolated people towards well-being with the 'Happiness Route': design of a randomized controlled trial for the evaluation of a happiness-based intervention. Health and Quality of Life Outcomes, 11(1), 1-11.

Weiss, L. A., Westerhof, G. J., \& Bohlmeijer, E. T. (2016). Can We Increase Psychological WellBeing? The Effects of Interventions on Psychological Well-Being: A Meta-Analysis of Randomized Controlled Trials. PLOS ONE, 11(6). 
Exploring the Blackbox of Positive Psychology 



\section{General Discussion}

/I

When I was 5 years old, my mother always told me that happiness was the key to life. When I went to school, they asked me what I wanted to be when I grew up. I wrote down 'happy'. They told me I didn't understand the assignment, and I told them they didn't understand life.

Attributed to John Lennon 
Chapter 7 


\section{General discussion}

Loneliness, health problems, and a low socio-economic status (SES) are all risk factors for a languishing condition (Golden et al., 2009; Kaplan et al., 2008; Pinquart \& Sörensen, 2000), associated with a considerable burden on the individual and society. In this thesis, a new positive psychology intervention (PPI) for people with an accumulation of these risk factors has been introduced. Our aim was to evaluate this intervention, the Happiness Route, and its effectiveness. In this last chapter, the general discussion, we would like to share what we have learnt from the studies and in the process of conducting them. We will first provide a summary of the main findings. Next, we will weigh the findings of the different studies against each other, to be able to draw preliminary conclusions about the relevance of the Happiness Route. We will then discuss the strengths and limitations of this thesis and describe implications for future research. Last, we will describe the implications for theory, as well as implementation and practice and draw a final conclusion.

\section{Summary of main findings}

We will start by summarizing the key findings by answering the research questions we posed in the general introduction, which were answered in greater detail in the previous chapters.

\section{* Why should we adopt a happiness-based approach in the health care and social sector?}

A happiness-based approach fits the new directions in health care policies.

In Chapter 2, we have presented indications that a holistic approach to healthcare, that strives to improve well-being in addition to treating problems and illness, could be beneficial to individuals and society (Weiss, Kedzia, Francissen, \& Westerhof, 2015). We showed that the traditional problem-focused system is not always able to optimally help chronically ill people (Van der Plaats, 2002). Furthermore, it does not meet the challenges of recent societal and economic developments (RVZ, 2010). We need alternatives to be able to help chronically ill people with a low SES in social isolation to lead a more pleasant, engaged and meaningful life. Although theories (Deci \& Ryan, 2000) and studies (Sin \& Lyubomirsky, 2009b) have shown ways how 
to realize this, these insights are rarely translated into practice, with the Happiness Route as one of the few exceptions in the field. We concluded that the development of more happiness-based interventions and the practical implementation of methods to promote well-being in health and social care are important. The Happiness Route is in line with the changing health policies that focus on promotion of well-being and can offer the positive focus these policies ask for.

\section{* Can behavioral interventions improve psychological well-being?}

Psychological well-being can be enhanced through behavioral interventions. There is a rapidly growing interest in psychological well-being (PWB) as outcome of intervention studies, and numerous interventions have been developed with the aim to increase it (Ryff, 2013). However, the effects on PWB measured as coherent outcome have not been examined across studies yet. In Chapter 3 , we conducted a meta-analysis to answer the question whether it is possible to enhance PWB (Weiss et al., 2016). Twenty-seven randomized controlled trials (RCTs) were included that examined behavioral interventions and measured psychological well-being with either Ryff's Psychological Well-Being Scales (Ryff \& Singer, 1996) or the Mental Health Continuum - Short Form (MHC-SF)(Keyes et al., 2008a). We found a moderate effect with an effect size of 0.44 . At follow-up, a small but still significant effect size of 0.22 was found. The results are promising for the further development and implementation of interventions to promote PWB. The meta-analysis revealed a need for more high quality studies. We recommended including more research on vulnerable groups in studies on psychological well-being.

\section{* How effective is a positive psychology intervention for vulnerable people?}

The Happiness Route is as effective as the problem-based approach in promoting well-being and decreasing depressive symptoms and feelings of loneliness.

As experience in the field and first pilot studies were promising (Francissen et al., 2010; Kedzia, 2009; Van der Plaats, 2007), we proposed to evaluate the Happiness Route in a systematic way. In Chapter 4, we described the research design of a practice-based multi-site RCT that evaluated this positive psychology intervention 
(Weiss et al., 2013). In Chapter 5, we presented the results of the study. Our objective was to evaluate whether the Happiness Route is more effective than an active control group with customized problem-focused care, with well-being as primary outcome. Of the 108 included participants, 58 were randomized to the Happiness Route, and 50 to the control group, called Customized Care. Three key findings emerged about the reach, effects and satisfaction. First, the group that was reached was extremely vulnerable, even more than to be expected from the inclusion criteria. Participants had a mean of more than three health conditions with a very low level of healthrelated quality of life, and a very high level of depressive symptoms. In addition, they were severely lonely, with low educational and income levels and most of them without paid employment. Almost half of them used psychotropic medication. Although the group we have included was clearly in need of help, it was very hard to reach them. Second, the Happiness Route was found to be as effective as the control group, which used a problem-based approach. The total well-being score, emotional and social well-being, depressive symptoms and loneliness improved significantly at follow-up in both groups. The Happiness Route appeared to be more successful in bringing people out of a languishing state. No effects were found for resilience, purpose in life, health-related quality of life, social participation, or care consumption. Third, participants of the Happiness Route were more satisfied with the intervention than participants in the control group. They gave the relationship with their counselor a mean grade of 8.5, compared to a 7.3 in Customized Care. Happiness Route participants were significantly more likely than the participants of the control group to be positive regarding their experiences with the home visits of the counselor and to experience positive effects at post-test and follow-up.

\section{* How do participants experience a positive psychology intervention?}

Participants experienced continuity or change in four prototypical ways that could be described well in terms of self-determination theory.

In Chapter 6, we evaluated and described participants' perceptions of the intervention. Studies on the perspective of participants of PPIs are rare but important to understand how PPIs work and how they can be improved to accommodate individual experiences (Elliott, 2010). We examined how participants in the Happiness Route experienced 
change in their satisfaction of the three basic psychological needs, as described in the self-determination theory (SDT): autonomy, relatedness and competence (Deci \& Ryan, 2000). We conducted semi-structured interviews with 20 former Happiness Route participants. The importance of the three needs in explaining change was confirmed. Four types of continuity or change were distinguished: all-over improved, partly improved, specific-need improved and non-changers.

Analyses yielded four main findings. First, in many cases, need fulfillment was low at the start of the intervention. Second, the counselor played an important role for need fulfillment. Third, the activity participants chose seemed to be crucial for change to occur. Fourth, people benefitted most when all three needs were fulfilled in the end. It is concluded that in the experience of participants, the Happiness Route contributed to their well-being by fulfilling basic psychological needs. The intervention is best offered to people who have a low psychological need satisfaction. This chapter demonstrated the relevance to assess processes of PPIs from the perspective of participants.

\section{Relevance of the happiness-based approach for vulnerable groups}

As we have not found evidence that the happiness-based approach is more effective than the problem-based approach in this particular group, we could ask ourselves if there is any relevance for the happiness based-approach: Is it advisable to use it for vulnerable groups? To be able to give a sensible answer, we have to look at the whole picture and weigh the results of the different studies against each other.

First of all, as described in the second chapter, the Happiness Route approach fits the new Dutch policies concerning health and social care better than the problem-based approach. Mental health promotion is seen as a new goal for public health (Slade, 2010), with a shift towards the promotion of well-being rather than only treating or preventing illness (Power, 2010; Slade, 2010). The Happiness Route represents a possible way to realize the new policies the Dutch government has introduced in the health care system lately, that ask for a shift from 'illness and care' towards 'behavior and health' (RVZ, 2010). Its approach matches the social and political strive for 
empowerment, personal responsibility, and use of one's own strengths, especially for vulnerable groups and chronically ill patients (Anderson et al., 1995; Boumans, 2012).

We did find positive effects on well-being and depressive symptoms in line with earlier meta-analyses that showed that these can be improved by PPIs (Bolier et al., 2013b; Sin \& Lyubomirsky, 2009b). Although there was no statistically significant difference between groups, it is remarkable that we did find these effects in an extremely vulnerable group, also at follow-up. In the RCT, we found that the effects lasted up to nine months. In the interview studies, we found even longer lasting effects. Furthermore, participants reported higher satisfaction with the happinessbased approach compared to the problem-based approach.

Although there were no differences in gains in the mean scores of well-being, the Happiness Route seems to have resulted in less languishing than Customized Care after nine months. On an individual level however, more people who have followed the Happiness Route have improved from a languishing condition to a state of being moderately mentally health. This is an important finding in line with the changing health policies. The Social Support Act (WMO) aims to enable all Dutch citizens to participate in society (Schäfer et al., 2010) and is directed to increase self-control, personal power, self-reliance, and personal responsibility (Brink, 2013). These are concepts that are impaired in languishing people, who are characterized by feelings of emptiness, stagnation, disinterest and disengagement (Keyes et al., 2010a). Nudging them to a moderate level of well-being could lay the basis for heightening their empowerment. The observed rise in social well-being indicates that participants felt part of and functioned in society again. Their feeling of being able to contribute something to the world again and feeling integrated, as measured with the social well-being scale (Keyes, 1998), improved.

Participants belonged to the $4 \%$ of the population that is severely or extremely lonely (De Jong Gierveld \& Van Tilburg, 1999). As evaluation studies, reviews, and meta-analyses showed that it is hard to improve loneliness, it is a remarkable 
result that loneliness was improved. Fokkema and van Tilburg (2006) evaluated loneliness interventions in the Netherlands and found that only 2 of the 10 included interventions were able to reduce loneliness amongst elderly people. Findlay (2003) concluded in his review that there is little evidence that interventions can decrease loneliness, especially amongst lonely older adults. In a more recent systematic review on interventions targeting social isolation of older people (Dickens, Richards, Greaves \& Campbell, 2011), it was found that the most effective interventions were theorybased interventions promoting social activity or support, which were organized in a group format and where participants were actively involved. The Happiness Route included most of these identified standards, as it is based on self-determination theory, uses social activities and active involvement. This could explain why the Happiness Route was found to be effective, although it does not explain why the control group was effective as well.

Our meta-analysis provides evidence that psychological well-being can be enhanced during behavioral interventions (Weiss et al., 2016), just as subjective well-being (Bolier et al., 2013b; Sin \& Lyubomirsky, 2009b). However, in our RCT, it turned out that in the field, with all problems that occur in a real life setting with a vulnerable target group, it is not easy to realize such an improvement. The RCT did not show effects for psychological well-being, it was the only of the three subscales of the MHCSF where no effects over time were found. However, our interview study strongly indicated that participants did improve on aspects of psychological well-being such as autonomy and positive relations.

Results from the open questions in the post-test and follow-up measure in the RCT were similar to what we found in the interviews: When talking or writing about the Happiness Route, most participants were enthusiastic about the intervention and many described that they have changed for the better due to the intervention. Participants were apparently more positive in these written or oral accounts than in the questionnaires. We have found that the Happiness Route was effective for 17 out of the 20 participants that took part in the interview in fulfilling their basic needs. Eight participants described the intervention as a turning point in their lives 
towards the better. The positive evaluations suggest that the intervention is not only accepted but valued by participants, an important aspect for the success of every intervention. This could mean that the scales were less sensible to detect change than self-reports. Yet self-reports could be less reliable, especially when they are reported retrospectively. Real time diary studies would address that problem.

The positive approach could also be more acceptable for vulnerable people who would normally not take part in a problem-based intervention. This is especially true for certain types of lonely people that keep health care rather out of the door (Machielse, 2015). Many of the structurally isolated elderly show such care-avoidant behavior (Machielse, 2011), especially the most vulnerable of them (Machielse, 2006). By addressing positive aspects in life such as values, strengths and passion in an intervention, instead of focusing on their short-comings, the happiness-based intervention could be accepted more easily and received better, as it is perceived as less stigmatizing than other approaches (Bolier, 2015).

To conclude, the Happiness Route appears to be a viable alternative to a problembased approach as it fits changing policies well, and shows that it is possible to promote well-being with a happiness-based approach in a very vulnerable group although not to a higher extend than a problem-based approach. Furthermore, it was well-accepted and valued by participants who also described changes we could not assess with the standardized questionnaires used. Hence, it appears to be a viable alternative for problem-based care. However, we also need to take strengths and limitations into account.

\section{Strengths, limitations \& recommendations for future research}

Before making recommendations for social work and care practice, we should be aware of both strengths and limitations of our studies. Based on the limitations, underexposed areas and unanswered questions, we provide recommendations for future research regarding methods, intervention approaches, research in practicebased settings and the question 'What works for whom?'. As we already weighed the strengths and limitation of each of the studies in the respective chapters, here, we focus more broadly on the strengths and limitations of the thesis. 


\section{Methods}

A strength of the thesis is that we applied a range of different methodologies and complemented quantitative with qualitative methods, thereby gaining insight in not only if, but how an intervention works (Elliott, 2010). As RCTs use means, they cannot provide us with information on individuals. Our interview study revealed different results than our RCT in some areas, which allowed us to look at the results in a more differentiated way. Another strength was that we distinguished between emotional, social and psychological well-being. The differences we found between the three well-being scales showed that it is important to not only examine the total score, but to distinguish between the three components as well. This enables us to gain information on the areas that are successfully improved and the aspects that need to be tackled in the future. Another quality of this study was that the meta-analysis and RCT were strengthened by using official guidelines, the PRISMA checklist (Moher, Liberati, Tetzlaff, Altman, \& Group, 2010) and the CONSORT statement (Schulz, Altman, \& Moher, 2010) respectively.

There are some areas our research has not included. We have not conducted a thorough cost-effectiveness study, which would be an important next step to be able to know if and how much health care could gain from the new happinessbased approach. Neither have we done a formal implementation study. This would be worthwhile to do in the future, as implementing a multi-site project with a new approach holds interesting implications for implementation and would be especially interesting for the emerging field of PPIs in the health care sector, as this is rarely done at this point.

Due to practical limits of our study, we have not assessed the vision of project leaders, counselor, and intermediaries and did not compare the reported changes in the interviews with the changes in scores of the MHC-SF the participants filled out. This could refine the findings in future research. Although we extensively studied self-determination theory (Ryan et al., 2010) in the interview study, we did not measure need fulfillment in the RCT. It would be interesting to do so in the future to see if outcome measures match with how participants describe their change of 
needs. Another idea for research is to conduct a meta-analysis on social well-being. Now that we have meta-analyses on both subjective and psychological well-being, it would be interesting to examine if RCTs on interventions measuring social well-being as defined by Keyes (Keyes, 1998) are also effective, to complete the picture.

\section{The conditions}

The involvement of an active control condition was another strength of this study. The majority of PPI studies still uses non-active control groups (Bolier et al., 2013a; Weiss et al., 2016), thereby not taking possible non-specific factors into account. However, this also created challenges. For example, control counselors had to be trained for the study, which happened mostly together with the Happiness Route counselors. This might have led to some form of contamination. Another limitation of the control condition was that it let to social support and activities in some cases. Customized Care also may somewhat differ from the traditional problem-based care. Normally, care is more fragmentized with care professionals who work on a specific problem. During Customized Care, counselors looked more globally at the whole (care) situation. Adherence was much lower in the Happiness Route than in the control group. A possible explanation is that the Happiness Route asked for a more active participation, while the control group passively received help for their problems. To address some of the limitations, the Happiness Route should be also compared to a waiting-list / care-as-usual condition in the future.

\section{Practice-based research}

The trial was not conducted in an ideal, experimental setting, but pragmatically followed the daily practice of an existing project. Evaluating the intervention in its natural setting increased the external validity of the study. The generalizability of the study also benefited from the fact that the professionals worked in some well-known organizations, comparable to other services in the Netherlands.

We used the same recruitment strategy for the study that was used for the project before the study was introduced, but the fact that a research study was linked to the project made it much harder to find participants. The intermediaries who normally 
find candidates and apply for them found it hard to recruit vulnerable people for a study, given the fact that participants would have to fill out long questionnaires. Also, they struggled with the possibility that a candidate could be assigned to the control group. Therefore, some intermediaries chose to not apply for someone at all. Based on the high level of vulnerability of the target group, it is possible that intermediaries had the impression that the study was only for the most extreme cases, which in turn increased the threshold to apply for them for a study.

\section{What works for whom?}

It is very important to get more insight in what does and does not work for whom, to be able to use the intervention as effectively as possible and to improve the person-fit. The person-fit may be inherently strong in the Happiness Route, as the participants autonomously choose an intrinsically motivated activity. We have made a start to examine the influence of a good person-fit for the effectiveness of the Happiness Route in the interview study.

We consciously included a broad and heterogeneous group. Unfortunately, due to the small sample size, it was not sensible to conduct moderation analysis. In future research, analyzing subgroups and conducting moderator analysis could help us determine which people should receive the intervention and for whom it makes less sense to participate. In the future, we could also sharpen our inclusion criteria even more. For example, our interview study indicated that the project might work better for people with low levels of need fulfillment at baseline. Therefore, we should include measures of need satisfaction in the questionnaire as well.

We cannot be sure if the intervention would work the same in other cultures, as it was exclusively studied in the Netherlands. The findings may be therefore limited to vulnerable people from Western, or even only Dutch culture, as some positive psychology concepts may require adaptation to other cultures and outlooks (Bolier, 2015). This point can also be seen as strength, as most PPIs have been conducted in North America. Replications are needed in other countries and cultures. The authors of the most recent meta-analysis on PPIs therefore called for studies in other 
countries and cultures (Bolier et al., 2013b). The same goes for the Happiness Route: it should be studied in other (non-Western) cultures as well.

\section{Theoretical implications: mechanisms of change}

After analyzing strengths and weaknesses, we want to discuss possible mechanisms that could explain why the interventions work.

The Happiness Route may have worked through initiating a positive spiral. In the interview study, we saw that when participants found an intrinsically motivated activity, they experienced positive emotions while participating in it and as an effect afterwards. The joy was partly caused because they autonomously chose and did something they felt competent in and (re)connected with others. Positive emotions may have worked as catalyzer for the more psychological aspects of well-being, which in turn led to positive emotions again and so on, leading to an upward spiral. A nudge (Thaler \& Sunstein) may be enough to initiate this upward spiral. Other researchers have showed that there are similar upward spirals processes towards happiness for other concepts and in others contexts (Fredrickson \& Joiner, 2002; Garland, Gaylord, \& Fredrickson, 2011; Kok et al., 2013; Sheldon \& Houser-Marko, 2001).

SDT offered insights in the working mechanisms, as described in the interview study. An important theoretical implication is that we demonstrated the relevance of applying SDT as framework to study change in PPIs. Other PPI studies could examine the typology we found for other groups and in other contexts.

Situation-selection might be another working mechanism of the intervention. Catalino, Algoe and Fredrickson (2014) showed that situation-selection (Gross, 2001; Gross \& Thompson, 2007) is likely to play a role in effectively pursuing happiness. They describe that the way people make choices and structure their time have farreaching implications for the situations they come across. An elaborate situationselection could lead to an improved probability to experience positive emotions. This indicates that engaging in pleasant activities is a possible way to increase happiness. Stimulating the best possible situation-selection is a key element of the Happiness 
Route, as someone is encouraged to choose what he really enjoys doing, while before the intervention, participants engaged in few or no pleasant activities at all.

A study by Sheldon and Lyubomirsky (2006) offers a possible explanation for the differences in working mechanisms between the two conditions. They compared students who had recently experienced a positive change in either life circumstances or their activities at two time points during a semester. Changes in circumstances were associated with well-being at the second assessment, but not at the third assessment. The authors proposed that this was because hedonic adaptation occurs more rapidly for positive circumstantial change than for activity change (Lyubomirsky, Sheldon, et al., 2005), so that people no longer benefited from the changes. This was different for those who had recently experienced a positive activity change, which predicted maintenance of these gains in well-being at the third assessment. This was explained with the steady stream of positive experiences that is induced by activity change, but not by circumstantial change. It also fits to Waterman's comparison of the hedonic treadmill versus the eudaimonic staircase (Waterman, 2007).

This could also apply for the RCT. Customized Care often resulted in circumstantial life change, such as getting more domestic help, while the Happiness Route resulted in activity change. People could have been very glad with a new started domestic help in the control group. This positive effect could wear off after a while, as people get used to it, an effect known as hedonic treadmill (Brickman \& Campbell, 1971). For the Happiness Route, an activity that is intrinsically motivated could have longer lasting effects, especially when it leads to a larger social network, an ongoing development of competencies, enjoyment, and positive experiences. When assessing the effects on well-being in an early stage, the model of longitudinal well-being would predict that we would find change in well-being in both groups, with no differences between conditions, as it was the case. When measuring again at a later stage, the effects are more likely to still be found for activity change (i.e. in the Happiness Route), but not for positive circumstantial change (i.e. in the control group), as changes in circumstances decay more quickly than the effects of positive activity changes, according to the model. Therefore, it would be very interesting to measure effects 
on well-being at a later point in time, also putting the model of longitudinal wellbeing (Lyubomirsky, Sheldon, et al., 2005) to a further test. However, it is not clear yet when the described differences should emerge exactly in which circumstances.

It is also not fully clear which approach works best for whom. For some, the problembased approach may be enough to get them back on track and may be all they need. For others, addressing problems is not enough and the happiness-based approach may work better. Our qualitative study indicated that need satisfaction might play a role in this. It is likely that people who have a low need satisfaction would profit more from an approach that is directed to need fulfillment, such as the Happiness Route. As a problem-based approach does not help need satisfaction directly, they would profit less from this approach. People who have high levels of autonomy, competence and relatedness may not need a happiness-based approach and are more likely to profit from an approach that is directed to a specific problem they have, such as needing more help in their household. Including measures of need fulfillment in the questionnaire would help getting insight into this topic. Also, interviews with participants of Customized Care could shed more light on this.

We can conclude that we made a start with unraveling the ways in which PPIs work, especially concerning the role of need satisfaction. Yet, future studies should explore additional ways in which PPIs might work, for example by using a longer follow-up period and examining for which kind of people the problem-based approach might be enough, and which groups would profit more from the happiness-based approach.

\section{Considerations for implementation}

Although no implementation research has been conducted so far, we can make some recommendations for further implementation, which are worth examining, based on our experience during the implementation process and work so far.

The Happiness Route has been successfully implemented in several municipalities in the Netherlands. Most cities will carry on with the project in some form. The process is ongoing. For example, shortly after the study inclusion has ended, a new 
municipality in Friesland has successfully implemented the intervention. During the implementation phase, we went through a learning process, with the following practical advice as learning points:

\section{Be open to new possibilities for implementation}

In the beginning, we expected that the newly implemented interventions would be running via the local municipalities, as it has been the case in almost all earlier projects. Yet, we found that many other options are possible. We included two cities in our empirical studies, where the Happiness Route was implemented earlier: Hengelo and Almelo. Hengelo was the only of the seven cities, where the project was led by the local municipality via the Social Service Office. Almelo, where the project was invented and initiated in the municipality, made the conscious choice to transmit the project from the local government to society. It is now successfully led by a foundation that supports leisure time activities for disabled people. The majority of the new cities implemented the project via professional project leaders in a mental health care or welfare organization. In two cities the project was initiated by volunteers, who implemented the project via the Rotary Service Club and a welfare organization. It is interesting to see that there are many options on how to implement such a project successfully. Most importantly, the implementation should fit the circumstances and local context of a city.

\section{Never underestimate the recruitment process and be patient}

Recruitment was the hardest part of the project. We learned that when a project is newly implemented, it takes time until it really 'lands' in a local community and gets well-known by the intermediaries. Intermediaries who have been informed can forget about the project in their daily work. It takes a while until intermediaries quickly identify the right candidates and until it is recognized as an option during their work routine. Therefore, it can take several months until the project delivers the first participants. Project leaders should prepare the counselors for this and take the slow starting period into account during the planning. In addition, it is not easy to find structurally social isolated people, as they have become 'invisible' to society. They need an outreaching approach, where they are actively searched for and approached (Machielse, 2011), which is already done quite well. 
Most project leaders expected the recruitment process to go smoothly beforehand and were surprised by the slow process. Although many actions were taken to reverse this process, none of the seven locations could deliver the amount of participants that was agreed on beforehand. A website with information was launched, thank-you cards with little gifts were sent to intermediaries who had applied for participants, many presentations were given at intermediary locations, media attention was used, newsletters were sent regularly to all involved stakeholders and intermediaries were called on a regular basis. Without these actions, the final number of participants probably would have been even smaller. As mentioned before, we expect that the recruitment will be easier without a study with a control condition linked to it.

\section{Involve the intermediaries}

Intermediaries need constant reminders of the existence of the project. It can help to keep them updated on how the participants developed during the project. Sending regular newsletters has been a helpful strategy in our experience. As we did not want to put a claim on the precious time of the intermediaries, we kept the contact to a minimum. Earlier projects have handled this differently by organizing regular meetings with all stakeholders, including the intermediaries. This strengthened the feeling of working on a common goal as a team (Barry \& Jenkins, 2007). In hindsight, we would advise to use a similar approach with regular contact with intermediaries while implementing the intervention. Involving all stakeholders actively in the implementation process as early as possible could strengthen commitment. For example, the implementation could be planned together with a couple of key figures in the health care system or focus groups could address the needs of stakeholders.

\section{The success of the project depends on the project leader}

Being committed and enthusiastic, but even more important having enough time and endurance, are essential features for project leaders and the success of the implementation. It is beneficial if the project leader already has a good network in social work and care. Yet it can also be successful without an existing network, if the project leader is willing and has the time to build this up. In the starting phase, a lot of time and effort has to be put in finding enough intermediary organizations and 
set up information meetings. We learned that informing professionals once in the beginning is not enough. People can forget things, misunderstand the method and new employees have to be informed. Therefore, it is vital that the project leader invests time to keep up the contact, constantly reminding organizations about the project. We experienced that the majority of intermediary organizations agreed to participate. Professionals often already had certain candidates in mind during the first presentation of the Happiness Route, but most never applied for anyone afterwards. It possibly could help to make agreements on how many participants an organization commits to deliver. Monthly contact with a contact person, e.g. a team leader, on the progress of recruitment could be a useful strategy to improve commitment.

\section{Allow the project to take on other forms if that makes it more viable}

After the study has ended, some cities decided to go on with the Happiness Route. Some wanted to keep the form of the intervention as it was, others decided to offer the project in a modified version. If that makes the project more viable in a city, we support this flexible approach. One successful example in the municipality of Hengelo is to use the Happiness Route as an option that social workers at the Social Services Office can offer to their clients. Instead of starting with more 'heavy' options, such as offering more health care, they can sign them up for the Happiness Route. In case that does not work, they can move towards other options. This is in line with the stepped-care approach, the practice of starting with the least intrusive and expensive intervention possible, and only move on to more intrusive and expensive interventions if the goal has not been reached (Davison, 2000), possibly resulting in less costs.

Another city has modified the Happiness Route as option that professionals in welfare organizations can use when they think it is appropriate. They can also use certain elements of the Happiness Route as methods in their daily work. In our experience, starting the project can works like an oil patch. People who work with the Happiness Route also start to use the approach in their daily work and 'infect' colleagues with the positive approach, so that it finally spreads to other care professionals, organizations and communities. As our final goal includes that more health care 
organizations will support the development of well-being, we believe that this is a very positive development.

\section{Implications for social work and care practice}

Based on the findings of the studies we conducted and our gained experience during the process of training, implementation and conduction of the project, we would like to offer some possible recommendations for professionals in social work and care.

\section{On top of treating problems, professionals should pay attention to well-being for vulnerable groups}

Although good care for physical, mental and other problems is vital, it would be in the advantage of vulnerable clients if health care professionals would also pay attention to their personal well-being. In line with the new policies in health care, they should make use of the potential, strengths, and social network of the individual client. However, in everyday practice, it is not always clear how to realize this. The Happiness Route could be a good option to realize this. The positive character of a happiness-based approach could be a viable alternative, especially for people who would not consider taking part in an intervention that targets their problems, like care avoiders (Koekkoek, van Meijel, \& Hutschemaekers, 2006). Being able to offer a more attractive, acceptable and less stigmatizing approach could reach groups that are normally hard to reach (Bolier, 2015), bridging the treatment gap (Kohn et al., 2004). When trying to help achieve long-lasting changes in people's lives, professionals can be more successful when they support their clients in changing their actions rather than their circumstances (Sheldon \& Lyubomirsky, 2006).

\section{Support the need for autonomy, competence and relatedness}

The fulfillment of the three basic psychological needs is a precondition for good levels of well-being. Not only PPIs, but also health and social care in general and interventions in these setting could make use of the self-determination theory. It can help during the beginning of an intervention to answer the question: 'Who needs which intervention?' It can also be helpful at the goal setting stage at the beginning of an intervention to find an answer to the question: 'Which support is 
needed for an individual?' Finally, it is useful to evaluate progress in achieving goals in need satisfaction and, if needed, adjust the intervention accordingly or stop with the intervention when the goals have been reached. Based on the findings of this thesis, we believe that social work and care can profit from incorporating autonomy, competence and relatedness support (Pelletier, Fortier, Vallerand, \& Briere, 2001; Sheldon \& Filak, 2008; Visser, 2010). This also fits in well with the concepts that are central in current social work: self-management, focusing on what a person can do and mobilizing the existing social network.

\section{Dare to change and rethink}

Many care professionals act from an inner urge to help and protect and have been educated in the problem-based tradition. They have often worked in a problembased manner for years. While we want to emphasize that work experience is important and the competences of the counselors are vital and should be used, counselors may need to incorporate a new vision when working in a happiness-based style. While using the Happiness Route or other positive approaches, it is important to let go off some automatic reactions patterns. That is not an easy process and can feel uncomfortable at first. During training, this should be explicitly discussed and practiced. Most importantly, counselors have to learn how to optimally offer autonomy support to clients (Visser, 2010). Instead of directly coming up with solutions or ideas, the focus is on how to empower the participants to think for themselves. The participant needs to get enough room for developing own ideas and being able to apply talents and competences. That also means that professionals have to take a step back. Autonomy support has to be trained again and again. It is vital that counselors at least recognize their urge to help and notice when they steer in a certain direction during the counseling process, in order to be able to step back again. It requires a different approach with confidence in the abilities of the client. This is also in line with methods like motivational interviewing (Rollnick, Miller, Butler, \& Aloia, 2009) and solution-focused support (Lohuis, van Vuuren, Sools, \& Bohlmeijer, 2016). 


\section{Do not assume that 'one size fits all'}

Our interview study clearly showed that individuals change in different ways. This indicates that one size does not fit all. The success of an activity is partly defined by the fit between the person and the activity. Certain kinds of activities work better for certain types of people (Lyubomirsky \& Layous, 2013). It is inherent to the Happiness Route to provide the best possible person-activity fit by searching for the passion of an individual. Although it is not possible and desirable to do this in every care situation and for every client, it is important that care professionals regularly check if an intervention fits a person. Intrinsic motivation (Ryan \& Deci, 2000b) could be a helpful indicator for the quality of the person-activity fit.

\section{Concluding thoughts}

In this thesis, we described a meta-analysis, a design protocol of an RCT and its effects, as well as an interview study to evaluate the efficacy and mechanisms of a PPI for a vulnerable group, the Happiness Route.

The studies provided us with new insights in the possibilities for the promotion of wellbeing for vulnerable groups. The positive psychology intervention Happiness Route is in line with the reorientation in health care in the last years. We have found that it is possible to increase psychological well-being in our meta-analysis. Although just as effective as the traditional problem-based approach, satisfaction with the treatment was significantly higher in the Happiness Route, concerning the relationship with the counselor, the judgment of home visits, and the experienced effects. The experience of participants, as expressed in the interviews, showed that the Happiness Route can initiate change and that people can profit from the intervention.

This was a first study on a vulnerable target group, which provided us with new insights that have to be evaluated more deeply prospectively. Based on the results, weighing strengths and limitations, we conclude that the happiness-based approach is worth to be used as a complement to the traditional focus on problems and illness. It can bring more balance into the care for vulnerable groups. They need happiness as much, and maybe even more, as everyone else. 


\section{References}

Anderson, R. M., Funnell, M. M., Butler, P. M., Arnold, M. S., Fitzgerald, J. T., \& Feste, C. C. (1995). Patient empowerment: results of a randomized controlled trial. Diabetes Care, 18(7), 943-949.

Barry, M. M., \& Jenkins, R. (2007). Implementing mental health promotion: Elsevier Health Sciences.

Bolier, J. (2015). Positive psychology online: using the internet to promote flourishing on a large scale. (Doctoral thesis). University of Twente, Enschede, the Netherlands.

Bolier, J., Haverman, M., Westerhof, G. J., Riper, H., Smit, F., \& Bohlmeijer, E. (2013a). Positive psychology interventions: a meta-analysis of randomized controlled studies. BMC Public Health, 13(1), 119.

Bolier, J., Haverman, M., Westerhof, G. J., Riper, H., Smit, F., \& Bohlmeijer, E. (2013b). Positive psychology interventions: a meta-analysis of randomized controlled studies. BMC Public Health, 13(1), 1.

Boumans, J. (2012). Tussen regie en repressie. Tijdschrift voor rehabilitatie, 1(2841.6), 218225.

Brickman, P., \& Campbell, D. (1971). Hedonic relativism and planning the good science. In. MH Appley (Ed.), Adaptation level theory: A symposium (pp. 287-302): New York: Academic Press.

Brink, C. (2013). Zelfregie, eigenkracht, zelfredzaamheid en eigen verantwoordelijkheid. De begrippen ontward: Utrecht: Movisie.

Catalino, L. I., Algoe, S. B., \& Fredrickson, B. L. (2014). Prioritizing positivity: An effective approach to pursuing happiness? Emotion, 14(6), 1155.

Davison, G. C. (2000). Stepped care: doing more with less? Journal of Consulting and Clinical Psychology, 68(4), 580.

De Jong Gierveld, J., \& Van Tilburg, T. (1999). Manual of the Loneliness Scale 1999. Department of Social Research Methodology, Vrije Universiteit Amsterdam, Amsterdam.

Deci, E. L., \& Ryan, R. M. (2000). The" what" and" why" of goal pursuits: Human needs and the self-determination of behavior. Psychological Inquiry, 11(4), 227-268.

Elliott, R. (2010). Psychotherapy change process research: Realizing the promise. Psychotherapy Research, 20(2), 123-135.

Fokkema, T., \& van Tilburg, T. (2006). Aanpak van eenzaamheid: helpt het. Een vergelijkend effect-en procesevaluatie onderzoek naar interventies ter voorkoming en vermindering van eenzaamheid onder ouderen. Den Haag: NIDI.

Francissen, A., Wezenberg, E., \& Westerhof, G. (2010). De gevolgen van geluk. Achtergronden en toekomst van het geluksbudget. Borne: Arcon.

Fredrickson, B. L., \& Joiner, T. (2002). Positive emotions trigger upward spirals toward emotional well-being. Psychological Science, 13(2), 172-175.

Garland, E. L., Gaylord, S. A., \& Fredrickson, B. L. (2011). Positive reappraisal mediates the stress-reductive effects of mindfulness: An upward spiral process. Mindfulness, 2(1), 59-67.

Golden, J., Conroy, R. M., Bruce, I., Denihan, A., Greene, E., Kirby, M., \& Lawlor, B. A. (2009). Loneliness, social support networks, mood and wellbeing in community-dwelling elderly. International Journal of Geriatric Psychiatry, 24(7), 694-700.

Gross, J. J. (2001). Emotion regulation in adulthood: Timing is everything. Current Directions in Psychological Science, 10(6), 214-219.

Gross, J. J., \& Thompson, R. A. (2007). Emotion regulation: Conceptual foundations. In J. J. Gross, \& R. A. Thompson (Eds.), Handbook of emotion regulation.(pp. 3-24). New York, NY, US: Guilford Press, 654 pp. 
Kaplan, G. A., Shema, S. J., \& Leite, C. M. A. (2008). Socioeconomic determinants of psychological well-being: the role of income, income change, and income sources during the course of 29 years. Annals of epidemiology, 18(7), 531-537.

Kedzia, S. (2009). What makes you happy? Evaluating an intervention aimed at promoting social participation of lonely people: identifying concepts that can serve as building blocks of self-chosen activities and developing and testing a questionnaire to measure the success of these activities. (Unpublished master thesis). University of Twente, Enschede, the Netherlands.

Keyes, C. L. (1998). Social well-being. Social Psychology Quarterly, 121-140.

Keyes, C. L., Dhingra, S. S., \& Simoes, E. J. (2010). Change in level of positive mental health as a predictor of future risk of mental illness. American Journal of Public Health, 100(12), 2366-2371.

Keyes, C. L., Wissing, M., Potgieter, J. P., Temane, M., Kruger, A., \& van Rooy, S. (2008). Evaluation of the mental health continuum-short form (MHC-SF) in Setswana-speaking South Africans. Clinical Psychology and Psychotherapy, 15(3), 181.

Koekkoek, B., van Meijel, B., \& Hutschemaekers, G. (2006). " Difficult patients" in mental health care: a review. Psychiatric Services, 57(6), 795-802.

Kohn, R., Saxena, S., Levav, I., \& Saraceno, B. (2004). The treatment gap in mental health care. Bulletin of the World Health Organization, 82(11), 858-866.

Kok, B. E., Coffey, K. A., Cohn, M. A., Catalino, L. I., Vacharkulksemsuk, T., Algoe, S. B., . . Fredrickson, B. L. (2013). How positive emotions build physical health perceived positive social connections account for the upward spiral between positive emotions and vagal tone. Psychological Science, 24(7), 1123-1132.

Lohuis, A. M., van Vuuren, M., Sools, A., \& Bohlmeijer, E. (2016). Ambiguities of 'doing what works': how professionals make sense of applying solution-focused support for people with intellectual disabilities. International Journal of Developmental Disabilities, 1-14.

Lyubomirsky, S., \& Layous, K. (2013). How do simple positive activities increase well-being? Current Directions in Psychological Science, 22(1), 57-62.

Lyubomirsky, S., Sheldon, K. M., \& Schkade, D. (2005). Pursuing happiness: The architecture of sustainable change. Review of general psychology, 9(2), 111.

Machielse, A. (2006). Onkundig en onaangepast: een theoretisch perspectief op sociaal isolement: Van Arkel.

Machielse, A. (2011). Sociaal isolement bij ouderen: een typologie als richtlijn voor effectieve interventies. Journal of Social Intervention: Theory and Practice, 20(4), 40-61.

Machielse, A. (2015). The heterogeneity of socially isolated older adults: A social isolation typology. Journal of Gerontological Social Work, 58(4), 338-356.

Moher, D., Liberati, A., Tetzlaff, J., Altman, D. G., \& Group, P. (2010). Preferred reporting items for systematic reviews and meta-analyses: the PRISMA statement. International Journal of Surgery, 8(5), 336-341.

Pelletier, L. G., Fortier, M. S., Vallerand, R. J., \& Briere, N. M. (2001). Associations among perceived autonomy support, forms of self-regulation, and persistence: A prospective study. Motivation and Emotion, 25(4), 279-306.

Pinquart, M., \& Sörensen, S. (2000). Influences of socioeconomic status, social network, and competence on subjective well-being in later life: a meta-analysis. Psychology and Aging, 15(2), 187.

Power, A. K. (2010). Transforming the nation's health: Next steps in mental health promotion. American Journal of Public Health, 100(12), 2343-2346.

Rollnick, S., Miller, W. R., Butler, C. C., \& Aloia, M. S. (2009). Motivational interviewing in health care: helping patients change behavior: Taylor \& Francis.

RVZ. (2010). Zorg voor je Gezondheid! Gedrag en gezondheid: De nieuwe ordening. Den Haag: RVZ. 
Ryan, R. M., \& Deci, E. L. (2000). Self-determination theory and the facilitation of intrinsic motivation, social development, and well-being. American Psychologist, 55(1), 68.

Ryan, R. M., Lynch, M. F., Vansteenkiste, M., \& Deci, E. L. (2010). Motivation and autonomy in counseling, psychotherapy, and behavior change: A look at theory and practice. The Counseling Psychologist.

Ryff, C. D. (2013). Psychological well-being revisited: Advances in the science and practice of eudaimonia. Psychotherapy and Psychosomatics, 83(1), 10-28.

Ryff, C. D., \& Singer, B. (1996). Psychological well-being: Meaning, measurement, and implications for psychotherapy research. Psychotherapy and Psychosomatics, 65(1), 14-23.

Schäfer, W., Kroneman, M., Boerma, W., Berg, M., Westert, G., Devillé, W., \& Ginneken, E. v. (2010). The Netherlands: health system review. Health Systems in Transition, 12(1), xxvii, 1-228.

Schulz, K. F., Altman, D. G., \& Moher, D. (2010). CONSORT 2010 statement: updated guidelines for reporting parallel group randomised trials. BMC Medicine, 8(1), 1.

Sheldon, K. M., \& Filak, V. (2008). Manipulating autonomy, competence, and relatedness support in a game-learning context: New evidence that all three needs matter. British Journal of Social Psychology, 47(2), 267-283.

Sheldon, K. M., \& Houser-Marko, L. (2001). Self-concordance, goal attainment, and the pursuit of happiness: Can there be an upward spiral? Journal of Personality and Social Psychology, 80(1), 152.

Sheldon, K. M., \& Lyubomirsky, S. (2006). Achieving sustainable gains in happiness: Change your actions, not your circumstances. Journal of Happiness Studies, 7(1), 55-86.

Sin, N. L., \& Lyubomirsky, S. (2009). Enhancing well-being and alleviating depressive symptoms with positive psychology interventions: A practice-friendly meta-analysis. Journal of Clinical Psychology, 65(5), 467-487.

Slade, M. (2010). Mental illness and well-being: the central importance of positive psychology and recovery approaches. BMC Health Services Research, 10(1), 1.

Thaler, R. H., \& Sunstein, C. R. Nudge: Improving Decisions About Health, Wealth, and Happiness: HeinOnline.

Van der Plaats, J. (2002). Eindrapportage Zorg in Beeld Verlicht. Almelo: Gemeente Almelo.

Van der Plaats, J. (2007). Eindrapportage Onderzoek PGB Welzijn. Almelo: Gemeente Almelo.

Visser, C. (2010). Self-determination theory meets solution-focused change: Autonomy, competence and relatedness support in action. InterAction-The Journal of Solution Focus in Organisations, 2(1), 7-26.

Waterman, A. S. (2007). On the importance of distinguishing hedonia and eudaimonia when contemplating the hedonic treadmill. American Psychologist, 62(6), 612-613.

Weiss, L. A., Kedzia, S., Francissen, A., \& Westerhof, G. J. (2015). Improving the health care sector with a happiness-based approach Well-Being in Contemporary Society (pp. 5971): Springer.

Weiss, L. A., Westerhof, G. J., \& Bohlmeijer, E. T. (2013). Nudging socially isolated people towards well-being with the 'Happiness Route': design of a randomized controlled trial for the evaluation of a happiness-based intervention. Health and Quality of Life Outcomes, 11(1), 1-11.

Weiss, L. A., Westerhof, G. J., \& Bohlmeijer, E. T. (2016). Can We Increase Psychological WellBeing? The Effects of Interventions on Psychological Well-Being: A Meta-Analysis of Randomized Controlled Trials. PLOS ONE, 11(6), doi:10.1371/journal.pone.0158092. 
General Discussion 



\section{Samenvatting}

Summary in Dutch 
Samenvatting 


\section{Samenvatting}

\section{Richting: Geluk \\ Welbevinden van kwetsbare groepen verbeteren}

In de algemene inleiding, hoofdstuk 1, stellen we dat gelukkig zijn een doel voor de meeste mensen is, voor henzelf, hun kinderen en naasten. We beschrijven dat de definitie van geluk of welbevinden altijd een punt van discussie tussen de hedonistische en eudaimonische stroming is geweest. De discussie die de Oude Grieken al voerden werd voorgezet binnen de positieve psychologie en had invloed op hoe welbevinden gemeten wordt. Nieuwere stromingen herenigen de twee definities en zien welbevinden als een combinatie van emotioneel (hedonistisch) welbevinden en sociaal en psychologisch welbevinden (eudaimonisch). Wij zien dit als de meest omvattende visie op welbevinden en definiëren en meten welbevinden op deze manier in dit proefschrift.

Positieve psychologie is de wetenschap over positief functioneren en geluk. Hoewel veel effectieve positief psychologische interventies (PPIs) zijn ontwikkeld voor de algemene populatie, is er nog beperkt onderzoek gedaan naar groepen met een laag welbevinden. De bestaande studies richten zich op specifieke aandoeningen of problemen. Wij kijken daarom naar een bredere doelgroep met meerdere risicofactoren voor een laag welbevinden: een lage sociaal-economische status (SES), chronische gezondheidsklachten (fysiek en/of psychisch) en eenzaamheid. Wij stellen een nieuwe PPI voor, die zich op deze doelgroep richt: de Geluksroute. Deze is gebaseerd op de zelfdeterminatie theorie van Deci and Ryan en speelt in op het vervullen van de basisbehoeftes autonomie, competentie en verbondenheid. Consulenten helpen de deelnemers om een intrinsiek gemotiveerde activiteit te vinden en deelnemers mogen $€ 500$ gebruiken om deze activiteit ook te kunnen uitvoeren. In de introductie stellen wij vijf vragen, die in de daaropvolgende hoofdstukken worden beantwoord. 
Waarom zouden we een geluks-gerichte aanpak in de gezondheidszorg en de sociale sector gebruiken?

In hoofdstuk 2 introduceren we een positieve benadering die zich richt op het welbevinden van mensen. Een holistische benadering binnen de gezondheidszorg, die streeft naar het verbeteren van het welzijn, aanvullend op de behandeling van problemen en ziekten, biedt individuele en maatschappelijke voordelen. Het traditionele probleemgerichte systeem is niet altijd in staat om chronisch zieken optimaal te helpen en voldoet niet aan de nieuwe uitdagingen van recente maatschappelijke en economische ontwikkelingen, die bijvoorbeeld naar zelfmanagement en participatie vragen. We hebben daarom alternatieven nodig voor chronisch zieke mensen om een aangenaam, betrokken en zinvol leven te kunnen leiden. Hoewel theorieën en experimentele studies manieren aanreiken om dit te realiseren, zijn deze inzichten zelden vertaald naar de praktijk, met de Geluksroute als één van de weinige uitzonderingen in het veld. Onze conclusie is dat ontwikkeling van geluksgerichte interventies en de praktische toepassing van methoden ter bevordering van het welzijn in de gezondheidszorg en sociale sector belangrijk zijn. De Geluksroute is daar een voorbeeld van en is in lijn met het veranderende gezondheidsbeleid.

\section{Kan psychologisch welbevinden worden verbeterd door gedragsinterventies?}

In hoofdstuk 3 tonen wij in een meta-analyse aan dat psychologisch welbevinden (PWB) verbeterd kan worden met de huidige gedragsinterventies. Eerdere metaanalyses hebben laten zien dat PPIs emotioneel welzijn kunnen verbeteren. Om een beter inzicht in de effectiviteit van interventies van niet alleen de hedonistische, maar ook eudaimonische vormen van welzijn te verkrijgen is het belangrijk om ook de effecten op psychologisch welbevinden te onderzoeken. Er is een snel groeiende interesse in PWB als uitkomstmaat van interventie studies en talrijke interventies zijn ontwikkeld met als doel psychologisch welbevinden te verhogen. De effecten op PWB, gemeten als coherente uitkomstmaat, zijn echter nog niet eerder in kaart gebracht tussen verschillende studies. Daarom beschrijven we een meta-analyse, waarin we de effecten van gedragsinterventies op psychologisch welbevinden onderzoeken. In onze meta-analyse vonden wij 27 randomized controlled trials (RCTs) over de 
effecten van gedragsinterventies, die aan de inclusiecriteria voldeden. We vonden een middelgroot effect met een effect grootte van 0.44 . Bij de follow-up vonden wij een kleine, maar nog steeds significante effect grootte van 0.22. Er was geen duidelijke indicatie voor een publicatie bias. Een beperking van de studie was de hoge mate aan heterogeniteit. Interventies in klinische groepen en individuele face-toface interventies bleken het meest effectief. De effecten waren groter bij studies van mindere kwaliteit en er is dus behoefte aan meer kwalitatief hoogwaardige studies. De resultaten zijn veelbelovend voor de verdere ontwikkeling en implementatie van interventies om PWB te promoten.

\section{Hoe effectief is een positief psychologische interventie voor kwetsbare mensen?}

In hoofdstuk 4 en 5 beschrijven we een evaluatieonderzoek naar een nieuwe PPI, de Geluksroute. De doelgroep zijn mensen met een opeenstapeling van psychosociale en gezondheidsproblemen, een groep die nauwelijks in huidig onderzoek binnen positieve psychologie is vertegenwoordigd. Daarom kan onze studie waardevolle informatie leveren over hoe PPIs werken voor kwetsbare groepen met meerdere risicofactoren voor een laag welzijn.

De door ons uitgevoerde RCT hoort bij de eerste multi-site PPI studies, uitgevoerd in zeven gemeenten in heel Nederland. De praktijkgerichte, naturalistische setting levert nieuwe kennis op hoe een PPI in de praktijk werkt.

In hoofdstuk 4 beschrijven we het onderzoeksdesign van onze studie in detail. Eenzame mensen met gezondheidsklachten en een lage SES worden random ingedeeld in de experimentele groep (de Geluksroute) of de controle groep (Zorg op Maat). Daarmee kan de effectiviteit tussen de geluksgerichte aanpak en de probleemgerichte aanpak worden vergeleken. Er wordt onderzocht of de Geluksroute effectief is in termen van een verbeterd welzijn, vergeleken met een actieve controlegroep, wiens deelnemers ook gesprekken met een consulent voeren. Verder wordt onderzocht of veerkracht, doelen in het leven, de kwaliteit van leven en sociale participatie verbeteren en wordt gekeken of er dalingen in eenzaamheid, depressie en zorggebruik worden gevonden. 
In hoofdstuk 5 beschrijven we de effecten van de uitkomsten van de RCT. Via randomisatie werden 50 deelnemers in de controlegroep en 58 in de experimentele groep ingedeeld. Alle 108 deelnemers werden met intention-to treat geanalyseerd. Bij aanvang waren de deelnemers extreem eenzaam en hadden gemiddeld drie gezondheidsproblemen. Minder dan 5\% had betaald werk, bijna $60 \%$ had een lage opleiding, en bijna $70 \%$ had een extreem laag inkomen.

Er werd geen significant interactie-effect tussen tijd en conditie gevonden. De totale score van de MHC-SF, de subschalen emotioneel en sociaal welzijn, depressie en eenzaamheid zijn in beide condities in de periode van 9 maanden significant verbeterd $(p<0,05)$. Er werd geen significante verbetering over tijd in psychologisch welbevinden, veerkracht, doelen in het leven, gezondheidsgerelateerde kwaliteit van leven en maatschappelijke participatie gevonden. Het percentage mensen in de laagste categorie van welbevinden, de 'languishers', is significant gedaald van $33 \%$ bij aanvang tot $16 \%$ bij de follow-up in de Geluksroute, terwijl het aandeel languishers niet significant is veranderd in de Zorg op Maat conditie. De tevredenheid over de interventie was bij de Geluksroute deelnemers significant hoger dan bij de controlegroep. Ook hadden de deelnemers, die de Geluksroute hadden gevolgd, meer het gevoel dat de interventie effect had gehad dan deelnemers aan Zorg op Maat.

Het bleek moeilijk om deze kwetsbare groep op te sporen, wat tot minder deelnemers leidde dan oorspronkelijk gepland. De Geluksroute bleek even effectief als de probleemgerichte aanpak, met echter een grotere daling van languishers en een grotere tevredenheid. De Geluksroute lijkt daarom een adequate alternatieve interventie voor kwetsbare mensen.

\section{Hoe ervaren deelnemers een positief psychologische interventie?}

Verbetering van de kennis over veranderingsprocessen is een belangrijke stap in de verbetering van de effectiviteit van interventies. Tot nu toe werd er in evaluatiestudies van PPIs weinig aandacht besteed aan het perspectief van de deelnemers. Dit is van belang om een dieper inzicht in de kwaliteit van een interventie te verkrijgen. In hoofdstuk 6 beschrijven we hoe deelnemers de interventie ervoeren. We konden 
het onderliggende theoretisch kader van zelfdeterminatietheorie testen door te onderzoeken hoe de deelnemers veranderen met betrekking tot de vervulling van hun behoefte aan autonomie, competentie en verbondenheid tijdens de Geluksroute. Verder onderzochten we of de deelnemers op een vergelijkbare manier ontwikkelen of hun eigen unieke ontwikkeling doormaken. We namen een kijkje in de blackbox van PPIs om beter te begrijpen waarom PPIs voor sommigen werken, terwijl anderen er nauwelijks baat bij lijken te hebben.

De drie behoeften werden duidelijk in de verhalen van deelnemers terug gevonden, alsmede intrinsieke en extrinsieke motivatie, activering, positieve emoties en zelfontplooiing. Analyses van de verhalen leverden vier belangrijk bevindingen op. Ten eerste was de behoeftevervulling bij de meeste deelnemers laag aan het begin van de interventie. Ten tweede speelde de consulent een belangrijke rol voor de behoeftevervulling. Ten derde bleek de door de deelnemer gekozen activiteit van cruciaal belang voor het wel dan niet optreden van veranderingen. Ten vierde profiteerden deelnemers het meest wanneer alle drie de behoeften aan het einde van de interventie waren vervuld. Daarnaast vond we vier verschillende verandertypes: de algeheel verbeterden $(n=8)$, de gedeeltelijk verbeterden $(n=6)$, de specifieke behoefte verbeterden $(n=3)$ en niet-verbeterden $(n=3)$. Concluderend kunnen we zeggen dat PPIs een bijdrage kunnen leveren aan het welzijn van kwetsbare mensen door omstandigheden te bieden die het vervullen van psychologische basisbehoeften mogelijk maken. De Geluksroute kan het beste worden aangeboden aan mensen die aan het begin van de interventie laag scoren op behoefte vervulling.

\section{Wat hebben we geleerd?}

In hoofdstuk 7, de algemene discussie, delen we onze visie over de toekomstige ontwikkelingen over hoe welzijn van kwetsbare groepen bestudeerd en verbeterd kan worden. We beginnen met een samenvatting van de belangrijkste bevindingen van de verschillende studies. We bespreken de relevantie van de geluksgerichte aanpak voor kwetsbare groepen, waarbij we sterke punten en beperkingen van het onderzoek meenemen, resulterend in aanbevelingen voor onderzoek en praktijk. 
De waarde van de geluksgerichte aanpak ligt bij de betere aansluiting aan het nieuwe beleid binnen de sociale sector van 'ziekte en zorg' naar 'gedrag en gezondheid'. De Geluksroute voldoet aan de vraag naar empowerment, persoonlijke verantwoordelijkheid en eigen kracht van cliënten. In de studie werd een extreem kwetsbare groep bereikt met een hoge mate aan eenzaamheid en depressieve klachten. Terwijl er geen significant verschil tussen de condities werd gevonden is het opmerkelijk dat we bij deze extreem kwetsbare groep alsnog effecten op welbevinden en depressie konden vinden, die tot negen maanden aanhielden. De Geluksroute scoorde beter dan de controle groep wat betreft de afname van languishers en de grotere tevredenheid en de door deelnemers beschreven effecten. We kunnen concluderen dat het met de Geluksroute mogelijk is om het welbevinden van kwetsbare groepen te verbeteren.

Een bijzonder sterk punt van het proefschrift was het gebruik van verschillende methodes, zowel kwantitatief als ook kwalitatief. Er is echter geen uitgebreide kosten-baten studie gedaan. Dit zou een belangrijke volgende stap zijn. Ook is er geen formele implementatie studie uitgevoerd, wat bij dit praktijkgericht project bijzonder interessant zou zijn. Terwijl het gebruik van een actieve controle groep een sterkte van de studie opzet was, bracht deze ook mogelijke beperkingen. Terwijl de externe validiteit door de praktijkgerichtheid van de studie hoog was, bracht dit ook de nodige uitdagingen met zich mee. Het bleek lastig om voldoende deelnemers te vinden en te werven. Door het beperkte aantal deelnemers was het niet mogelijk om moderatie-analyses uit te voeren. Vervolgstudies zouden beter in kaart moeten brengen wat precies het beste voor wie werkt.

In het proefschrift zijn de eerste stappen genomen om de werkingsmechanismen van de Geluksroute te ontrafelen. Zo lijkt de Geluksroute een positieve spiraal te hebben uitgelokt bij de deelnemers bij wie het werkte. Door een intrinsiek gemotiveerde activiteit uit te voeren leken positieve emoties te worden veroorzaakt en de basisbehoeftes aan autonomie, competentie en verbondenheid te worden vervuld, wat op zijn beurt weer tot meer positieve emoties leidde, en zo verder. Door de nudge die door de consulent en de activiteit werd gegeven, kon deze opwaartse spiraal worden geïnitieerd. 
Onze aanbevelingen voor implementatie zijn om open te blijven voor nieuwe mogelijkheden om de Geluksroute in bestaande arrangementen in te bedden, het proces van het vinden van deelnemers niet te onderschatten en geduldig te zijn en intermediairs in het proces te betrekken. Het implementatiesucces lijkt voor een groot deel van de projectleider af te hangen. De manier waarop de Geluksroute wordt aangeboden kan worden aangepast aan de locale omstandigheden van een project.

Er worden verschillende implicaties voor de praktijk en in het bijzonder de sociale sector bediscussieerd. Ten eerste zouden zorgprofessionals naast het aanpakken van problemen ook aandacht voor het welbevinden van kwetsbare groepen moeten hebben. Ten tweede kan er veel worden bereikt door autonomie, competentie en verbondenheid te ondersteunen. Ten derde is het voor de geluksgerichte aanpak noodzakelijk om denkpatronen en gedrag te veranderen bij het omgaan met kwetsbare mensen. Tot slot is het belangrijk om te zien dat de uitspraak 'one size fits all' niet past bij het verbeteren van het welbevinden van kwetsbare mensen.

Wij concluderen dat dit proefschrift meer inzicht heeft gegeven in de mogelijkheden om welbevinden van kwetsbare groepen te verbeteren. De geluksgericht aanpak lijkt een waardevolle toevoeging te zijn voor de traditionele aanpak en kan voor meer balans zorgen in de omgang met kwetsbare mensen. 


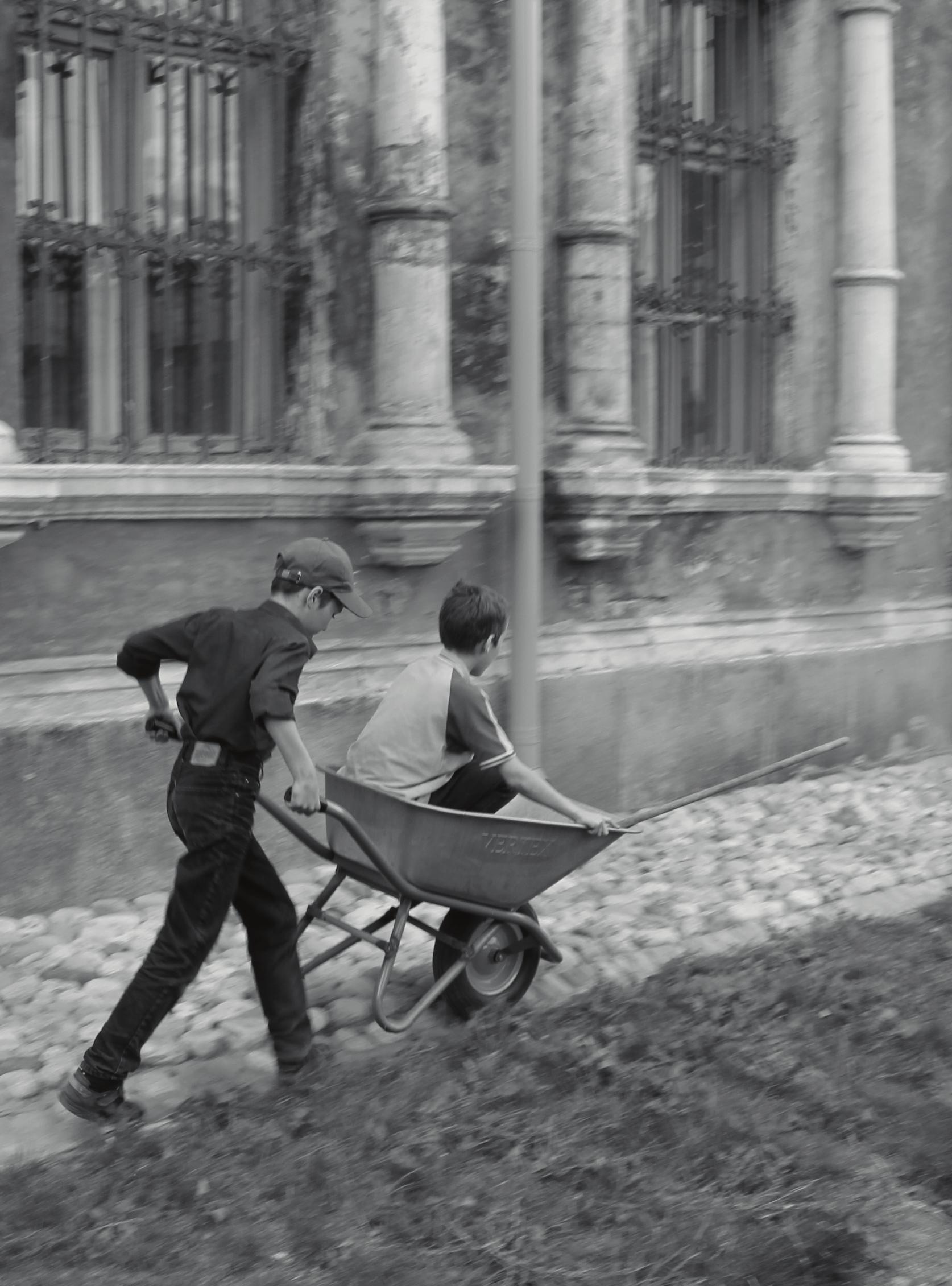


Dankwoord Acknowledgements in Dutch

\section{Publications}

About the author 
Dankwoord (Acknowledgements in Dutch)

11

How lucky am I to have something that makes saying goodbye so hard.

$$
\text { 川 }
$$

Winnie the Pooh 


\section{Dankwoord}

This last couple of years, I have walked down my own route. I want to thank the people who truly made it a Happiness Route. The ones who have always supported me so that I could start the walk in the first place, such as my parents. Travel companions I encountered along the way. People that showed me which way to turn to on a crossroad. And the people that never left my side, even when the walk got a little rocky. If I have learned one thing during my study of positive psychology, it is the following: there is nothing more important for happiness than other people.

Fitting to my daily life, I will write this acknowledgment in three languages.

First of all, I want to thank the members of my committee: Richard Ryan, it is a true honor that you are part of my committee. I deeply admire your work; the self-determination theory is not only the foundation of my thesis, but I recognize it in everyday life as well. Ruut Veenhoven, u bent één van de eersten die geluk wetenschappelijk onderzocht hebben en uw invloed op het veld kan niet worden overschat. Karlein, jij was één van de 'wegwijzers' voor mij. Toen ik twijfelde tussen wetenschap en praktijk wees jou raad mij de weg. Nu ben ik helemaal verknocht aan de wetenschap. Jij bent het beste voorbeeld van hoe je wetenschap en praktijk kunt combineren. Anja Machielse, uw werk over eenzaamheid is indrukwekkend en heeft mij steeds weer geïnspireerd. Ariana Need, bedankt dat u de tijd en moeite heeft genomen om in mijn commissie plaats te nemen. Johnny, I had the opportunity to see how you combine philosophy and positive psychology on several occasions, and what you do is absolutely unique. When it comes to presenting, you are my absolute role model. Lew, you have made a real difference in my life by giving me the opportunity to work as a post-doc in South Africa for the next three years. You are such a positive, enthusiastic and inspiring person!

Ik wil ook graag van harte de mensen bedanken, die het project mogelijk gemaakt hebben en die mij begeleid hebben.

Ernst, er is veel wat ik aan jou bewonder. Jij bent een schrijftalent, een compassievolle vakgroep-voorzitter met een oprecht interesse in jouw medewerkers en op het juiste moment kom jij met vernieuwende ideeën. Maar wat ik vooral aan je waardeer is je open en warme persoonlijkheid. Met veel plezier denk ik terug aan onze trip naar Florida. Jij hebt me altijd gerustgesteld met bemoedigende woorden en leek soms 
meer vertrouwen in me te hebben dan ik zelf. Ik kijk ernaar uit om verder samen te werken.

Gerben, jij was een echte leermeester voor mij en ik had me geen betere begeleiding kunnen wensen. Om het in het kader van de door ons zo veel gebruikte zelfdeterminatie theorie uit te drukken: Ik ken weinig mensen die zo competent zijn en ben elke keer weer onder de indruk van je enorme kennis en hoe je die over kunt brengen. Met veel geduld heb je al mijn vragen beantwoord (en dat waren er altijd héél wat) en bij elke afspraak heb ik weer iets geleerd. Je hebt me vanaf het begin ontzettend veel autonomie gegeven en vertrouwen in mij gehad en daardoor kon ik mij ontplooien en floreren. Veel kleine en grote dingen maakten dat ik me met je verbonden voelde. Om maar een paar te noemen: je had altijd een luisterend oor voor me, we hebben allebei (schoon)familie in het mooie Weserbergland en een gedeelte liefde voor boeken en reizen. Jij bent een groot voorbeeld voor mij hoe je als wetenschapper moet zijn: transparant, integer en met een onfeilbare ethische kompas.

Eddy, je rustige uitstraling en steun in de achtergrond waren altijd fijn. Dat je regelmatig even bij me langs kwam om te vragen hoe het gaat heb ik zeer gewaardeerd. Veel plezier in Las Vegas!

Aad, we hebben veel samen beleefd. Om maar een paar voorbeelden te noemen: in Moskou met loodzware koffers tijdens rushhour de metro nemen, samen naar de uithoeken van Nederland reizen en als afsluiting in een kerk in Frankijk dansen. Vooral in het eerste jaar hebben we intensief samengewerkt om alles voor elkaar te krijgen. Het is ons dan ook gelukt om Zorg op Maat in zeven gemeentes te implementeren, wat zonder jou overtuigingskracht niet was gelukt. Als het gaat om presenteren heb ik veel van jou geleerd. Jij lijkt voor het podium geboren te zijn. Het was leuk om 'jouw kindje', de Menselijke Maat, te zien ontwikkelen van idee tot pilot tot iets dat nu in gemeentes zoals Den Haag draait. Jij brengt de omzetting van het gedachtegoed van de positieve psychologie in de Nederlandse zorgsector enorm vooruit. Ik hoop dat je je passie hiervoor nooit verliest.

Ik wil ook graag ZonMw bedanken, die het PhD-project financieel mogelijk hebben gemaakt. 
Ik wil natuurlijk ook de 'Zorg op Maat familie' bedanken. De projectleiders Lizzy en later Chantal, Marja, Adri, Johan, Anoeska, Jan, Janet en Carla, bedankt voor jullie inzet en enthousiasme! Zonder jullie was dit onderzoek niet mogelijk geweest. Ik heb intens van het contact genoten en veel van jullie geleerd. Ook de consulenten waren onbeschrijfelijk belangrijk voor dit onderzoek, ook van jullie kon ik veel opsteken. Zonder jullie was het onderzoek niet mogelijk geweest. Helaas kan ik niet alle namen noemen, maar ik ben een ieder van de 66 consulenten erg dankbaar en velen liggen mij nauw aan het hart. Ook een bijzondere dank aan de vrijwilligers. En één iemand mag hier natuurlijk niet missen: Gerard, jij hebt de Geluksroute bedacht en zonder jou was er dit onderzoek dus niet. Ook bedankt voor je hulp (onder andere het bellen met intermediairs, dat niemand zo charmant als jij had kunnen doen)! Het is altijd gezellig om met jou te praten, want je zit vol levensvreugde. Er waren ook veel anderen, die op de één of anderen manier hebben geholpen, onder anderen Pieter van Haren en Leny Claessens.

Mijn grote dank gaat uit naar alle deelnemers voor de deelname aan het onderzoek, het invullen van de vragenlijsten en degenen die zijn geïnterviewd voor de openheid en de mooie verhalen. Jullie zijn de helden van dit boek!

Terwijl de UT wel mijn 'homebase' was, heb ik ook veel uurtjes bij Arcon gewerkt. Ik voelde me altijd welkom en jullie hebben mijn promotietijd erg verreikt. Het was altijd gezellig in de torenkamer, dankzij mijn kamergenoten Anne, Ester, Ria, en daarvoor Sybren en Leonie. Ook bedankt aan het Menselijke Maat team, vooral de altijd aardige en geïnteresseerde Marlou en Irene. Eelco, bedankt dat je ons bij het training hielp! En Janny, Brenda en Leni, bedankt voor jullie hulp met allerlei zaken en Hetty voor de samenwerking rondom de 3-daagse. Ook Nicole had altijd een luisterend oor voor me en Frans wakkerde vaak mijn 'Fernweh' aan. Ik wil ook zeker niet de mensen vergeten, die er ooit gewerkt hebben, en dan met name Coby, Leo en Maarten, Marlous en Marek. Veel succes allemaal, blijf zo een leuk clubje, aangestuurd door Marleen.

Mijn geweldige collega's van PGT, wat had ik geluk met onze afdeling, met mensen die zo aardig en hulpvaardig zijn! Jullie lukt het een hele fijne sfeer in de lelijke Cubicus te verspreiden. Bijzonder dank aan het PPT team, jullie hebben me altijd geïnspireerd. 
Hartelijke dank aan het secretariaat voor alle ondersteuning, vooral aan het hart van de afdeling, Marieke, maar ook aan Marion, Sandra, Marja en Elize. Leuk om met een aantal mensen te mogen samenwerken, zoals met de mentorgroepjes, het coördineren van het vak 'Mental Health Promotion' met Zwenny en Marloes en het begeleiden van studenten samen met Mirjam. Dankzij onder andere Stans, Annemarie, Marcel en Martine was het, ondanks de brug tussen ons en de rest, toch altijd leuk in de C-vleugel. Er waren altijd collega's voor een goed gesprek of advies, sommigen in ruil voor drop $(;)$, onder andere Lisette, Christina, Olga, Anneke, Peter en Farid (wat grappig dat we al zo lang bijna buren zijn zonder het te weten).

Ernst, Sanne, Peter en Wendy, wat leuk om samen van Florida te genieten (en Moscow, Peter)! Marijke, het was heel gezellig om met je een kamer te delen in Florida. Ik ga nooit vergeten dat je mij na twee uur Disneyland ziek naar huis begeleide. Wat een eer dat ik je paranimf mag zijn! Jij bent een hele goede onderzoeker en ik ben zeker dat je net zo een goede coach wordt.

Het begon allemaal (heel sprookjesachtig) in de torenkamer. Wat een gezellig boel, dankzij onder andere Ingrid (wat leuk dat we samen de schrijfcursus konden doen in een oud klooster), Liseth (wat fijn om iemand te hebben die altijd rustig blijft), Hester (ik ben zeker dat jij een beroemd wetenschapper wordt) en Roos (ik weet nog dat ik ooit iemand vroeg hoe te kleden op congres. Antwoord: zoals Roos). En natuurlijk Martijn: jij bent een heel bijzondere mens. Ik hou er erg van om met je te discussiëren, in de pauzes of op de fiets op weg naar huis. Je analytische geest is indrukwekkend.

Mijn pauze-genootjes en het rookie-clubje, zonder jullie was mijn tijd hier lang niet zo leuk geweest: Noortje, die de leukste weetjes rondstuurt en een vrolijke roze sfeer verspreid. Teuntje, die aanstekelijk vrolijk en enthousiast is en heel lief, aan jou kon ik de summerschool met een gerust hart overdragen. Jochem, die de Faculty Club onder inzet van zijn charme voor ons reserveerde. Ik hoop dat ik met jullie twee ooit nog naar Italië kan. Carly, een verrijking voor de vakgroep. Saskia A., Anne, Hanneke, Anniek (hartelijk gefeliciteerd met je verjaardag!) Annemieke (bedankt voor de thee!), Moniek, Robin, Wouter, Mareike, Youri (wat fijn om iemand te hebben om ervaringen over meta-analyses uit te wisselen), Marion, Sander (het was gezellig om met je in Angers te lunchen), en oud-koorgenootje Christina. Naast hard werken en 
pauze houden hebben we ook na werktijd leuke dingen gedaan, zoals proberen uit een escape room te ontsnappen.

Sanne, jij werkt inmiddels niet meer op de UT, maar toch wil ik je graag noemen. Ik mis je oneindige vriendelijkheid, geduld en lieve manier hier op de UT. Linda, jouw proefschrift was een soort bijbel voor mij en ik heb veel bewondering voor jou. Saskia, ik heb heel veel zin om met je samen te gaan werken! Liisa and Josep, it was great to have you as colleagues for a little while!

Aleisha, you have the best reason in the world to miss my promotion (:) You have been an informal mentor for me and your kindness is inspiring. Thank you so much for your support, especially when I visited Galway. I also want to thank Margaret Barry and her colleagues for welcoming me at the NUI Galway.

Floor en Jobke, bedankt voor jullie vriendschap en alle gezellige etentjes met $z^{\prime} n$ vijven met als hoogtepunt samen Barcelona verkennen. Jobke, ik hou van je directe, grappige manier en dat je zo authentiek bent. Floor, jij was eigenlijk een vierde roomie, maar dan wat verder weg. Het was leuk om samen te sporten (heel soms), en koffie te halen en pauze te houden (héél vaak). Hoe het met je ging was altijd aan je mooie krullen te zien.

Nadine en Nienke, mijn roomies. Wie kan er nou van zich zeggen elke dag met twee van zijn beste vrienden door te brengen? Zonder jullie advies, afleiding, tranen drogen, samen lachen, stoom afblazen, en kletsend samen thee drinken was ik nooit tot hier gekomen. Daarom ben ik ook heel blij dat jullie mij als paranimfen terzijde staan tijdens mijn verdediging. Nienke, je bent een ontzettend stoere en slimme meid. Jij kunt gewoon alles! Ik ben heel blij dat ik zo veel belangrijke fases in je leven mocht meemaken. Jij hebt me ook in de laatste moeilijke fase geweldig ondersteunt. Nadine, we hadden gelijk een klik. Je bent een charmant een aangenaam mens, relaxed, sociaal en empathisch en een harde werker met veel veerkracht. Ik voelde me door jou altijd ondersteund en het was fijn om over alles te kunnen praten. Ik heb met weinig mensen zo veel tijd doorgebracht als met jullie twee, dat ga ik ontzettend missen! Op naar nog vele high-teas meiden!

Ook wil ik mijn studenten bedanken. Mijn eerste studentengroepje ga ik nooit vergeten (Sabrina, Tobias, Rebecca en Thomas, die ook nog zijn master over de Geluksroute heeft geschreven), net als mijn eerste masterstudente Kim, die het 
door haar zelfstandige en zorgvuldige manier heel makkelijke heeft gemaakt. Mijn tutorgroepjes, de masterstudenten van het vak 'Geestelijke Gezondheidsbevordering', dat ik twee keer mocht coördineren, Marieke en Marlie, Mirjam, die bij de metaanalyse hielp en Leonie en Milou voor het voeren en transcriberen van de interviews. Maria, ik kijk er naar uit om binnenkort weer samen te werken. Een bijzonder dank aan Pauline, die niet alleen haar master bij me schreef, maar me ook daadkrachtig als student-assistente heeft ondersteund. Ik ben jou ontzettend dankbaar voor al het werk dat je hebt verzet, je vrolijke aanwezigheid en enthousiasme voor de Geluksroute. Het was ontzettend fijn met je samen te werken en zonder jou was ik waarschijnlijk verdronken in de vele vragenlijsten.

Wie weet of ik deze weg had ingeslagen zonder mijn allereerste begeleiders Hans en Jan van der Meij. Hans, jij hebt mijn wetenschappelijk hart laten beginnen te kloppen. Het is leuk om te zien hoe iemand zo op kan gaan in zijn werk. Ton de Jong, ik heb van jou veel over de wetenschap geleerd en grote bewondering voor jou.

Ik wil ook graag alle betrokkenen van CuriousU bedanken. Suzanne en Sikke, jullie zijn geweldig! Ik heb onwijs veel genoten van het samenwerken met jullie. Ik moest zelden zo veel lachen tijdens werk als met jullie en heb heel veel mooie herinneringen aan onze gezamenlijke tijd bij CuriousU (en daarbuiten, bijvoorbeeld bij onze legendarische mord-diners). Rianne, jij hebt de leukste lach die ik ken. Ik kan me geen betere projectleider voor CuriousU voorstellen, maar volgens mij maak je alles tot een succes. Shanton \& Robbie, you are the greatest couple I ever met!

Anne Marie, samen in de wereldstad Borne werken verbindt $;$; Het was leuk om met jouw te schilderen, zo lang te kletsen totdat we bijna uit Appeltjes van Oranje zijn gegooid en in een eng huis schrijfweekend te houden.

Irma en Onnie, zonder jullie zou de Cubicus niet de Cubicus zijn.

De redactie en management van de Tijdschrift voor Positieve Psychologie wil ik bedankten dat ik deel van dit eerste tijdschrift in ons vakgebied mag uitmaken, die de wetenschappelijk kennis naar de praktijk brengt. Ik heb er veel van geleerd dankzij jullie.

A beautiful memory was the summerschool in Oslo, I was so lucky to attend. A big thanks to all the participants who made it a special experience. Grazie, Antonella! Ook wil ik mijn yoga groep en vooral Christine Michon danken voor de nodige in- en 
ontspanning. Tijdens de lessen heb ik veel van de principes die ik in theorie heb geleerd, zoals mindfulness en flow, aan eigen lijf kunnen ervaren. Mijn oude koor Speechless, en vooral de 'altos', bedankt voor de mooie tijd!

Janina, wir kennen uns seit der Krabbelgruppe. Seitdem sind wir unzertrennlich (manchmal im wahrsten Sinne des Wortes...) und haben eine tolle Kindheit zusammen verbracht, begleitet von Beatles Liedern. Du bist ein fabelhafter, lustiger, schöner, schlauer und verrückter Mensch! Vielen Dank, dass du mitten in der Nacht noch meine Diskussion verbessert hast!

Katha, seit 20 Jahren bist du meine 0.-beste Freundin. Wie deine Oma sagen würde: die Schwatte und die Blonde. Du lädst meine Energie auf, bist treu, offen, unkompliziert und eine wahre Freundin, die immer für mich da ist und mit der ich stundenlang quatschen kann. Du hast mich auf so viele Arten unterstützt und bist mir unendlich wichtig! Schön, um zu wissen, dass du den fabelhaften Joe an deiner Seite hast.

Irina, mein Engelchen. Mit dir steht die Zeit still... Uns verbindet so viel, du hast viel dazu beigetragen wie ich heute bin und ich bin so froh, dich als Freundin zu haben. Du hast sogar an dieser Dissertation beigetragen mit deinem medizinischen Wissen. Jan (wir kennen uns inzwischen auch schon so lang), Leif und Bebi natürlich nicht zu vergessen!

Charlin und Jan, ihr seid so charmante und tolerante Menschen mit großem Herz. Mit euch ist es immer super, ob wir nun Seerobben beobachten oder auf den Abschleppwagen warten... Danke für eure Freundschaft! Hannie, meine Kleine, schön, dass es dich gibt! Ich hoffe, wir alle feiern noch viele Sylvester zusammen.

Wiebke, Schwester im Herzen, egal wie weit weg du bist, ich fühle mich immer mit dir verbunden. Ich bin so froh, dich als Freundin zu haben, wir ergänzen uns irgendwie perfekt. Danke für deine Unterstützung in alles Lebenslagen und dein Feedback für die Diskussion. Du bist nicht nur anmutig, sondern auch sehr mutig! Ich wünsche dir und Clement ein fantastisches Abenteuer!

Christoph, ich bewunder echt, was du alle hinkriegst; gleichzeitig promovieren und die Ausbildung zum Psychotherapeuten. Aber wenn einer das schafft, dann du. Blöd, dass wir bald nicht mehr einfach mal eben vorbei kommen können, das werd ich vermissen! Thomas, ik vind het ontzettend leuk waar je mee bezig bent en wens je 
onwijs veel succes met je arboretum.

Mijn lieve schoonfamilie, ook jullie wil ik van harte bedanken voor alle steun. Ik ben harstikke blij met mijn 'tweede familie'. Wout, jij begreep altijd goed waar ik mee bezig was en ik kon uren met jou over wetenschappelijke kwesties spreken. Jacq, wat ben jij voor een ongelofelijk lief mens! Bedankt dat ik een schrijfweek bij jullie in Mulhouse mocht houden, waar zelfs de foto op de kaft is ontstaan, en dat jullie naar mijn inleiding hebben gekeken. Eva, Anke en Max, met jullie is het altijd gezellig! Kleine Louna, gelukkige maan, de aarde draait weliswaar niet om de maan, mij wij draaien om jou heen (:) Ook alle ooms, tantes, neefjes en nichtjes aan de de Boer kant bedankt voor alle gezelligheid.

Liebste Oma, danke, dass du einfach meine Oma bist. Mach dir keine Sorgen um mich, Frank passt auf mich auf. Bärbel, du bist die Coolste! Dein Humor und deine Herzlichkeit sind fabelhaft und deine Besuche in Holland waren immer toll. Marlies, ich will später mal genauso aktiv sein wie du, mit 80 noch nach Thailand reisen und ins Fitnessstudio gehen ist einfach genial! Lini, es ist mir eine Ehre dass alle immer sagen wie ähnlich wir uns sehen/sind. Resi, du bist so ein süßer Spatz und hast die unglaublichste Stimme! Maribär und Augi, schön um so sympathischsten Vertreter der männlichen Gattung in unserer Männer-armen Verwandtschaft zu haben :-; Bine, Olaf und Erika, ihr bringt eure gute Kölner Laune überall mit hin. Jutta, Johanna, Josefine und Jezabel, ich hab aber auch Glück mit so ner tollen Verwandtschaft und bei euch in Freiburg war und ist es immer toll!

Frauke und Charlotte, als Sandwichkind hab ich die beste Ober- und Unterseite die ich mir vorstellen kann (sprich: Schwesties). Ihr seid ein Teil von mir und werdet es immer sein, allein schon durch alle Kindheitserinnerungen. Lottie, du bringt mich immer zum Lachen und bist der süßeste Geschenkeaussucher aller Zeiten. Fabi, pass gut auf meine kleine Lottie auf! Sven, du bist der Ruhepool in unserer chaotischen Familie, danke dafür! Frauke und Sven, es war jedes Mal wunderschön, wenn ihr bei uns zu Besuch wart!

Emma und Leo, ich hab euch lieb bis zum Mond und zurück. Ich werde euch wohl am meisten vermissen, wenn ich in Südafrika bin. Emma, wenn ich mal groß bin will ich so werden wie du! Leo, du bist das süßeste (und frechste) Wesen das ich kenne.

Mama und Papa, ihr habt mir Wurzeln und Flügel gegeben, und so viel mehr. Eure 
bedingungslose Liebe bedeutet mir die Welt, ob nah oder fern. Mama, du bist die Personifizierung von positiver Psychologie. Dich als Mama zu haben war eigentlich ein Grundkurs über Glück und Resilienz. Ihr habt meine Neugier und Wissensdrang schon immer stimuliert, allein schon durch uns in einem Haus voller Bücher aufwachsen zu lassen. Mama, wenn du mal eine Frage nicht beantworten konntest, hast du immer eins der großen Lexika aus dem Schrank geholt. Papa, du bist an so vielen Dingen interessiert und weißt dadurch wahnsinnig viel. Ein gutes Beispiel, wie du mein wissenschaftliches Interesse schon früh unterstützt hast war, als ich als Kind mit meinem ersten Mikroskop unbedingt mal Blut angucken wollte: Du hast dir kurzerhand in den Finger gestochen. Sogar jetzt konnten wir zusammen arbeiten. In der Glücksroute geht es auch über Werte, und was mir wichtig ist, habe ich von euch vermittelt bekommen: Mut, Toleranz, Offenheit, Authentizität und Herzlichkeit. Danke für alles und dass ihr mich immer meinen eigenen Weg habt finden und gehen lassen. Dadurch, dass ich eure Unterstützung immer als Rückhalt hatte, habe ich mich auch ins große Unbekannte getraut!

Frank, mien lutje laif, mijn reisgenoot. Samen hebben we al veel avonturen beleeft. Gelukkig had ik jou aan mijn zijde, 'every step of the way'. Jij hebt heel veel geduld gehad en liefdevol voor mij gezorgd (en gekookt) als ik in de stress zat. Ik voel me eindeloos geliefd door jou, inclusief al mijn gekke kanten. Dit is ook een beetje jouw promotie (:) Er is zo veel waar ik je dankbaar voor ben dat ik er een nieuw boek mee vol zou kunnen schrijven. Binnenkort slaan we samen weer een nieuwe weg in. Weliswaar gaan we naar de andere kant van de aarde, maar waar jij bent, ben ik thuis.

Jij bent mijn happy end. 
Publications 


\section{Publications}

\section{Published articles and chapters}

Weiss, L. A., Westerhof. G. J., \& Bohlmeijer, E. T. (2016). Can we increase psychological well-being? The effects of interventions on psychological well-Being: A Meta-Analysis of Randomized Controlled Trials. PLOSONE, 11(6). doi:10.1371/journal.pone.0158092

Weiss, L. A., Kedzia, S., Francissen, A. A., Westerhof, G. J. (2015). Improving the health care sector with a happiness-based approach. The case of the Happiness Route. In J. H. Søraker, J. W. van der Rijt, J. de Boer, P. H. Wong \& P. Brey (Eds.), Well-Being in Contemporary Society (pp. 59-71). Cham, Germany: Springer. doi:10.1007/978-3319-06459-8_4

Weiss, L. A., Westerhof. G. J., \& Bohlmeijer, E. T. (2013). Nudging socially isolated people towards well-being with the 'Happiness Route': Design of a randomized controlled trial for the evaluation of a happiness-based intervention. BMC Health and Quality of Life Outcomes, 11(1),1-11. doi:10.1186/1477-7525-11-159

\section{Selection of scientific presentations}

June 2016

June 2015 $8^{\text {th }}$ European Conference on Positive Psychology, Angers, France

Presentation: Can we enhance psychological well-being? Results from a meta-analysis on the promotion of psychological well-being

Poster: Exploring the blackbox: An interview study of a positive psychology intervention for vulnerable people $4^{\text {th }}$ World Congress on Positive Psychology, Orlando, Florida, USA

Symposium: Can We Enhance Flourishing? Evidence from RCTs and Meta-Analysis, chair: Laura Weiss

Presentation: Can We Enhance Psychological Wellbeing? Results from a Meta-analysis on the Promotion of Psychological Well-being 
July 2014

April 2014

November 2013

February 2013

July 2012

June 2012 $7^{\text {th }}$ European Conference on Positive Psychology, Amsterdam, the Netherlands

Workshop: How to improve well-being of lonely people with a happiness-based approach: the Happiness Route Dutch Nephrology Days 2014, Veldhoven, the Netherlands Invited presentation: Positive Psychology and Happinessbased working

$1^{\text {st }}$ National Congress Positive Psychology, Ede, the Netherlands

Invited workshop: Strengthen well-being for people in social isolation

$2^{\text {nd }}$ 'Association for Researchers in Psychology and Health' Conference, University of Twente, Enschede, the Netherlands

Symposium: Positive aspects of health, chair: Ernst Bohlmeijer

Presentation: Nudging socially isolated people towards positive mental health with the 'Happiness Route'

Philosophy Conference 'Well-being in Contemporary Society', University of Twente, Enschede, the Netherlands Presentation: The 'Happiness Route': From problemoriented to happiness-based work in the social and health care

$6^{\text {th }}$ European Conference on Positive Psychology, Moscow, Russia

Symposium: Positive psychology for vulnerable groups - a focus on resilience, chair: Linda Bolier

Presentation: Evaluation study 'Happiness Route'. A practice-based multi-site RCT about a happiness-based intervention aimed at the socially isolated to increase positive mental health and decrease health care consumption 


\section{Invited presentations for the general public}

September 2016

August 2016

September 2012

November 2013
Conference: Positieve gezondheid meets positieve psychologie, Enschede, the Netherlands

Keynote: Improving well-being in a vulnerable group

Workshop: Werken vanuit de ZDT met de Geluksroute (Working based on SDT with the Happiness Route)

$2^{\text {nd }}$ International summer school festival CuriousU, University of Twente, Enschede, the Netherlands Keynote/inspirational talk: HappyU

Opening seminar for the 'Week against Loneliness' Zeist, the Netherlands

Invited pitch presentation: The Happiness Route. There are no pitiable people

Symposium Zorginkoop met de Menselijke Maat (Purchase of healthcare with the Human Measure), Almelo, the Netherlands

Invited presentation: Measuring effects of happinessbased working.

\section{Blogs for the 'Tijdschrift Positieve Psychologie' (TPP)}

http://www.tijdschriftpositievepsychologie.nl/blogs/straf http://www.tijdschriftpositievepsychologie.nl/blogs/hoe-het-geluk-naar-mijn-dorpje-kwam http://www.tijdschriftpositievepsychologie.nl/blogs/de-onvrijwillige-sponsorloop http://www.tijdschriftpositievepsychologie.nl/blogs/het-net-iets-andere-dorp http://www.tijdschriftpositievepsychologie.nl/blogs/vluchtelingen-en-positieve-psychologiekan-dat-samen 
About the author 


\section{About the author}

Laura Weiss is a positive psychology researcher. She was born in Hamlin, Germany. For her study, she came to the Netherlands, where she graduated cum laude in two masters specializations in psychology: Learning Sciences and Mental Health Promotion.

Laura completed her PhD study at the University of Twente in the Centre for eHealth and Wellbeing Research. She has specialized in positive psychology. Her expertise and research interests are improving well-being in vulnerable groups. During her PhD project, she examined the effects of the Happiness Route, a positive psychology intervention directed to lonely people with health problems and a low socioeconomic status. This intervention helps people to find and act on their passion and is based on self-determination theory.

For her PhD-project, Laura implemented and supervised the project in seven municipalities throughout the Netherlands. She coordinated the masters course 'Mental Health Promotion', supervised several master students and was a tutor for several Bachelor groups. She was part of the team that organized the first international summer school festival at the University of Twente, CuriousU, and was track leader for the track 'A boost for health and happiness'. She is part of the editorial board for the Journal 'Tijdschrift Positieve Psychologie' (TPP), the first Dutch Journal on Positive Psychology, and writes blogs for TPP. She was awarded an IPPA-scholarship for the $4^{\text {th }}$ World Conference of Positive Psychology in Florida, where she organized a symposium with Corey Keyes. She also organized a masterclass on self-determination theory in the health care sector with Richard Ryan.

Laura trained more than 100 professionals from the health-care sector and gave several (invited) talks, workshops and keynotes both during scientific conferences and for the general public on the topic of positive psychology. 



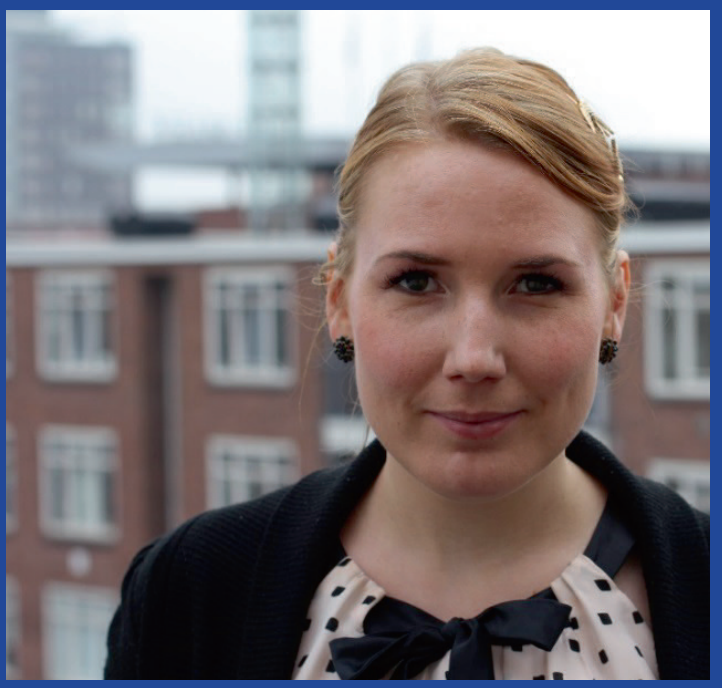

Laura A. Weiss is a positive psychology researcher. Her PhD research was a collaboration between the Centre for eHealth and Well-being Research at the Department of Psychology, Health and Technology (University of Twente) and non-profit foundation Arcon.

She has specialized in positive psychology interventions for vulnerable groups. In her PhD thesis, she evaluated the effects of the Happiness Route, an intervention for lonely people with health problems and a low socio-economic status. She examined how we can improve well-being for this vulnerable group by helping them to find a passion and act on it. 